\title{
EARLY CHILDHOOD CURRICULUM IN THAILAND: AN INVESTIGATION INTO PERCEPTIONS OF THE CULTIVATION OF THAINESS IN YOUNG CHILDREN
}

BY

\section{SUREEPAN IEMAMNUAY}

\author{
A thesis \\ submitted to Victoria University of Wellington \\ in fulfilment of the requirements for the degree of \\ Doctor of Philosophy
}

Victoria University of Wellington

2019 


\begin{abstract}
In 2003, the Thai Government introduced a revised early childhood curriculum to replace the 1997 Pre-Primary Curriculum (Ministry of Education, 1997a). This was in response to social and economic changes in Thailand such as both parents working, increasing cultural diversity, and influences from other countries (Ministry of Education, 2003b; Renard, 2006). According to the Ministry of Education, these changes had a negative impact on the cultivation of Thainess and citizenship in a changing society. The 2003 Early Childhood Curriculum (2003-2017) provides a framework and specific guidelines for early childhood education and care for children from birth to 5 years of age (Ministry of Education, 2003b).

This study investigates how early childhood services addressed young children's learning of Thai culture and identity when the early childhood services implemented the official curriculum. The investigation explored how services perceived the role of the government in supporting the cultivation of Thainess with young children. Parents' perceptions of their participation in promoting Thainess with their children is also addressed.

The research design included a survey and a multiple case study, both carried out in two districts of central Bangkok: Klongtoey and Wattana. The survey received 235 responses while the multiple case study involved eight services. Semi-structured interviews were conducted with principals, head teachers, early childhood teachers, and parents. Document analysis was also used.

Findings revealed that the majority of the services integrated various aspects of Thai culture and identity into their daily programme despite the 2003 Early Childhood Curriculum not providing specific guidelines in this area. However, government regulations were key in promoting Thainess through young children's participation in cultural activities and practices when attending early childhood services.
\end{abstract}




\section{ACKNOWLEDGEMENTS}

I would like to express my sincere gratitude and thanks to the following people for their excellent support in different ways.

First of all, my supervisors, Dr Mary Jane Shuker and Dr Sophie Alcock for their continual support, delightful encouragement, positive motivation, suggestions, and contributions to my Ph.D study. Their guidance helped me throughout my research journey. I could not have completed this research without the help and support of both of my wonderful supervisors. I cannot put into words how overwhelmed I have come to value your dedication. My thanks, too, to Victoria University of Wellington Faculty of Education staff and administrators, Victoria International Office, the Librarian staff, and the Student Learning Team for their incredible support and assistance during my $\mathrm{PhD}$. journey.

My sincere gratitude goes to the principals, head teachers, early childhood teachers, teaching assistants, and children's parents who participated in this study. Thank you for your willingness in allowing me to learn from you and your insightfulness in providing me with rich data. It was such a worthwhile experience of this research. My gratitude also goes to the school administrators who facilitated my visit to carry out the study.

With much love, I also acknowledge my Iemamnuay Family - Dad Noy, Mum Tik, and my younger brother Moss for their spiritual and financial support. This also included my aunties and uncles, the most generous people in the world, for their moral support: Lek and Somchai, Tid, Aoung, Tippavan and Thanongsak, and Aoy Somporn. Special thanks to my best friend in Thailand, Tem Titirat, and to a lot of other lovely friends - Praveen Kumar, Pat and Thomas, Thichawee and Jagraphob, Lisa, Alex, Ahmed, Jenny, Molly, Tara, and the pre-opening Sterling team in New Zealand - for making my four-year journey a rewarding one. In particular, I am thankful to Anan Chanhom for his infinite support and positive reinforcement throughout this agonising journey. 


\section{TABLE OF CONTENTS}

$\begin{array}{ll}\text { Abstract } & \text { ii }\end{array}$

Acknowledgements

Table of Contents iv

List of Figures $\quad$ ix

List of Tables $\quad x$

\section{Chapter 1 Introduction}

1.1 Thailand's Social and Political Context 1

$\begin{array}{ll}1.2 \text { Rationale for the Study } & 7\end{array}$

1.3 Aim of the Study and Research Questions 8

1.4 Overview of the Thesis 8

\section{Chapter 2 Background of the Study}

2.1 History of Early Childhood Education in Thailand 10

2.1.1 Period Before Education Reforms (1238 - 1868) 10

2.1.2 Education Reform $(1869-1931) \quad 11$

2.1.3 Education after the Political Reform $(1932$ - 2002) 12

2.2 Thailand's Early Childhood Education Provision 14

2.2.1 Implementation of the 2003 Early Childhood Curriculum 15

2.2.2 The Manual of the 2003 Early Childhood Curriculum 20

2.2.3 Early Childhood Services in Thailand 24

2.2.4 The Government's Role in Early Childhood Education Provision $\quad 27$

2.2.5 Initial Early Childhood Teacher Education and Qualification 27

2.3 Thai Society, Culture, and Identity 28

2.3.1 Thai Manners 30

2.3.2 Thai Traditions 31

2.3.3 Thai Folk Wisdom 33

2.3.3.1 Thai Language $\quad 33$

2.3.3.2 Thai Costumes 34

2.3.3.3 Performing Arts, Folk Play, and Food 37

2.3.4 Thai Social Values and Norms 38 


\section{Chapter 3 Literature Review}

3.1 Definition of a Curriculum 43

3.2 Early Childhood Curriculum Framework 46

3.3 Learning Theories that Underpin Early Childhood Education in 48 Thailand

3.4 Thai Concepts Underpinning the 2003 Early Childhood Curriculum 56

3.5 Theoretical Framework: Socio-Cultural Theory 67

$\begin{array}{ll}3.6 \text { Chapter Summary } & 71\end{array}$

\section{Chapter 4 Research Methodology}

$\begin{array}{ll}4.1 \text { Research Paradigm } & 72\end{array}$

$\begin{array}{ll}\text { 4.2 Research Design } & 73\end{array}$

4.2.1 A Qualitative Approach $\quad 74$

4.2.1.1 Documentation $\quad 75$

$\begin{array}{ll}\text { 4.2.1.2 Interviews } & 76\end{array}$

$\begin{array}{ll}\text { 4.2.2 Survey } & 78\end{array}$

4.3 Selection Strategies Used to Select Participants 78

4.4 Phase One: The Survey $\quad 82$

$\begin{array}{ll}\text { 4.4.1 Piloting the Survey } & 85\end{array}$

4.4.2 Gaining Access for the Survey 85

4.4.3 Distributing the Survey to Early Childhood Services 86

$\begin{array}{ll}\text { 4.5 Phase Two: The Multiple Case Study } & 87\end{array}$

4.5.1 Gaining Access for the Multiple Case Study 87

$\begin{array}{ll}\text { 4.5.2 Semi-structured Interviews } & 88\end{array}$

4.5.3 Conducting the Multiple Case Study $\quad 89$

4.6 Data Analysis: Survey and Multiple Case Study 97

$\begin{array}{ll}4.7 \text { Validity and Reliability } & 100\end{array}$

4.8 Ethical Considerations and Role of the Researcher 101

$\begin{array}{lr}4.9 \text { Chapter Summary } & 102\end{array}$ 


\section{Chapter 5 Survey Result}

$\begin{array}{ll}\text { 5.1 Demographic Data } & 104\end{array}$

$\begin{array}{ll}\text { 5.1.1 The Survey Respondents } & 104\end{array}$

$\begin{array}{ll}\text { 5.1.2 The Services' Characteristics } & 109\end{array}$

5.2 Implementing the 2003 Early Childhood Curriculum 110

5.3 Integrating Thainess and Thai Culture into Teaching Practices 115

$\begin{array}{ll}\text { 5.3.1 Thai Manners } & 115\end{array}$

5.3.2 Learning About Thailand 116

$\begin{array}{ll}\text { 5.3.3 Learning Other Values } & 117\end{array}$

5.3.4 Buddhist Principles and Buddhists' Practices 118

5.3.5 Thai Traditions and Other Important Dates 120

5.4 Survey Respondents' Perceptions of the Role the Government in 121

Promoting Thai Culture

5.5 Survey Respondents' Perceptions of the Parents' Participation 122

$\begin{array}{ll}5.6 \text { Chapter Summary } & 124\end{array}$

Chapter 6 Early Childhood Services' Perception of How Thai

Culture and Identity are Promoted with Young Children

6.1 Perceptions toward the 2003 Early Childhood Curriculum 127

6.2 The Role of the Government and the Umbrella Organisations 132

$\begin{array}{ll}\text { 6.3 Parents' Participation } & 140\end{array}$

6.3.1 Communication with Parents from the Services' Perspectives 149

6.3.2 Parents' Communication with Early Childhood Teachers 151

6.3.3 Parents' Perceptions of their Participation at the Services 152

6.3.4 How Parents Promote Songkran Festival and Visakha Bucha Day 154

$\begin{array}{lc}\text { 6.4 Chapter Summary } & 156\end{array}$

\section{Chapter 7 Integrating Thai Culture and Identity into Teaching}

Practices

$\begin{array}{ll}7.1 \text { Thai Manners } & 158\end{array}$

$\begin{array}{ll}7.2 \text { Thai Traditions } & 164\end{array}$

$\begin{array}{ll}\text { 7.2.1 Festivals } & 164\end{array}$

$\begin{array}{ll}\text { 7.2.2 Important Thai Dates } & 167\end{array}$ 
$\begin{array}{ll}\text { 7.3 Thai Folk Wisdom } & 171\end{array}$

$\begin{array}{ll}\text { 7.3.1 Thai Language } & 172\end{array}$

$\begin{array}{ll}\text { 7.3.2 Traditional Thai Costumes } & 173\end{array}$

7.3.3 Thai Food, Dessert, and Folk Play 175

$\begin{array}{lc}\text { 7.4 Thai Social Values and Norms } & 176\end{array}$

$\begin{array}{ll}7.5 \text { Buddhism } & 181\end{array}$

$\begin{array}{ll}\text { 7.5.1 Buddhist Principles } & 181\end{array}$

7.5.2 Buddhist Practices 186

7.6 Chapter Summary 192

\section{Chapter 8 Discussion}

$\begin{array}{ll}\text { 8.1 Thai Manners } & 197\end{array}$

$\begin{array}{ll}\text { 8.2 Thai Traditions } & 199\end{array}$

8.2.1 Thai Festivals 199

8.2.2 Thai Important Dates 200

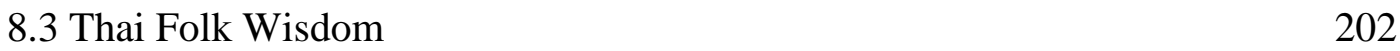

8.3.1 Thai Language $\quad 202$

8.3.2 Wearing Costumes 203

8.4 Thai Social Values and Norm 205

$\begin{array}{ll}8.5 \text { Buddhism } & 207\end{array}$

8.5.1 Incorporating Buddhist Principles 207

$\begin{array}{ll}\text { 8.5.2 Visiting a Temple } & 209\end{array}$

$\begin{array}{ll}\text { 8.6 How Thainess Underpin the Curriculum } & 211\end{array}$

8.7 Thai Government's Role in Early Childhood Service Programmes 216

8.8 Implications of the Research 219

8.9 Limitations and Recommendations for Further Studies 221

$\begin{array}{ll}8.10 \text { Conclusion } & 222\end{array}$

$\begin{array}{lr}\text { References } & 223\end{array}$

Appendices

Appendix A: Thailand's Festivals and Important Dates 243

Appendix B: Survey for Early Childhood Teachers 247 
Appendix C: Information Letters and Consent Forms for Umbrella

Organisations, Principals, Early Childhood Teachers, and

Teacher Assistants: Phase One (The Survey)

Appendix D: Information Letters and Consent Forms for Principals,

Head Teachers, Early Childhood Teachers, Parents: Phase

Two (The Multiple Case Study)

Appendix E: Examples of Interview Questions for Case-Study Early

Childhood Services (Phase Two: The Multiple Case Study)

Appendix F: Qualitative Codebook

Appendix G: Cross-Tabulation Analysis

285

Appendix H: Ethics Approval Letter (*) 


\section{LIST OF FIGURES}

Figure 1 Three levels of Wai practices 30

Figure 2 Eight styles of the Thai Phraratchaniyom outfits 35

Figure 3 Selection and location of services involved in the multiple 81

$\begin{array}{lll}\text { Figure } 4 & \text { Respondents' age group and gender } & 105\end{array}$

$\begin{array}{lll}\text { Figure } 5 & \text { Respondents' role and years of experience in their current }\end{array}$

Figure 6 Years of experience working with the 2003 Early Childhood 106 Curriculum

$\begin{array}{lll}\text { Figure } 7 & \text { Respondents' highest qualification and their field of study } & 107\end{array}$

$\begin{array}{lll}\text { Figure } 8 & \text { Size of the early childhood services } & 109\end{array}$

$\begin{array}{lll}\text { Figure } 9 & \text { Implementing curriculum guidelines } & 110\end{array}$

Figure 10 How respondents used the curriculum guidelines 111

$\begin{array}{lll}\text { Figure } 11 \text { How respondents enhanced children's key experiences } & 114\end{array}$

$\begin{array}{lll}\text { Figure } 12 \text { Integrating Thai manners in the curriculum } & 116\end{array}$

$\begin{array}{lll}\text { Figure } 13 \text { Teaching practices promoting Thai national pride } & 117\end{array}$

$\begin{array}{lll}\text { Figure } 14 & \text { Other roles and responsibilities taught at early childhood } & 118\end{array}$

$\begin{array}{lll}\text { Figure } 15 & \text { Teaching Buddhist principles and practices } & 120\end{array}$

$\begin{array}{lll}\text { Figure } 16 & \text { Promoting Thai traditions and other important dates } & 121\end{array}$

Figure 17 How respondents perceived the role of the Government 122

$\begin{array}{lll}\text { Figure } 18 & \text { How respondents viewed the parents' role } & 123\end{array}$

Figure 19 The Government's aspiration regarding the cultivation of 215 Thainess 


\section{LIST OF TABLES}

Table 1 Types of early childhood services, age group, and supervising organisations

Table 2 Size of the services in Thailand

Table 3 The link between the 12 Core Values and the 2003 Early

Childhood Curriculum

Table 4 Number of services from each umbrella organisation that participated

Table 5 Pseudonym list of the multiple case study participants

$\begin{array}{lll}\text { Table } 6 \text { Demographic data of the survey respondents } & 108\end{array}$

Table 7 Comparison of Thailand's early childhood curricula 


\section{CHAPTER 1}

\section{INTRODUCTION}

This study investigates how Thai culture and identity are addressed in the revised 2003 Early Childhood Curriculum (Ministry of Education, 2003a,b) ${ }^{1}$. Culture includes language, literature, artworks, sculpture, and Thai dance. Thainess (in Thai: Khwaam Bpen Thai) is a combination of culture and identity, and is an important part of becoming Thai. Culture is seen as very significant in Thailand and includes the common belief that young children need to be aware of, and conserve traditional Thai culture (Rattanathongkam, 2007). Extending the importance of culture, Athikomnantha (1998) believes that Thai people need to engage with Thai traditions and express Thainess. In this study, identity is understood as "culture inclusive" and culture as "self-inclusive" by Hermans (2001, p. 243; see also Hermans, 2012). According to the Office of the Basic Education Commission (2008), Thainess involves a consciousness of Thai nationality. Country, Buddhism, and the Monarchy are all highly valued aspects of Thai nationality. Young children are encouraged to demonstrate their love and to be proud of Thailand, their local origin, their families, and themselves. The promotion of Thainess is a significant aspect of this cultural awareness.

The revised curriculum reflects the Government's aspirations for developing a future generation of good citizens by nurturing children's morality, intelligence, and happiness (Ministry of Education, 2003a,b). The 2003 Early Childhood Curriculum is a developmentally based curriculum which aims to provide young children with education and care appropriate to their age to foster their holistic development (Office of the Basic Education Commission, 2008). The provision of early childhood education in Thailand takes into consideration the context of community, society, and Thai culture (Ministry of Education, 2003a,b). This means that young children should be encouraged to behave in line with their local culture, identity, and Thainess.

\subsection{Thailand's Social and Political Context}

Thailand is located in South East Asia. The country has a diversity of language and ethnicities in a population of approximately 70 million, eight million people living in

\footnotetext{
${ }^{1}$ Ministry of Education 2003a,b reference refer to Thailand's Ministry of Education
} 
the capital city, Bangkok. Most of the population is ethnically Thai, with Chinese, Indian, Malay, Mon, Khmer, Burmese, and Lao making up the rest. The Thai language is the official language for education and government and is spoken throughout the country; however, English is also widely spoken throughout many parts of Thailand. Buddhism is the most common religion, but other beliefs and religions are also observed and practised.

Historical data reveal that Thailand was known as Siam until 1939 when it was officially changed to Thailand. The word Thai means to be free (Renard, 2006). According to Farrelly (2016), Thailand represents the "land of the free" (p. 331). This links to the proclamation that Thailand remains the only country in the South East Asian region that has not been colonised by any European nation. Therefore, Thailand has had a long history regarding its social, economic, and political development. It can be said that its national culture and identity have also evolved and flourished for almost 1,000 years (Department of Cultural Promotion, 2017). Nevertheless, Thai people have survived and succeeded in blending Western influential elements with their own way of life with some perceptible dualism instead of being totally Westernised (Department of Cultural Promotion, 2017). As Traitongyoo (2008) puts it, Thainess may refer to the acceptance of other cultures by Thai society as a way to strengthen the nation's economy. Therefore, preserving and promoting Thai culture (in Thai: Wat Tha Na Tham) is the best way to strengthen the national sovereignty and maintain Thai national identity (in Thai: Aehk Ga Lak Thai), which includes language, traditions, beliefs, and religion. "Official notions of Thai cultural identity involves the foundations of which are the monarchy, Buddhism, and aristocratic artistic forms" (Jory, 1999, p. 462).

Due to the influence of Western capitalist ideas and globalisation, Thai society and culture, including education, were dramatically changed during King Rama V's reign (1853 - 1910) (Rattanathongkam, 2007). In 1874, slavery was abolished by King Rama V for two main reasons. Firstly, the large number of slaves had constrained the expansion of the country's new economic system (Pupphavesa, 2002). Another reason was to close the gap between citizens in relation to socio-economic status and equality (Athikomnantha, 1998). This change gave Thai people more freedom and equity (Office of the National Education Commission, 2009), which led to the establishment of the uniqueness of Thai society and culture: "Thainess became essentialised, 
palpable something that could be codified in law and bureaucratic regulation" (Reynolds, 1998, p. 130).

New concepts of socialism, liberalism, and democracy were introduced to Thai people (Thongsawang, 1994). King Rama V invested in social infrastructures, including trade agreements with foreign countries, signing treaties and policies that were beneficial (Pupphavesa, 2002). Western capitalist ideas also had an impact on Thailand's trading system (Thongsawang, 1994). People became reliant on private enterprises run through middlemen whereas formerly they were independent and had freely exchanged goods and food among their community members (Srisantisuk, 2000). They became more competitive and interested in investments and running businesses (Athikomnantha, 1998). Thai society changed from being agricultural to industrially based. As a consequence of all these changes, Thailand's conservative society adopted and integrated Western ideas that greatly influenced Thai culture and identity, lifestyle, beliefs, and social values. Therefore, promoting Thai social values and raising awareness of local culture are parts of the cultivation of Thainess (Kanoksilapatham \& Channuan, 2018). The representatives of Thainess within a society with cultural diversity are referred to as "Thai identities such as language, traditional arts, food, manners, ways of life, and so on" (Kerdarunsuksri, 2015, p. 4). Thainess can also refer to the outcome of the transfer process in aspects of social, cultural, and religious beliefs (Watkhaolarm, 2005).

The Education Reform (1869 - 1931) also took place during King Rama V's reign (Pupphavesa, 2002). The King encouraged his princes and senior noblemen to study overseas. When they returned to Thailand they were responsible for reforming the education system as well as health care, the military, public administration, transportation and the justice system. Western capitalist ideas were adopted and applied along with technology to the existing structures. The Education Reform established a strong foundation for the Thai education system (Namuang, 2010). The aim was to raise the standard of the education system to be comparable with those in other foreign countries while maintaining Thailand's unique culture and identity (Thambaworn, 2008).

During the period of Thailand's education reform, King Rama VI (1910 1925) established the concept of Thainess, or the nationalistic ideology which was derived from European influence, as he was the first King who studied abroad (Batson, 1977). "King Rama VI advocated the adoption of many Western ways to promote Thai 
national progress and national pride" (Vella, 1978, p. 176). However, King Rama VI argued that when integrating Western cultural aspects, Thai people needed to take them into consideration while maintaining their Thai culture and identity as "the promotion of Thai nationalism depended on a comprehension of nationality" (Vella, 1978, p. 177). The rise of this ideology aimed to protect the nation from the threat of Western colonial powers, including capitalist ideas, and promote the monarchy as a symbolic representative of Thainess (Connors, 2005; Reynolds, 1998; Traitongyoo, 2008; Vella, 1978)

According to Vella (1978), being Thai means that people must know who founded the nation and how the country's identity, referred to as Thainess, was established. This includes such things as Thai history, art and literature, language, respect for the royal leaders and families, and a sense of the Thai spirit (referring to piety and devotion), and Buddhism. "Because the King is seen to embody what it means to be Thai, this has implications for how issues of language and religion are viewed in the context of national identity" (Rappa \& Wee, 2006, p. 108). King Rama VI also strongly promoted the important concept of the three pillars: The nation, religion, and monarchy (Selway, 2007). As Traitongyoo (2008) puts it, "Thainess has become an ideology or even norms which may have more to do with people's faith and beliefs than the cultural traditions or way of living" (p. 238). The major themes of Thainess include inspiring Thai people "to be united, to put their nation first, to love their land, their religion, and their king above all" (Vella, 1978, p. 249). The notion of Thainess can also be defined as displaying the distinct quality, personality, and morality of Thai people (Premsrirat, 2014).

Western capitalist ideas also caused two other major reforms in Thai society: industrialisation and political reform (Srisantisuk, 2000). The industrial reform instigated the rise of capitalism and led to an improvement in the education system in terms of the quality of management and provision. Thai people were exposed as well to new beliefs and religions. The political reform occurred in 1932 and was initiated by a military junta (Ministry of Culture, 2013). The political system changed from an Absolute Monarchy to a Constitutional Monarchy (Srisantisuk, 2000). Thailand's first Constitution of the Kingdom of Thailand was promulgated in 1932 in order to maintain the democratic regime of the Government and ensure that the sovereign power derived from all Thai people. The Constitution also aimed to bring happiness, prosperity, and unique and perpetual dignity to His Majesty's subjects throughout the Kingdom in 
every respect, according to the will of His Majesty. Thai people, including young children, will be instilled with Thainess, discipline and awareness of public interests, and they will believe firmly in a democratic form of government with the King as Head of State (Office of the Council of State, 2017). This reform had a positive impact on Thai society as there was an influx of skilled workers, and new knowledge was gained through information and technology, which also led to increased opportunities in the education sector (Office of the National Education Commission, 2009).

Vella (1978) argued that "one of the greatest dangers to the Thai nation was the failure of its own people to appreciate the strengths and the virtues of Thai culture" (p. 177). In 1979, the National Culture Commission was established under the administration of the Ministry of Education, while the National Identity Board was formed under the supervision of the Office of the Prime Minister in the following year (Connors, 2005). These two important organisations were set up to be responsible for expanding "the meaning of Thai culture and identity so as to integrate broader social forces into more pluralised notions of Thainess, and to ideologically rehabilitate the Monarchy" (Connors, 2005, p. 530). Additionally, Thainess can refer to the concepts related to "kingship, hierarchy, moral leadership, social obligation, and Buddhist ethics and arts", and aims to strengthen the Thai national identity and "support a centralised political regime" (Dayley, 2011, p. 345).

The promotion of Thai nationalism and the formation process of Thainess have become more concrete and have been highlighted through many aspects of Thai society, for example, "from formally in the Thai education system (including early childhood services) to informally in popular media or day-to-day life" (Traitongyoo, 2008, p. 234). By supporting this process, the Ministry of Culture was officially established in 2002 to maintain Thai identity and protect "the trinity of Thailand", which consists of the nation, religion, and monarchy (Traitongyoo, 2008, p. 222). According to Renard (2006), children are inculcated with the notion of Thainess through the Thai language, history, manners, etiquettes, and other concepts of being Thai. "Regardless of their cultural background, if students stay in a Thai school for several years they will acquire many Thai cultural attributes" (p. 297).

The country is currently governed by a military government under a constitutional monarchy in the reign of King Rama X, who ascended to the throne on 1 December 2016, and who is from the Chakri Dynasty. As a nation, Thailand has been officially mourning the death of King Rama X's father, King Bhumibol Adulyadej 
(King Rama IX) since October 2016. He was the world's longest reigning monarch (1946 - 2016). The King mentioned throughout this study refers to King Rama IX, who passed away after the data collection was completed. The military government brought about the ideas of "the defence of the Monarchy, the unity of the nation, and the elimination of subversive threats" (Farrelly, 2016, p. 332). Thainess is the concept which is influenced from these notions and beliefs about national identity.

As already pointed out, Thailand's industrial, political, and education reforms were significantly influenced by Western capitalist ideas. They also had an impact on early childhood education. In light of this, the principles, standards, and concepts of early childhood education provision in Thailand must be consistent with the following: the 2007 Constitution of the Kingdom of Thailand (amended in 2017), which was first promulgated in 1932 (Office of the Basic Education Commission, 2008); the 1999 National Education Act (third amendment in 2010); the National Education Plans; and the 2003 Early Childhood Curriculum (which is the second revision). The revised 2017 Constitution of the Kingdom of Thailand additionally refers to early childhood education as being included in the basic education system of Thailand although it is not regarded as compulsory education.

The revised constitution states that the Government must provide a minimum of 12 years' education from early childhood education to the junior secondary level (Grade 9) free of charge. However, since 2009 the Government has promulgated the regulation of a 15-year free education policy in order to encourage Thai students to complete their education to the senior secondary level. Compulsory education in Thailand currently covers three years of early childhood education (pre-primary) and six years of both primary and secondary education (Jangdecha \& Larpkesorn, 2018).

The Government is responsible as well for early childhood education provision in order to foster young children's physical, emotional, social, and cognitive development and their self-discipline (Ministry of Education, 2003a,b). The constitution also states that Thai people, including local community members, "shall have the right to conserve or restore their customs, local traditional knowledge, arts or good culture of their community and of the nation" (Office of the Council of State, 2017, p. 12). Additionally, this reflects the official documents promoting the cultivation of Thainess, including Thai culture and identity.

The 2010 National Education Act defines education as the learning process for personal and social development through instructions, practice, training, transmission 
of culture, and enhancement of academic progress. This includes building a body of knowledge by creating a learning environment and society with factors available for lifelong learning (Office of the National Education Commission, 2010). The Act mentions as well that education provision aims to develop Thai people to reach their full potential regarding their physical, emotional, social, and cognitive development. This also includes inculcating morality, integrity, and cultural ways of living so a person can live happily with other people (Office of the National Education Commission, 2010). The cultivation of national and cultural pride, Thai identity, culture, arts, folk wisdom, and the promotion of Buddhism are also referred to in this Act. The 2010 National Education Act stated that education through formal, nonformal, and informal approaches shall focus on the learning process and integration of knowledge that is appropriate for each education level.

Thailand's first national education plan was promulgated after the political reform in 1932. Due to constant political, social, cultural, technological, and economic changes the national education plans were revised to reflect this. The current plan, the National Education Plan B.E. 2560 - 2579 (2017 - 2036), provided educational strategic planning for Thailand's education system from 2017 to 2036. This plan supports the education of Thai people with the aim of fostering quality lifelong learning and improving the quality of provision of early childhood education. This is one of the Government's aspirations for the recently revised 2017 Early Childhood Curriculum.

Early childhood education and care provision in Thailand is shaped by the country's national regulations, including the Government's aspiration along with cultural and societal changes and the notion of Thainess, which incorporate the promotion of Thai culture and identity. In the next section, the reasons why I carried out this study are presented.

\subsection{Rationale for the Study}

The focus for this study emerged after completing my master's degree in education. My family and close relatives were very interested in setting up a small private kindergarten in Thailand and this was the motivation for undertaking my $\mathrm{PhD}$ in the area of early childhood education despite my not being a qualified early childhood teacher. Growing up in Thailand I was taught by my parents and aunts to pay respect to my elders by performing the practice of Wai, a form of greeting, and visiting a 
temple to perform religious activities during the Songkran festival and on other important religious occasions. At the early childhood service and at the school I attended I was involved in the flag ceremony and in praying to the Buddha every morning. These cultural practices from my personal experiences, including the beliefs and attitudes that I have been inculcated with, influenced me to investigate how Thai culture and identity are framed in the official early childhood curriculum and taught in Thailand's early childhood education services.

\subsection{Aim of the Study and Research Questions}

After reviewing relevant literature, I found six studies that explored how Thai culture, identity, and Thainess underpin Thailand's national education, though only three of them examined how Thai concepts were incorporated into the Thai early childhood education services and the official curriculum (Arphattananon, 2018; Jatuporn, 2016; Klibthong, 2013; Pinyoanuntapong, 2013a,b; Thambaworn, 2008). Nonetheless, these studies did not investigate in depth how Thai culture and identity addressed the 2003 Early Childhood Curriculum (Ministry of Education, 2003a,b). "The inheritance of Thai culture and ways of life of the youths and children of the new generation can be obtained through education with the context of Thai ways of life" (Pinyoanuntapong, 2013a, p. 321). This study therefore aimed to explore what activities and practices early childhood services implemented in their programmes to promote Thai culture and identity. Three key questions were used to guide this investigation:

1. What activities and practices do early childhood services implement to promote Thai culture and identity with young children?

2. How do early childhood services perceive the roles of the Government in promoting Thai culture and identity with young children?

3. How do early childhood services view parents' roles in promoting Thai culture and identity with young children, and how do parents perceive their roles?

\subsection{Overview of the Thesis}

This chapter has introduced the topic of this thesis, outlined the three research questions and provided the rationale for carrying out this study. The broad context for 
the study has been considered by explaining Thai culture and identity and Thainess. The last section outlines the organisation of this thesis.

Chapter 2 will provide a brief history of Thailand's education system, including how early childhood education was established and has changed over time. The 2003 Early Childhood Curriculum (Ministry of Education, 2003a,b) and its accompanying manual, the Manual of the 2003 Early Childhood Curriculum (Ministry of Education, 2003c), are outlined in depth. Information regarding Thai society, culture, and identity is discussed and then five major aspects of Thai culture and identity are explored.

A review of relevant literature is outlined in Chapter 3. This literature review includes a focus on curriculum and the ideologies and theories underpinning the 2003 Early Childhood Curriculum (Ministry of Education, 2003a,b). The literature regarding the establishment of the notion of Thainess and the promotion of Thai culture and identity are then discussed. The chapter also provides a discussion on how the Government's 12 Core Values (Office of the Basic Education Commission, 2014) align with the curriculum. The theoretical framework of this study is also presented.

Chapter 4 provides the details of the methodology used in this study including a survey and a multiple case study. Phases One and Two of the study are explained. Ethical issues and data analysis are also addressed.

Chapters 5, 6, and 7 report the research findings. Chapter 5 reports on the survey findings. Chapter 6 reports on both multiple case study findings and the survey's open-ended questions. These questions relate to the first three themes that emerged from both research methods. The three themes concerned perceptions towards the 2003 Early Childhood Curriculum, the role of the Government and the umbrella organisations, and parents' participation. Chapter 7 discusses the multiple case study findings in relation to a key theme that emerged from the multiple case study data involving the integration of Thai culture in, and identity of daily teaching practices.

Finally, in Chapter 8 the key findings from the survey and multiple case study are discussed and analysed. Key themes are discussed in relation to how the services promoted Thai culture and identity with young children. 


\section{CHAPTER 2 \\ BACKGROUND OF THE STUDY}

This chapter presents an overview of the national education system in Thailand, with a focus on early childhood education. The 2003 Early Childhood Curriculum (Ministry of Education, 2003a,b) as well as the relevant national documents are examined to show how they have informed the current organisation of early childhood education. The importance of the Government's role in these education reforms is outlined. The last part of this chapter explores aspects of Thai culture and identity. The specific cultural activities and practices discussed are Thai traditions, manners, folk wisdom, social values and norms, and Buddhism. These aspects are explored as early childhood services may take these into consideration when implementing the official curriculum.

\subsection{History of Early Childhood Education in Thailand}

Thailand has a long history of providing early childhood education for young children. Before the promulgation of the 2003 Early Childhood Curriculum (Ministry of Education, 2003b) there were three distinct periods, the first occurring before education reforms were put into place $(1238-1868)$. The second phase occurred during the education reforms 1869 - 1931, while the third took place during the political reforms between 1932 and 2002. Each one is examined in this section.

\subsubsection{Period Before Education Reforms (1238 - 1868)}

Three types of early childhood programmes were in existence during this period, which were designed for children in relation to their socioeconomic status (Thambaworn, 2008). One programme was set up for the children from the royal family who were 3 to 7 years of age. Another existed for wealthy families who hired teachers to educate their children at home. A third programme, which took place in temples under the supervision of Buddhist monks, was for children whose families could not afford to pay or for those who had no-one to look after them (Daechakupt, 1999; Thambaworn, 2008).

From 1379 the education system became more focused on literacy and numeracy. Children were taught Thai language, drawing and carving skills, moral 
education (learning about Thai traditions, Thai culture, and the concept of gratitude), and martial arts. However, as Roumkid (1996) pointed out, there was a lack of consistency in the information being taught due to the small number of schools, and no formalised curriculum, teaching or learning assessment. Later on, Thai education was significantly influenced by Western countries including Portugal, France, England and the Netherlands as a result of these countries trading and doing business with Thailand. In 1862, King Rama IV invited Mrs Anna H. Leonowens from England to teach English to his princes and other royal princesses. According to Thambaworn (2008), the reason for doing this was to improve the education system.

\subsubsection{Education Reform (1869 - 1931)}

During King Rama V's reign an 'Orphanage House' was established for orphans and poor children to provide them with a safe and secure place to live (Daechakupt, 1999; Thambaworn, 2008). It was started in 1890 by one of King Rama V's wives, Phra Ong Chao Saisawaleepirom. Children were fed and clothed and taught good moral behaviourin order to earn a living later (Roumkid, 1996). It catered for girls from birth to 11 years of age and for boys until aged 13:

The Queen was in mourning for the loss of her beloved fiveyear-old daughter. She had empathy for other mothers or parents who might encounter the same situation. The Queen thought of those poor families who could not afford to provide appropriate care to their young children. Therefore, she decided to establish a place where all children could receive good care and education, which was an 'Orphanage House'. The house welcomed all children from any family background, for instance lower-class, middle-class, and especially orphans. (Roumkid, 1996, p. 87)

The Orphanage House teaching programme was developed by Phra Ong Chao Ditsawarakuman (now known as Damrong Rajanubhab), who was a half-brother of King Rama V. He outlined ten things that children needed to learn in order to live good lives: literacy, numeracy, good manners, cookery, embroidery, tree climbing, swimming, shelter building, planting, and looking after animals and these were all taught at the Orphanage House (Roumkid, 1996).

Early childhood education was officially introduced in the 1898 National Education Project (Thambaworn, 2008). The project outlined four education levels: early childhood, primary, secondary, and tertiary education (Roumkid, 1996). Early 
childhood programmes were attached to primary schools (Daechakupt, 1999). However, no details were given for the type of early childhood education provision provided. The project was revised and in the 1909 National Education Project two types of early childhood service were outlined: a preschool class attached to a primary school and a learning programme held at a temple. These services provided education and care for children aged 3 to 6 years and the following subjects were taught: Thai language, numeracy, self-protection such as taking care of yourself with basic needs, and morality, which included gratitude, sharing, and Buddhist principles (Roumkid, 1996).

Thambaworn (2008) noted that late in King Rama V's reign early childhood education was also provided through kindergarten programmes (in Thai: Anuban), in which children learnt to read, write, and count. The word 'kindergarten' was introduced for the first time in the Private School Act promulgated in 1918 (Phoonsub, 2010; Roumkid, 1996). The Act was issued by the Government to control the management and provision of private schools, including early childhood services, which were established by the private sector or individuals. The private kindergarten programmes drew on the ideas and methods of Fredrick Froebel and Maria Montessori. The first known private kindergarten was founded in 1911 at Wattana Wittayalai School, seven years before the Private School Act. The second one was established in 1923 at Rajini School, while Mater Dei School began in 1927. Although these kindergartens applied Western ideologies and methods, they also promoted Thai culture and identity through their daily teaching practices, for example, praying to Buddha in the morning and performing traditional Thai dances (Roumkid, 1996).

\subsubsection{Education after the Political Reform (1932 - 2002)}

Early childhood education flourished after the Political Reform (Roumkid, 1996). The sector was included in the 1932 National Education Plan, the first education plan in Thailand. It highlighted that the Government was responsible for early childhood education provision. The involvement of other non-government organisations was also encouraged (Phisanbut, 1982; Thambaworn, 2008). In 1937, the Ministry of Education emphasised the importance of early childhood education by offering scholarships for early childhood teachers to be trained in Japan (Chayaniyayodhin, 1970). 
In 1940 the Ministry of Education established the first public kindergarten, named La-Orutis School, which also applied the Montessori method of education in their teaching practices (Chayaniyayodhin, 1970). Two years later, provincial public kindergartens outside Bangkok were set up: Anuban Ratchasima in Ratchasima province, Anuban Chonburi in Chonburi province and Anuban Tak in Tak province (Daechakupt, 1999). By 1973, the Ministry of Education had established another 72 public kindergartens in every province of Thailand (Tongthaworn, 2003). Early childhood education was also included in the 1977 and 1992 National Education Plans.

The Ministry of Education began developing an early childhood curriculum in 1993 in order to provide guidelines for the appropriate care and education of young children. It needed to be compliant with the 1992 National Education Plan (Office of the National Education Commission, 1992). This education plan outlined pre-primary (early childhood) education as nurturing and developing children's desirable characteristics in each age range along with their physical, mental, social, cognitive, and behavioural development in order to be ready for primary school (Office of the National Education Commission, 1992). In 1997, Thailand's first early childhood curriculum, the 1997 Pre-Primary Curriculum, was promulgated (Ministry of Education, 1997a). The Government also promulgated the curriculum's accompanying manual (Ministry of Education, 1997b). The curriculum outlined care and education for three different age groups: birth to 1 year, 1 to 3 years, and 3 to 6 years (Ministry of Education, 1997a). The curriculum only provided learning content for the age group of 3 to 6 years. This included: children's self, family, early childhood services, people around children, Thai important dates, natural environment, environment conservation, and transportation and communication,.

In 2001, the country's economic and social crisis had brought about changes that made it necessary to revise all levels of the education system, including early childhood education. The 1997 Pre-Primary Curriculum was revised in response to these issues that Thailand was facing at that time (Ministry of Education, 1997a). One of the key aspirations for revising the 1997 Pre-Primary Curriculum was to maintain Thai culture and identity, as well as to take into consideration the social and cultural context of children's settings (Rattanathongkam, 2007). Another concern was the impact of having both parents working which meant that children were spending less time in their home environment (Ministry of Education, 2003b; Tongthaworn; 2003). 
A further issue was the increase of diverse ethnic groups from a variety of different cultures influenced by Western capitalist ideas, which had an impact on the Thai social structure (Renard, 2006).

After the review and consultation process, the 2003 Early Childhood Curriculum was promulgated in both the Thai and English versions, including an accompanying Manual of the 2003 Early Childhood Curriculum (Ministry of Education, 2003a,b,c). These are the curricula and the Manual referred to in this study. In August 2017, after the collection of data for this study was carried out, the newly revised third early childhood curriculum was released together with its Manual. The 2017 Early Childhood Curriculum has been implemented throughout the country since May 2018 (Ministry of Education, 2017a,b).

\subsection{Thailand's Early Childhood Education Provision}

In Thailand the importance of early childhood education was highlighted in the 1999 National Education Act, which stated that it is necessary to provide early childhood education provision (Thambaworn, 2008). According to Pinyoanuntapong (2013a), the principles of cultivation and the care and education of young children are based on a "child centred approach, individual differences, and life styles of children within the context of community, society and Thai culture" (p. 322). The main goals of Thailand's early childhood education, including the 2003 Early Childhood Curriculum, are to foster desirable qualities in young children to support them to become good citizens, to behave in a moral manner, and to be disciplined, develop national and cultural pride, become experts in what they are good at, and be responsible to their families, communities, societies, and the nation (Ministry of Education, 2003b). This includes assisting them to successfully adapt in a rapidly changing society. It also aims to ensure that parents, caregivers, and teachers nurture children to grow up in a safe and healthy environment. Further goals are set to guide children to be capable learners in today's society (Thambaworn, 2008), and to enhance their desirable characteristics within the standards of age appropriateness (Thongdee \& Kanjanakij, 1994). The focus of the curriculum was on children's holistic development through learning experiences and developmentally based practices.

The 2003 Early Childhood Curriculum outlines five broad principles taking into consideration that each child has the right to be taken care of and educated by 
being encouraged through appropriate learning with interactions that are positive between the children and their parents, and caregivers and early childhood teachers (Ministry of Education, 2003b). Children should be encouraged to develop at their own rate and potential with a holistic, balanced approach. The first principle states that every child's learning process and development must be fostered in each age group. The second affirms that children should be taken care of and educated with "attention to individual differences and their lifestyles within their context of community, society and Thai culture" (Ministry of Education, 2003b, p. 4). The third principle declares that the whole child concept needs to be taken into consideration in order to develop children through play and age-appropriate learning activities. The fourth states that teachers, caregivers and the child's parents need to provide learning experiences with the intention of supporting children's quality of life and happiness. The final principle maintains that collaboration with "families, communities, and education institutions" is important for fostering children's development (Ministry of Education, 2003b, p. 4).

\subsubsection{Implementation of the 2003 Early Childhood Curriculum}

The curriculum is designed to enhance children's development in four domains: physical, emotional, social, and cognitive, with the aim of producing well-rounded human beings. It states that learning entails "building children's knowledge, their skills and their familiarity, attitudes, and values" (Ministry of Education, 2003b, p. 30). The curriculum's philosophy is:

Based on an approach of taking care of and enhancing the child's learning process, which is responsive to each individual's nature, development, and potential. The approach also considers the child's socio-cultural context. Caregivers and teachers should use love, thoughtfulness, and care in laying the foundation for a good quality of life for both the individual and for society. (Ministry of Education, 2003b, p. 3)

This curriculum is developmentally based; it focuses on age-appropriate learning which aligns with children's development in all four developmental domains: physical, emotional, social, and cognitive (Ministry of Education, 2003b). However, the curriculum also states that learning must be in line with children's cultural background and way of life so that they can develop to their full potential as Thai citizens; the curriculum also acknowledges that culture plays a role in development. 
Early childhood education in Thailand aims to provide quality education and care for young children; the early years are also regarded as the most important stage of life in the development of their personality (Daechakupt, 1999).

The 2003 Early Childhood Curriculum was originally written in the Thai language (Ministry of Education, 2003a) and then translated into English by the Ministry of Education (Ministry of Education, 2003b). Some of the wording of the Thai and English versions varies slightly. For example, the Thai version mentions performing Wai, while the English one does not. The word Khwaam Bpen Thai, which means Thainess (Ministry of Education, 2003a) in Thai, was translated into English as "Thai identity" (Ministry of Education, 2003b, p. 32). The words "desirable characteristics" are written in the Thai version of the curriculum, and they are translated as "characteristics by age" and "age-related characteristics" in some places in the English version (Ministry of Education, 2003b, p. 27).

In the 2003 Early Childhood Curriculum two specific age groups are identified: birth to 3 years and 3 to 5 years. The curriculum states that " 5 years means 5 years 11 months 29 days" (Ministry of Education, 2003b, p. 3). Within the curriculum there were two sub-curricula for each age group. The sub-curricula for birth to 3 years indicate that "a child's development in each age range may be faster or slower than the criteria provided, teachers may instead note whether children's maturity or readiness continuously develops in the order of each stage described" (Ministry of Education, 2003b, p. 7). It also illustrates children's age-related characteristics at each age interval in correspondence to their four developmental domains; for example, at the age of 6 to 8 months children are able to pull themselves up into a sitting position and crawl, to show pleasure with laughter, to imitate simple actions and to repeat sounds like ma-ma or mum-mum (Ministry of Education, 2003b, pp. 8-13). The relevant information regarding children aged 3 to 5 years is mainly explained in this chapter, as this is the age group that is the focus of this study.

The official curriculum and its pedagogy are viewed as a reflection of Thai society's dominant beliefs and values that can be implicitly and explicitly transmitted and transferred within its members (Jatuporn, 2016). These are "widely believed to affect the construction and reconstruction of societal and national identities" (Jatuporn, 2016, p. 130). Thailand's curriculum also focuses on: "learn with fun, play to know, and balanced-develop with age-appropriate" activities (Office of the Basic Education 
Commission, 2008, p. 4). In other words, it is important to take into consideration children's age and experience and focus on their holistic development by maintaining their learning and development experiences and creating new meaningful experiences. Providing a suitable environment is also important; children are encouraged to learn both inside and outside of their early childhood services.

The 2003 Early Childhood Curriculum provides guidelines for overseeing early childhood education (Ministry of Education, 2003b). Twelve developmental goals are outlined to assist each child (aged 3 to 5 years) to reach their potential in relation to their physical, emotional, social and cognitive development. These goals are perceived to be "the standards of children's desirable characteristics" (Ministry of Education, 2003b, p. 27). The first goal states that children's bodies need to grow and develop within the standard for their age alongside having good health habits while the second one notes that when children's large and small muscles are well developed then their co-ordination and dexterity improves. The third points out that when children are happy, their mental health is good. The next one maintains that morality and good emotions need to be expressed, and this is followed by the fifth goal that children's emotions can be expressed through art, music, physical exercise and movement. The sixth goal affirms that children need to become independent in order to be able to help themselves, while the seventh states that "nature, environment, and culture are appreciated, and pride is taken in being Thai" (Ministry of Education, 2003b, p. 27). The next goal states that children should get along well with others and become good members of "a democratic society, under a regime of constitutional monarchy" (Ministry of Education, 2003b, p. 27). The ninth goal outlines that children need to use language in order to communicate in a meaningful way within ageappropriate standards. The next states that children should be able to think and solve problems as appropriate for their age, and the next notes that they need to demonstrate imagination and creative thinking. The final goal points out that a child needs to express a positive attitude to learning and demonstrate appropriate skills in searching for new knowledge (Ministry of Education, 2003b).

Characteristics by age follows the goals for three to five years. This shows the levels of competency associated with the stages of normal development that a child displays at 3 years, 4 years, and 5 years of age. The curriculum stresses that teachers need to comprehend the age-related characteristics for children aged 3 to 5 years to 
ensure that appropriate learning experiences are provided for each age. The curriculum provides a list of children's levels of competency for the age of 3 to 5 years. Under each age there are five to six bullet points. To illustrate, the curriculum lists what children should be able to do physically at the age of 3 in relation to their gross and fine motor development, for example, catching a ball with their full arms and trunk and using scissors with one hand. At age 4 a child should be able to catch a ball with both hands and use scissors to cut paper in a line, and at age 5 they should be able to catch a ball that is bounced and cut on a curved line with scissors.

Regarding children's emotional development at the age of 3 they should, for instance, be able to show their emotions and do things to please adults and receive praise for these. At age 4 children should be able to express appropriate emotions in some situations, and begin to appreciate their abilities in relation to their work. At age 5 children should express their emotions in situations that are appropriate and be able to admire their own abilities regarding their work and that of others. Pertaining to children's social development at age 3 they should be able to learn how to wait, and at age 4 share things with other children. When children are 5 years of age they are expected to say thank you when receiving something from adults, and show respect when meeting other adults. In conjunction with children's cognitive development, at age 3 they should be able to say their name, and ask for help if it's needed if they have a problem. At age 4 children should be able to say their full name and classify objects using their five senses, while at the age of 5 they should be able to talk to others and tell stories, and to ask why, how, and where questions.

The curriculum also has four "learning contents" that can be used by teachers as a framework to prepare appropriate activities for young children's learning development. These include "the self, people and places around children, natural environment, and things around children" (Ministry of Education, 2003b, pp. 33-34). The first learning item, the self, concerns children needing to know their names, family names, body parts, and how to take care of themselves, and to keep their bodies clean and safe. Another item is people and places around children. This entails young children learning about their families, their early childhood service, local communities, and the people around them in their daily lives. Natural environment is another learning item where children learn about living and non-living things around them, including the world's normal changes such as seasons, and day and night. The fourth 
learning content is things around children. This involves children learning about such things as colours, sizes, shapes, tools, vehicles, and communication that is used in their daily lives (Ministry of Education, 2003b).

"The contents in children's everyday lives can be used as a framework to provide activities for their learning and development" (Ministry of Education, 2003b, p.33). Teachers could design learning activities in accordance with children's interests and needs by taking into account the four learning contents. The range of learning contents is flexible and designed by teachers on the basis of children's real-life experiences and environment. Teachers should not focus on children memorising the items above, but rather they should set details for the key experiences, which should be in line with children's age, needs, and interests (Ministry of Education, 2003b).

The next section in the curriculum discusses the provision of experiences. The curriculum stresses that the experiences for children aged 3 to 5 must not be organised into subject matters but instead be "integrated into activities through play" (Ministry of Education, 2003b, p. 34). This allows children to learn through their own experiences in order to gain new skills and knowledge, righteousness and morality as well as develop physically, emotionally, socially and cognitively. The curriculum provides a brief list of principles and guidelines for providing these experiences under three headings. The first is principles in provision of experiences, which includes providing play and activities for the ongoing development of the whole child, and the importance of working in partnership with the child's parents and the local community to foster development.

The second lists guidelines in providing these experiences. This outlines how to provide experiences for young children in accordance with developmental psychology that are appropriate for an individual child's age, maturity and his/her development range. Also included in this section is the need for experiences to ensure that children learn through using all their senses by being active, exploring, playing and so forth. The final heading is the provision of everyday activities. This outlines what activities should be set up each day to foster children's learning in the different domains. Also, there are suggested times associated with the activities. For example, those where the children choose freely "such as playing in play areas or outdoor playing, should use approximately 40-60 minutes" (Ministry of Education, 2003b, p. 35). In regard to enhancing a child's imagination and creative thinking, teachers are 
expected to use art-related activities, music and movement as well as rhythm to enhance imagination. Children are also seen as needing to have opportunities to create things, play in different play areas and to play with water, sand as well as blocks of varying sizes to construct buildings and so forth (Ministry of Education, 2003b).

In addition to the official curriculum document, the Ministry of Education issued an accompanying Manual. The Manual of the 2003 Early Childhood Curriculum is outlined in the next section.

\subsubsection{The Manual of the 2003 Early Childhood Curriculum}

The Ministry of Education wrote the Manual of the 2003 Early Childhood Curriculum to accompany the official curriculum (Ministry of Education, 2003c). The Manual is written in the Thai language but has not been translated into English. The aim is to provide additional information for the early childhood education sector for children at the age of 3 to 5 years in order to enhance young children's physical, emotional, social, and cognitive development.

When writing the Manual of the 2003 Early Childhood Curriculum, the curriculum's philosophy and five broad principles were considered (Ministry of Education, 2003c). The learning content and process for curriculum implementation are explained in more detail, including guidelines for children's learning experiences such as writing lesson plans, learning activities to support children's holistic development, and criteria for evaluating these as well as supporting children's learning in the natural environment. It also explains the importance of building reciprocal working relationships between early childhood education teachers and those teaching children in the first year of primary school.

The Manual of the 2003 Early Childhood Curriculum outlines six guidelines for early childhood provision (Ministry of Education, 2003c). These include:

1. Designing an appropriate curriculum by considering children's age and focusing on their holistic development by creating new meaningful experiences.

2. Ensuring that the learning environment is suitable for children to learn both inside and outside the classroom. 
3. Providing key experiences and activities that enhance children's holistic development by building reciprocal relationships between teachers and children.

4. Integrating children's learning by providing a variety of relevant learning activities

5. Evaluating children's holistic development using observations, children's portfolios and performances, and information from children's families.

6. Building relationships between teachers and children's families by encouraging parents' participation and aiding their understanding of how children learn and develop.

The Manual of the 2003 Early Childhood Curriculum identifies four key concepts that underpin early childhood education provision in Thailand (Ministry of Education, 2003c). It states that the official curriculum was developed in relation to these concepts. The first concept is children's development. Children's physical, emotional, social and cognitive development must be fostered by taking into consideration their individual differences and potential. Another concept is about children's learning. It is believed that learning occurs as a result of children's personal experiences. By interacting with people and places around them children's behaviours may change accordingly. It is important that children actively learn and gain real-life experiences within appropriate learning environments and activities. Thirdly, children's play is another concept underpinning the curriculum's manual. Play is an important activity in every child's life. Children need to enjoy themselves, have fun, use their creativity, solve problems, discover, and explore by themselves. Play has an impact on children's growth by enhancing their holistic development. Playing in a meaningful way is one of the most important factors in the provision of key experiences. The final concept is children's social and cultural context. Individual children's social and cultural context can vary and it will have an influence on their development (Ministry of Education, 2003c).

The Manual of the 2003 Early Childhood Curriculum contains more in-depth information in comparison to the official curriculum (Ministry of Education, 2003c). By way of example, the Manual describes in detail what should be covered when teaching the learning content of people and places around children. The learning 
content includes: I (name of child) am a Thai citizen; there are a number of important dates in relation to the Nation, Religion, and Monarchy; I have several unique culture and traditions; my friend and I either have the same or different religious beliefs; every religion teaches everyone to be good person; and I am proud that I am a Thai national citizen (Ministry of Education, 2003c). Another significant aspect noted is the activity around the flag ceremony. The Manual contains samples of early childhood services' daily programmes and the flag ceremony is mentioned as one of the daily activities.

The Manual outlines six main activities that early childhood services should encourage children to participate in daily (Ministry of Education, 2003c). The first activity concerns an independent play activity (or corner play) which involves role play (such as wearing costumes), block play, reading in the book corner (for example, a folk tale), and exploring in a nature studying corner. The second one is a creative activity which requires learning material including drawing, painting, and colouring, cutting, and kneading (clay or dough). A further activity is related to educational games such as matching pictures, puzzles, dominoes, ordering (size or situation in a story), and a basic mathematic game. A circle activity is another one which aims to enhance learning experience to enable children to learn about natural resources and man-made materials. One more key activity is outdoor pursuits which include playing at a playground or with sand and water. The final one involves an aesthetic activity such as playing a rhythmic musical instrument.

Providing learning activities, including the six main activities stated in the Manual of the 2003 Early Childhood Curriculum (Ministry of Education, 2003c), should also be related to children's family situation, community, society, and Thai culture (Office of the Basic Education Commission, 2008). The intention of the curriculum is also to build relationships amongst families, communities, and early childhood services (Office of the Basic Education Commission, 2008). "They are jointly responsible for raising children to meet the desirable characteristics standards and expectations of society" (Ministry of Education, 2003b, p. 40). This involves children's learning from their interactions with things and others around them, including parents and other family members, teachers and the wider community, in order to provide them with a high-quality lifestyle and for them to be happy.

The Project Approach is one of the learning strategies mentioned in the Manual of the 2003 Early Childhood Curriculum, which states children should explore by 
themselves topics that they are interested in with help from teachers (Ministry of Education, 2003c). Children are responsible for searching and seeking answers to their own questions which is facilitated by support from their teachers and in some instances their parents. The project comprises three stages: initial stage, developing the project, and summarising the project. Within each stage, children learn through discussion, fieldtrips or field study, doing research, presentation, and demonstration (Ministry of Education, 2003c).

As stated earlier, Thailand's early childhood education provision and curriculum is congruent with the national laws and regulations. To illustrate this point, the curriculum's learning contents and key experiences mentioned in the Manual are closely associated with the different groups of knowledge identified in the 1999 National Education Act (third amendment in 2010). The first two learning items from the curriculum - the self, and people and places around children -- are aligned with the knowledge group that involves knowledge about oneself and the relationship between people and society, for example, family, community, the nation, including the history and the Constitutional Monarchy of Thailand.

From the Manual, the guidelines of key experience and learning activities are matched with another knowledge group which relates to knowledge about religion, arts, culture, sports, and Thai folk wisdom and its application. For instance, cultivating morality and righteousness is one of the key experiences enhancing emotional development. It is important to encourage children to behave in line with their religion, for example, visiting a temple (including a mosque or church). Another example is Thai folk play, which is a part of the Thai folk wisdom and regarded as one of the outdoor activities. When children are involved in folk play, their social development skill may develop. For example, playing in a group following the folk play's instruction; for example, Ree Ree Khao Sarn (Catching the last one in the line).

Moreover, the curriculum and its accompanying Manual mentions learning about numbers which involves counting numbers, measuring, and comparing more than or less than. Another learning experience is using language to convey meaning for children's thoughts and feelings, for example, expressing feelings in words, describing objects, listening to stories and rhymes, reading storybooks and symbols, and talking about personal experiences. These learning activities are aligned with the other group of knowledge identified in the 1999 National Education Act that includes 
knowledge and skills in the area of mathematics and language, especially correct usage of the Thai language.

In the next section the types of early childhood services in Thailand are explored alongside their supervision organisations.

\subsubsection{Early Childhood Services in Thailand}

There are different types of early childhood services in Thailand. According to the Office of the National Education Commission (2010), early childhood services can be classified as "early childhood development institutions, namely: childcare centers; child development centers; pre-schools; child development centers of religious institutions; initial care centers for disabled children or those with special needs, or early childhood development centers under other names" (p. 9). The Government expects parents and families to be the primary caregivers for their children, particularly from birth to 3 years of age. However, if this is not possible there are several early childhood services available that are run by the public or private sector (UNESCO International Bureau of Education, 2006).

Early childhood education in Thailand is split into two distinct age groups. The first includes infants and toddlers aged from birth to 3 years. The second group, 3 to 5 year-olds, usually attend some type of early childhood service. This is the age group that is the focus of my research study. There are three types of early childhood education available for children aged 3 to 5: pre-school classes, kindergartens, and child-care centres. "In general terms, private schools offer a three-year kindergarten programme" (UNESCO International Bureau of Education, 2011, p. 10). For the governmental (public) services, there are two types: two-year kindergarten and oneyear pre-school classes attached to primary schools in rural areas. Table 1 below provides a summary of early childhood provision in Thailand and the supervising agencies responsible for overseeing each one. 
Table 1

Types of early childhood services, age group, and supervising organisations

\begin{tabular}{|c|c|c|c|}
\hline $\begin{array}{c}\text { Age } \\
\text { Group }\end{array}$ & Types of services & Location & Supervising Organisations \\
\hline $\begin{array}{c}\text { Birth to } 3 \\
\text { years }\end{array}$ & $\begin{array}{l}\text { - Nursery } \\
\text { - Day Care } \\
\text { (Mostly located in or nearby } \\
\text { parents' workplaces, } \\
\text { designed by the government) }\end{array}$ & $\begin{array}{l}\text { Rural/ } \\
\text { Urban }\end{array}$ & $\begin{array}{l}\text { - Ministry of Public Health } \\
\text { - Ministry of Social Development } \\
\text { and Human Security } \\
\text { - Ministry of Labour } \\
\text { - Ministry of Defence } \\
\text { - Private sectors/foundations }\end{array}$ \\
\hline \multirow{3}{*}{$\begin{array}{l}3 \text { to } 5 \\
\text { years }\end{array}$} & $\begin{array}{l}\text { - Child Development Center } \\
\text { (under the Sub-district } \\
\text { Administration Organisation } \\
\text { - SAO) }\end{array}$ & $\begin{array}{l}\text { Mostly in } \\
\text { rural }\end{array}$ & $\begin{array}{l}\text { - SAO under Department of Local } \\
\text { Administration (DLA), Ministry of } \\
\text { Interior }\end{array}$ \\
\hline & $\begin{array}{l}\text { - Private Kindergarten } \\
\text { - Public Kindergarten }\end{array}$ & $\begin{array}{l}\text { Rural/ } \\
\text { Urban }\end{array}$ & \multirow{2}{*}{$\begin{array}{l}\text { - Office of the Basic Education } \\
\text { Commission (OBEC), Ministry of } \\
\text { Education } \\
\text { - Office of the Private Education } \\
\text { Commission (OPEC), Ministry of } \\
\text { Education } \\
\text { - Office of the Higher Education } \\
\text { Commission (OHEC), Ministry of } \\
\text { Education } \\
\text { - Department of Education, Bangkok } \\
\text { Metropolitan Administration (EDU } \\
\text { BMA) } \\
\text { - Department of Local } \\
\text { Administration (DLA), Ministry of } \\
\text { Interior }\end{array}$} \\
\hline & $\begin{array}{l}\text { - Preschool classes } \\
\text { (Prior Grade 1, always } \\
\text { attached to public primary } \\
\text { schools) }\end{array}$ & $\begin{array}{l}\text { Rural/ } \\
\text { Urban }\end{array}$ & \\
\hline
\end{tabular}

Note: Adapted from http://unesdoc.unesco.org/images/0014/001472/147249e.pdf. Copyright 2006 by UNESCO International Bureau of Education. Reprinted with permission.

The supervising agencies each have different responsibilities (The Office of the Education Council, 2013; UNESCO International Bureau of Education, 2006). The Ministry of Education has accountability for making policies related to education development, education quality, and learning and teaching approaches. In addition, its aim is to provide high quality education along with providing guidelines for early childhood teachers, parents and caregivers to foster young children's learning and development. The Ministry of Education administers three key organisations. The OBEC has responsibility for public kindergartens and preschools while the OPEC oversees the private kindergartens and preschools. The OHEC is responsible for the demonstration of preschools attached to universities. 
The Ministry of Public Health also plays a significant role in supporting and educating parents including pre and post-natal care, and related physical, well-being, and nutritional care. Additionally, this Ministry has responsibility for immunity vaccinations, iodine supplement, and other related physical well-being and nutritional care.

The Ministry of Social Development and Human Security has responsibility for families. Its function is to help and support poor families and their children, children with special needs, and orphans. It also oversees the standards and qualifications of early childhood services catering for children 3 years and under. The Ministry of Labour is another important establishment. Its function is overseeing teacher or caregiver training for the early childhood sector (overseeing children under 3 years old) and setting up early childhood centres for governmental organisations and units, for instance, Army, Navy, and Air Force (Teptien \& Trakulwong, 2007).

The Ministry of Interior's role is to ensure that all children aged 3 to 5 years living in urban and rural areas receive early childhood education and care. This is supervised and managed by the Department of Local Administration (DLA). A significant job of the DLA is to promote participation of family, community, the private sector, and any other related organisations. Another responsibility is providing equipment and supplementary food and milk for early childhood centres. The EDU BMA, which is a sub-department of the BMA, has responsibility for education provision and administration of services and schools in Bangkok.

According to the Office of the Basic Education Commission (n.d.), the size of an early childhood service in Thailand is determined by the number of children attending as illustrated in the Table below.

\section{Table 2}

Size of Services in Thailand

\begin{tabular}{|c|c|c|}
\hline Size of services & In Bangkok & In a rural area \\
\hline Small & Not more than 150 children & Not more than 120 children \\
\hline Medium & Between 151 and 300 children & Between 121 and 280 children \\
\hline Large & More than 301 children & More than 281 children \\
\hline
\end{tabular}


The Government plays an important role in supporting early childhood education as well as the other education sectors in Thailand. The next section discusses how Government's funding is allocated to the early childhood sector.

\subsubsection{The Government's Role in Early Childhood Education Provision}

Prior to 2009 the Government provided a minimum of 12 years of education to all Thai people free of charge, including early childhood education (Angeles-Bautista, 2004). Since 2009, a 15-year free education policy launched by the Ministry of Education has been in effect providing three years of early childhood education and six years for both primary and secondary education. The Government pays for tuition fees, textbooks, learning materials, school uniforms, and extracurricular activities (Office of the Basic Education Commission, 2018).

Most early childhood services are fully sponsored by the Government (Office of the Basic Education Commission, 2018). The funding received is used for purchasing classroom materials and equipment along with paying the salary of teachers and other educational personnel. Additional funding is allocated for food and other utilities, and expenses related to extracurricular activities. Supplementary funding sources are obtained from the private sector, parents' contribution, communities, and other non-government organisations.

The Ministry of Education also has responsibility for funding initial teacher education programmes and professional development for early childhood teachers, faculty staff, and educational personnel. Educational administrators, as well as supporting teaching staff, including teacher assistants, head teachers and principals and management teams, are all considered educational personnel (Office of the National Education Commission, 2010).

\subsubsection{Initial Teacher Education and Qualification}

Early childhood teachers are required to complete a four-year undergraduate bachelor's degree in education (Angeles-Bautista; 2004; UNESCO International Bureau of Education, 2011). The Office of the National Primary Education Commission requires early childhood teachers to have the following: a degree in early childhood education or teaching experience in early childhood education; comprehensive understanding about guidelines and principles of key experience 
provision; and knowledge of children's learning and development and its implications (Yodjew, 2012). Teaching staff in the early childhood sector includes "classroom teachers (kindergarten/preschool classes), caregivers (child development centres/daycare), and administrators" (UNESCO International Bureau of Education, 2006, p. 6).

According to the 1999 National Education Act, early childhood teachers, educational administrators, and other educational personnel need to hold professional licences. The Teacher Council of Thailand is a legal representative for teachers and educational personnel, and is under the supervision of the Ministry of Education. It is responsible for issuing teaching licences, determining and monitoring professional standards, supervising compliance and the ethics code, and designing professional development plans and policies (The Teacher Council of Thailand, 2003).

In this study, classroom teachers are referred to as early childhood teachers. This also includes teachers who have responsibilities in other roles rather than as teachers, for example, principals and head teachers. In the next section, different aspects of Thai culture and identity are presented.

\subsection{Thai Society, Culture, and Identity}

Thai society has been described as hierarchical with flexibility (Kuwinpant, 2002). Thai people identify themselves using a hierarchical system in relation to their age, gender, socio-economic status, and education level; for instance, children are expected to pay respect to their parents as well as to other adults and early childhood teachers. To clarify further, an older person from a village is supposed to show respect to a younger government officer who is seen as having a higher socio-economic status. However, the younger officer is expected to perform Wai, to demonstrate respect as the other person is older. Interestingly, Buddhist monks hold the highest social position in the Thai hierarchical system. The King and Queen and other royal family members must pay respect to Buddhist monks. This reflects the importance of Buddhism, which will be explained later in this section. Paying respect to the King and Queen, and the royal family is one of the key social values of Thai society. For instance, royal news is given priority on both television and radio and is normally presented before the other news (Servaes, 2017). 
Thailand's social structure is made up of families, villages (referring to a local community), temples, and the nation (referring to the monarchy and country) (Moore, 1974; Walliphodom, 2011). In Thai society, a family is a nuclear unit that may also include grandparents, uncles, and aunts. Family members know their roles, duties, and responsibilities (Servaes, 2017). Based on a hierarchical system, "children are taught to respect their elders" (Moore, 1974, p. 11). They are expected to obey their parents and other older family members and to treat their teachers with respect.

Thai people are generally perceived as being polite, humble, friendly, and kind (Rattanathongkam, 2007). This includes being willing to forgive others and paying respect to elders. In earlier times Thai people's social values were based around interdependence, kindness, generosity, and willingness to help others (Athikomnantha, 1998). Thai people's friendliness "is made smooth by the ways of politeness. Manners are an inherent part of the Thai character" (Moore, 1974, p. 9). Being polite and friendly has become a part of the country's culture and identity.

Factors that have influenced Thai culture and identity are Thailand's geographical features, agricultural society, Thai people's personality, social values, cultural diffusion, Westernisation, and Buddhism which includes Buddha's teaching, Buddhist principles, and ways of practice. In addition to these there are two other important aspects that can precisely represent Thai culture and identity: the unique Thai language and the Monarchy ruling system.

Thailand was and still is an agricultural society (Office of the National Education Commission, 2002, 2009). The country's geographical mainland, made up of plateaux, highlands, lowlands, mountainous areas, and rivers, has shaped the way Thai people have lived (Srisantisuk, 2000). "Abundance of rivers has not been only providing a sound economic base but has also focused on those customs and practices that focus on life-giving water; for example, Loy Kratong and Songkran festival" (O’Sullivan \& Tajaroensuk, 1997, p. 11).

There are five major aspects of Thai culture and identity: Thai manners, traditions, folk wisdom, social values, and norms, and Buddhism. These are explored next starting with Thai manners. 


\subsubsection{Thai Manners}

A significant aspect of Thai culture is Thai manners, which include having proper etiquette when standing, walking, sitting, eating, and handing over and receiving things from other people (Department of Cultural Promotion, 2010b). Thai manners are regarded as a sub-component of Thai culture which reflects Thai national identity. There are two traditional types of posing and gesturing, Wai and Kraab, which are considered everyday practice in Thailand. As mentioned, Wai is a way of greeting, it is also a way of paying respect to people, places and objects indicated by different positions used for holding one's palms and bowing one's head (Phaphijitr, 2006). Figure 1 shows the three distinct levels of performing Wai. The first level is used when paying respect to Buddha images, Buddhist monks, and historical places and objects. The second one is used when greeting parents, relatives, teachers, and others who need to be greeted in this way. People use the third level to pay respect to those who are of the same age or slightly older and are of a higher socio-economic status (Department of Cultural Promotion, 2010b).

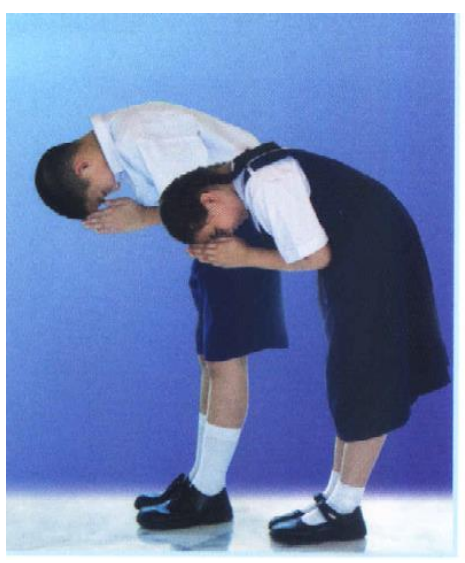

The first level of Wai

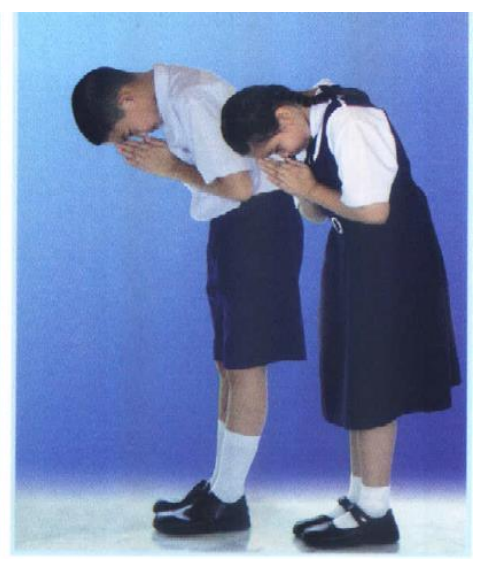

The second level of Wai

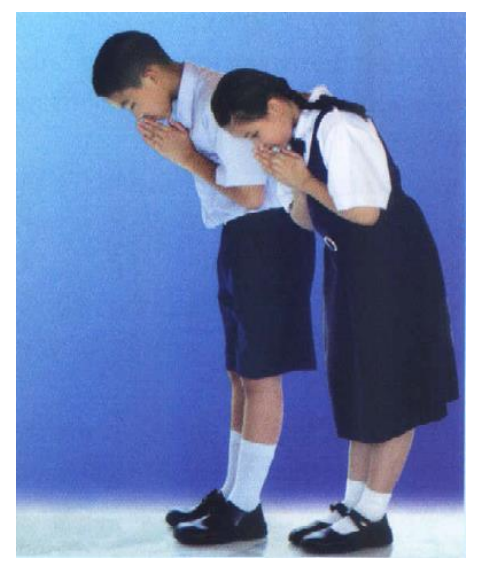

The third level of Wai

Figure 1. Three levels of performing Wai

Note: Reprinted from Maa ra yaat Thai [Thai manners] (p. 3), by Department of Cultural Promotion, 2010b, Bangkok, Thailand: Ministry of Culture.

Copyright 2010 by Department of Cultural Promotion. Reprinted with permission.

Thai people are expected to pay respect to one another and behave in a polite manner, which is an important aspect of Thai culture. A Wai traditional gesture is one way that this is demonstrated and it was developed from Thai people's attributes such as humbleness, gratitude, and respect for one's elders. Presently, Thai people often greet 
one another by smiling and saying Sawasdee (means hello) without performing Wai. This could be the impact of Westernisation.

Kraab is another gestural way of paying respect with gratitude and gratefulness to people and sacred objects. This is demonstrated by sitting on the floor with one's legs tucked behind to one side and prostrating. There are two types of Kraab practised in Thailand. The first one is Benjangkapradit prostration, which is used to pay respect to Buddha images and Buddhist monks. Thai people normally prostrate three times with one's palms opened when performing Benjangkapradit Kraab. Another type of Kraab which is used to pay respect to adults such as parents and older relatives is by prostrating once with one's palms closed (Department of Cultural Promotion, 2010b).

\subsubsection{Thai Traditions}

Traditions in Thailand have been practised and passed down through the generations. Tradition means "continued behaviours and practices of activities based on the lifestyle and society of the community" (Department of Cultural Promotion, 2017, p. 18). Two significant traditions are the Songkran and Loy Kratong festivals, which had been celebrated for many centuries and were revived during King Rama V's reign (1868-1910). Thai people from every region of the country celebrate these two festivals, but each one may have its own specific activities reflecting the local culture (Department of Cultural Promotion, 2017).

The Songkran festival is a celebration of the Thai New Year on the Buddhist calendar and is held in mid-April, during the school holidays (usually occurs between late March and the middle of May), which is the hottest month of the year. People normally celebrate this festival with water splashing and getting soaked (Thongsawang, 1994). It is very well known as a water festival to many foreign people. Songkran is also a religious holiday, a time for expression of love and unity in families. Thai people usually return to their home town and family. They perform water pouring and ask older family members for their blessing for auspiciousness and prosperity. In addition, Thai people usually clean their houses and visit a temple as a way of gaining merit by offering food to Buddhist monks and listening to Buddha's doctrines as they begin the new year.

Loy Kratong is the second-best known festival and is held over one day. It is also referred to as the Thai festival of light and is celebrated in November on the full- 
moon day of Thailand's twelfth lunar month, which marks the end of the rainy season and the start of the harvest period. The Ministry of Culture (2015) suggested that the following activities should be organised on Loy Kratong day: traditional Thai dances; promotion of the local culture of a community; and getting rid of garbage in a river or any other water source in a community. At most early childhood services, children are involved in performing the traditional Thai dance on a stage and dressing up in traditional Thai costumes. During the evening people usually take a basket (in Thai: Kratong) which is typically made from banana trunks and leaves (easily biodegradable) and is decorated with flowers, candles, and joss sticks, to float in a river. Today floating baskets are also made from bread, which can be food for marine animals.

Many temples in local communities normally organise an event to celebrate the Loy Kratong festival with food stalls, games and activities, and stalls selling decorated baskets, and the traditional Loy Kratong song is played to provide background music. In earlier times at a temple, Thai people performed a type of Thai folk dance called Ram Wong, where a group of males and females danced together in a circle. Thai folk dance is different to traditional Thai dance in terms of the number of participants. A person can perform a traditional Thai dance alone whereas Thai folk dance requires a group of people and usually takes place during special festivals. These two festivals are considered a part of Thai tradition as these are celebrated every year.

Thai traditions also involve important dates. The two important dates are Father's Day and Mother's Day (see Appendix A) and are normally observed by Thai people in every region. The first celebration of Father's Day took place on December 5, 1980 in order to express gratitude and respect to every father. The date was chosen as it was King Rama IX's birthday. It is also referred to as Thailand's National Day. In relation to Mother's Day, this yearly celebration started on 12 August, 1976, which was the birth date of Queen Sirikit (Department of Cultural Promotion, 2011). Thai people usually celebrate these two important dates by putting up the national flag and the royal flags of the King and Queen in front of their houses, extending their best wishes to the King and Queen, expressing gratitude to their parents or guardians by giving garlands, and visiting a temple in order to offer food to Buddhist monks and listen to Buddha's doctrines. It is common for early childhood services and schools to celebrate these two important dates on the day before the actual day as they are public 
holidays in Thailand. Schools and services usually organise activities to express gratitude on Father's Day and Mother's Day. Children perform Kraab to their fathers/mothers and give garlands to them to show that they are grateful to them.

\subsubsection{Thai Folk Wisdom}

Alongside practising Thai manners and celebrating festivals, Thai folk wisdom is significant in Thai society and helps promote Thai culture and identity (Athikomnantha, 1998). Thai folk wisdom has been passed on from generation to generation and is a by-product of Thai people's ability to develop their own traditions and adopt various cultures and civilisations that impact on their lives. "Folk wisdom of each locality is the heritage that ancestors had created, collected, and retained through generations. Thai local people should realise its value and be proud of sustaining the heritage" (Department of Cultural Promotion, 2017, p. 17). Thai culture and traditions of local communities may differ by geography, natural resources and environment, but the identity of Thai folk wisdom remains. Thai folk wisdom can be reflected through language, costumes, performing arts, folk plays, and food. Each of these is presented below as sub-sections of Thai folk wisdom.

\subsubsection{Thai language}

Thai language is another significant symbol of Thailand's national culture and identity. It is the national and official language in Thailand, which "reflects and expresses Thai culture" (O'Sullivan \& Tajaroensuk, 1997, p. 51). Historical data have revealed that Thai alphabets, derived from the Old Khmer script, were invented during the Sukhothai Kingdom in 1283. Thai language has been widely used in Thailand since the reign of King Rama IV.

Thai language can be categorised into two groups: ethnic group language and local Thai language (Department of Cultural Promotion, 2017). Ethnic group language refers to the language spoken amongst groups such as the Mong tribes. In central Bangkok, where this study was carried out, ethnic group language is spoken by a minority. Local Thai language denotes dialects used in each region for communication among specific local groups, for example, the central, northern, southern, and north eastern Thai dialect. These four dialects have different tones, vocabularies, and pronunciation; however, "they all share the same grammar system. Central Thai 
language is regarded as standard and is taught in schools throughout the nation" (O’Sullivan \& Tajaroensuk, 1997, p. 51). Throughout this thesis, Central Thai language is referred to as 'Thai language'.

Thai language also has levels of vocabulary and ranking used by groups. For instance, reverence terms are set for royal family members and are more formal than colloquial vocabulary used with Buddhist monks. Thai people can be referred to as family members even though they do not have direct family kinships such as brother, sister, uncle, aunt, and grandparents.

Through language children express their feelings in words, communicate with each other, share their personal experiences, and explain situations and objects. One of the goals of the 2003 Early Childhood Curriculum is for language to be "used to communicate meaningfully within appropriate age standards" (Ministry of Education, 2003b, p. 27). As mentioned earlier, by age 5 children are expected to state their own name and age, talk with others and be able to tell stories and ask why and how questions. They are also expected to say 'thank you' if they receive anything from adults and express appropriate emotions depending on the circumstances.

As Thai language is a vital part of Thai culture, the Government has highlighted how important it is to maintain and correctly use Thai language (Department of Cultural Promotion, 2017). This was reinforced in 1999 when the Government established the National Thai Language Day to be held on 29 July. It was inspired by King Bhumibol's aspiration to preserve the unique Thai language (The Association of Thai Language Teachers of Thailand, 2015).

\subsubsection{Thai costumes}

Thai culture is reflected through traditional Thai costumes. These have changed over time due to the influence of Western ideas of what has been fashionable since 1850 . People in different regions have distinct styles of costumes; for example, the northern region of Thailand has its own specific costume design and the material used is mainly silk. During the reign of King Rama IX, Her Majesty Queen Sirikit had difficulty sorting out which traditional clothing to take overseas for a long trip. She asked to see historical photographs of what former queens wore. After viewing these, she realised there was a mismatch between the top and skirt and they were not fashionable (Sarobol, 2007). Therefore, Queen Sirikit decided to modernise and westernise the 
Thai national costume and established 'Thai Phra Ratchaniyom' outfits for women in 1960 and the 'Phra Ratchatharn' top for men in 1979.

A

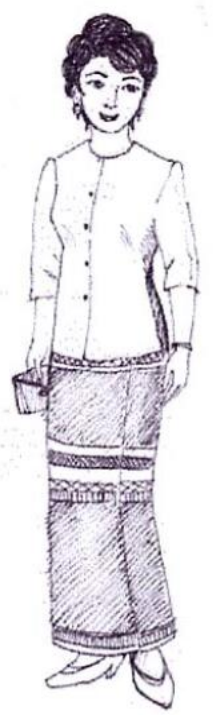

B

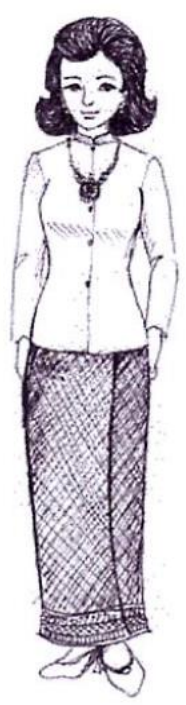

C
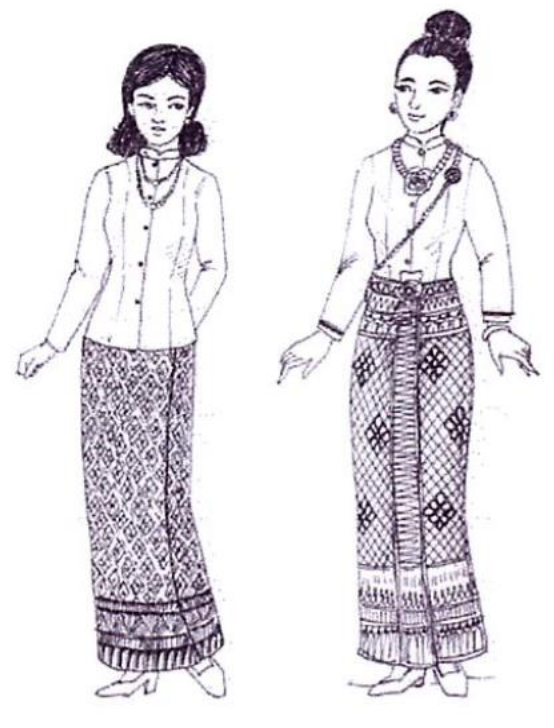

$\mathbf{E}$

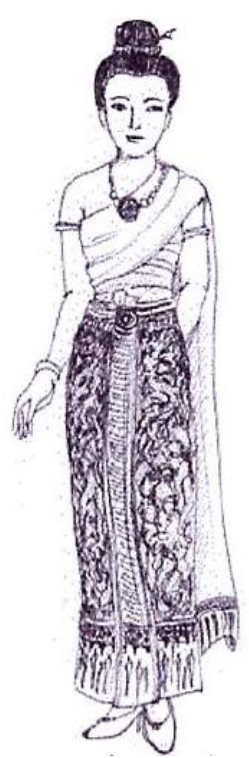

$\mathbf{F}$

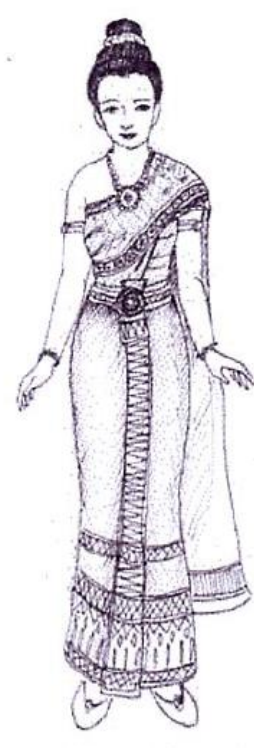

G

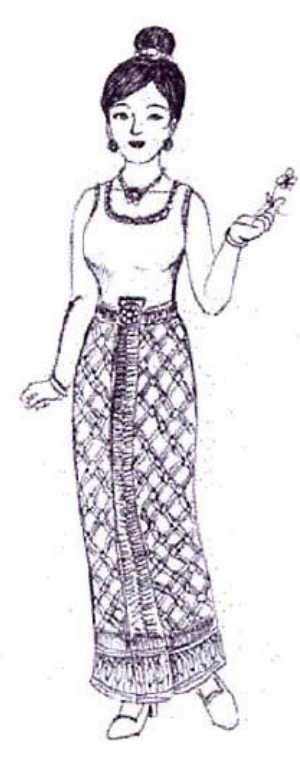

$\mathbf{H}$

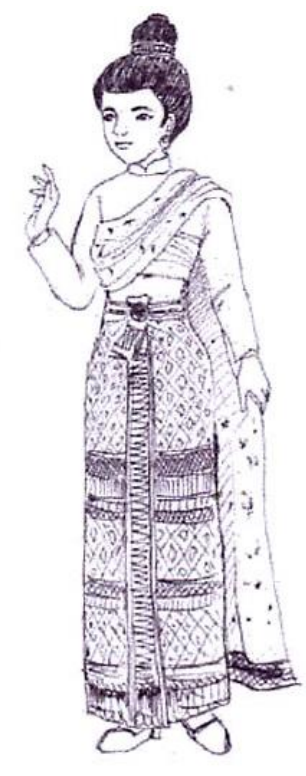

Figure 2. Eight styles $(\mathrm{A}-\mathrm{H})$ of the Thai Phraratchaniyom outfits (Sarobol, 2007). Note: Reprinted from http://www.human.cmu.ac.th/home/hc/ebook/006216/00621603.pdf

Copyright 2007 by Atchara Sarobol. Reprinted with permission. 
The Thai Phra Ratchaniyom outfits consist of eight styles (see Figure 2). The basic component of all the various styles for women is a Sarong (in Thai: Phaa-sin), which is made from silk and worn as a skirt. Each of the styles is designed to be worn on different occasions. Thai Ruen Ton (style A) is a casual outfit for informal events, including visiting a temple on important religious dates. Thai Chitlada (style B) is worn during daytime formal events and when welcoming Heads of State from overseas. Thai Amarin (style C) is an outfit for formal events and royal ceremonies while Thai Boromphiman (style D) is worn for formal welcoming dinners. Thai Chakri (style E) is another formal, more elegant, outfit for dressing up in for evening ceremonies. The distinctive element of this outfit is 'Sabai', a shawl used to wrap over one shoulder around one's chest and back. This is the outfit most people consider a traditional Thai costume. A further outfit, Thai Chakkraphat (style F), is worn at royal and national ceremonies in the evening and is like the Thai Chakri but uses two Sabai shawls. This outfit is considered an authentic Thai costume (Sarobol, 2007, p. 36). Another style, Thai Dusit (style G), is designed for formal evening events and is suitable for wearing a shoulder strap while Thai Siwalai (style $\mathrm{H}$ ) is suitable for wearing during the colder weather.

The Thai national costume for males is a top called 'Phra Ratchatharn'. It was designed in 1979 by Gen. Prem Tinsulanonda, who was the Minister of Defence at that time. He was also the $16^{\text {th }}$ Prime Minister of Thailand. While visiting other ASEAN countries, he noticed that every country had its own styled top but not Thailand. On his return to Thailand he spoke to Queen Sirikit about this matter. The Queen gave him one of King Bhumibol's tops (Sarobol, 2007). This became the standardised top that all Thai males wear. The Phra Ratchatharn top is a jacket, typically worn with long black pants. The jacket has a Mandarin collar that is slightly tapered and has five buttons and two outside pockets. There are three styles: a short-sleeved top, a longsleeved top, and a long-sleeved top with a sash. A sash is made from a piece of fabric, which is called 'Phaa Khaao Maa'.

Traditional costumes have commonly been worn by Thai people for different occasions, including at early childhood services. For example, the female styles A and $\mathrm{B}$ are worn when people attend a religious ceremony at a temple, while the female style $\mathrm{F}$ is usually worn when children (or adults) perform traditional Thai dancing on a stage for various festivals and on special occasions. Males normally wear the long- 
sleeved top when attending any formal events such as being a guest at a wedding or for a graduation ceremony. Wearing traditional Thai costumes is an important practice to promote Thai culture and identity.

\subsubsection{Performing arts, folk play, and food}

Thai folk wisdom can be expressed in many ways. One of these is performing arts, which refers to such things as Lakorn (drama), modern dance, traditional dance, and stories conveyed through music. These can be formal or adapted from original folk tales and performed in front of audiences for different purposes, for instance stage performance for celebrating festivals and important occasions. Folk tales are another and these are used to teach children morality and righteousness. They can be classified by content or a character, for example, myths, fairy tales, legends, didactic tales, animal tales, jokes, and 'tall' tales (Saranukromthai, n.d.). A further example of Thai folk wisdom is Thai performing arts, which involves music and singing such as playing musical instruments and participating in ritual performances. At the Loy Kratong festival, during the traditional dancing people sing the Loy Kratong song. Thai performing arts also involves the dramatic arts (or drama), which includes a storytelling performance, such as Khon, and non-story role-play.

Another aspect is Thai folk play, which is considered an intangible cultural activity because of its artistic value in terms of movement, method, patterns, tactics, and language uses. Thai folk play requires little playing equipment, but if needed this is usually made from natural material such as a stem of a banana tree and coconut shells. Various types of folk play reflect Thai people's distinctive living style and folk wisdom in different communities. The main objective of folk play seen in several festivals is to create the solidarity of the community members as well as enjoyment for such activities. For instance, during the Songkran festival a folk play is practised by children when they gather at a temple. Thai folk plays also contribute to children's physical and social-emotional development, harmony, and compassion for others (Department of Cultural Promotion, 2017).

Thai food and the cultural behaviours associated with this also reflect Thai folk wisdom. As stated earlier, people in Thai society generally live together as a big family. The family's main meal is dinner and the tendency is for all family members to eat together. In central Thailand, the set menu is not only served as a daily meal, 
but also as offerings to Buddhist monks in religious activities (Department of Cultural Promotion, 2017). The set dishes for monks generally are comprised of a set of main dishes, including both curry and clear soup, and five to six kinds of dessert and fruit (Department of Cultural Promotion, 2017). Thai folk wisdom therefore plays an important role in promoting Thai culture and identity.

\subsubsection{Thai Social Values and Norms}

Social values, beliefs, and norms have been taught from one generation to another and are perceived as normal behaviour in Thai society. The concept of gratitude and sharing are commonly practised among Thai people, including children. Gratitude involves paying respect, valuing, and expecting to give something in return to one's parents, the Nation, and the King. In the 2003 Early Childhood Curriculum sharing, along with being kind and helping others, is viewed as an important attribute to promote with young children (Ministry of Education, 2003b).

The 12 core values are another important part of Thailand's social values. In July 2014, the Government initiated these values for Thai people to further strengthen Thailand's stability and cultivate good citizenship. As a result, the Ministry of Education promotes these national core values in all early childhood services and schools. The aim of these values is to raise awareness of Thai nationalism and cultivating Thainess, including promoting the highly respected precedence to the Monarchy. The Prime Minister also aspired to identify precise core values for Thai people so that the country could become a stronger nation (Farrelly, 2016). These 12 core values underpin Thai people's way of life as they are based on patience, perseverance, diligence, wisdom, and prudence. It is important for people to create balance and be resilient in order to cope with the rapid socioeconomic, environmental, and cultural changes in Thailand and the rest of the world. In the next chapter, I will critique how these values fit in the 2003 Early Childhood Curriculum (Ministry of Education, 2003b).

In relation to traditional Thai norms, one of the cultural practices is the national flag and singing an anthem. In Thailand there are official regulations on how to raise and display the national flag, which were first issued in 1986 (Office of the Prime Minister, 2018). The national anthem is sung twice a day during the flag ceremony. The flag is raised at 8.00 am and lowered at $6.00 \mathrm{pm}$ (Office of the Prime Minister, 
1986). The Thai national flag is called the "Three Colours Flag" (Thongsawang, 1994). The red strip refers to the land and people, which symbolises the Nation, the white strip is for religions, while the blue strip represents the Monarchy. These three pillars of the flag are highly valued in Thailand. During the flag ceremony Thai people, including young children, are expected to stand up and sing the national anthem. To illustrate the importance of the flag ceremony (twice daily) all the television channels broadcast the Thai national anthem. The radio also plays the national anthem on every station. The following is spoken in the broadcast prior to the national anthem: "Thai national flag and anthem are symbols of Thainess. All Thai people stand together with respect to the national flag. They should be proud of the nation's independence and their ancestors' sacrifice for the nation" (Translated by the author). These words signal that the national anthem is about to be sung.

The Thai national anthem was first sung in 1932 after the political revolution, signifying the change from an absolute monarchy to a constitutional monarchy. The lyrics were written by Khun Wichitmatra and the English translation was done by the Public Relations Department of the Office of the Prime Minister of Thailand (Hoonchamlong, 2007).

\section{Thai National Anthem Lyrics}

Thai Language

Bpra Thaeht Thai Ruaam Leuuat Neuua Chaat Cheuua Thai

Bpen Bpra Chaa Rat Pha Thai Khaawng Thai Thook Suaan

Yuu Dam Rohng Khohng Wai Dai Thang Muaan

Duay Thai Luaan Maai Rak Saa Mak Khee

Thai Nee Rak Sa Ngohp Dtaae Theung Rohp Mai Khlaat

Aehk Ga Raat Ja Mai Hai Khrai Khohm Khee

Sa La Leuuat Thook Yaat Bpen Chaat Phlee
English Translation

Thailand is the unity of Thai blood and body

The whole country belongs to the Thai people

Maintaining thus far the Thai nation

All Thai people intend to unite together

Thai people love peace but are not afraid to fight

They will never let anyone threaten their independence

They will sacrifice every drop of their blood to contribute to the nation 
Tha Leerng Bpra Thaeht Chaat Thai Tha Wee Mee Chai

Chai Yo!
They will serve their country with pride and prestige, full of victory.

Chai Yo! (Hurrah)

When the national anthem is played all Thai people, including children, are expected to stand still until the end of the song if they are in a public space such as an educational institution, railway station, bus stop, or in the hospital. However, it is acceptable not to stand up if people are in situations where it is not convenient to do so, for instance riding on public transport. The lyrics strongly emphasised Thai identity, denoting that Thailand belongs to every Thai person.

The Thai national flag must also be displayed in all public areas and governmental organisations on importantoccasions in addition to the everyday practice of the flag ceremony (Office of the Prime Minister, 2018). Every educational institution, including early childhood services, needs to have a real-sized Thai national flag displayed in a flag holder all day long, either in front of or inside their premises, on New Year Day and during the Songkran festival. This also occurs on the following important religious dates: Father's Day and Mother's Day and more recently, to celebrate King Rama X's birthday.

\subsubsection{Buddhism}

Buddhism is another way to promote Thai culture and identity. Thai culture has been significantly influenced by religion. Buddhism has been a mainstream part of Thai culture and identity since 1782 (the reign of King Rama I of the Chakri Dynasty), although it is not Thailand's national religion (Rattanathongkam, 2007). Around 95\% of the country's population are 'Theravada' Buddhist (Klibthong, 2013). The belief system and values of Buddhism play a huge role in people's day-to-day lives. Theravada is the ancient branch of Buddhism, which is conservative in regard to the Buddha's doctrines and monastic disciplines. Religion, and particularly Buddhism, is one of the key factors that influence Thai people's way of life. Throughout the country, the most important values for Thai people are respect, self-control, and a nonconfrontational attitude (O’Sullivan \& Tajaroensuk, 1997).

Buddhist principles and religious ceremonies are an important part of Thai people's daily lives, including observing important religious dates. For instance, 
parents normally arrange a welcoming ceremony for a new-born infant which involves a Buddhist or Brahman monk being at their house to bless the baby. Another aspect of Buddhism is how people behave themselves in accordance with local folkways called Buddhists' practices. This includes visiting a temple daily and observing important religious dates, offering food to a monk, listening to preaching (Buddhist monks incorporate the Buddha's doctrines to teach Buddhists), praying to the Buddha, and practising meditation.

Thai education is closely associated with Buddhism due to temples serving as a place to study. Buddhist monks act as teachers delivering both Buddhism doctrines, including morality, righteousness, and principles, along with the Thai language and basic numeracy (Athikomnantha, 1998). In Thailand, temples (in Thai: Wat) play an important role in the everyday life of Thai people. Temples are public places for traditions and other folkway activities. The term 'temple' includes various buildings in a temple like the Ubosot, which is the central sanctuary hall, the Viharn, the Buddha image hall where important Buddha images are kept, and a Chedi where Buddhist relics are enshrined. Believers can access most of the areas or even all the main buildings of temples, except those that are restricted from doing so.

A temple is a symbolic object for religious or spiritual rituals and activities such as prayer and sacrifice (O'Sullivan \& Tajaroensuk, 1997). Thai people visiting temples to pray to the Buddha ask for things such as good health, good fortune and wealth, as well as seek advice from Buddhist monks (Moore, 1974). There are literally tens of thousands of Buddhist temples in Thailand. Temples are usually located in each village or community. They function as an important part of a community, providing storage for art and cultural works, a place to cure people with traditional Thai medication (herbal medicines) and performing religious ceremonies as well as providing shelter for visitors (Thongsawang, 1994).

Thai people always perform religious ceremonies at a temple, for example Buddhist monks oversee funerals that proceed cremation. On Buddhist Lent Day, they walk with lighted candles in their hands around a temple (Thongsawang, 1994). These religious activities reflect that Thai society, culture and identity, and Buddhism are all connected. 


\subsection{Chapter Summary}

Thailand was influenced by Western capitalist ideas which had a huge impact on the country's political and educational systems. The first early childhood programme was started in 1880 and early childhood education was officially introduced in the 1898 National Education Project. In 1997, the first early childhood curriculum of Thailand was promulgated. Due to economic and social changes that the country was experiencing, the curriculum was revised in 2003. The aim of the 2003 Early Childhood Curriculum (Ministry of Education, 2003b) was to provide early childhood education and care to every child in accordance with the Constitution and 1999 National Education Act.

The curriculum has five broad principles: care and education must take into consideration their individual differences and their background within the context of their surrounding community, the wider society, and Thai culture (Ministry of Education, 2003b). The curriculum's learning contents and key experience provision, including the Manual of the 2003 Early Childhood Curriculum (Ministry of Education, 2003c) were outlined. The Government, including the Ministry of Education, in Thailand is the key organisation for early childhood education and care provision. Five key aspects of Thai culture and identity, including Thai manners, traditions, folk wisdom, social values and norms, and Buddhism, were discussed.

In the next chapter, a review of relevant literature is presented in relation to defining a curriculum and its framework, learning theories, and Thai concepts that underpinned the 2003 Early Childhood Curriculum (Ministry of Education, 2003b). At the end of the chapter, the theoretical framework is outlined. 


\section{CHAPTER 3}

\section{LITERATURE REVIEW}

This chapter provides a review of relevant literature in relation to early childhood curricula. How curriculum is defined and shaped by its framework in a broader context is examined. A review of dominant theories and philosophies that have underpinned and influenced early childhood curriculum development in Thailand is then explored. The theoretical framework for this thesis is presented at the end of the chapter.

To conduct the literature review, several library online databases were used, including A+ Education, Education Source, Education Information Centre (ERIC), Google Scholar, ProQuest Education, Wiley Online Library and PsycINFO. The library database of Chulalongkorn University in Thailand was also used. The databases were searched using the following key words "early childhood curriculum", "early childhood education in Thailand", "Thainess", "a cultivation of Thainess", "Thai nationalism", "Thai culture and society", "Thai culture and identity", "learning theories" and "socio-cultural theory". The search was specifically aimed to target research-based texts, peer-reviewed scholarly journal articles, empirical studies, and official Government documents. However, this search was not limited to theoretical or research papers published within a selected timeframe.

\subsection{Definition of a Curriculum}

To date there have been many different definitions of curriculum. Oberhuemer (2005) and Vartuli and Rohs (2007) argue that curriculum can be viewed as an organised framework that provides teachers with ideas about the content and methods to achieve curricular goals in specific teaching and learning settings. Alternatively, many researchers seek to find a connection between what children learn and how they experience learning in order to make their understandings more meaningful (see, for example, Hua, 2009; Nuttall \& Edwards, 2007; Perkins, 2011; Saracho \& Spodek, 2002).

The word curriculum has been collectively associated with "the image of the whole child", meaning "the child's complete integration of intellectual (cognitive), emotional, social, and physical capabilities" (Williams, 1999, p. 1). Curriculum, as described by Williams, includes the concept of teaching the whole child and creating experiences through play. Curriculum also "was derived from teachers' observations 
of children's interests and developmental needs" (p. 14). Within a typical curriculum, learning experiences could be arranged into a number of "interest centres such as the block corner, library, art area, family or sociodramatic play corner, and sand/water area" (p. 14). This view of curriculum aimed to promote children's social interaction and development.

In line with Williams (1999), curriculum can be seen as guidelines and frameworks for the provision of educational activities in early childhood services (Samuelsson, Sheridan, \& Williams, 2006). As Saracho and Spodek (2002) put it, the provision of experiences and planned instructions are based on the educational goals of individual institutions with social influences from society. Henson (2015) further explained that a curriculum can be defined as a set of planned experiences monitored by teachers in which a child-centred approach is applied. The conception of a childcentred programme was initiated in the 1960s, an era known as "romantic, cultural transmission, and progressive" (Saracho \& Spodek, 2002, p. 11). Various other names have been used for related approaches, for example, the Project Approach, and the Reggio Emilia Approach (Saracho \& Spodek, 2002). Romantic programmes can also refer to "free schools, child-centred schools, or developmentally appropriate programs" while cultural transmission programmes may be regarded as "back-tobasics approaches, or preparation for primary school" (Saracho \& Spodek, 2002, p. 12). The Project Approach allows children to investigate the topics that they are interested in (Beneke \& Ostrosky, 2009). Teachers can provide children with learning experiences that may help to further their understanding as they explore and observe what they learn by themselves.

A curriculum can also be identified using the following two models of curricula: performance curriculum and competence curriculum (Bernstein, 1996). The performance model offers the learners to learn within provided subjects/contents, designed teaching practices, and explicit assessment criteria, for example, the Canadian (Ontario) curriculum (Ministry of Education, Canada, 2007). On the other hand, the competence model, commonly applied to early childhood education, allows learners to contribute in selecting, regulating, and sequencing of a curriculum, for example, New Zealand's early childhood curriculum, Te Whāriki (McLachlan, Fleer, \& Edwards, 2013, 2018; Ministry of Education, New Zealand, 2017). This type of curriculum provides more opportunity for teachers to spend more time on developing 
their own teaching practices and learning activities. This is also referred to as a childcentred approach.

Tanner and Tanner (2007) have identified that a curriculum can be viewed through two concepts both of which focus on the learning processes and instruction, including methods and strategies in relation to how learners (including children) develop and become more capable. The first is a traditional view of a curriculum that is based on subject matter with a set of instructed knowledge leading to measurable learning outcomes. A traditionalist curriculum can also be seen as "the cumulative tradition of organised knowledge" that represents learning content of basic education strictly determined for learners (Tanner \& Tanner, 2007, p. 100).

The other concept of a curriculum identified by Tanner and Tanner (2007) is called progressivist and focuses on experience. A progressive curriculum is perceived as a range of guided experiences based on cultural values within a practical learning environment. The new conception about the curriculum highlighted changes in knowledge conception and the knowledge of learning process as a result of a childstudy movement. This includes concerns as well about the need to link formal school study with learners' lives and societal changes within "a dynamic process of individual and social growth" (Tanner \& Tanner, 2007, p. 99). Another conception of this curriculum can refer to a child-centred approach. As Yang and Li (2018) put it, the socio-cultural context can be one of the forces that shapes an early childhood curriculum.

A curriculum is also drawn from a government's aspiration for their country (McLachlan et al., 2013, 2018). There are four components that can make up a curriculum. The first is what outcomes are expected to be achieved when implementing a curriculum. This refers to aims, goals, objectives or outcome statements. The second component is concerned with what learning content should be included such as domains or subject matter. The third component is in relation to what teaching methods and approaches should be implemented to achieve the outcome. The final component is evaluation and assessment which involves how to evaluate development or achievement. In a similar way, a curriculum can also be defined as "the totality of policies and practices, the relationships among all involved in the setting, the provision of experiences, the resources, the physical environment (indoor and outdoor), the teaching and learning styles, and the system of assessment" (French, 2007, p. 22). 
The definition of a national early childhood curriculum differs from country to country. In other words, a curriculum's philosophy and component varies. For example, in Norway curriculum is defined as a framework plan that includes aims, methods and specific subject areas for early childhood teachers' work in a programme (Ministry of Education and Research, 2014). In Sweden, however, the curriculum is made up of a set of guidelines that target the educational goals without mentioning methods (Ministry of Education, Sweden, 2018; Oberhuemer, 2005). In the United States, "the curriculum must cater for and engage children in developmentally appropriate ways, but be responsive to cultural diversity" (McLachlan et al., 2018, p. 37). Here in New Zealand, Te Whäriki, the early childhood curriculum (Ministry of Education, New Zealand, 2017) is a framework that provides goals and visions for teachers to aspire to by interweaving the principles and strands while viewing children as competent and capable and emphasising the role of the family and wider community. Although Te Wharriki does give explicit formulated goals and directions for teachers working with young children, it does not outline methods to use or what content to choose (Alvestad \& Duncan, 2006). In Thailand, the early childhood curriculum is defined as a framework for the provision of experiences for the whole child, influenced by child-centred pedagogy and developmental psychology (Ministry of Education, 2003a,b). Education and care draw also on the Government's aspirations for Thai people.

\subsection{Early Childhood Curriculum Framework}

Each early childhood curriculum framework varies according to the goals of early childhood education. McLachlan et al. (2018) maintain that an early childhood curriculum framework consists of three key elements. Firstly, they state there is a perception of how children's learning and development should take place. Another element is encouragement and support from teachers which can enhance children's learning. The types of expected learning outcomes are the third key element. For example, the United Kingdom's early childhood curriculum clearly states three learning outcomes which are communication and language, physical development, and personal, social, and emotional development (Department of Education, 2014; McLachlan et al., 2013, 2018). In addition, a curriculum framework is influenced by the context in which it is developed, illustrating how early childhood education can be related to children's experiences and their families in a local community. 
Three significant elements of a curriculum are discussed by Wood and Hedges (2016): curriculum content, coherence, and control. Curriculum content is seen as "subject matter knowledge, skills, dispositions, understanding, and values that constitute a programme of study" (p. 389). The second element is coherence and is defined as how content is systematically sequenced to ensure young children's learning processes. In early childhood education, coherence involves how play, pedagogy, assessment, learning materials, and the relationship between a service, family, and community are structured. Control is the third element which refers to the Government's practices and influences in early childhood education provision. These three elements coexist in various ways as they contain "historical and socio-political influences, values, cultural beliefs, and aspirations" (Wood \& Hedges, 2016, p. 389).

According to Wood and Hedges (2016), an early childhood curriculum framework is derived from the following principles: the concept of a child-centred approach, learning through "play and freely chosen activities", outlining learning activities and experiences, matching "children's interests and needs", and planning "group activities to introduce specific curriculum content" (p. 390). Thailand's early childhood curriculum also outlined these principles for early childhood teachers to take into consideration when implementing the curriculum (Ministry of Education, 2003a,b).

Oberhuemer (2005) argues that there are six main reasons for developing a curriculum framework. First, within the context of a global economy, education is a valuable resource, and early years education provides an essential foundation. Second, the recent neuro-scientific research carried out on brain development during the early years has alerted policy makers to the educational potential of good quality early childhood programmes. A third reason is that curricular frameworks are viewed as a "necessary goal steering device and as a public accountability measure within the education system as a whole" (Oberhuemer, 2005, p. 30). A further reason is that countries that have an early childhood sector represent diverse communities and cultural groups which have distinctive pedagogical and philosophical approaches. Having curriculum guidelines is helpful in establishing a shared framework of standard principles. Another reason is that in countries that are wanting to expand their poorly resourced early childhood sector, mandatory guidelines are seen as one way to improve quality and equity measures. Finally, providing early childhood professionals with 
curricular guidelines gives everyone a common framework to enhance communication between teachers in an early childhood setting and parents.

An understanding of definitions and attributes of curriculum are important when taking into consideration how to implement a curriculum. When a new curriculum is promulgated nationwide, this does not necessarily mean that it will bring about certain changes in teachers' practices (Alvestad \& Duncan, 2006). These factors can affect teachers' knowledge of the curriculum and their ability to carry it out in practice. The design of a curriculum is "free to draw implications leading to a variety of approaches to addressing the socioemotional and cognitive characteristics of young children" (Williams, 1999, p. 14). In the next section, the early childhood curriculum in Thailand is discussed in relation to underpinning learning ideologies.

\subsection{Learning Theories that Underpin the Early Childhood Curriculum in}

\section{Thailand}

As stated previously, early childhood education in Thailand aims to provide fundamental education for children from birth to 5 years of age and it supports them to grow and develop in each age range (Office of the Basic Education Commission, 2008). It focuses on children's holistic development in four areas: physical, emotional, social, and cognitive. The curriculum provides criteria for specific developmental stages in these four areas. For children under 3 this is broken into the following ages: birth to 2 months, 2 to 4 months, 4 to 6 months, 6 to 8 months, 8 to 12 months, 12 to 18 months, 18 to 24 months, and 24 to 36 months. For children aged 3 to 5 years the developmental criteria for each of the four domains are outlined for each year. The 2003 Early Childhood Curriculum provides teachers with guidelines for key experiences to assist children to develop important skills through interacting with people around them as well as objects and materials, and by "cultivating morality and righteousness" (Ministry of Education, 2003b, p. 31). These are outlined in terms of children's age, individual differences, and social and cultural context.

In Thailand, historical and ongoing economic and social changes in society have influenced theory and ideology around curriculum development (Schiro, 2008). Two main influences on the 2003 Early Childhood Curriculum have been social reconstructionism and learner-centred ideology (Ministry of Education, 2003a,b).

Firstly, social reconstructionist ideology has been viewed as a concept of education that can provide solutions to problems existing in and caused by a society. 
It provides children with opportunities to explore values, feelings, injustices, alternatives, and solutions within a society; what children learn can shape their beliefs and behaviour. Social reconstructionists view the child as "a product of society, a social actor, and a society member which can assist in a social reconstruction" (McLaren, 2007, p. 94).

Learner-centred ideology, on the other hand, involves the understanding that children control what they would like to learn, rather than teachers (Schiro, 2008). Learning is derived from interactions between children and the environment, as in constructivism. Learners construct learning through interactions with their surrounding "physical and social world" (Fosnot \& Perry, 2004, p. 34). This ideology emphasises the learner's needs and an individual's personality. A learner-centred curriculum promotes children developing naturally within their potential. The education provision of a learner-centred curriculum focuses on the capability of children to adapt themselves and encourages them to express their identity within society and a wider environment. The learner-centred ideology views a child as "a whole child" who can form knowledge by interacting with the environment (McLachlan et al., 2018, p. 18).

Alongside these two ideologies are three predominant learning theories. Saracho and Spodek (2002) argue that there are three streams of educational ideology of a child-centred approach. They point out that each stream is related to developmental theories. They link "romantic" with Maturationism theory, "cultural transmission" with behaviourism, and "progressive" with constructivism (p. 12). Maturationism, behaviourism, and constructivism all underpin the Thai 2003 Early Childhood Curriculum (Ministry of Education, 2003b). The official curriculum is also influenced by learner-centred ideology. Pinyoanuntapong (1994) stated that the provision of learning experience of the official curriculum was drawn on these three psychological theories. The 2003 Early Childhood Curriculum aims to provide education and care by using a child-centred approach with a focus on children's age and individual differences and their social and cultural context, and to implement appropriate activities for each age group to enhance children's holistic development (Ministry of Education, 2003b). Therefore, the theory around Developmentally Appropriate Practice (DAP) also underpins Thailand's early childhood education (National Association for the Education of Young Children [NAEYC], 2009). 
Maturationism is defined as "the movement towards an increasingly complete and fully developed state of being" (MacNaughton, 2003, p. 14). The key theorist is Gesell (Arnold Gesell: 1880 - 1961). Jitsom (2003) and Phoonsub (2010) stated that Gesell's theory underpins the 2003 Early Childhood Curriculum (Ministry of Education, 2003b). Gesell placed an emphasis on infant development stages; this theory is still considered predominant today (Phoonsub, 2010). Maturational theory allows development to occur naturally (Daechakupt, 1999; Fosnot \& Perry, 2004). Children develop and learn whenever they are ready, which is an automatic process. However, according to Morrison (2015), some individual traits are determined by genetics.

Although the study's focus is children aged 3 to 5, behavioural learning theory also underpins the curriculum (Daechakupt, 1999). This theory emphasises observable behaviours and focuses on children's thoughts, feelings, and interpretation of performed activities (Gray \& MacBlain, 2012). The theory "explains learning as a system of behavioural responses to physical stimuli" (Fosnot \& Perry, 2004, p. 8), and it is derived from social and physical circumstances, not by intrinsic biological structures (MacNaughton, 2003). Unlike maturationists, behaviourists believe that experience is important for children's learning (Weber, 1984). Children's readiness and capability are key factors contributing to their learning, not heredity (Daechakupt, 1999; Weber, 1984).

Another significant theory that underpins Thai's official early childhood curriculum is constructivism. New knowledge is constructed from children's existing knowledge through interactive actions (Daechakupt, 1999; MacNaughton, 2003). Children, therefore, learn and "construct knowledge through active exploration and discovery in their physical and social environment" (Catron \& Allen, 2008, p. 8). Liu and Chen (2010) note that learning in a constructivist classroom requires learners to construct, create, invent, and develop their own knowledge and meaning. John Dewey and Jean Piaget are two constructivist theorists who have influenced the 2003 Early Childhood Curriculum (Ministry of Education, 2003b; Thambaworn, 2001).

John Dewey (1859 - 1952) valued "personal experience in learning” (Lutz \& Huitt, 2004, p. 1) and believed that individuals can learn through interaction within the surrounding environment and construct their own knowledge. Children learn from their direct experiences that are related to their daily lives (Phoonsub, 2010; Thambaworn, 2001, 2008). Moreover, children are encouraged to have social 
responsibility. Teachers must take children's interests and capabilities as a priority when designing lesson or classroom plans. Learning content should be flexible and consist of situations and occasions related to children's daily lives. Teachers should support young children to use everyday concepts and knowledge, including applying 'authentic' teaching materials and activities 'determined by children's dominating interests" in classrooms in order to enhance children's learning process (Hedegaard, 1998, p. 118).

Jean Piaget (1896 - 1980) is another key theorist. He believed children drive assimilation and accommodation through physically manipulating their environment in active learning and learning by doing (Catron \& Allen, 2008). Children's cognitive development is enhanced through interacting with their surrounding environment (Thambaworn, 2008). According to Piaget (1952), adaptation consists of two complementary processes of assimilation and accommodation, which involve an innate tendency of how children interact with their environment. Children's learning occurs when they interpret their experiences within their physical and social worlds and "construct their own knowledge, intelligence, and morality" (DeVries, Edmiaston, Zan, \& Hildebrandt, 2002, p. 35).

The two developmental stages of Piaget's theory related to early childhood are, firstly, sensory-motor intelligence; children from birth to 2 years learn from all their senses. The second is preoperational thought; children aged 2 to 7 years start to learn verbal and body language through communication (Jitsom, 2003). At this stage, children associate objects with words and become involved in make-believe play by using objects for purpose rather than their intended function (Saracho \& Spodek, 2002). Piaget believed that developmental stages were universal, no matter what type of environment children live in. One of the most important implications of Piagetian cognitive development theory is the concept of encouraging children to learn by doing and to be active in exploring the world around them (Thambaworn, 2008). Piaget's cognitive development theory promotes children to be "powerfully and actively engaged in the learning process" (Gray \& MacBlain, 2012, p. 46). This also allows them to follow on from each developmental stage. Adults play an important role in children's learning by supplying materials and hands-on experiences for them (Epstein \& Schweinhart, 2018).

According to DeVries et al. (2002), constructivist education provision involves establishing a "cooperative sociomoral atmosphere" that links to Piaget's two types of 
morality: heteronomous (morality of obedience) which means that children follow given rules without any questions, and autonomous morality referring to when they follow that rule due to "the necessity of respect" for other peers (p. 36). Another constructivist classroom strategy is to promote children's reasoning by asking openended questions and encouraging them to think, provide sufficient time for their experiments and investigations, and conduct assessment of children's performances and the implemented curriculum. By implementing a constructivist approach, it is important to take into consideration knowledge (which may also refer to learning content) that appeals to children's interests and choosing learning content that challenges them to progress through their developmental stages. Regarding Piaget's cognitive theory, physical and social interaction are important in early childhood education (Lutz \& Huitt, 2004). Physical knowledge is derived from a child's direct interaction with objects, while social knowledge occurs when interacting with others.

Tongthaworn (2003) argued that constructivist teaching practices are significant for early childhood education in Thailand. Her qualitative study was based on the 1997 Pre-Primary Curriculum, which was the previous version of the 2003 Early Childhood Curriculum. Tongthaworn carried out semi-structured interviews and classroom observations to identify constructivist beliefs and practices among 10 Thai early childhood teachers who taught children aged 4 to 5 years in Chiangmai province. The teachers were selected from 37 teachers using cluster sampling. She found that the teachers expressed beliefs that were associated with constructivism in their teaching practices.

From Tongthaworn's (2003) finding the teacher-participants stated that children should have hands-on activities, work in groups, and interact directly with learning materials and the environment. She noted that the education paradigm of Thailand had shifted from teacher-centred to child-centred education. However, Tongthaworn's study was carried out in only one province with children aged 4 to 5 years. She recommended that further studies should include various societal and cultural contexts within early childhood settings and should explore further the implementation of constructivist practices.

Powell and Kalina (2009) suggested that "constructivist teaching strategies have great effect in the classroom both cognitively and socially for the students" (p. 241). Two concepts of constructivism are Piaget's cognitive development theory and Vygotsky's socio-cultural theory and they have some characteristics in common 
(Davis \& Sumara, 2002), for example, the idea of providing a "constructivist-learning environment" (Liu \& Chen, 2010, p. 66), and the focus on "language and social experience in developing children's cognition" (Catron \& Allen, 2008, p. 11). In contrast, Piaget's and Vygotsky's views on the concept of play and the construction of knowledge are different. Piaget considered it to be an individual activity, whereas Vygotsky saw it as a social interaction. Vygotsky also focused on the following phenomena: how society and culture influence children's development; how language enhances children's cognitive skills; and how pretend play is important to "enhance children's socially cooperative behaviour" (Catron \& Allen, 2008, p. 9). Saracho (2017) added that the development of children's language and literacy can provide structure to their cultural development. With language, children "learn systems of cultural behaviours, including means of reasoning" (Saracho, 2017, p. 301).

As stated, DAP also underpinned Thailand's early childhood curriculum (Copple \& Bredekamp, 2009). Sanders and Farago (2018) describe DAP as a developmental approach that provides learning activities through interactions between adults and children. According to Copple and Bredekamp (2009), DAP provides "a framework for best practice" for providing early childhood education and care for children from birth to 8 with an aim to "promote young children's optimal learning and development" (p. 1). DAP is regarded by some as "the most influential document guiding the field of early childhood education" since its publication in the late 1980s (Hart, Burts, \& Charlesworth, 1997, p. 1). It was developed to highlight the cognitive learning of young children (Hart et al., 1997).

DAP adopted and adapted Piaget's theory which is based on activities initiated by children, instructions guided by teachers, and play-based activities that reflect their age and individual appropriateness (Copple \& Bredekamp, 2009). Child-centredness means that teachers also take account of children's interests and skills as a foundation for learning. This child-centred approach was "informed by what we know from theory and literature about how children develop and learn" (Copple \& Bredekamp, 2009, p. 10). Teachers and practitioners have implemented DAP's guidelines in early childhood services to promote children's growth across developmental domains and prepare them for their formal schooling (NAEYC, 1993, 1997, 2003, 2009). School readiness refers to "early signs of cognitive ability and maturity, children's work-related and learning-related social skills, and self-regulatory skills" (Encyclopedia on Early Childhood Development, 2017, p. 4). Children's school readiness is also key in DAP. 
Accordingly, children's maturational readiness is seen as central to their learning (Choothai, 2007; Sanders \& Fargo, 2018). In other words, learning experiences that are beyond children's biological maturational level do not align with DAP (Fleer, 1995).

The concept of DAP has been criticised over many years. A key cultural criticism is "children's role in relationship to adults is not compatible with many families' cultural values and practices" (Florez, 2008, p. 5). Challenges include the overlooking of culture in DAP's developmental approach, as well as reliance on maturational theory. Florez (2008) suggested that socio-cultural theory "can help early childhood best practice move past the DAP debate" (p. 11). From a socio-cultural perspective, Bodrova and Leong (2001) have also pointed out that through sociodramatic play children may act beyond their developmental age and they can learn and acquire early literacy skills.

The 2009 revision of the DAP guidelines recognises both developmental processes and to some extent socio-cultural influences in children's learning (Kim, 2011). The DAP statements published in 2009 continue to emphasise appropriateness of ages, stages, and individualism (NAEYC, 2009). However, these revised principles and guidelines for DAP also present the following five provisions: creating a caring community of learners, teaching to enhance children's development and learning, planning curriculum to achieve important goals, assessing children's development and learning, and establishing reciprocal relationships with families (Copple \& Bredekemp, 2009; NAEYC, 2009).

The previous version of Thailand's early childhood curriculum, the 1997 PrePrimary Curriculum, aimed to encourage children to behave in accordance with Thai culture and identity (see section 2.1.3). Its learning content included several aspects of children's social and cultural contexts. Therefore, the previous version of Thailand's early childhood curriculum was influenced by one of the important points of the 1997 NAEYC position statements, which took into consideration children's social and cultural contexts (Ministry of Education, 1997a; NAEYC, 1997; Thambaworn, 2008). When revising the 2003 Early Childhood Curriculum, the Ministry of Education considered three key points from the 1997 NAEYC position statement. These points were: knowledge about children's development and learning; their strengths, interests, and individual needs; and their social and cultural contexts (NAEYC, 1997). This was also reflected in three of the four key concepts stated in the Manual of the 2003 Early 
Childhood Curriculum: how children learn and develop, and their social and cultural contexts (Ministry of Education, 2003c). For example, teachers need to take into consideration children's individual differences and interests, including the social and cultural factors in relation to their early childhood settings. The 2003 Early Childhood Curriculum was influenced, too by the 1997 NAEYC position statement, evident in the five broad principles of Thailand's early childhood education provision which focused on: children's learning and development processes; providing age-appropriate learning activities through play within children's social and cultural contexts; and enhancing collaboration among children's families, communities, and early childhood services (see section 2.2) (Ministry of Education, 2003a,b; NAEYC, 1997). Therefore, the DAP theory was clearly reflected in Thailand's early childhood curriculum.

In Western countries, play is seen as the activity that can be directed by children, led by adults, or "jointly constructed" (Fleer, 2011, p. 225). For most researchers in the area of early childhood education, play is regarded as a child-centred activity that is free from determined rules and is usually formed by children through their pretending action (Fleer, 2011). Piaget (1952) stressed that children need to be engaged in object play to develop cognitively. When children engage with "imaginary situation play", they are involved in both internal and external processes of imagination (Fleer, 2011, p. 227). Through external engagement, children see what the objective meaning is of what they see, while they think about meanings associated with the external engagement through their internal process of imagination (Fleer, 2011). For example, a piece of wood is separated from the object itself when a stick becomes a horse. Children "tend to substitute objects with meanings" (Fleer, 2008, p. 5).

DeVries (2002) explored the implementation of play-based curriculum using DAP in four different classrooms and what effect this had on children's learning experiences. The study revealed that play was viewed differently in each classroom. DeVries (2002) suggested that play should be viewed as "a program where social and emotional goals are integrated in center-based play that is a mixture of activities rich in developmental possibilities and activities with little intellectual challenge" (p. 32). She further explained that the ideal play in a constructivist classroom involves combining more intellectual challenge and moral goals in both play and academic learning. 
The Thailand Government also adopted Thai concepts and Buddhism when writing the 2003 Early Childhood Curriculum (Ministry of Education, 2003a). These are discussed in the next section.

\subsection{Thai Concepts Underpinning the 2003 Early Childhood Curriculum}

Thambaworn $(2003,2006,2008)$ is one of the key early childhood educators in Thailand. She has written many books in relation to Thai early childhood education; for instance, three editions of the Early Childhood Curriculum (2003, 2006, 2008). She also wrote two versions of the Evaluation of Young Children's Development published in 1997 and 2001 and the other two versions of the Cognitive Development of Young Children published in 2001 and 2006. The database of Chulalongkorn University in Thailand has four more books by Thambaworn. One is an evaluation report done in 1997 on the implementation of the integrated project for the development of children and family to promote family development. Another one is a research report which examined the role of the family and education published in 1998. This contributed to the consultation process when drafting the 1999 National Education Act (Office of the National Education Commission, 2010). A study report in the following year investigated the education reform project in Khonkean province, which aimed to develop a child-centred learning approach. Another is an analysis report published in 1999 about early childhood education provision. Furthermore, she was the principal of the first public kindergarten, La-Orutis, established in 2003.

The third edition of Thamaworn's Early Childhood Education Curriculum (2008) provided basic knowledge of Thai early childhood education provision. This included the history of early childhood education in Thailand, planning and developing a curriculum, young children's play and learning and creating learning environments for young children. The content also dealt with the child-centred learning approach, promoting collaboration amongst family and the wider community regarding the provision of education, and how to evaluate the early childhood curriculum. Drawing on data from other studies, Thambaworn analysed the Buddhist principles underpinning the provision of early childhood education in Thailand. She argued that Thai educators combined Thai folk wisdom, Thai folkway, Buddhist principles and values of Thai society with Western ideologies in the 2003 Early Childhood Curriculum (Ministry of Education, 2003b). 
As Thambaworn (2008) puts it, Buddhism and Thainess are extremely important and have influenced early childhood education and curriculum in Thailand. According to Thambaworn, a Buddhism perspective refers to the holistic development of children in terms of their behavioural, intellectual, and spiritual growth by focusing on their cognitive development. Early childhood education provision incorporates Buddhist principles to provide appropriate factors that can facilitate children's learning and development, and aim to benefit both the learners and the wider society. Teachers need to create learning environments that attract and retain children's interests and enhance their learning and development.

In her book, Thambaworn (2008) described two classrooms that applied Buddhist principles as part of their teaching strategy; however, there was no information in relation to participants involved in that study. One of the classrooms implemented the Buddhist principle called Patiyatti - Patipatti - Pativedha. This principle encourages children to learn things by taking into consideration their experience from their own actions and insight and then link what they have learnt to their current situation. In this classroom, children shared their own similar stories while they were reading story books. The other classroom incorporated the Buddhist principle named Sikkhàttaya the Threefold Learning or the Three Studies: morality, concentration, and wisdom. This principle focuses on behaviour or performance development, virtues and children's morality, for example, self-discipline, spiritual security, self-comprehension and understanding others. Thambaworn noted that as a result of implementing this Buddhist principle, children were more focused when doing tasks, and this in turn enhanced their cognitive development skills.

Another study carried out by Pinyoanuntapong (2013a) suggested that promoting moral and ethics in young children is also considered significant and is one of the 2003 Early Childhood Curriculum's goals (Ministry of Education, 2003b). In her large-scale quantitative study, early childhood teachers evaluated the basic moral traits among 1,088 children aged 5 to 6 years. The teachers were selected by using cluster sampling of 13 teachers in different early childhood services in 11 provinces of Thailand. The study was carried out by using an evaluation form with three levels of rating scales to evaluate development among those children. The study found that there were eight basic morals that young children could express by themselves or with assistance from teachers or their friends, including "diligence, saving, honesty, discipline, politeness, cleanliness, unity, and kindness. These morals are the principles 
of merit, correct and proper behaviour" (p. 46). This is regarded as one aspect of Buddhism.

Another further study undertaken by Pinyoanuntapong (2013b) explored "the development of Thai early childhood education curriculum to promote desirable characteristics of preschool children" (p. 321). Her quantitative study was carried out in the eight provinces of Thailand using purposive sampling to select 1,000 teachers and parents. The data gathered through the open-ended constructed questionnaire showed that children's Thai-way desirable characteristics involved: being generous and helping others; being responsible and honest; behaving oneself with Thai manners; having national and cultural pride; and valuing Thai identity (i.e., the nation, religion, and monarchy). She mentioned as well that these specific traits could enhance children's readiness and holistic development. Pinyoanuntapong (2013b) also stated that "Thai language, Thai food, Thai costumes, Thai manners, Thai folk plays, Thai traditions and culture, Thai important places, Thai music and classical dances, Thai arts and Thai folk wisdom" were included in the Thai-way early childhood curriculum that was developed for her study (p. 325). Although this article was published in 2013, it appeared to have been carried out just after the promulgation of the 2003 Early Childhood Curriculum. Nonetheless, it highlighted the importance of taking into consideration how Thainess fits within the early childhood curriculum in Thailand.

Klibthong (2013) carried out a case study of how Thai teachers understood and believed in inclusive education for young children. Her qualitative study used group discussions from nine early childhood teachers who taught children aged 2 to 6 years at one large early childhood service in Bangkok. She discussed the improving of early childhood inclusive education in Thailand requires teachers to have good knowledge about children's development. Moreover, Klibthong suggested that teachers should be provided with training in topics of Thai culture and religious beliefs. It is noticeable in this study that there is no mention of Thainess and Thai culture in relation to early childhood teachers' teaching practices.

Recently, Arphattananon (2018) examined multicultural education in Thailand on how to balance national unity and cultural diversity. This study was carried out using interviews, observation, and documentation at eight primary schools (early childhood services were included as these schools had attached preschool classes) within the two provinces, Pattani and Ranong, located in the Southern region of Thailand. There was a diversity of cultures: Muslim, Buddhist, Burmese, Cambodian, 
and Thai. The study's data were drawn from 50 interviews with: students (including children), teachers, and administrators; relevant government and non-government officials such as Ministry of Education and local education offices; and people in the community, including employers of migrant workers.

Arphattananon's (2018) findings revealed that "current educational policies provide opportunity for migrant children to access public education and the curriculum encourages students to live in harmony with people from different cultures" (p. 149). She affirmed that Thailand's Government had taken into consideration children's cultural and socio-economic context when formalising educational regulations. The study indicated that learning content of other religions and culture was included in teaching practices and was taken into account when implementing the curriculum as well as Thailand's unique culture and identity in four regions. In Arphattananon's (2018) study, Muslim children living in the Southern region of Thailand were able to wear uniform in accordance with their cultural costume, while Chinese children were allowed to take time off school when observing their important occasions with regard to their religion and traditions.

Another study was carried out by Jatuporn (2016) but not in an early childhood education context. The study explored how "the social studies curriculum became the centerpiece of public schools' efforts to cultivate younger generations into what it means to be Thainess" (p. 130). Her findings revealed that the practices of cultivating Thainess appeared to be included in the Social Studies Curriculum (applied for primary and secondary education) through five learning contents of the curriculum. They included: religion, morality, and ethics; civics, culture, and living in society; economics; history; and geography" (p. 131).

More recently, Rhein (2017) discussed "the causes of the problems in international higher education in Thailand and offered potential solutions to ameliorate the negative impacts" (p. 281). The article did not specify what methodology was employed. Rhein found that one of the problems was the country's cultural, political, and social instability since 2006 when the military-led Government took over the administration of the country. The launch of and requirement to recite the Government's 12 core values for the purpose of cultivating Thainess has caused academics to leave Thailand for other countries where they could express their rights more independently. 
Rhein (2017) defined Thainess as "the promotion of Thai values and traditions" (referring to the 12 Thai core values) but stated that these values "are not in-line with global citizenship" (p. 291). Thainess refers to how Thai people respect the hierarchical status in their society (see section 2.3). Rhein explained that by engaging within such a culture students and faculty staff in higher education are not in a position where they can easily oppose the country's prescribed hierarchical organisation. Another impact of promoting Thai values relates to the social relationships between the faculty staff and students. If they do not align with correct protocol, this could impact on graduate students' future job opportunities as they may not be given character references from faculty staff. Rhein (2017) further suggested that "if the promotion of Thai culture supersedes the promotion of ethics, problems of transparency and accountability will remain" and it is important to balance assimilating international values while retaining the value of Thainess (p. 291).

In line with Rhein (2017), Farrelly (2016) indicated that 12 Thai core values have "drawn on cultural ideas that have existed for many decades" (p. 333). Farrelly critiqued the promotion of Thainess under the current military Government. He argued that this "military coup has been deliberate in its beliefs to cultivate a narrow vision of Thainess, focusing on the Nation, Religion, and Monarchy" (p. 335).

From the researcher's point of view, these values are aligned with the official early childhood curriculum's aspiration regarding the cultivation and promotion of Thai culture, identity, and morality (Ministry of Education, 2003b). These core values are presented alongside children's age-related characteristics and guidelines of learning experiences stated in the 2003 Early Childhood Curriculum (Ministry of Education, 2003b) shown in Table 3.

Table 3

The link between the 12 Core Values and the 2003 Early Childhood Curriculum

\begin{tabular}{ll|l}
\hline \multicolumn{1}{c|}{ Core Values } & \multicolumn{1}{c}{ Age-related Characteristics } \\
\hline 1. & $\begin{array}{l}\text { Upholding of the three main } \\
\text { pillars: the nation, the religion, } \\
\text { and the monarchy }\end{array}$ & $\begin{array}{l}\text { Mentioned as the detail of the } \\
\text { learning contents, the Self (Ministry } \\
\text { of Education, 2003c) }\end{array}$ \\
\hline $\begin{array}{l}\text { Showing honesty, sacrifice and } \\
\text { patience, with a positive attitude } \\
\text { for the interest of the public }\end{array}$ & $\begin{array}{l}\text { Mentioned as one of the everyday } \\
\text { activities regarding developing } \\
\text { emotions and cultivating morality }\end{array}$ \\
\hline
\end{tabular}




\begin{tabular}{|c|c|c|}
\hline & & $\begin{array}{l}\text { and righteousness (Ministry of } \\
\text { Education, 2003a,b) }\end{array}$ \\
\hline & $\begin{array}{l}\text { Practising filial piety towards } \\
\text { parents, guardians and teachers }\end{array}$ & $\begin{array}{l}\text { Mentioned as the detail of the } \\
\text { learning content, People and Place } \\
\text { Around Children (Ministry of } \\
\text { Education, 2003c) }\end{array}$ \\
\hline 4. & $\begin{array}{l}\text { Seeking both direct and indirect } \\
\text { knowledge and education }\end{array}$ & N/A \\
\hline 5. & $\begin{array}{l}\text { Preserving Thai traditions and } \\
\text { cultures }\end{array}$ & $\begin{array}{l}\text { - Explicitly stated in the curriculum } \\
\text { that children behave in line with } \\
\text { Thai culture (Ministry of } \\
\text { Education, 2003a,b) } \\
\text { - Mentioned as one of the standard } \\
\text { indicators (Standard 4) for } \\
\text { desirable characteristics (Ministry } \\
\text { of Education, 2003c) }\end{array}$ \\
\hline 6. & $\begin{array}{l}\text { Practising morality, integrity, } \\
\text { considerateness, generosity, and } \\
\text { sharing }\end{array}$ & $\begin{array}{l}\text { "Share things with others" (Ministry } \\
\text { of Education, 2003b, p. 29) }\end{array}$ \\
\hline 7. & $\begin{array}{l}\text { Understanding and learning true } \\
\text { democratic ideals with His } \\
\text { Majesty the King as Head of } \\
\text { State }\end{array}$ & $\begin{array}{l}\text { Mentioned as one of the standard } \\
\text { indicators (Standard 8) for } \\
\text { desirable characteristics (Ministry } \\
\text { of Education, 2003c) }\end{array}$ \\
\hline 8. & $\begin{array}{l}\text { Maintaining discipline and } \\
\text { respect for laws and the elderly }\end{array}$ & $\begin{array}{l}\text { - Self-discipline is mentioned as } \\
\text { one of the everyday activities } \\
\text { regarding developing emotions } \\
\text { and cultivating morality and } \\
\text { righteousness (Ministry of } \\
\text { Education, 2003a,b) } \\
\text { - Paying respect to elders is } \\
\text { mentioned as one of the standard } \\
\text { indicators (Standard 7) for } \\
\text { desirable characteristics (Ministry } \\
\text { of Education, 2003c) } \\
\text { - Obeying common rules is } \\
\text { mentioned as one of the everyday } \\
\text { activities regarding developing } \\
\text { social character (Ministry of } \\
\text { Education, 2003a,b) }\end{array}$ \\
\hline 9. & $\begin{array}{l}\text { Being conscious and mindful of } \\
\text { one's actions in line with His } \\
\text { Majesty's the King's royal } \\
\text { statements }\end{array}$ & N/A \\
\hline & $\begin{array}{l}\text { Applying His Majesty the King's } \\
\text { sufficiency economy to save } \\
\text { money for times of need, being } \\
\text { moderate with surplus for sharing } \\
\text { or expansion of business, while at }\end{array}$ & N/A \\
\hline
\end{tabular}




\begin{tabular}{l|l}
\hline $\begin{array}{l}\text { the same time having immunity to } \\
\text { hardships along the way }\end{array}$ & \\
\hline $\begin{array}{l}\text { Keeping physically and mentally } \\
\text { strong, unyielding to evil powers } \\
\text { or desires and having a sense of } \\
\text { shame over guilt and sins in } \\
\text { accordance with religious } \\
\text { principles }\end{array}$ & $\begin{array}{l}\text { - "Bodies grow with good health" (Ministry } \\
\text { of Education, 2003b, p. 27). } \\
\text { Mentioned as one of the everyday } \\
\text { activities regarding developing emotions } \\
\text { and cultivating morality and righteousness } \\
\text { (Ministry of Education, 2003a,b) }\end{array}$ \\
& $\begin{array}{l}\text { A sense of shame over guilt is promoted } \\
\text { through social development (Ministry of } \\
\text { Education, 2003c) }\end{array}$ \\
\hline $\begin{array}{l}\text { Putting the public and national } \\
\text { interest before one's own interest. }\end{array}$ & $\begin{array}{l}\text { Taking into consideration the public } \\
\text { interest; for example, the classroom rules } \\
\text { and shared books (Ministry of Education, } \\
\text { 2003c) }\end{array}$ \\
\hline
\end{tabular}

Note: Adapted from "Being Thai: A Narrow Identity in a Wide World" by N. Farrelly, 2016, Southeast Asian Affairs, 2016, pp. 333-334.

The Government's 12 core values were not specifically mentioned in the curriculum documents (Ministry of Education, 2003a,b,c). They were, however, implicitly referred to as one of the everyday activities promoting children's developmental domains and one of the standard indicators, while some of the values were addressed in the additional details of the learning contents in the Manual of the 2003 Early Childhood Curriculum (Ministry of Education, 2003c).

In addition, the Ministry of Education published a guideline book indicating how early childhood teachers should integrate these 12 core values into their daily teaching practices (Office of Basic Education Commission, 2014). This book also provides aspects of Thai culture that children should learn, background knowledge for teachers in relation to these, learning activities for teaching children, and recommended activities for parents to teach their children at home.

To illustrate, under the first core value, the book suggests six main activities which consist of the following topics: "I am Thai, Thai national flag, I love Thailand, I learn Thai history, To be happy as Thai, and I love the King" (Office of Basic Education Commission, 2014, p. 32). Also included is detailed information in relation to each of the topics, for example, a history of the Thai national flag, the virtues of King Rama I - IX during the Chakri dynasty, and a brief overview of Thailand's history and geography. Examples of activities for teachers to do at early childhood services and for parents to engage with their children at home are also addressed in this book, such as drawing and colouring a picture of the Thai national flag at their 
early childhood setting, and parents supporting their children to stand still respectfully when listening to the national anthem at home.

Jamjuree (2017) reviewed teachers' education and professional development in Thailand. The level of education was not addressed, nor the research methodology. Her article revealed that when implementing a curriculum or any teaching practices that employed Western learning ideologies, it is important for teachers to take into account how to "balance an emphasis on Thainess with a need to create global citizens" (p. 10). She suggested that the curriculum should provide specific guidelines for teachers on how to achieve this goal.

In addition to these studies discussed above, there were a number that examined Thainess, Thai culture, and identity in other contexts and disciplines. In line with Thambaworn (2008) and Pinyoanuntapong (2013a), McCargo (2004) argued that Thailand utilised Buddhism in order to help their citizens by incorporating Buddhist teachings to teach them to find "their own moral directions" (p. 167). Buddhist concepts in the form of the religion tend to be highlighted through images, which may refer to Buddha images and temples, and rituals involving festivals and important occasions. As previously stated, 95 percent of Thai citizens are Buddhist; however, there are no regulations in place stating that Buddhism is the national religion. This was despite the King's profession of the Buddhist faith and the existence of diverse nationalities and culture in Thailand (McCargo, 2004). Buddhism has also been a source of Thai identity for a long period of time. "Its main themes include the core of his teaching (Dhamma), for example, popular preoccupation with fate (in Thai: Karma)" which refers to the law of Karma (McCargo, 2004, p. 160).

As stated earlier about the organisation overseeing Thai culture and identity, the formation of the Ministry of Culture in Thailand was examined by Connors (2005) to gain a better understanding of its role in promoting Thai culture. In his article, the word culture is linked to a concern of defining and shaping "collective and individual identity" (pp. 524-525). Connors explained that Thainess has become the nationalistic ideology which has gone beyond promoting national pride and good citizenship in the last two decades. This nationalistic ideology, focusing on the activities and practices of Thai culture and identity, are tools to express and represent "local culture, multiple ethnic identities, and national identity into a Thainess for the global age" (Connors, 2005, p. 544): 
Thai culture means an identity of the Thai nation, which is the fundamental of establishing harmony and the nation's stability. It indicates Thai people's prestige, honour, and pride. Therefore, it is necessary to promote Thai culture and identity. This is an important tool in strengthening social security and Thai people's quality of life. Conserving Thai culture is maintaining Thai nation's spirit and soul. (Ministry of Culture, 2016, p. 1)

Connors (2005) argued that Thainess "aims to call forth loyalty and commitment to the nation and to ensure identity between people and the nation" (p. 525).

Connors (2005) also pointed out that instead of cultivating the abstract concept of Thainess in relation to the three significant pillars (i.e., the nation, religion, and monarchy), the National Culture Commission and the National Identity Board inculcated the understanding of Thainess in citizens through local culture. This involved: "melodic intonations of local accent; the colourful play of local dress; and expressions of local knowledge about health, agriculture, and social wisdom (also referred as folk wisdom)" (p. 530). The Government introduced identity reminders such as the national flag, music and songs (can be referred to Thai national anthem and other Thai music), and portraits of the King and Queen, including other Royal Family members. These artefacts expressed Thai culture and were used as materials for “identity-producing projects" (Connors, 2005, p. 525).

In another study, Traitongyoo (2008) explored how notions of Thai identity influenced the ways in which the Government's policies on immigration and citizenship were constructed. Her mixed-method study was carried out in Bangkok and the other five provinces of Thailand that border other countries in the Greater Mekong subregion. The study involved reviewing governmental documents and semistructured interviews. A series of interviews was conducted with two factory managers and six government officials from the Ministry of Labour, the National Economic and Social Development Board, the Ministry of Interior, the Ministry of Foreign Affairs, the Ministry of Social Development and Human Security, and the International Organisation for Migration (Bangkok Office).

The conception of Thainess was critically analysed with the purpose of the changes in migration management policies. Traitongyoo (2008) also elaborated that the notion of Thai nationalism and Thainess was "derived from the attempt to create the Thai hegemony and the ethic unity of the Thai nation-state" (Traitongyoo, 2008, 
p. 90). Thainess was also shaped by the conception of how Thai people have loyalty and commitment toward the nation. From her study, she included some examples that illustrated the cultivation of nationalism and patriarchy in Thai citizens which was promoted by King Rama VI, firstly, the promulgation of public holidays such as Chakri Day (Chakri is the Royal Family name of Thailand's current dynasty and Chakri Day is still one of Thailand's public holidays), and secondly, all the schools received essays and other writings of King Rama VI that were disseminated in order to raise awareness of "the idea of nation" and the precedence for the three pillars of Thai identity (Traitongyoo, 2008, p. 96). This was done in 1921 through compulsory education. Therefore, "nationalism was used as an approach to create a shared sense of belonging and loyalty to Thai society" (Traitongyoo, 2008, p. 95).

A more recent study was undertaken by Pinthong (2015). This was a qualitative study that used documentation about the Tourism Authority of Thailand website's process and design. Pinthong defined Thainess as "Thai people's way of living and culture" (p. 234), which involves Thai festivals (including Songkran and Loy Kratong); food; religion (referred to as Buddhism) in aspects of identifying temples and places for meditation; and folk wisdom (for example, performing arts and music, and herbal medicine and traditional massage, and language). According to Pinthong, Thainess is constructed by the following characteristics that are used to attract tourists to visit Thailand: tourist attractions with Thai-artistic style of architecture; a polite gesture of greeting; and stories and pictures about Thai culture (these may include pictures illustrating celebration of the festivals). Pinthong pointed out that Thai social values, folk wisdom, and ways of living also represent characteristics of Thainess.

From the research discussed above, Thainess is connected to Thai culture and identity. According to the 2010 National Culture Act, culture refers to the ways of life, thoughts, beliefs, values, norms, customs and traditions, rituals, and folk wisdom that a group of people in a community or society incorporates in accumulation, cultivation, transfer, learning, and improvement (Department of Cultural Promotion, 2010a). These are inherited through many generations and must be maintained for national and cultural pride and sustainable conservation (Department of Cultural Promotion, 2017). Culture is a tool used to unite social members, to engage them to work together in harmony, and to cultivate appropriate attitudes, beliefs, and values. In addition, culture is subject to a never-ending process of changes through time. Malikhao (2017) recently described Thai culture as a local community culture based on the mutual trust and 
informal social relationships among the local people, including the family. Identity formation shapes, and is shaped by artefact mediated sociocultural processes (Penuel $\&$ Wertsch, 1995). This focus has been particularly important in relation to the impact of internationalisation with other cultures immigrating to Thailand. "The homogeneity of Thai identity or Thainess is essential for national security and sovereignty to be protected" (Traitongyoo, 2008, p. 4).

Recently, Meesuk (2017) examined how the notion of Thainess was performed in light of the mourning practices during the grieving period after King Rama IX passed away. Her study was carried out through eight interviews, social media observation, online questionnaire, and participant observation. She mentioned that she received 30 responses from a diverse group of respondents who came from different regions of Thailand and overseas. The open-ended question of what being Thai means to the respondents was posed in the questionnaire. One of the respondents clearly stated that Thai people should be proud to be born in the reign of King Rama IX and they should take into consideration His Majesty's guidance to lead their lives and maintain the uniqueness of Thai culture for the next generation. Two other respondents identified that being Thai involves loyalty, respect, and valuing the nation, religion, and monarchy. Moreover, the following cultural and social values were referred in the questionnaire: "unity, charitableness, generosity, loyalty, and hospitality (expressing the characteristic of the Land of Smile)" (Meesuk, 2017, p. 47).

The conception of Thai culture and identity was also addressed by the Thai early childhood curriculum. This involved cultivating morality, incorporating Buddhist principles, and promoting self-discipline and generosity. The literature reviewed in this chapter regarding the notion of Thainess stresses that it is important to maintain Thai culture and identity as a way to promote nationalistic ideology. Cultivating Thainess may involve learning about Thai manners, way of living, social values, traditions, and folk wisdom (for example food, medicine, and arts). This also includes inculcating morality and ethics. Another practice is giving precedence and paying respect to the three pillars: the nation, religion (refers to Buddhism), and monarchy.

The study's theoretical framework is presented next. 


\subsection{Theoretical Framework: Socio-Cultural Theory}

Theoretical perspectives associated with socio-cultural theory (Rogoff 2003; Vygotsky, 1978) have contributed significantly to views of childhood. Sociocultural theory highlights that children's learning and development is a part of their social networks (Göncü \& Gauvain, 2012). As Merewether and Fleet (2014) put it, children construct their understandings through interactive collaboration between themselves and adults. "In this approach to research, both interventions and documentation of everyday life are captured and analysed so that the process of development can be determined" (Fleer \& Van Oers, 2018, p. 24). Children's development, however, is not viewed as a maturational process; socio-cultural theory focuses more on how children engage with social, cultural, historical, and material contexts (Fleer \& Van Oers, 2018).

Socio-cultural theory was used to analyse the data and inform key findings in this study (Vygotsky, 1934/1986, 1978). Accordingly, understanding core concepts underpinning this theory is significant. From a socio-cultural perspective, culture is transmitted, transformed, internalised, and learned through children's engagement in the social and cultural world around them (Cole, 1996; Rogoff, 2003; Vygotsky, 1978, 1986; Wartofsky, 1979; Wertsch, 1985). Vygotsky's sociocultural theory focuses on how children's culture is mutually guided by socially mediated activities. Culture is defined here as "artistic products and the processes of creation" which involve the description of people's way of life "as expressed in their religion, art, and beliefs, including their everyday practices" (Cole \& Gajdamaschko, 2007, pp. 193-194). Culture is also identified as a process and outcome of children's engagement in everyday socio-cultural practices, including interacting with other people (Vygotsky, 1978, 1981). Within society, culture "contributes to the behaviour, values, attitudes and beliefs" that social members hold (Siraj-Blatchford, 1994, p. 28). In addition, culture is viewed as "a system of meaning" which specifies goals for children's learning and development (Göncü \& Gauvain, 2012, p. 129).

Vygotsky's analysis of culture was "part of his attempt to elaborate the notion of mediation" (Wertsch \& Tulviste, 2005, p. 65). Mediation is described as the use of certain tools, signs, and symbols within socially and culturally organised activity in 'human-environment' interaction (Vygotsky, 1978). Tools and signs are "created by societies over the course of human history and change with the form of society and the level of its cultural development" (Vygotsky, 1978, p. 8). By employing an existing 
cultural tool in a new mediated action or process, "the transformation of an existing pattern of action" occurs (Wertsch \& Tulviste, 2005, p. 72). Cultural tools are both inherited and transformed by each generation (Rogoff, 2003). In this study I examine how Thailand's early childhood curriculum (considered as an artefact) has evolved and how services say that they utilise cultural activities (as artefacts) in their teaching practices.

From a cultural psychologist's perspective, developmental and learning goals are believed to be conveyed to children through a process of social interaction (Cole, 1996; Göncü \& Gauvain, 2012; Rogoff, 2003). This enhances children's understandings and provides them with the necessary skills for them to live their lives. As Göncü and Gauvain (2012) put it, "Vygotsky conceptualised children's development as a process of participation in and appropriation of cultural meanings that are historically determined and socially situated" (p. 132). To illustrate, this process involves young children's cultural development that shapes the mediation of inherited capacities by cultural artefacts. Through the mediation process, children learn to "regulate their higher psychological functions through speech and other signs" (Göncü \& Gauvain, 2012, p. 132). Children use language to modulate their psychological functions by either interacting with more experienced members within a society or during their sociodramatic play. Vygotsky's account of internalisation involves social processes and analysing how language mediates social and individual functioning (Wertsch \& Stone, 1985).

The internalisation and learning of culture, including Thai culture in this study, is mediated through the use of tools, signs, and symbols with language and words being particularly important tools for social communication and therefore learning (Vygotsky, 1978; Wartofsky, 1979; Wertsch 1991). The word 'mediated' also refers to "the structure of behaviours" that develop within the 'specification' of social context, and conditions understanding through children's participation and engagement with cultural artefacts (Hedegaard, 2001; Rogoff, 2003). Children can also learn through "noticing trappings of culture, like clothes, books, toys, and ways of posing and gesturing" (Trevarthen, 1998, p. 88).

Participant perceptions of how children learn Thai culture and identity through language were also investigated in this study as language is regarded as one of the goals for maintaining Thainess. Language is regarded as "a primary mediator of knowledge for humans" and a communicative tool that developed "within a specific 
sociohistorical context" (Lee, 2005, pp. 248-249). Written language was created as a way of communicating among social individuals (Wertsch \& Tulviste, 2005). Vygotsky (1978) stated that written signs are regarded as 'first-order' symbols which directly signify objects and/or actions and the 'second-order' symbolism is "a major contributor to the development of written language" (p. 110), and is considered as "written signs for the spoken symbols of words" (p. 115).

Children learn language through the use of words, pictures, and writing systems. Words are also tools for thinking and feeling (Vygotsky, 1986). "The child begins to perceive the world not only through his [or her] eyes but also through his [or her] speech" (Vygotsky, 1978, p. 32). Language, words, and other symbols can mediate children's learning about Thai history, folk wisdom, and the local culture of Thailand. When children learn language, "they are using a system of meanings constructed by their culture that shapes their attempts to make sense of their world. They are learning to participate in a system of meaning provided by the culture" (Miller, 2011, p. 182). Language acquisition and learning instruction can take place both at early childhood services, as a formal school setting, and within children's experiences and practices.

Children's cultural development is entrenched in their society and culture. This involves internalising the cultural values of that world, which is a part of an individual's development. "Every function in the child's cultural development appears twice: first on the social level (i.e. between people and things), and later on at the individual level (i.e. inside the child)" (Vygotsky, 1978, p. 57). In other words, individual psychological development involves social processes. According to Rogoff (2003), "cognition is (also) a collaborative process". This study focused on "the interdependence of social and individual processes in the co-construction of knowledge" (John-Steiner \& Mahn, 1996, p. 191), particularly Thai cultural knowledge and identity.

"Identity is embedded in culture" (Jones, 2009, p. 37). Identity formation from a socio-cultural approach places the socio-cultural process at one side and individual functioning at the other side (Wertsch, 1991). Both sides are considered "as interacting moments in human action, rather than as static processes that exist in isolation from one another" (Penuel \& Wertsch, 1995, p. 84). Identities can be defined as "long-term, living relations between persons and their place and participation in communities of practice. Thus identity, knowing, and social membership entail one another" (Lave \& 
Wenger, 2007, p. 148). As Thai identity is closely linked with Thai culture, this aspect of Thai culture will be examined in this study.

Vygotsky also placed great importance on how role-play mediates young children's learning. He wrote that "in play, a child always behaves beyond his average age, above his daily behaviour; in play it is as though he were a head taller than himself" (Vygotsky, 1978, p. 102). Play is considered "a system of signs that generalise reality" (Vygotsky, 1978, p. 94), and a rule of behaviour in play is formed by a child's experience in real life. Vygotskian play consists of three significant characteristics: "children create an imaginary situation; take on and act out roles; and follow a set of rules formulated by those specific roles" (Bodrova \& Leong, 2015, p. 374). Meaningful play involves collaborative assignments, role-plays, and any other activities that require children to apply their language, memory, and self-management (Copple \& Bredekamp, 2009).

This study will investigate the ways in which tools, signs and symbols (artefacts) associated with the practices of the early childhood services mediate children's learning Thai culture and identity. Wartofsky (1979) usefully outlined three overlapping levels of artefacts to explain how they represent and mediate cultural activities and practices. The first level, primary artefacts, involves words and material objects which directly signify what they are. Secondary artefacts are symbolic representations of primary artefacts and are used "in the preservation and transmission of the acquired skills or modes of action or praxis by which this production is carried out" (p. 202). A further level is tertiary artefacts, which emphasise the use of imagination in the artefact mediation process. These three levels of artefacts will be used as a guideline to discuss and analyse the key findings in Chapter 8.

Family and people around children are significant features of children's environment (Woodhead, 2005), including their "neighbourhoods and communities" (Rogoff, 2003, p. 102). “All environments are culturally constructed” (Woodhead, 2000 , p. 23) and are generated from the creation of human activity with creativity. These are mediated by appropriate approaches for children's development. "There is nothing fundamentally natural about modern environments for childcare, either at home or within a pre-school setting" (Woodhead, 1999, p. 13). This study will investigate how the roles of families and wider communities were involved in the enculturation process as well as the role of the Government. This includes examining 
early childhood services whereby everyday practices mediate children's learning culture and identity.

\subsection{Chapter Summary}

This chapter has presented how curricula are defined and categorised in different ways. Some curricula are designed by determined teaching objectives, while others provide some guidelines and open opportunities for teachers to create their own teaching plans. Several learning theories and philosophies that have influenced Thailand's early childhood curriculum have been outlined in this chapter. This has highlighted their impact on children's learning and development. The literature review has shown that early childhood education in Thailand took into consideration children's age appropriateness, individual differences, and social and cultural context. Therefore, maturationism, behaviourism, cognitive and social constructivism, and DAP are evidently underpinned by the 2003 Early Childhood Curriculum (Ministry of Education, 2003b).

The chapter has also discussed Thai concepts that involve Buddhism and Thai culture that have also been addressed in Thailand's curriculum. Aspects and cultural practices of Thai culture and identity were also presented in light of the cultivation of Thainess. At the end of this chapter, socio-cultural theory was discussed as the study's theoretical framework that influenced and reflected my viewpoints of early childhood education in Thailand. In the next chapter, the methodology of carrying out this study is presented. 


\section{CHAPTER 4}

\section{RESEARCH METHODOLOGY}

The aim of this research is to explore how early childhood teachers perceived their teaching practices in promoting Thai culture and identity when implementing the 2003 Early Childhood Curriculum in Thailand. Three key research questions were used to guide this investigation:

1. What activities and practices do early childhood services implement to promote Thai culture and identity with young children?

2. How do early childhood services perceive the role of the Government in promoting Thai culture and identity with young children?

3. How do early childhood services view the parents' role in promoting Thai culture and identity with young children, and how do parents perceive their role?

The research paradigm used in this study is presented first. Next, an overview of the methodology used in the study, which used both qualitative and quantitative methods, is discussed. Following this the data collection procedures using a multiple case study and a survey are outlined. The steps taken to ensure validity and the ethics associated with this study are then discussed.

\subsection{Research Paradigm}

There are various research paradigms used in educational research (Creswell, 2014, 2018; File, Mueller, Wisneski, \& Stemmel, 2016). According to Guba and Lincoln (1994, p. 107), a research paradigm can be defined as the set of "basic belief systems based on ontological, epistemological, and methodological assumptions" about how researchers view and interpret the world, including the theoretical lens they use (see also Crotty, 1998; Mackenzie \& Knipe, 2006). Ontology is concerned with how reality is viewed by the researcher and involves assumptions on "what kind of world we are investigating" (Crotty, 1998, p. 10), whereas an epistemological approach relates to how researchers actually know about reality and what forms of knowledge can be obtained. Crotty has defined this as "the theory of knowledge embedded in the theoretical perspective and thereby in the methodology" (p. 3). The theoretical perspective concerns what approach researchers can use to get the knowledge while methodology is what procedures are used to acquire this information. 
Researchers' ontology and epistemology create a holistic view of how knowledge is perceived and how they can position themselves in relation to this knowledge, and what methodological strategies are used to examine the problem. Having an awareness of philosophical assumptions was important for this study to increase the quality of research undertaken, and to narrate it when writing up the research findings.

Three common paradigms used in research are positivist, pragmatist, and constructivist. In this study a constructivist approach was applied as constructivists believe there is no single reality or truth (ontology). Researchers need to construct meaning for what they investigate to discover the underlying meanings of the events and activities studied (epistemology). The theoretical perspective is interpretivism as reality needs to be interpreted (Thomas, 1994). Constructivism is commonly employed to identify how researchers understand the world by drawing on participants' perceptions and experience based on their personal background, and constructing meaning through social interaction between participants and the environment they live in (Creswell, 2014, 2018; Crotty, 1998; File et al., 2016; Guba \& Lincoln, 1994). In this research, I used myself as a research tool to interpret the data based on my Thai cultural background (Crotty, 1998).

In the next section, the study's research design is presented. Both qualitative and quantitative approaches are outlined. Constructivist researchers are more likely to make use of quantitative data to support qualitative data which generate meaningful information (Creswell, 2014, 2018).

\subsection{Research Design}

To address the research questions, the research design for this study incorporated several features:

- Documentation of the history of early childhood education in Thailand, including the development of the early childhood curricula (all three versions; Ministry of Education, 1997, 2003, and 2017). Official and Government documents were also used, such as the national education plans, and the Government's legislation Acts. 
- A multiple case study involving eight early childhood services in Klongtoey and Wattana districts in Bangkok was undertaken. The age group focus was 3 to 5-year-old children. The multiple case study involved semi-structured interviews as well as documentation gathered from some of the services.

- A survey of early childhood teachers currently teaching in the Klongtoey and Wattana districts, along with other multiple sources of evidence used in the multiple case study, provided the opportunity to collaborate findings to enhance the validity of the data.

\subsubsection{A Qualitative Approach}

Qualitative research methods were predominantly used in this thesis because it is primarily a multiple case study with present day dimensions. Qualitative research involves an understanding and interpretation of the world and explores individuals' experiences where they live and work by developing the subjective meanings of their experiences in a social setting (Creswell, 2018; Fraenkel, Wallen, \& Hyun, 2015). This type of study often takes place in a particular context and focuses on human interactions (File et al., 2016). Qualitative researchers investigate things as they are and do not manipulate the environment (Given, 2008).

Using a qualitative approach allows researchers to adopt a flexible and datadriven research design in order to highlight the vital role of subjectivity. This "can enable readers to allow for any effects of how the research was carried out that might obscure or threaten the validity of the analysis" (Hammersley, 2013, p. 16). Qualitative research involves the investigated use and gathering of diverse empirical materials such as a case study, an individual's experiences, self-examination, life stories, interviews, artefacts, observations, and historical texts, which explain routines and meanings in people's lives. Moreover, qualitative research methods are commonly used to conduct studies that focus on culture and society. It was an important consideration for this study (Marshall \& Rossman, 2016; Sandelowski, 2004).

Merriam (2009) points out that the decision as to whether to use a qualitative case study instead of other research strategies is dependent upon what researchers want to know; it is how researchers define the problem and what questions are raised that determine the design of the study. Generally, 'what' questions can either be exploratory, which means that any strategies can be used, or about prevalence, in 
which case surveys or the analysis of archival records would be preferable. The use of 'how' and 'why' questions is more likely to be used in case studies, and historical or experimental research (Yin, 2014). How and why questions are the focus of my study, which uses a multiple case study approach.

A case study is suitable for investigating a complex issue within a real-world context where the boundary between the context and issue is unclear and contains many variables (Creswell, 2014; Harrison, Birks, Franklin, \& Mills, 2014; Merriam, 2009; Stake, 2006; Yin, 2014, 2018). In educational research, a case study is used as a method to "evaluate curriculum design and to explore participants' perspectives" (Harrison et al., 2014, p. 4). A multiple-case design refers to a research study containing more than a single case, the reason being that a multiple case study employs "the same methodological framework" as a (single) case study design (Yin, 2014, p. 56). A multiple case study was used for this research to explore similarities and differences between early childhood services (Creswell, 2014; Yin, 2014, 2018). In line with this, a multiple case study involving six to 10 cases is reasonably effective for an investigation; consequently, the number of eight early childhood services is a suitable number for this study (Stake, 2006; Yin, 2014, 2018).

Case studies, including a multiple case study, are bounded by time and activity. This allows researchers to collect detailed information using a variety of data collection procedures over a sustained period (Cohen, Manion, \& Morrison, 2018; Stake, 2006; Yin, 2014, 2018). The data collection for (multiple) case studies relies on six important sources of evidence (Yin, 2014, 2018) including interviews, documentation, archival records, physical artefacts, direct observation, and participant observation. He states that no source is privileged over the others. Moreover, the different sources are extremely complementary; therefore, a good multiple case study will make use of as many sources as possible. In this study, documentation and interviews were used, and in the next section I consider the utility of each.

\subsubsection{Documentation.}

One source of data relevant for this thesis was documentation. It was used to access official documents, including curriculum documents. This allowed me, as a researcher, to access meaningful data such as official governmental documentation and reports, field notes, lesson plans, books, academic journal articles, and unpublished theses 
(Bogdan \& Biklen, 2007; Bryman, 2016; Cohen et al., 2018). These included for example, the 2010 National Cultural Act, the training manual for integrating 12 Core Values into teaching practices, the 2017 Constitution of the Kingdom of Thailand, the 2010 National Education Act, and Thailand's national education plans (Department of Cultural Promotion, 2010b; Office of the Basic Education Commission, 2014; Office of the Council State, 2010; Office of the National Education Commission, 2010, 2017). The documents were used to authenticate and augment the evidence gathered from other sources. Documents were significant as they played a vital role in gathering information necessary to undertake this multiple case study. Although documents may be sometimes outdated, they are considered "stable, unobtrusive, specific, and broad evidence" (Yin, 2018, p. 114).

During the semi-structured interviews, the head teachers and early childhood teachers were asked about what documentation they used at their early childhood services. At three of the services I was given various pieces of documentation, including a sample of assignments (Foxglove Service), lesson plans (Anemone Service), and curriculum development plans (Jamesia Service). Another service (Kalmia Service) shared a sample of the lesson plan they used but I was not allowed to take a copy away. Early childhood teachers at two of the services, Cherry Blossom and Sunflower Services, showed me around their classrooms so that I could have a look at the teaching materials they used with the children.

Throughout the data collection I kept field notes and memos. Memos helped me as a researcher to synthesise ideas and keep me on track (Bryman, 2016). For example, I wrote a memo after finishing the interview with the principal at Anemone Service. This gave me a better understanding of how she defined Thai culture and identity, and Thainess. As Bogdan and Biklen (2007) put it, memos and field notes are useful as an additional source for the data to refer to. During the semi-structured interviews, I was able to write comments regarding the set-up of the early childhood services as well as record the perspective of the participants and their personal comments in relation to how they promoted Thai culture and identity.

\subsubsection{Interviews.}

Interviews are an important source of information when carrying out qualitative research. In this study they were used to explore participants' experiences with, and 
their opinions about the 2003 early childhood curriculum (Creswell, 2014, 2018). The interviews involved the principals, head teachers, early childhood teachers, and children's parents from the eight early childhood services. This meant that certain types of information were wanted from all the multiple case study participants but the particular wording of the questions and how they were asked were clear to draw on the direct experience related to their different roles (Cohen et al., 2018; Creswell, 2018).

Although interviews consume a lot of time and energy for both interviewers and interviewees, they are a flexible tool for researchers to use to explore in-depth ideas, values, events, opinions, and behaviours. In this study, semi-structured questions were used to ask for additional information and further clarification in response to participants' responses and to ensure "cross-case comparability" (Bryman, 2012, p. 472). Such interviews are beneficial for researchers who know what they are investigating (Fraenkel et al., 2015). This type of interview "consists of a series of questions designed to elicit specific answers from participants and shapes responses to the researcher's perceptions of how things are," enhancing a flow of data gathering (Fraenkel et al., 2015, p. 449) and allowing researchers to target directly the research's focused topics and ask any additional questions if further clarification is required (Yin, 2018). This included discussing the interpretations between the researcher and participants in relation to "the world in which they live and express how they regard situations from their own point of view" (Cohen et al., 2018, p. 506).

Yin (2014) notes that interviews should always be regarded as verbal reports only. This is because they are subject to issues of bias, poor recall, and poor or imprecise verbalisation. Therefore, it is important to validate interview material with information from other sources of evidence. Triangulation is one of the most commonly used tactics for the validation of data. Using more than one source of data when doing research also serves to clarify meaning by identifying the various ways the phenomenon is being viewed (Bryman, 2016).

One of the main advantages of using a multiple case study approach is that it allows the researcher to use several research methods. Along with documentation and interviews, a survey was used in this study. Using a variety of sources in this multiple case study allowed me to perceive things from a different point of view and provided the opportunity to validate the findings to enhance the validity of the data. 


\subsubsection{Survey}

Quantitative research was also used in this thesis. A quantitative approach focuses on gathering numerical data and generalising it across groups of people or to explain a particular problem (Creswell, 2018). One of the common instruments for this approach is a survey (File et al., 2016). The purpose of a survey is to gather factual information from large groups, stipulating "quantitative or numeric description of trends, attitudes, or opinions of a population by studying a sample of that population" (Creswell, 2018, p. 147). A survey of early childhood teachers currently teaching in the Klongtoey and Wattana districts in Bangkok was carried out to further enhance the validity of the data.

A cross-sectional survey was conducted to collect information from the predetermined population - early childhood teachers currently working in 34 early childhood services (Fraenkel et al., 2015). The survey was a mixture of quantitative and qualitative questions to generate a large amount of data and describes "the nature of the existing conditions" within a limited timeframe (Cohen et al., 2018, p. 334). As Johnson and Onwuegbuzie (2004) point out, surveys consume less time and resources to collect, generate, and analyse the data. However, they are less effective at capturing important instructive features of the study (Patton, 2015).

In Thailand, there is not a central database of early childhood services, nor a database of current early childhood teachers' personal information. Consequently, this study carried out a paper-based survey. The following section outlines in more detail Phase One and Phase Two of this study.

\subsection{Selection Strategies Used to Select Sampled Participants}

Convenience sampling was used to select Bangkok, the capital city of Thailand, to carry out the research. This sampling method (also called opportunistic) is often used in case studies (Cohen et al., 2018). Furthermore, as Cohen et al. put it, convenience sampling ensures that participants are easily accessed during the data collection period. One of the considerations taken into account was that Bangkok is my home town and I am familiar with the landscape, facilities, and transportation system.

In Bangkok, there are 50 districts. Due to time constraints, purposive sampling was used to select two districts of central Bangkok, Klongtoey and Wattana, to undertake this research. Purposive sampling is another non-probability sampling often used in case studies. It differs to convenience sampling in that it requires researchers 
"to select a representative sample of elements" (Battaglia, 2011, p. 149). Purposive sampling is applied to select units of analysis and "participants in a strategic way, so that those sampled are relevant to the research questions that are being posed" (Bryman, 2016, p. 408). The selected samples are based on the researcher's judgement "of their typicality and particular characteristics being sought" (Cohen et al., 2018, p. 218).

Purposive sampling was used to choose Klongtoey and Wattana districts for two reasons. Firstly, social and cultural diversity is evident in both districts. This includes expensive housing as well as slum areas. Klongtoey district is the largest slum area of Bangkok (Klongtoey District Office, n.d.). Another reason was that these two districts are very well known to me. I was able to find my way around easily with the accessible transportation system as I used public transport to visit the eight services. This helped minimise expenses and I was able to complete the data collection within a limited time frame.

In 2015, there were 1,115 early childhood services with approximately 10,000 early childhood teachers in Bangkok. Four umbrella organisations are responsible for overseeing and supervising early childhood services in Bangkok. Three of the four organisations are under the supervision of the Ministry of Education. These include: the OPEC which administers 635 early childhood services; the OBEC which oversees 35 services; and the OHEC which supervises seven early childhood services. The fourth organisation is the BMA EDU which reports directly to the Bangkok Metropolitan Administration and is responsible for 438 early childhood services. Selecting Klongtoey and Wattana districts ensured that all these four umbrella organisations overseeing early childhood services were included in the study.

Due to the large number of early childhood services as well as time and size constraints, early childhood services providing education and care for children aged 3 to 5 years were chosen. As stated earlier, the Government expects parents and families to provide some childcare support for children under three (UNESCO International Bureau of Education, 2006), which was another reason this age group was not included in my study. Islamic and international early childhood services were also excluded as the study's focus was to investigate how early childhood services integrated Thai culture and identity in their curriculum programmes.

Within Klongtoey and Wattana districts, 36 early childhood services were invited to take part in this study; however, two services from the OPEC declined to 
participate, making an overall total of 34 service participants who took part in Phase One. In Bangkok, early childhood services are either kindergartens, which are standalone providers, or preschool classes which are attached to primary schools.

In Phase One, early childhood teachers and teaching assistants within the 34 services were invited to fill out the survey. Generally, an early childhood teacher (as well as a head teacher) is responsible for a single classroom, designing the learning contents and activities for daily teaching, and evaluating their learning performance. At some services, early childhood teachers who filled out the survey held other roles including that of principals or head teachers. The teaching assistant's role was to help early childhood teachers with class instruction and preparing lessons, assisting with children's routines, and supervising them in a classroom. When an early childhood teacher is absent, a teaching assistant serves as a substitute teacher. The table below shows the number of participants who participated in this study from each of the umbrella organisations.

Table 4

Number of services from each umbrella organisation that participated

\begin{tabular}{ccccccc}
\hline & OPEC & BMA EDU & OBEC & OHEC & Total \\
\hline Phase One: The Survey & 22 & 8 & 3 & 1 & $\mathbf{3 4}$ \\
\hline $\begin{array}{c}\text { Phase Two: The Multiple Case } \\
\text { Study }\end{array}$ & 4 & 2 & 1 & 1 & $\mathbf{8}$ \\
\hline
\end{tabular}

For Phase Two, a multiple case study was undertaken involving eight early childhood services in Klongtoey and Wattana districts. To ensure that services from each umbrella organisation in each of these two districts were represented in the study, four services were first selected using purposive sampling and are highlighted in green below in Figure 3. The first service, Cherry Blossom, was included and selected using purposive sampling due to being the only service administered by the OHEC and it was important to include all four organisations in this study. The other three were chosen owing to their "information-rich cases" characteristics (Wiersma \& Jurs, 2009, p. 342). By way of illustration, Anemone Service was chosen due to its interesting characteristics (Cohen et al., 2018). It is a preschool class attached to a Buddhistoriented school and the early childhood teachers took into consideration the promotion 
of Thai culture and identity, and Buddhism. Another service, Jamesia, was selected for historical reasons. It was established in 1911 during King Rama V's reign (see 1.1).

Foxglove Service was another service that was purposefully selected as it has a variety of social contexts. Some people live in large and expensive houses, while others live in a very crowded slum area. Some locals work as white-collar employees, while others work for their living as labourers or construction workers (Klongtoey District office, n.d.). In relation to the background of this district, it was Bangkok's central business district in the 1950s (Klongtoey District office, n.d.). The Port Authority of Thailand is also located in this area. An influx of labourers from other areas and provinces entered Klongtoey District to work at the port, in industrial factories, and for the large-scale fresh market. Without management of the area, those workers built their residential shelters on empty wasteland when they were relocated from their home towns to work in this district. Issues for residents resulting from living in Klongtoey include quality of housing and pollution, as well as other social problems such as drug, crime, and prostitution (Klongtoey District office, n.d.).

The four other services were chosen through convenience sampling by "selecting whomever happens to be available" (Cohen et al., 2018, p. 307). This meant I chose the services from those that agreed to participate in Phase Two.

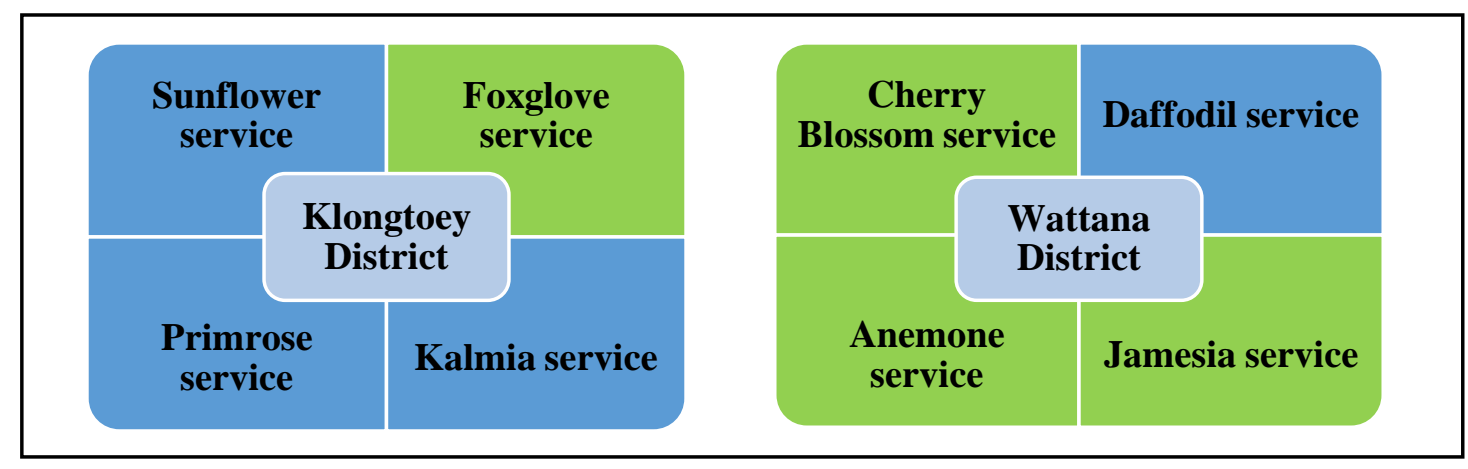

Figure 3. Selection and location of services involved in the multiple case study

In each service, I carried out the semi-structured interviews with the principal, head teacher, two early childhood teachers, and two children's parents. The 2003 Early Childhood Curriculum (Ministry of Education, 2003b) defines staff who are involved in early childhood education provision and management for children aged 3 to 5 years as follows: educational institution administrators (referred to as principals in this study) and early childhood teachers (referred to as head teachers and early childhood teachers in this study). 
Principals are responsible for overseeing educational administration and management within the services (both kindergarten and preschool). Furthermore, this ensures "systematic educational links between early childhood education and primary education" (Ministry of Education, 2003b, p. 38). At small services, some principals may also teach in a classroom. Head teachers are key people who take part in educational management and supervise early childhood teachers. Criteria for selecting the early childhood teacher participants to be interviewed were applied in order to gain in-depth information during the semi-structured interviews. They were required to hold a Bachelor's degree in education and to have two years of teaching experience or more.

The 2003 Early Childhood Curriculum also identifies parents or caregivers (referred to as parents in this study) along with primary teachers as key persons who enhance a child's learning and development (Ministry of Education, 2003b). It is necessary for parents to understand the provision of both early childhood and primary education. They also need to collaborate with early childhood teachers and participate in activities at their children's early childhood service. On the other hand, the role of primary teachers is to ensure that the first year of primary education is directly linked to children's learning experiences in early childhood education.

\subsection{Phase One: The Survey}

For Phase One, a paper-based survey was distributed to 34 early childhood services in the two districts of Central Bangkok: Klongtoey and Wattana. The items for the survey consisted of categorical questions, Likert scale questions, and another descriptive rating scale (see Appendix B). The survey was written in English and then translated into the Thai language. It had five main sections containing 59 closed-ended questions for ease of answering and eight open-ended questions for the survey respondents to provide additional clarification regarding their responses if they wished to do so. Overall, the survey had 65 questions.

The survey began with items that were relevant to the research focus and easy to answer by most of respondents (Czaja \& Blair, 2005). Among the survey questions, 11 of them contained negative wording in order to minimise acquiescent response bias. These were designed to avoid respondents agreeing to all the questions irrespective of item content (Costello \& Roodenburg, 2015). The survey took approximately $30-45$ minutes to complete. According to Czaja and Blair (2005), survey respondents may 
not complete a survey that requires a lot of writing, and this was taken into consideration when preparing the survey questions.

The response rate was $76.3 \%$ (235/308), which was very good for selfadministered surveys (Punch, 2003). Descriptive statistical data, analysed using SPSS software, was used to present the results.

The five sections in the survey were organised as follows:

(i) Demographic Data

In this section, the respondents were asked questions regarding their age, gender, current role and years of experience in their positions, years of experience working with the 2003 Early Childhood Curriculum, and their highest qualification as well as their study majors. Demographic data were useful for identifying the respondents' characteristics and ensuring that the representative sample was relevant to the study's focus. The survey respondents were also asked about their service's characteristics: location, type of service, and the number of children and early childhood teachers in their services. This information indicated whether a service was a standalone kindergarten, or a preschool attached to a primary school.

(ii) Implementing the 2003 Early Childhood Curriculum

The respondents were asked how they implemented the 2003 Early Childhood Curriculum by marking responses that most clearly matched their teaching practices using a three-point scale of frequency $(1=$ Never/Rarely, 2 = Sometimes, and 3 = Always). They were asked questions such as how often they followed the curriculum guidelines, how frequently their services covered the learning contents addressed in the curriculum, and how often early childhood teachers took into consideration children's interests, age and abilities, individual differences, and their socio-cultural contexts. The questions posed also asked how frequently the survey respondents took into account aspects of children's learning and development when designing their lesson plans. This part was designed to provide a comprehensive insight into how the survey respondents implemented the curriculum. 
(iii) Integrating Thai culture and identity

This section aimed to gather information on how the survey respondents integrated this in their daily teaching practices by ticking responses that best matched their practice using the three-point scale of frequency $(1=$ Never/Rarely, 2 = Sometimes, and $3=$ Always). In this section, the word Thainess was addressed as referring to Thai culture and identity. They were asked how their services encouraged children to practise the following aspects of Thai culture and identity: performing Wai, bowing when walking past elders, paying respect to elders, and demonstrating selfdiscipline and responsibility. Moreover, this section explored how the survey respondents promoted Thai culture and identity in relation to raising awareness of Thai identity, incorporating Buddhist principles, teaching about Thai traditions and observations of important religious dates, and inculcating Buddhist ways of living in children. The questions asked for specific aspects of Thai culture and identity that survey respondents considered and applied in their teaching practices.

(iv) The survey respondents' views of the role of the Government

This section investigated how the survey respondents regarded the Government's aspirations and the role it played in promoting Thai culture and identity. They were asked a set of questions to which they responded using a five-point Likert scale ( 1 = Strongly disagree, 2 = Disagree, $3=$ Neither agree nor disagree, $4=$ Agree, and $5=$ Strongly agree). For example, the survey respondents were asked whether the Government should provide training manuals for early childhood teachers in relation to promoting Thai culture and identity; and whether they needed to give more specific guidelines and sample activities related to promoting Thai culture and identity. This section also included two optional open-ended questions which asked the survey respondents what support they would like from the Government. These questions were designed to see how the survey respondents perceived the Government's role. 
(v) The survey respondents' perception of the parents' contribution In this section, the respondents were asked how they viewed the role of children's parents in promoting Thai culture and identity by marking their responses on the close-ended questions with the three-point scale $(1=$ Never/Rarely, 2 = Sometimes, and 3 = Always) for their best matched answers. They were asked how often they consulted parents when developing lesson plans, how they viewed parents' participation in the services' activities, and their opinions on parents' contribution in promoting Thai culture and identity with their young children. In this section, there were three optional open-ended questions to explore how early childhood teachers usually communicated with parents and how often, and their views of how important parental collaboration was in promoting Thai culture and identity. This provided an understanding of the relationship between early childhood teachers and parents, including how the survey respondents viewed a parent's role.

\subsubsection{Piloting the Survey}

A pilot survey was carried out to ensure clarity and validity prior to it being widely distributed. Early childhood teachers from a preschool class attached to a primary school in Phayathai District piloted this survey. This service was not included in the study as it was in another district. The pilot respondents included 12 early childhood teachers, including the head teacher. The feedback I received was very useful as the early childhood teachers clearly understood all the questions asked and did not seek any further clarification. They did leave one question blank, which asked them to state the location of their service. There were only two answers available to be selected Klongtoey or Wattana - so this explained why this was unanswered. As Czaja and Blair (2005) put it, pretesting helps researchers to estimate how much time should be given before following up after giving out the survey.

\subsubsection{Gaining Access for the Survey}

There were 34 early childhood services in Klongtoey and Wattana Districts that participated in the survey. At the time of the study they were administered by four different umbrella organisations. I sent each of the organisations a formal letter with 
an Information Letter about the study and a Consent Form to request permission to carry out my study in their service (see Appendix C). Only the information letters and consent forms from the EDU BMA are included in the appendix but they were the same for everyone. Representatives from each umbrella organisation asked for further information about my study, including a copy of the survey. The organisations also asked for additional details about my proposed research. Once they had their questions answered, each organisation gave permission for me to undertake my study in their early childhood service. Only the umbrella organisation EDU BMA stated that all early childhood services under their supervision would be informed that I had permission to carry out my study.

\subsubsection{Distributing the Survey to Early Childhood Services}

I was advised to send official letters to the principals at each service. In Thailand, official letters are required to gain access to governmental organisations and the same protocol was expected when approaching the selected services. The Information Letters, which outlined Phases One and Two of the research, were sent. Some services were happy for me to drop off the documentation in person while others asked that they be sent via a courier.

When collecting the filled-in survey, two methods were used. I rented a PO Box at the post office near my residence. Each survey respondent was given a prepaid envelope with the address of the PO Box written on it. When the survey was finished they put it into the envelope and mailed it to me. Some of the services, however, asked me to pick up their completed surveys. The school administrators contacted me when they were ready to be picked up. To comply with ethics requirements, the survey respondents were asked to put their filled-in survey in the envelopes provided to ensure that their responses were confidential.

I was informed through informal conversations with some of the school administrators that teaching assistants were not invited to fill out the survey. Those administrators pointed out that "teacher assistants were not teaching" (personal communication, December 14, 2015). Therefore, only a small number of teaching assistants from some of the services participated in the survey.

Distributing the survey to the 34 early childhood services took five weeks. Two weeks after initial contact with the services, I followed up with a phone call to make 
sure that they received the relevant information. Three services stated that they did not receive the Information Letters via a courier. I visited those services in person to deliver them. A second follow-up call was made two weeks later to all the services that had not sent in their filled-in surveys. A total of 308 surveys were distributed to the 36 early childhood services. I received 235 filled-in surveys (76.3\%), which is considered a very good response rate (Punch, 2003).

\subsection{Phase Two: The Multiple Case Study}

Eight early childhood services were involved in the multiple case study for Phase Two of this study. Data were gathered using semi-structured interviews and document analysis to gain in-depth information on how early childhood teachers implemented the 2003 Early Childhood Curriculum and integrated Thai culture and identity in their daily teaching practices.

\subsubsection{Gaining Access for the Multiple Case Study}

Once the eight services were selected, the principals from each one was sent a formal letter requesting permission to be involved in Phase Two (see Appendix D). Along with the formal letter were Information Letters and the Consent Forms for each of the participants, including the principal, the head teacher, the early childhood teachers, and the parents. The school administrator was responsible for giving out the Information Letters and the Consent Forms to the other participants. Some of the participants requested a list of sample questions beforehand to be asked at the semistructured interviews, which I provided (see Appendix E).

Permission to participate in the multiple case study from each of the services took two weeks, but this occurred over a period of time. When I received confirmation that the services had agreed to participate in this study an interview schedule was arranged, taking into consideration the participants' agreed date and time. At four of the services, the school administrators assisted with the scheduling of the interviews for all the participants. For three of the services I arranged all the interview schedules with the head teachers. At the remaining service, the Vice-Principal (authorised by the principal) helped arrange the interview sessions with all interviewees. 


\subsubsection{Semi-structured Interviews}

In this study, semi-structured interviews were undertaken at each service with the principal, the head teacher, two early childhood teachers, and two parents to investigate what activities and practices they implemented to promote Thai culture and identity at their service.

Regarding the selection of the early childhood teachers who participated in the semi-structured interviews, either the principal or the head teacher took on the responsibility to communicate with early childhood teachers and invited those who held a Bachelor's degree in education and had two years' teaching experiences or more to be part of my study. Due to cultural constraints, I was unable to make direct contact with the early childhood teachers. With regard to the selection of parents, either the head teacher or the early childhood teachers assisted by approaching children's parents. The participating parents from the services in some instances were not from the classrooms of those early childhood teachers who were interviewed but selected instead from those they who had given their consent to participate in the study.

All the principals interviewed were asked their views about the implementation of the 2003 Early Childhood Curriculum and how they incorporated Thai culture and identity at their service. They were also given the opportunity to discuss their views on the Government's support and contribution, parental collaboration, and policies or strategies related to early childhood education in Thailand. Four principals were interviewed. At two of the services, Daffodil and Foxglove, the principals authorised the Vice-Principals to be interviewed in their place. At Jamesia and Kalmia Services, the head teachers were interviewed on behalf of their principals. Their interview responses are reported as principals and head teachers.

The interviews with the principals took longer than the other interviews carried out, approximately $30-45$ minutes, as they needed additional time to answer the questions. For example, the Vice-Principal from Foxglove Service spent 10 minutes during his interview describing the 'special' characteristics of the Klongtoey community while Primrose Service's principal took 15 minutes to explain how children's parents participated in their service's activities.

The head teachers who took part in the study were asked to share their ideas about early childhood education provision at their early childhood service, the implementation of the 2003 Early Childhood Curriculum, and how they designed 
teaching strategies and lesson plans when integrating Thai culture and identity with young children. These interviews took approximately $25-40$ minutes.

The early childhood teachers were interviewed as well to explore how they delivered the 2003 Early Childhood Curriculum and integrated Thai culture and identity into their teaching practice. They were asked about the role of the Government and parents in promoting Thai culture and identity with young children. These interview sessions lasted approximately $20-40$ minutes. The selection of the early childhood teachers interviewed was undertaken by either the principal or head teacher. Due to Thailand's hierarchical system it was not appropriate for the researcher to select who to interview. The early childhood teachers were interviewed individually except at Cherry Blossom Service where the two teachers were interviewed together due to their busy teaching schedule. At Foxglove Service, only the head teacher was interviewed as she was the sole early childhood teacher.

In order to hear the parents' voices, they were also invited to be interviewed. They were asked about their understanding of the 2003 Early Childhood Curriculum and how it was implemented. The semi-structured interviews also examined how the parents promoted Thai culture and identity with their children. Their interviews took approximately $10-30$ minutes.

\subsubsection{Conducting the Multiple Case Study}

The data collection for the multiple case study began before the completion of the first phase of my study. This was due to the delay caused by three of the services not receiving the Information Letters for Phase One via a courier.

The data collection at the first service, Anemone, began in the second week of December in 2015, five weeks after my initial contact. One of four purposively selected services, the Buddhist-oriented preschool, is attached to a primary school and located in the Wattana District and is under the supervision of the umbrella organisation OPEC. There were 159 children enrolled with 18 early childhood teachers, including an early childhood head teacher. The head teacher gave me samples of their lesson plans, including documentation giving details of a project that aimed to promote Thai culture and identity which had taken place before the data collection period. It took 10 days to complete all the semi-structured interviews. 
Data gathering for Primrose Service was undertaken during the last week of January in 2016. This is another service under the supervision of the OPEC. The preschool is attached to a primary school located in Klongtoey. There were 84 children enrolled at the service with six early childhood teachers, including an early childhood head teacher. The principal stated that the service provides early childhood education and care that incorporates both Thai and Chinese cultures. One of the early childhood teachers showed me around her classroom after the semi-structured interview and shared some of her lesson plans. The classroom was decorated with children's coloured pencil drawings such as the Thai national flag, the King's and the Queen's portrait, and figures of numbers $1-10$.

The collection of data for another purposively selected service, Cherry Blossom, was carried out during the first week of February in 2016. This preschool, under the OHEC's supervision, is attached to a primary school located in Wattana. There were 220 children enrolled with eight early childhood teachers, including the head teacher. The two early childhood teachers selected to be interviewed had a very busy teaching schedule as they were the only early childhood teachers in a 55-children classroom. This meant that they could not be released to be interviewed during the teaching day. Consequently, they ended up being interviewed together. At this service three parents volunteered to participate in the study and they were all interviewed. This was the only service where more than two parents were interviewed. It took almost two weeks to complete all the semi-structured interviews due to the busy work schedule of the principal and the head teacher.

In early February 2016, data collection was started at Daffodil Service. This is a preschool attached to a primary school in the Wattana district, which is under the supervision of the BMA EDU. The service is located near a temple and is surrounded by local community residents. There were 119 children enrolled at this service with four early childhood teachers, including the head teacher. Each early childhood teacher has a teaching assistant helping in the classroom. It took two days to complete the semi-structured interviews at this service. The principal authorised the Vice-Principal to be interviewed on her behalf. One of the parents from the service was interviewed over the phone instead of face-to-face; she had agreed to come to the service but an urgent call from her workplace meant that she had to cover a colleague's shift.

The data collection for the third purposively selected service, Jamesia, was undertaken during the second week of February 2016. This preschool is attached to a 
Christian-oriented school which offers education for primary and secondary students as well and being under the supervision of the OPEC in the Wattana district. The preschool, established in 1911, is based on Dr Maria Montessori's method of education. The early childhood teachers are encouraged to follow the Bible's scriptures and incorporate these values into their teaching practices; however, they also value Thainess and integrate some aspects of Thai culture and identity in their learning lessons and activities for young children. The preschool caters for 395 children and there are 26 early childhood teachers, including the head teacher. The principal authorised the head teacher to be interviewed in her place. The head teacher showed me their curriculum development plans, which I was allowed to photograph. I also observed some of the classrooms. All the semi-structured interviews were completed in one day.

In the middle of February in 2016, data were gathered at Foxglove Service, which was also purposively selected. This is a preschool attached to a primary school in the Klongtoey district under the supervision of the BMA EDU. There were 69 children enrolled who were taught by one early childhood teacher and two teaching assistants. Four individual semi-structured interviews were carried out with the VicePrincipal who was authorised to be interviewed on the Principal's behalf, the head teacher, and two parents. It took almost an hour to do the interview with the head teacher as she explained in depth how she implemented the 2003 Early Childhood Curriculum and what aspects of Thai culture and identity she integrated into her teaching practice. She also described her lesson plans and supplied a sample of a learning exercise used to teach the children. I was shown some teaching resources as well that were used with the children including a colourful clock made from coloured paper to teach them about time, a coloured-drawing of a person performing a Wai gesture, and a presentation board illustrating the history of the importance of the Loy Kratong Festival and the festival's ritual activities.

Data collection for the seventh service was carried out in the third week of February in 2016. Kalmia Service is a kindergarten in the Klongtoey district, under the OPEC's supervision, which had a role of 230 children with a teaching team of 30 early childhood teachers, including the head teacher. Like Jamesia Service, the head teacher attended the interview on behalf of the principal. She also invited the advisor responsible for the service's quality assurance and curriculum development to attend 
the interview. It took three days to conduct all the semi-structured interviews at this service.

During the first week of March 2016 data were gathered at Sunflower Service which is under the OBEC's supervision. This is a preschool attached to a primary school in the Klongtoey district. There were 163 children enrolled and there were eight early childhood teachers, including the head teacher. The service is located across the road from a secondary school that is also administered by the OBEC. It took 10 days to gain permission to arrange the interview schedules with the participants. During the semi-structured interview with the head teacher I was shown some teaching materials used in the classroom. I was also invited to observe children's activities to celebrate the preschool's annual celebration. This included the children performing traditional Thai dance and dressing up in traditional Thai costumes. The early childhood teachers and parents were also involved in these activities.

The multiple case study participants were asked different questions depending on the role they held at each of the eight early childhood services. A total of 46 participants were involved in Phase Two and they are presented in Table 5 with their pseudonyms. The semi-structured interviews were conducted separately with two exceptions. The two early childhood teachers at Cherry Blossom Service were interviewed together. At Foxglove Service there was only one early childhood teacher at this service with the assistance of two caregivers. She was asked the set of questions regarding her role as head teacher as well as those put to early childhood teachers. All the interviews were conducted face-to-face with one exception. One of the parents from Daffodil Service was interviewed over the phone. Thirty-five of the interviews were audio-recorded with the participants' permission. The semi-structured interviews were conducted in Thai and later translated into English. Those participants who asked for a summary of their interviews for accuracy checking were given a copy, but noone requested any changes to be made. 
Table 5

Pseudonym List of the Multiple Case Study Participants

\begin{tabular}{|c|c|c|c|c|c|c|c|}
\hline No. & Pseudonyms & Participants & Abbreviation & Gender & $\begin{array}{l}\text { Years of Experience } \\
\text { Working in their Roles }\end{array}$ & Service's Name & $\begin{array}{l}\text { Supervising } \\
\text { Organisation }\end{array}$ \\
\hline 1 & Apinya & Principal & (P1) & Female & More than 10 years & \multirow{6}{*}{$\begin{array}{l}\text { Anemone } \\
\text { (Service 1) }\end{array}$} & \multirow{6}{*}{$\begin{array}{c}\text { The Office of the } \\
\text { Private } \\
\text { Education } \\
\text { Commission } \\
\text { [OPEC] }\end{array}$} \\
\hline 2 & Anyamanee & Head teacher & (HT 1) & Female & More than 10 years & & \\
\hline 3 & Amornrat & EC Teacher A & (T1) & Female & More than 10 years & & \\
\hline 4 & Anchalee & EC Teacher B & (T1) & Female & More than 10 years & & \\
\hline 5 & Apirak & Parent A & $(\operatorname{Pr} 1)$ & Female & - & & \\
\hline 6 & Areeya & Parent B & $(\operatorname{Pr} 1)$ & Female & - & & \\
\hline 7 & Parkpoom & Principal & $(\mathrm{P} 2)$ & Male & More than 10 years & \multirow{6}{*}{$\begin{array}{c}\text { Primrose (Service } \\
2 \text { ) }\end{array}$} & \multirow{6}{*}{$\begin{array}{l}\text { The Office of the } \\
\text { Private } \\
\text { Education } \\
\text { Commission } \\
\text { [OPEC] }\end{array}$} \\
\hline 8 & Pannee & Head teacher & (HT2) & Female & More than 10 years & & \\
\hline 9 & Prannapha & EC Teacher A & (T2) & Female & More than 10 years & & \\
\hline 10 & Pinyo & EC Teacher B & (T2) & Female & $6-10$ years & & \\
\hline 11 & Patcha & Parent A & $(\operatorname{Pr} 2)$ & Female & - & & \\
\hline 12 & Pensri & Parent B & $(\operatorname{Pr} 2)$ & Female & - & & \\
\hline
\end{tabular}




\begin{tabular}{|c|c|c|c|c|c|c|c|}
\hline No. & Pseudonyms & Participants & Abbreviation & Gender & $\begin{array}{l}\text { Years of Experience } \\
\text { Working in their Roles }\end{array}$ & Service's Name & $\begin{array}{l}\text { Supervising } \\
\text { Organisation }\end{array}$ \\
\hline 13 & Chanin & Principal & (P3) & Male & Not indicate & \multirow{7}{*}{$\begin{array}{c}\text { Cherry Blossom } \\
\text { (Service 3) }\end{array}$} & \multirow{7}{*}{$\begin{array}{c}\text { The Office of the } \\
\text { Higher } \\
\text { Education } \\
\text { Commission } \\
\text { [OHEC] }\end{array}$} \\
\hline 14 & Chanhom & Head teacher & (HT3) & Female & More than 10 years & & \\
\hline 15 & Chitchan & EC Teacher A & (T3) & Female & More than 10 years & & \\
\hline 16 & Chadapha & EC Teacher B & (T3) & Female & More than 10 years & & \\
\hline 17 & Chanjira & Parent A & $(\operatorname{Pr} 3)$ & Female & - & & \\
\hline 18 & Chanikarn & Parent B & (Pr3) & Female & - & & \\
\hline 19 & Chaat & Parent C & $(\operatorname{Pr} 3)$ & Male & - & & \\
\hline 20 & Danai** & Vice-principal & (P4) & Male & Not indicate & \multirow{6}{*}{$\begin{array}{c}\text { Daffodil (Service } \\
\text { 4) }\end{array}$} & \multirow{6}{*}{$\begin{array}{l}\text { The Department } \\
\text { of Education } \\
\text { Bangkok } \\
\text { Metropolitan } \\
\text { Administration } \\
\text { [EDU BMA] }\end{array}$} \\
\hline 21 & Darunee & Head teacher & (HT4) & Female & More than 10 years & & \\
\hline 22 & Duangkamon & EC Teacher A & (T4) & Female & More than 10 years & & \\
\hline 23 & Dawadee & EC Teacher B & (T4) & Female & More than 10 years & & \\
\hline 24 & Duangjai & Parent A & $(\operatorname{Pr} 4)$ & Female & - & & \\
\hline 25 & Deejai & Parent B & $(\operatorname{Pr} 4)$ & Female & - & & \\
\hline
\end{tabular}




\begin{tabular}{|c|c|c|c|c|c|c|c|}
\hline No. & Pseudonyms & Participants & Abbreviation & Gender & $\begin{array}{l}\text { Years of Experience } \\
\text { Working in their Roles }\end{array}$ & Service's Name & $\begin{array}{l}\text { Supervising } \\
\text { Organisation }\end{array}$ \\
\hline 26 & Jandee* & Head teacher & (HT5) & Female & More than 10 years & \multirow{5}{*}{$\begin{array}{c}\text { Jamesia (Service } \\
\text { 5) }\end{array}$} & \multirow{5}{*}{$\begin{array}{l}\text { The Office of the } \\
\text { Private } \\
\text { Education } \\
\text { Commission } \\
\text { [OPEC] }\end{array}$} \\
\hline 27 & Jintana & EC Teacher A & (T5) & Female & $6-10$ years & & \\
\hline 28 & Jaruwan & EC Teacher B & (T5) & Female & $6-10$ years & & \\
\hline 29 & Jeerapa & Parent A & (Pr5) & Female & - & & \\
\hline 30 & Jutamas & Parent B & $(\operatorname{Pr} 5)$ & Female & - & & \\
\hline 31 & Fahprataan** & Vice-principal & (P6) & Male & Not indicate & \multirow{4}{*}{$\begin{array}{c}\text { Foxglove (Service } \\
6 \text { ) }\end{array}$} & \multirow{4}{*}{$\begin{array}{c}\text { The Department } \\
\text { of Education } \\
\text { Bangkok } \\
\text { Metropolitan } \\
\text { Administration } \\
\text { [EDU BMA] }\end{array}$} \\
\hline 32 & Fangkhaw & Head teacher & (HT6) & Female & More than 10 years & & \\
\hline 33 & Fundee & Parent A & (Pr6) & Male & - & & \\
\hline 34 & Fahrung & Parent B & (Pr6) & Female & - & & \\
\hline 35 & Kanyakorn* & Head teacher & (HT7) & Female & More than 10 years & \multirow{6}{*}{ Kalmia (Service 7) } & \multirow{6}{*}{$\begin{array}{c}\text { The Office of the } \\
\text { Private } \\
\text { Education } \\
\text { Commission } \\
\text { [OPEC] }\end{array}$} \\
\hline 36 & Kanjana & Advisor & (HT7) & Female & More than 10 years & & \\
\hline 37 & Keawkamon & EC Teacher A & (T7) & Female & More than 10 years & & \\
\hline 38 & Kanda & EC Teacher B & (T7) & Female & More than 10 years & & \\
\hline 39 & Kingkarn & Parent A & (Pr7) & Female & - & & \\
\hline 40 & Kanokporn & Parent B & $(\operatorname{Pr} 7)$ & Female & - & & \\
\hline
\end{tabular}




\begin{tabular}{|c|c|c|c|c|c|c|c|}
\hline No. & Pseudonyms & Participants & Abbreviation & Gender & $\begin{array}{l}\text { Years of Experience } \\
\text { Working in their Roles }\end{array}$ & Service's Name & $\begin{array}{l}\text { Supervising } \\
\text { Organisation }\end{array}$ \\
\hline 41 & Surasak & Principal & (P8) & Male & More than 10 years & \multirow{6}{*}{$\begin{array}{l}\text { Sunflower } \\
\text { (Service 8) }\end{array}$} & \multirow{6}{*}{$\begin{array}{l}\text { The Office of the } \\
\text { Basic Education } \\
\text { Commission } \\
\text { [OBEC }]\end{array}$} \\
\hline 42 & Sutana & Head teacher & (HT8) & Female & More than 10 years & & \\
\hline 43 & Somjai & EC Teacher A & (T8) & Female & $6-10$ years & & \\
\hline 44 & Salinthip & EC Teacher B & (T8) & Female & $6-10$ years & & \\
\hline 45 & Sawittree & Parent A & (Pr8) & Female & Not Applicable & & \\
\hline 46 & Supatcha & Parent B & (Pr8) & Female & Not Applicable & & \\
\hline
\end{tabular}

* These head teachers are reported as being in a principal's role as they were asked the same set of questions as the principals as well as those related to their own roles.

** These vice-principals are reported in a principal's role as they were authorised to be interviewed on behalf of their principals. 


\subsection{Data Analysis: Multiple Case Study and Survey}

As this study contained both qualitative and quantitative research inquiries, the data from both were separately collected and analysed. I started with the document analysis of published dissertations, journals, and books to find out more about the history and background of early childhood education in Thailand. This included Thailand's early childhood curriculum documents, national education plans, and related educational Acts. I then analysed the quantitative data from the survey, and this was followed with the qualitative data obtained from both the open-ended survey questions and the semistructured interviews.

The two datasets were then merged together; the quantitative data are reported in Chapter 5. The qualitative findings from the multiple case semi-structured interviews and the open-ended questions from the survey are reported in Chapters 6 and 7 and themes are identified (Creswell, 2018). The discussion chapter draws on the key findings from both databases and the analysis of official Government documents and reports.

The quantitative data analysis was processed using the Statistic Package for Social Scientists (SPSS) software. I also use tables with numbers and percentages to present the survey results, to illustrate the data, and to show comparisons. The response rate was also discussed. Results are presented in Chapter 5 and are used to support the key findings in the discussion chapter. I also carried out cross-table analysis to see if the survey respondents from different demographic groups gave similar or different answers to the questions asked, especially in relation to their practices of integrating Thainess and Thai culture.

Once the filled-in surveys were collected, the data were tallied into an Excel sheet consisting of nominal data, ordinal data, and short answers. The nominal data were used to represent answers for questions $1-9$, and each item was reported as a percentage illustrated in a pie chart. The ordinal data from the close-ended questions $(10-53 ; 56-62)$ were also recorded on the Excel sheet. I grouped them under the same category and illustrated this by bar charts. Textual data were used to manage the short answers from the open-ended questions (54 - 55; $63-65)$ and are presented along with the qualitative data in Chapter 6.

Regarding question 40, a respondent wrote that she was confused about what the sentence asked. Two other respondents underlined several questions with negative wording, answering them with "Never/Rarely" (for example, questions 14, 26, 37, 40, 
and 58). For these three participants, I recorded their answers as they were marked on their surveys. Four other respondents provided clarification of their answers by adding positive comments on the back of the questions that contained negative words, as well as the reasons why they gave negative responses to these items (for example, questions 14, 17, 20, 30, 33, 37, and 47).

Six survey respondents marked "Never/Rarely" as their responses to questions $32,34-36,38-39$, while they answered "Always" to question 33 which contained a negative word. These questions were asked in relation to Buddhism, Buddhist principles, and Buddhist ways. The respondents provided comments to those questions stating that they were working in a Christian school, so they never organised or integrated those Buddhist ways. They also explained later in the survey that they encouraged children to perform Christian rituals instead.

Apart from the survey respondents' amendments and comments mentioned above, all the questions containing negative wording were reversed into positive denotation. The three-point frequency scale of these items was also reordered. The percentage of "Never/Rarely" was inverted to be represented by "Always", and this also worked conversely.

In relation to analysing qualitative data, this required me to work through the written comments. The qualitative data of this study comprised the short answers from the open-ended survey questions, the interview responses from the semi-structured interviews, and documentation. The data from the multiple case study participants' interviews was the primary source for analysing the qualitative data. Creswell (2018) also suggests six steps for qualitative data analysis, which are preparing data, reading through data, coding data, generating and creating themes for analysis, planning and designing how to present data, and making an interpretation of data. These specific steps were used as a guideline for analysing this study.

Regarding preparing the data, I transcribed and organised the data from the different sources of information: semi-structured interviews, official Government documents and reports and other documentation. The audio-recorded interview responses were transcribed from the Thai language into English. This enabled me to carefully analyse what the respondents said (Bryman, 2016). It took approximately six weeks to transcribe the responses. When I finished transcribing the interview transcripts a summary was sent to those participants who had asked to see their transcripts for accuracy checking. No changes were requested. 
The next stage involved reading through the data and writing a summary for each service involved in the multiple case study. While reading through each of the services' semi-structured interview transcripts, I looked closely at the words and terms used for consistency. I utilised Nvivo software to organise and code the data by identifying 'nodes' to process qualitative data analysis (Bazeley \& Richards, 2000; Bryman, 2016). Nodes are defined as a collection of data that are categorised under specific themes (Bryman, 2016). When coding, nodes were incorporated with the coded references from the interview scripts. During this stage, I contacted some of the participants for more clarification regarding their interview responses.

Through the coding process three types of codes were constructed: predetermined, emerging, and quotation. Predetermined codes were created by the researcher before starting the coding process. I came up with major categories which were considered in relation to my research focus and these corresponded to key themes in Chapter 5, such as Thai manners, Thai traditions, and Buddhism. Within these categories I used sub-codes; for example, under Thai Traditions I included festivals and important dates, and Buddhist principles and Buddhist practices were under Buddhism.

In relation to the emerging codes, the following terms were developed based on information collected from the multiple case study participants' perspectives; the Government's 12 Core Values, Thainess, Buddhism and other aspects of promoting Thai culture and identity. Once again, I used sub-codes for some of these categories. For instance, under the heading Other Aspects of Promoting Thai Culture and Identity, I included traditional Thai costumes and Thai language.

Quotation codes were also used. These included interesting and meaningful quotations from the participants presented in the multiple case study findings and discussion chapter. Pseudonyms were used to present the interview responses of each participant (See Table 5). During the coding process, I created a "qualitative codebook" (Creswell, 2018, p. 196) which was a table containing a list of the codes and their descriptions (see Appendix F).

After finishing the coding process, I read through the reference data for each code and reclassified nodes to be more precise and not overlapping with any other nodes. The predetermined codes were reorganised to provide a better understanding of the data findings. Because of doing this, some of the codes were expanded and became a sub-classification. Further analysis was undertaken to identify the key themes. I used 
tables to manipulate the data through content analysis using the latest version of the reference data from Nvivo and the summaries of the eight services involved in the multiple case study. This allowed me to do a cross-tabulation analysis which generated a comparison between the eight services, including those under the same umbrella organisation (see Appendix G). This involved in-depth exploration of similarities and differences across the services and provided a "detailed description of the setting or individuals, followed by analysis of the data for themes or issues" (Creswell, 2014, p. 196).

When key themes and sub-themes were identified through content analysis, I planned and designed how to present and report the data in Chapters 6 and 7. I started with the results from the multiple case study using the data from the comparison tables to interpret the data. Then, I supported the findings with the textual data from the openended survey questions which I grouped and labelled into the same classification of codes as the interview responses were encoded. The multiple case study findings chapters contain the identified key themes, which are presented with the multiple perspectives of the participants and their quotations (Creswell, 2018). This also included the review of the relevant official documents from the Government, particularly the interpretation of the 2003 Early Childhood Curriculum (Ministry of Education, 2003a,b).

\subsection{Validity and Reliability}

According to Cohen et al. (2018), validity can be enhanced through the quality of instrument, which must be accurate and effective. Internal validity involves "confidence in the data, authenticity of the data, and credibility of the data" (Cohen et al., 2018, p. 136). In relation to the quantitative method of this study, all the survey respondents were anonymous. The original copies of the completed surveys were collected and kept confidential. I was aware, too, of content validity when designing the survey. This involves content and questions which are relevant to the research focus. Content covers all the aspects that are investigated in the study. Moreover, the pilot testing also enhanced the content validity (Creswell, 2018).

For the validity of the qualitative method, the multiple case study used two different sources of data: semi-structured interviews and documentation. The interview responses were interpreted and reported in the participants' own words to reflect their point of view to enhance construct validity of the research. The interviews 
were audio-recorded for further interpretation. As Stake (2006) puts it, listening to recorded tapes several times can enhance validity in interpretation. Moreover, after the interviews were transcribed, those participants who asked for a summary of their interviews, these were sent to them for accuracy checking but no one requested any changes to be made.

The city of Bangkok was selected using convenience sampling as it is regularly used in case studies (Cohen et al., 2018). The two central districts of Klongtoey and Wattana in Bangkok were then selected using purposive sampling, which is also commonly used in case studies (Bryman, 2016; Cohen et al., 2018). The early childhood services located in these two districts were administrated by all four umbrella organisations. The services involved in the multiple case study were selected by using convenience and purposive sampling before the survey data were analysed. This also enhanced the validity of this study as the sample selection was not influenced by the survey data (Bryman, 2016).

Triangulation involves more than one source of data when doing research (Bryman, 2016). This research gathered data from multiple sources including a survey, semi-structured interviews, and documentation. Triangulation enhanced the validity and reliability of this study (Creswell, 2018; Yin, 2018).

\subsection{Ethical Considerations and Role of the Researcher}

The ethics application was approved by Victoria University of Wellington's Human Ethics Committee (Approval Number: RM 22229) before carrying out the study (see Appendix H). In Thailand, a very strict protocol must be followed when undertaking research at Governmental organisations. A formal letter with the information letters was sent to the umbrella organisations to obtain permission before approaching the early childhood services under their administration. The same protocol was applied for Phase Two of this study. A formal letter was sent to the principals of each service with the information letters and consent forms before approaching the services.

In Thailand, Thai people value hierarchical relationships where one person is held in higher esteem than another; for example, early childhood teachers hold a higher level of respect in relation to their students as do senior colleagues in relation to those in junior roles. When carrying out this study, I was a student and therefore considered holding a junior role in comparison to the participants at the eight early childhood services. I was very polite and demonstrated very good Thai manners when 
communicating with anyone from these services. I was also very respectful when carrying out the semi-structured interviews, especially when interacting with the principals. For those participants who were approximately the same age as me, I still needed to show respect towards them by being humble and courteous (Yin, 2014). As participating in this study was voluntary, I prepared a contingency plan regarding services that did not want to be involved in my study or wanted to withdraw. One early childhood service did withdraw at very short notice. However, I was able to gain permission from another service to be involved and so was able to complete all the data collection within my tight timeline.

The participants were informed that they did not have to answer all questions asked. They were also informed about the research details and objectives, including that the data would be used for academic purposes. The participants' and services' identities were treated as confidential and anonymous. Only my supervisors and I were allowed access to the collected data, which will be destroyed three years after the thesis is completed.

This research used a multiple case study, so I was conscious of being the primary instrument when carrying out this study and this raises concerns regarding bias (Chenail, 2011). As the researcher, therefore, I needed to be sensitive and responsive to contrary results as I was responsible for maintaining the accuracy and verifiability of the gathered information and reporting the participants' words. During the research process I was cognisant of how my subjective position might influence how I analysed and interpreted the data (Chenail, 2011; Norris, 1997).

\subsection{Chapter Summary}

This chapter has introduced the methods used for carrying out this study. There were two phases of the study: a survey and a multiple case study. The study was carried out in two districts of Central Bangkok - Klongtoey and Wattana. The survey was distributed to 36 early childhood services administrated under four umbrella organisations and there was a very good response rate. The multiple case study was undertaken at the eight services using semi-structured interviews involving principals, head teachers, early childhood teachers and children's parents, and relevant curriculum documentation. This chapter also explained how participants and services were selected and the ethical protocols that were used to gain access throughout the research process. 
In the next chapter, the quantitative data from the survey are presented in five main sections. The first includes the demographic data of the survey respondents and the survey services. The other four sections concern the perceptions of the survey respondents. 


\section{CHAPTER 5 \\ THE SURVEY FINDINGS}

This chapter presents the findings from Phase One of the study. The purpose of the survey was to investigate how Thai culture and identity were addressed in the 2003 Early Childhood Curriculum by examining what activities and practices early childhood services integrated into their daily teaching practices (Ministry of Education, 2003b). The research questions also asked how early childhood services perceived the role of the Government and children's parents in promoting Thai culture and identity.

The survey had five main sections. The first part requested demographic data about the respondents and their services. The second section asked questions on how the 2003 Early Childhood Curriculum was implemented at the respondents' early childhood services (Ministry of Education, 2003b). In the next part of the survey the ways in which Thai culture and identity were integrated into the respondents' daily teaching practices were probed. The fourth section had questions which asked for respondents' views about the role of the Government while the last part questioned their perceptions towards parents' participation. The survey did have some open-ended questions but in this chapter the focus is mainly on the quantitative data, starting with the demographic information.

\subsection{Demographic Data}

Demographic questions were asked to help determine factors that could influence a respondent's choice of answers. The respondents were requested to indicate their age group, gender, qualifications, roles and years of working with the 2003 Early Childhood Curriculum. Questions were also posed to learn about the location and type of services. These findings are presented in this section.

\subsubsection{The Survey Respondents}

Respondents were asked for their age band as this can sometimes impact on how they answer the questions posed. This is one of the most used demographic questions in surveys. In relation to age, the largest number of respondents $(31.5 \%, \mathrm{n}=74)$ were aged between 30 and 39 years, while $19.1 \%(n=45)$ were 50 years and over. In regard to gender, the majority of respondents were female $(96.2 \%, \mathrm{n}=226)$, whereas only 
$3.8 \%(n=9)$ were male. In the largest age group, $30-39$ years, there were only three males. This statistic of gender is similar to that in other countries (Peeters, 2007).
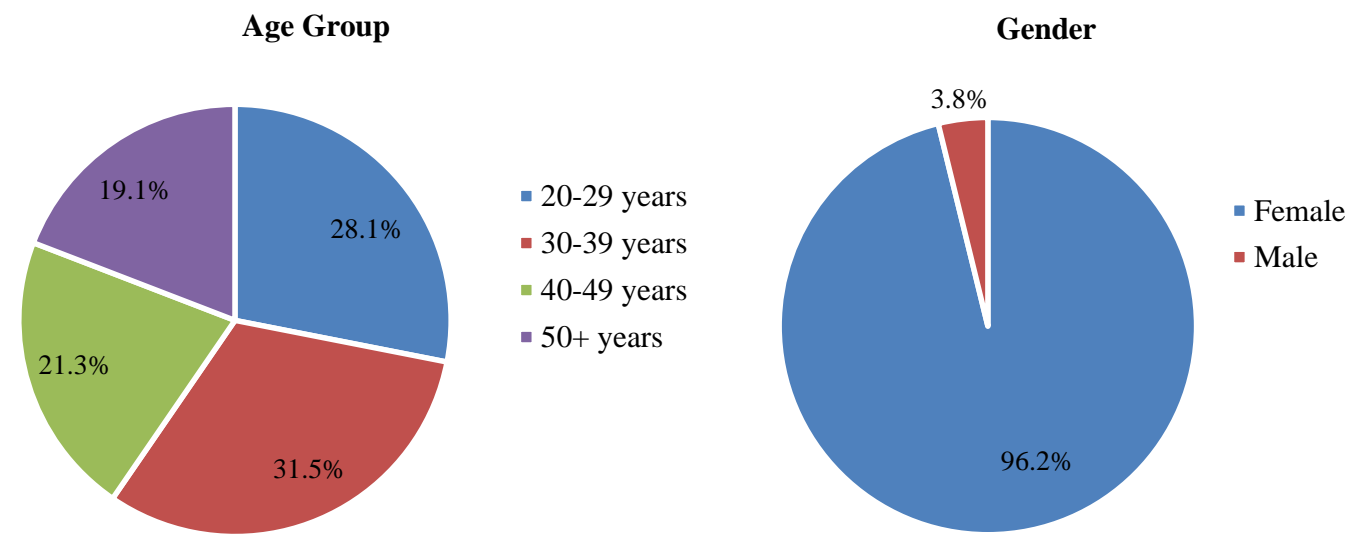

Figure 4. Respondents' age group and gender

The survey data revealed the different teaching positions held by the respondents. Principals, head teachers, early childhood teachers and teacher assistants filled out the survey. Most of the respondents were early childhood teachers (67.2\%, $\mathrm{n}=158)$, with teacher assistants making up the next largest group $(23.4 \%, \mathrm{n}=55)$. At some of the services, teaching assistants were not asked to participate in the survey. Some of the administrators who distributed the survey on my behalf considered teaching assistants to be unqualified so did not invite them to participate. I was concerned that teaching assistants may have had different views on the questions asked to the fully trained teaching staff, but the data revealed their responses were similar.

In response to how many years respondents had been in their current roles, $40 \%(\mathrm{n}=94)$ mentioned that they had been working for more than 10 years. The survey showed that four principals, 12 head teachers, 85 early childhood teachers, and 28 teaching assistants had been working in their current positions for more than five years. Only a small number, 30 early childhood teachers and 11 teaching assistants, had fewer than two-years' work experience. 
Role of Respondents

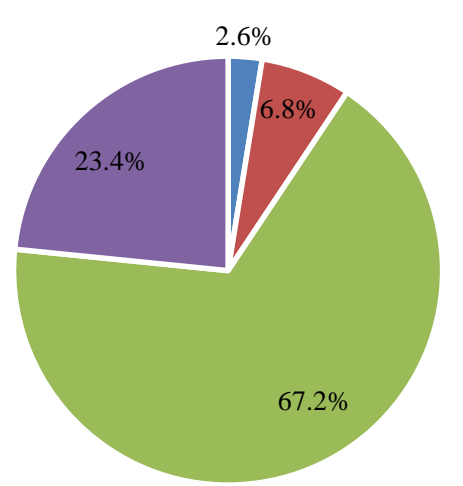

Years of experience working in their current roles

- Principal

- Head Teacher

- EC Teacher

- Teacher Assistant

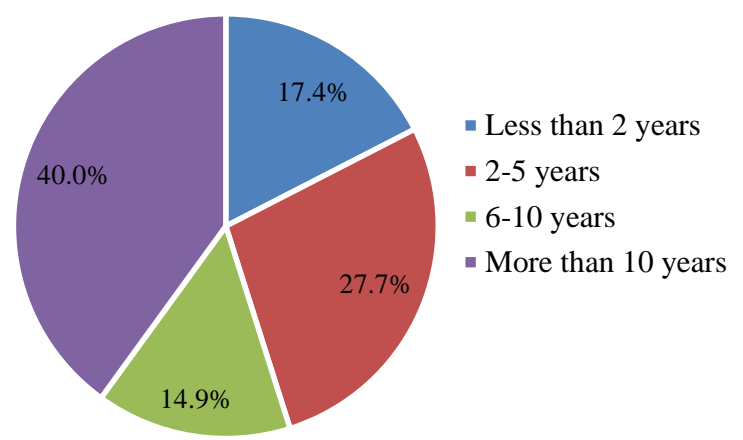

Figure 5. Respondents' role and years of experience in their current position

The respondents were also asked to state how many years of experience they had working with the 2003 Early Childhood Curriculum (Ministry of Education, 2003b). The largest group of respondents $(35.4 \%, \mathrm{n}=83)$ had more than 10 years' experience working with the curriculum. In this group there were three principals, seven head teachers, 59 early childhood teachers, and 14 teaching assistants. Those who had two to five years working with the official curriculum were the next largest group $(29.8 \%$, $\mathrm{n}=70)$, while $19.1 \%(\mathrm{n}=45)$ had been working with the curriculum for six to ten years. The smallest group $(15.7 \%, \mathrm{n}=37)$ had fewer than two years' experience, including 23 early childhood teachers and 14 teaching assistants.

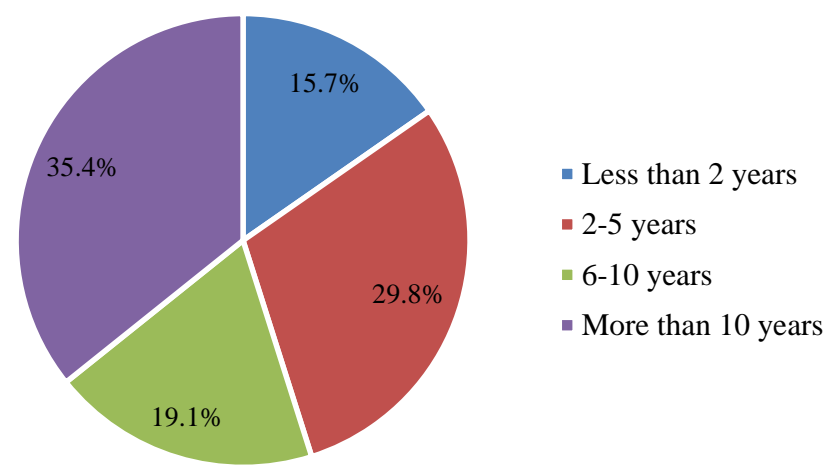

Figure 6. Years of experience working with the 2003 Early Childhood Curriculum

Along with years of experience working with the 2003 Early Childhood Curriculum, respondents were asked as well to give their level of education as this could affect the answers that they gave to certain questions. 
In terms of the qualifications held by the respondents (see Figure 7), the majority $(77.4 \%, \mathrm{n}=182)$ graduated with a Bachelor's degree. The respondents were also requested to indicate in an open-ended question the area of study undertaken. Just over half $(52.8 \%, \mathrm{n}=124)$ studied for a major in early childhood education. A very small number held a Master's degree $(3 \%, \mathrm{n}=9)$, and two respondents had a Doctoral degree. Another $12.3 \%(\mathrm{n}=29)$ graduated from other education fields; for example, education administration, primary education, Thai language education, and health education. Forty respondents $(17 \%, \mathrm{n}=40)$ did not answer this question. The survey results revealed that the years of experience working with the official curriculum and the qualification levels of the respondents did not indicate any significant differences in the responses given.

Highest qualification

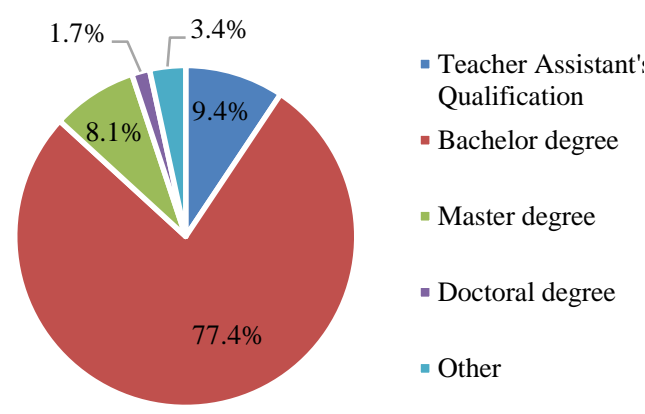

Fields of Study

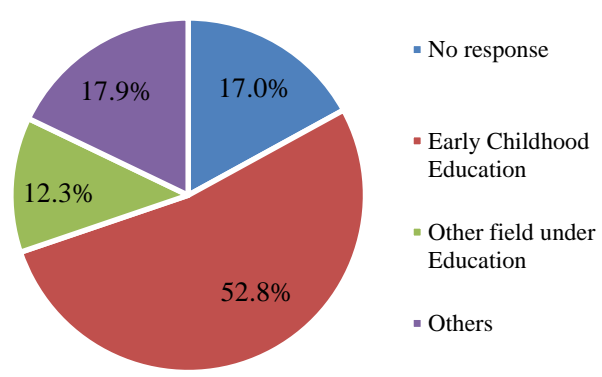

Figure 7. Respondents' highest qualification and their field of study

The table below provides an overall summary of the survey respondents' demographic data. The data are presented in the same order as written in the survey and are illustrated by their frequency and valid percentage. 
Table 6

Demographic data of the survey respondents

\begin{tabular}{|c|c|c|c|}
\hline & Nominal Scale & $\mathbf{n}$ & Valid (\%) \\
\hline \multirow[t]{4}{*}{ Age Range } & $20-29$ years & 66 & 28.1 \\
\hline & $30-39$ years & 74 & 31.5 \\
\hline & $40-49$ years & 50 & 21.3 \\
\hline & $50+$ years & 45 & 19.1 \\
\hline \multirow[t]{2}{*}{ Gender } & Female & 226 & 96.2 \\
\hline & Male & 9 & 3.8 \\
\hline \multirow[t]{4}{*}{ Role } & Principal & 6 & 2.6 \\
\hline & Head Teacher & 16 & 6.8 \\
\hline & Early Childhood Teacher & 158 & 67.2 \\
\hline & Teacher Assistant & 55 & 23.4 \\
\hline Years of & Less than 2 years & 41 & 17.4 \\
\hline Experience & $2-5$ years & 65 & 27.7 \\
\hline Working at the & $6-10$ years & 35 & 14.9 \\
\hline $\begin{array}{l}\text { Service in their } \\
\text { Current Role }\end{array}$ & More than 10 years & 94 & 40.0 \\
\hline Years of & Less than 2 years & 36 & 15.3 \\
\hline Experience & $2-5$ years & 70 & 29.8 \\
\hline $\begin{array}{l}\text { Working with } \\
\text { the } 2003 \text { Early }\end{array}$ & $6-10$ years & 45 & 19.1 \\
\hline $\begin{array}{l}\text { Childhood } \\
\text { Curriculum }\end{array}$ & More than 10 years & 84 & 35.7 \\
\hline \multirow[t]{5}{*}{ Qualification } & $\begin{array}{l}\text { Teacher Assistant's } \\
\text { Qualification }\end{array}$ & 22 & 9.4 \\
\hline & Bachelor's degree & 182 & 77.4 \\
\hline & Master's degree & 19 & 8.1 \\
\hline & Doctoral degree & 4 & 1.7 \\
\hline & Other & 8 & 3.4 \\
\hline \multirow[t]{3}{*}{ Field of Study* } & Early Childhood Education & 124 & 52.8 \\
\hline & Other fields of study & 29 & 12.3 \\
\hline & $\begin{array}{l}\text { Teaching Assistant's } \\
\text { Qualification and other fields }\end{array}$ & 42 & 17.9 \\
\hline
\end{tabular}

*Only valid percentages are presented 


\subsubsection{Location and Type of Early Childhood Service}

The survey asked for the location and type of service in order to identify whether a service was a kindergarten, or a preschool attached to a primary school. The respondents were also requested to indicate the size of their early childhood service. As previously mentioned, 34 early childhood services from two districts of central Bangkok - Klongtoey and Wattana - participated in this study. In regard to the services' location, the majority of respondents $(60.9 \%, \mathrm{n}=143)$ were from the Wattana district, while $38.6 \%(n=91)$ were from the Klongtoey district. One respondent did not fill in these two dichotomous questions which explains the missing values. The survey data revealed that $60 \%(n=141)$ of the services were preschool classes that were part of a primary school, while $39.6 \%(n=93)$ were kindergartens.

The survey respondents were asked in an open-ended question to state the total number of early childhood teachers working in early childhood education and the number of children enrolled at their service. This indicated the size of the early childhood services (see Figure 9).

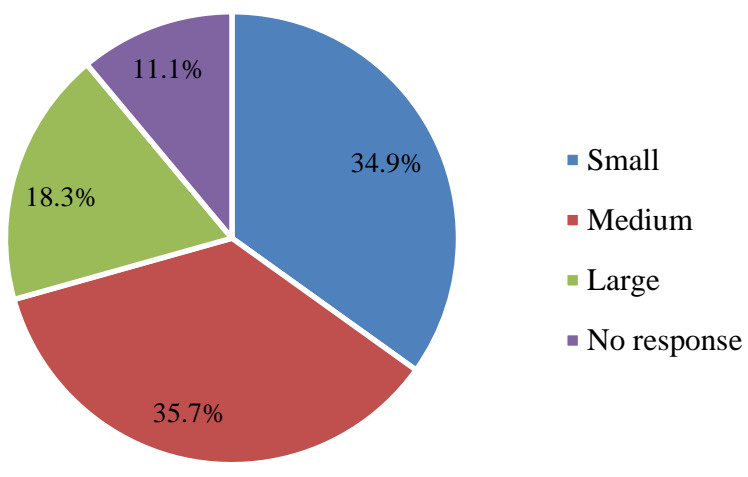

Figure 8. Size of the early childhood services

The survey results indicated that the question regarding the size of service was answered by only 26 respondents (11.1\%). This included 23 who were early childhood teachers, two teaching assistants and one head teacher. Despite the very low response rate to this open-ended question, Figure 8 does show that the services did vary in size. The services' location and size did not appear to have any impact on the survey responses. 


\subsection{Implementing the 2003 Early Childhood Curriculum}

This section of the survey aimed to explore to what extent the early childhood services followed the guidelines of the 2003 Early Childhood Curriculum for children aged 3 to 5 years (Ministry of Education, 2003b). The curriculum provides a guideline for overseeing early childhood education which aims to support young children's physical, emotional, social and cognition development relevant to their age and individual potential. The majority of respondents $(77.9 \%, \mathrm{n}=183)$ claimed they always based their teaching programme on the guidelines of the 2003 Early Childhood Curriculum (Ministry of Education, 2003b). Only a very small percentage (4.7\%, $\mathrm{n}=$ 11) rarely took into consideration the specific guidelines to direct their service's programme.

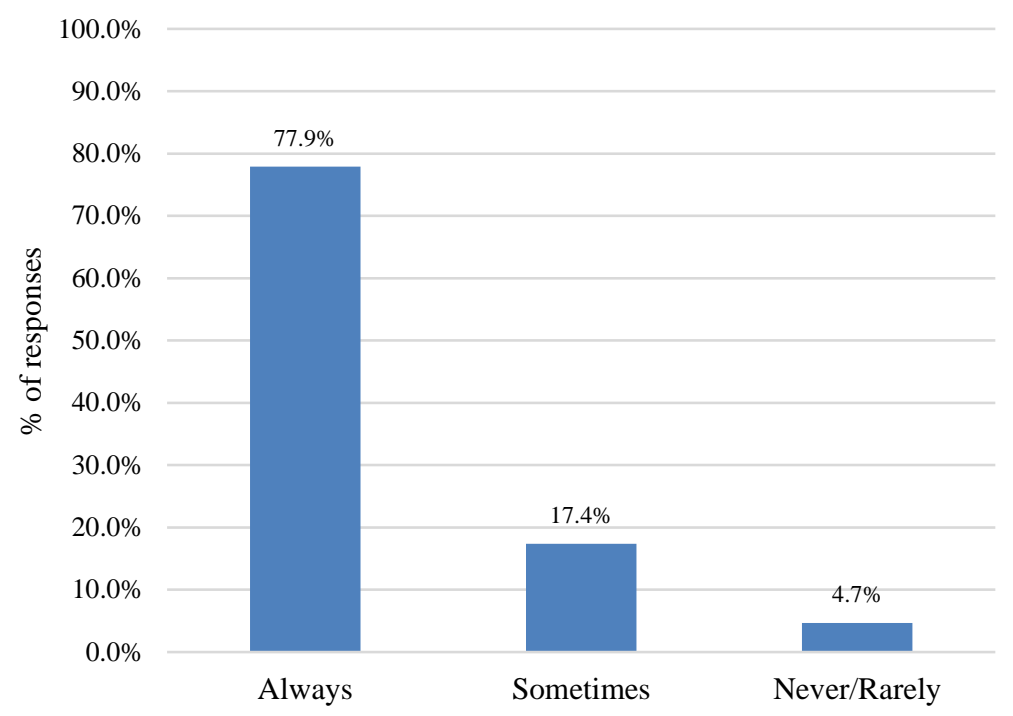

Figure 9. Implementing curriculum guidelines

The survey asked respondents how they applied the curriculum guidelines in their daily teaching programme. As Figure 10 shows, many of the respondents $(82.1 \%, \mathrm{n}=193)$ always relied on the guidelines of the 2003 Early Childhood Curriculum when they designed their lesson plans and daily activities and teaching practices, while only $7.7 \%$ $(\mathrm{n}=18)$ never/rarely took this into consideration (Ministry of Education, 2003b). Most respondents always created their teaching plans and learning activities to extend children's interests $(77 \%, \mathrm{n}=181)$ and matched their plans and activities with 
children's ages and abilities $(89.3 \%, \mathrm{n}=210)$. Only a very small percentage $(3 \%, \mathrm{n}=$ 7) did not consider these two factors when designing their lesson plans.

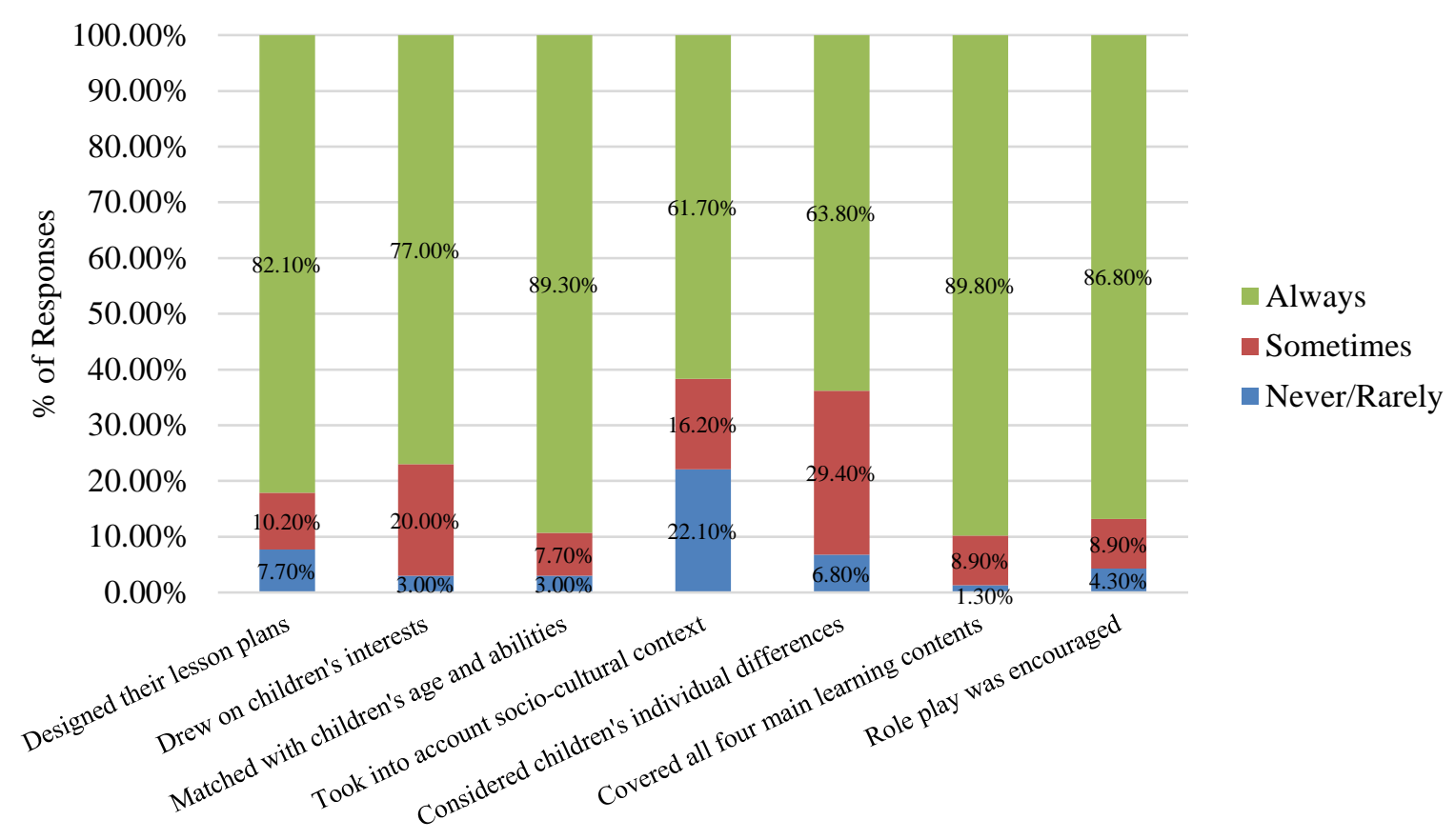

Figure 10. How respondents used the curriculum guidelines

The official curriculum's philosophy is based on an approach of caring for and fostering young children's learning process and the need to be responsive to each child's development, nature and capability. Such an approach also needs to take into consideration an individual's socio-cultural context. Figure 10 illustrates that more than half of the respondents $(61.7 \%, \mathrm{n}=145)$ stated that they always considered children's social and cultural context, while $22.1 \%(\mathrm{n}=52)$ claimed that they never/rarely thought of children's social class and culture in which they lived when designing their lesson plans and learning activities. Children's individual differences were another factor that many respondents $(63.8 \%, \mathrm{n}=150)$ took into consideration, while only a few $(6.8 \%, \mathrm{n}=16)$ never/rarely did.

The survey respondents were also asked how often they took into consideration the curriculum's four learning contents, which includes the child, people and places around children, the child's natural environment and things around children. As already discussed (see 2.2.1), the happenings in the everyday lives of young children can be used by early childhood teachers as a framework to provide them with 
appropriate activities to foster their learning and development. The majority of respondents $(89.8 \%, \mathrm{n}=211)$ claimed that they always used the four learning contents of the official curriculum.

The data showed that $86.8 \%(n=204)$ of the respondents always encouraged role play opportunities at their services, whilst a very small number $(4.3 \%, \mathrm{n}=10)$ stated that they never/rarely did. The curriculum mentions play in the section called Characteristics by Age under social development for children aged 3 to 5 years. For the 3-year-old child there are four bullet points listed and two discuss play. One of the points states that children should be able to play with similar toys alongside others, which is parallel play, while the other lists role play as children ought to be able to assume the roles of teachers, doctors, and so forth. For the 4-year-old child playing alongside others is one of the bullet points, while in the 5-year-old category children should be able to play or work with others when they have a similar purpose. Play is also specifically mentioned under the heading Learning Content and Processes in relation to key experiences in order to enhance a child's physical, social and emotional development. Children playing on equipment in the playground is seen as important for their physical development in relation to the balance and coordination of their large muscles. Playing is listed too as one of the key experiences for enhancing children's emotional development. Three types of playing are noted, which include free play, individual and group play and playing in the indoor and outdoor environments. Furthermore, key experiences to enhance a child's social development include playing and working with other children and solving issues when playing (Ministry of Education, 2003b).

In relation to the implementation of the 2003 Early Childhood Curriculum, the respondents were asked to evaluate how often they provided key experiences which are important for enhancing children's physical, emotional, social, and cognitive development (Ministry of Education, 2003b). The curriculum mentioned that the services should provide everyday activities in their programmes each day in order to enhance children's large and small muscles, emotional and moral development, social development, thinking and language, and their imagination and creative thinking. In addition to the age-related characteristics outlined in the 2003 Early Childhood Curriculum, its accompanying Manual (for children aged 3 to 5 years) states that key experiences assist children to develop significant skills by interacting with objects and 
people around them, and by cultivating morality and righteousness (Ministry of Education, 2003c).

Figure 11 shows that the largest number of respondents declared that they always supported children learning desirable characteristics through enhancing their emotional development $(95.7 \%, \mathrm{n}=225)$. As already discussed, the curriculum lists key experiences for early childhood teachers to take into consideration in order to help children develop relevant skills to enhance their emotional development, including music, which can involve playing musical instruments and singing songs. Aesthetics is another key experience, which includes appreciating as well as making artwork as well as being able to express amusement or one's enjoyment using jokes, funny stories or events. Playing is another aspect listed as is "morality and righteousness", which involves behaving in a manner expected with "one's religious rites" (Ministry of Education, 2003b, p. 32).

With regards to providing key experiences for enhancing children's cognitive development a considerable number of respondents $(92.3 \%, \mathrm{n}=217)$ stated they did. The official curriculum outlines six key experiences for improving a child's cognitive development, which consist of thinking, using language, observing, classifying and comparing, numbers, spatial relations and time. The bullet points under thinking include children being able to recognise objects by using their five senses, imitate actions and sounds, make a link between pictures and real objects or places, understand and express their feeling by using materials, toys and other products, and express their creative thinking in various ways. Taking this last bullet point into account, most of the survey respondents $(92.8 \%, \mathrm{n}=218)$ indicated that they supported children's imagination and creative thinking through learning activities.

The data further revealed that $87.2 \%(n=205)$ of the respondents indicated that they supported children's language and communication skills through key experiences. Using language is listed as one of the six key learning experiences for enhancing children's cognitive development. According to the official curriculum, for example, children should be able to express their feelings in words, describe things in their lives, and listen to stories (Ministry of Education, 2003b).

Many of the survey respondents $(86 \%, \mathrm{n}=202)$ indicated that they integrated key experiences to enhance children's physical development. The curriculum lists four key experiences to take into consideration in order to do this. These include children's balance and coordination of their large muscles and coordination of their small 
muscles. Some key experiences to enhance children's gross and fine motor skills are moving with objects, manipulative play, drawing, and making models with clay or blocks. Children's health in relation to having good hygiene and keeping oneself safe and others in daily routines are also listed (Ministry of Education, 2003b).

A fewer number of respondents $(81.7 \%, \mathrm{n}=192)$ indicated that they provided key experiences to enhance children's social development. The curriculum lists seven bullet points as to how a child's social development can be supported, including children doing things for themselves, playing alongside and working with others, being able to plan, make choices and to carry out a plan, and taking into consideration the feelings, interest and needs of one own's self and others. The other points are children being able to share their thoughts and respect those of others, solve problems while playing, and behave themselves in accordance with their local culture and with Thai identity (Ministry of Education, 2003b). Only a small number of respondents (11.9\%, $\mathrm{n}=28$ ) indicated that they never/rarely promoted these aspects.

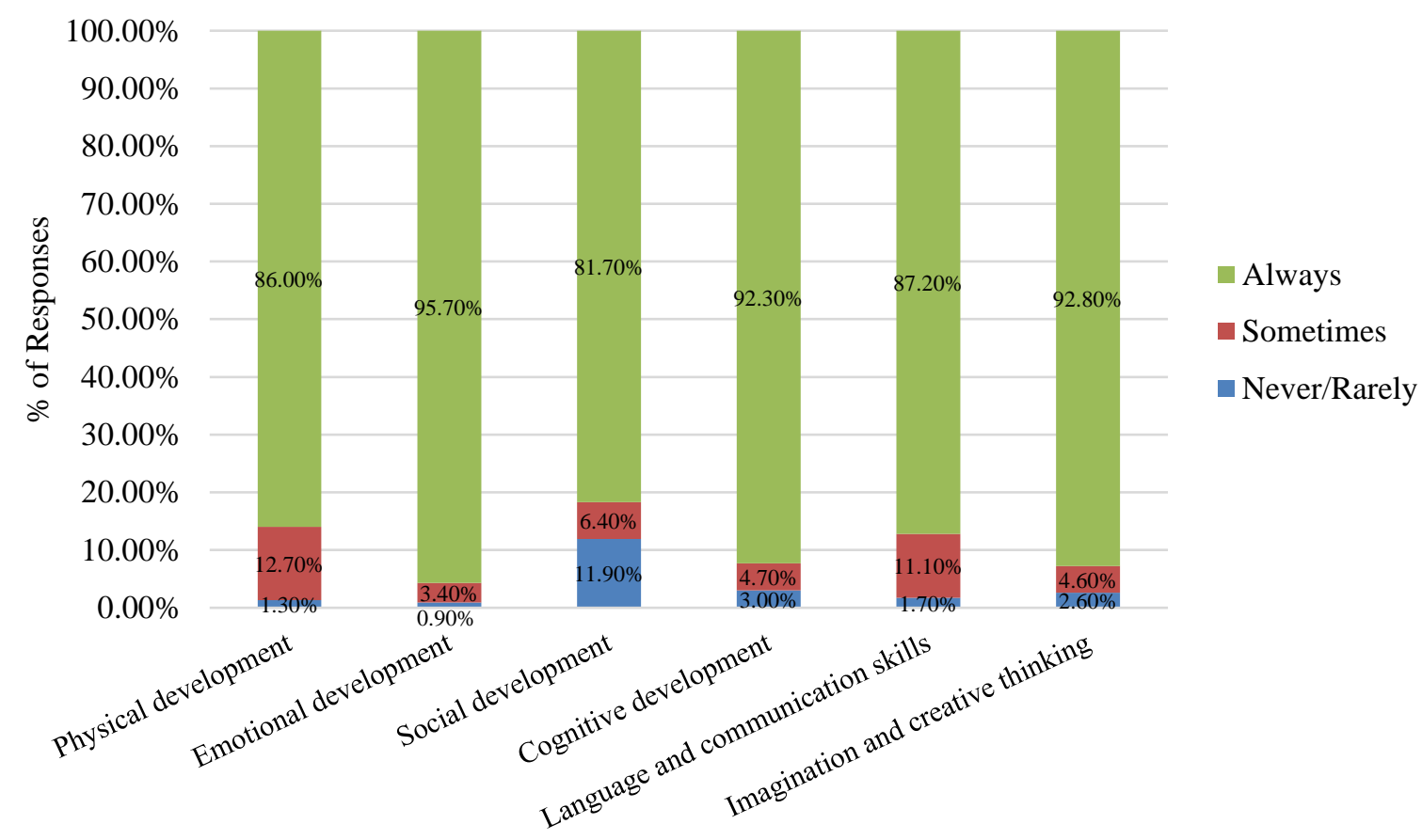

Figure 11. How respondents enhanced children's key experiences

In summary, most of the survey respondents applied and complied with the guidelines from the 2003 Early Childhood Curriculum when designing their lesson plans and teaching activities and practices. They always took into account children's interests, individual differences, ages and abilities, including their social and cultural 
context. The respondents also covered all the four learning contents stated in the curriculum and encouraged children to have play opportunities to enhance their learning and development. All the four developmental domains (i.e., physical, emotional, social, and cognitive), language and communication skills, and imagination and creative thinking were fostered by the majority of the respondents through their learning activities (also refers to key experiences).

\subsection{Integrating Thai Culture and Identity into Teaching Practices}

This section of the survey aimed to explore how the respondents integrated Thai culture and identity into their teaching practices. The results were categorised into five sub-sections for ease of reporting: Thai manners, learning about Thailand, learning other values, Buddhist principles and Buddhists' practices, and Thai traditions and other important dates. These categories were taken from the guidelines of the 2003 Early Childhood Curriculum and the accompanying Manual (Ministry of Education, 2003b,c). Early childhood teachers are expected to foster in young children good manners, to share, and to show respect for others. They also need to encourage children to behave in accordance with their local culture and Thai identity. In addition, early childhood teachers need to nurture children in order for them to become selfdisciplined and to teach them how to conserve the environment. Furthermore, early childhood teachers are expected to teach young children about religious rites, for example, visiting a temple, as well as learning about and being involved in Thai traditions and important occasions. Each of the subsections is presented below.

\subsubsection{Thai Manners}

Wai is the traditional Thai style of greeting and paying respect in Thailand. A question in relation to this gesture was included in the survey. Sharing and helping are also other aspects of Thai manners.

When the respondents were asked how they promoted Thai manners with children, the majority $(91.4 \%, \mathrm{n}=215)$ responded that they always encouraged children to perform Wai. Bowing when walking past elders was always promoted by $88.5 \%(n=208)$ of respondents. Only a very small number $(2.6 \%, n=6)$ claimed that they never/rarely promoted these. When questioned about encouraging children to pay respect to others and elders, $77 \%(\mathrm{n}=181)$ of the respondents stated that they always did but $21.3 \%(\mathrm{n}=50)$ claimed that they never/rarely did. The results revealed that 
most respondents $(93.6 \%, \mathrm{n}=220)$ always taught children concepts of sharing, helping, and respecting others. Only a few $(3.4 \%, \mathrm{n}=8)$ indicated that they never/rarely did (see Figure 12).

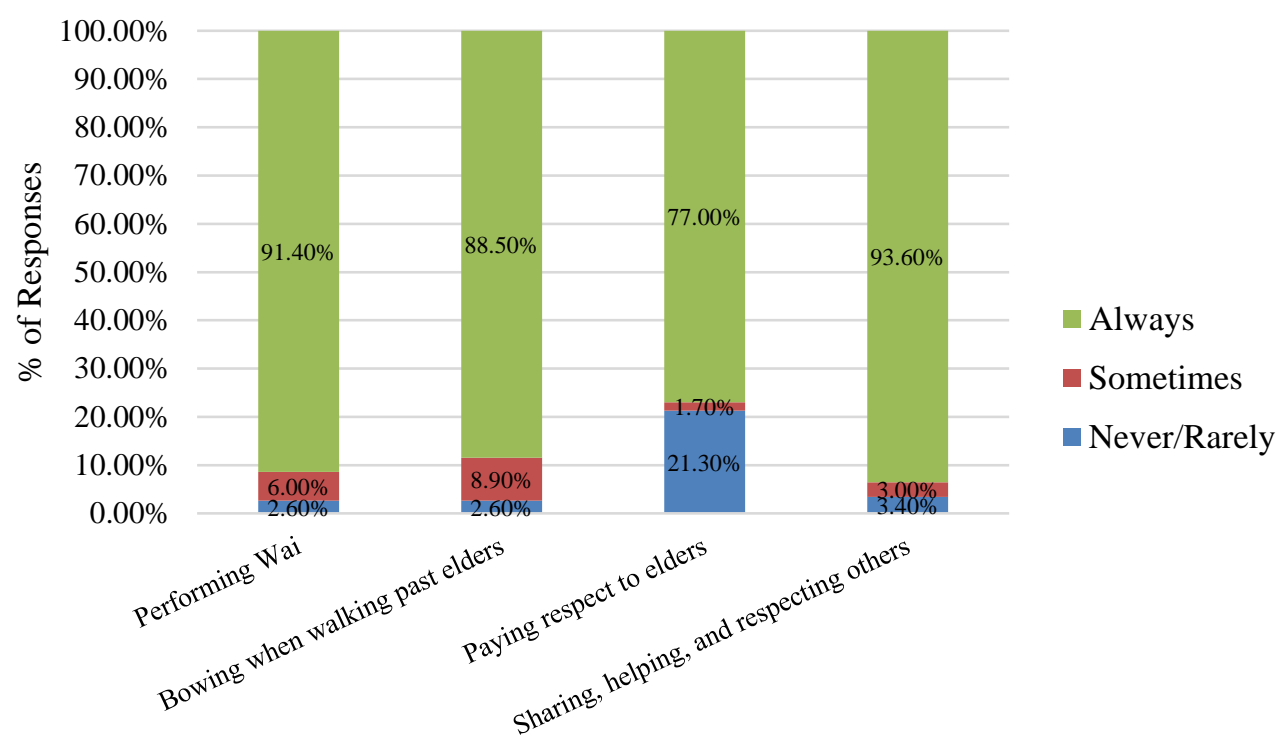

Figure 12. Integrating Thai manners in the curriculum

\subsubsection{Learning About Thailand}

In Thailand, children in early childhood services are taught about their country, so survey respondents were asked how they taught Thai history to young children. Attending the flag ceremony was one of the everyday activities stated in the curriculum's Manual (Ministry of Education, 2003c). The survey respondents were asked in relation to this if they taught about the Thai national flag to children. Another question in relation to the Thai national flag posed to the survey respondents was whether they identified and explained each stripe of the Thai national flag to children. They were also asked how often they informed children about Thai identity, including the Nation, religion, and the Monarchy.

The survey results revealed that a large number of respondents said that they always taught about the Thai national flag $(78.7 \%, \mathrm{n}=184)$, including singing the national anthem which is part of their daily routine (see 2.7.3). Many of the respondents stated that they encouraged young children to have national pride in their Thai identity $(83 \%, \mathrm{n}=195)$. A very small number claimed that they never/rarely did both. In addition, Figure 13 shows that more than half of the respondents $(53.2 \%, \mathrm{n}=$ 
125) always taught children about Thai history, while $37 \%(\mathrm{n}=87)$ said that they sometimes did.

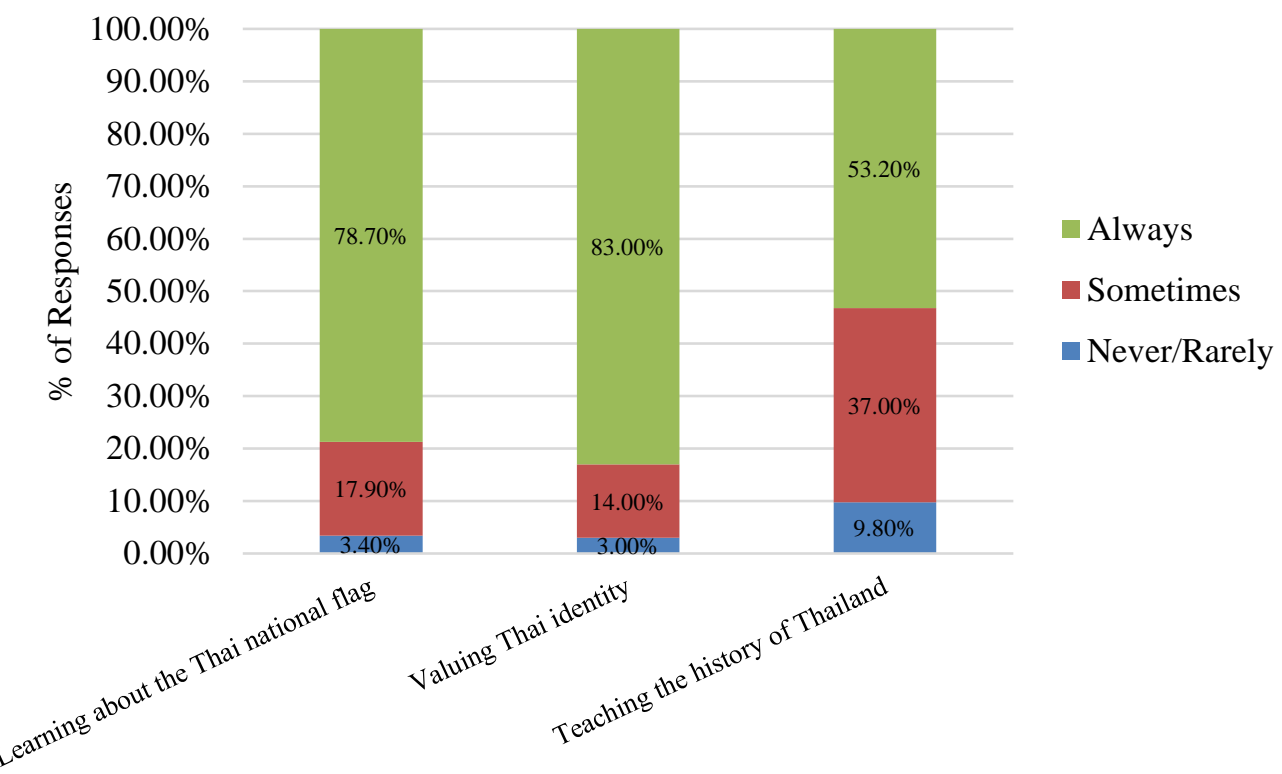

Figure 13. Teaching practices promoting Thai national pride

\subsubsection{Learning Other Values}

One of the 2003 Early Childhood Curriculum's "learning contents" is the natural environment (Ministry of Education, 2003b). Early childhood teachers are expected to use the contents in a child's everyday life as a framework to provide activities for his/her learning development. In addition, early childhood teachers are expected to make available key experiences in the learning contents based on a child's age, needs, and interests. In relation to the natural environment, early childhood teachers need to teach children about living and non-living objects, including such things as learning about the seasons, the difference between day and night, and other relevant changes that affect the world. The curriculum also states that early childhood teachers should foster children to have self-responsibility, self-discipline, and honesty. Additionally, the curriculum outlines other values that early childhood teachers are expected to encourage children to have such as taking a leadership role or supporting a leader during playing or working in a group (Ministry of Education, 2003b). Questions in relation to these were posed to find out whether the survey respondents integrated these aspects into their daily teaching practices. 
Teaching children to know how to care for the environment was always encouraged by $69.4 \%(n=163)$ of survey respondents. However, $24.2 \%(n=57)$ never/rarely did. The respondents also indicated that their teaching promoted other values and knowledge with children as ways of fostering their desirable characteristics. These were included in the 2003 Early Childhood Curriculum's guidelines (Ministry of Education, 2003b); for example, the majority, 70.2\% ( $\mathrm{n}=165)$ stated that they encouraged children to become more self-disciplined, take on responsibility, and be honest. Another $26 \%(n=61)$ said that they never/rarely did. The majority of these respondents $(77 \%, \mathrm{n}=181)$ agreed that children should always learn to take a leadership role, while a few $(1.3 \%, \mathrm{n}=3)$ claimed that they never/rarely promoted this.

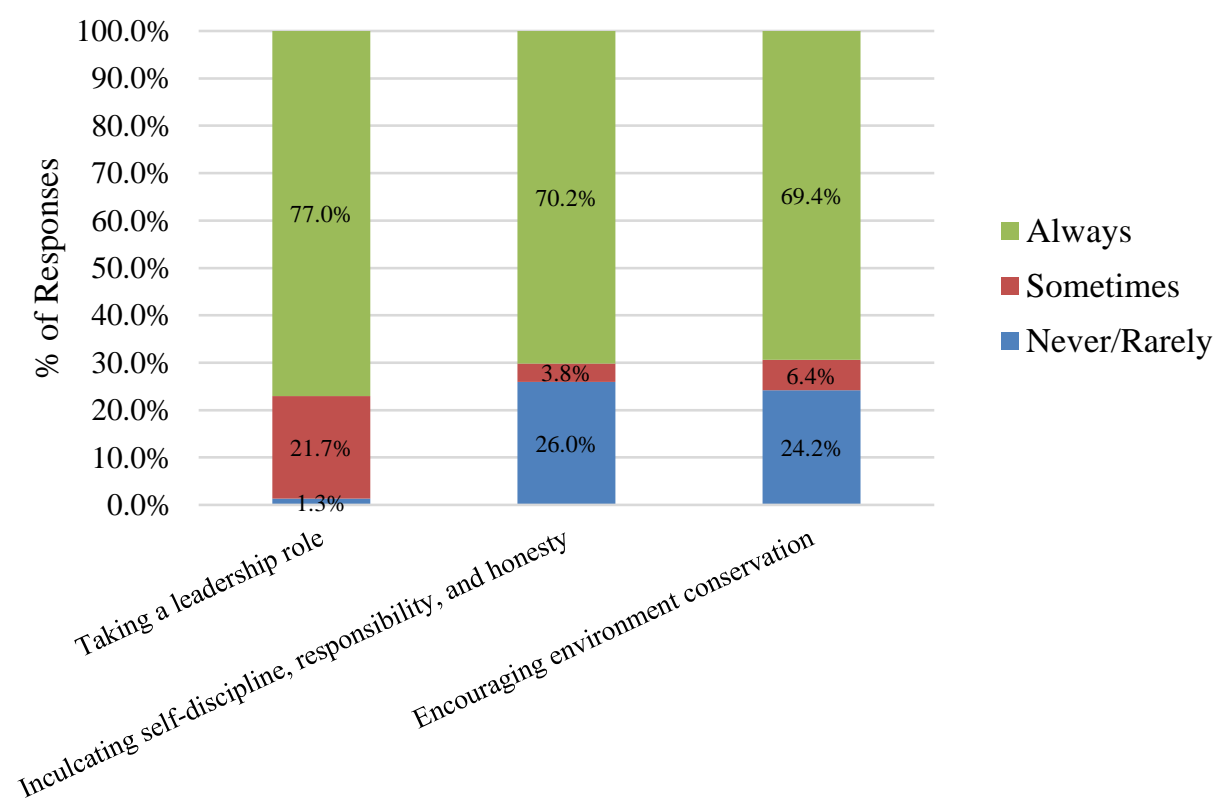

Figure 14. Other roles and responsibilities taught at early childhood services

\subsubsection{Buddhist Principles and Buddhists' Practices}

The 2003 Early Childhood Curriculum states that children should "behave in accordance with their religious rites" (Ministry of Education, 2003b, p. 32) while the Manual specifies that early childhood teachers need to teach children about their religion when implementing the curriculum area of People and places around children (Ministry of Education, 2003c). Early childhood teachers should consider that individual children have different religions and beliefs. Every religion teaches everyone to be good person" (Ministry of Education, 2003c). Buddhism is regarded as the dominant religion in Thailand. 
The survey respondents were asked how often they incorporated Buddhist principles into their daily teaching practices. The survey results revealed that many of the respondents $(63 \%, \mathrm{n}=148)$ always did this, while $28.5 \%(\mathrm{n}=67)$ claimed that they sometimes took these into account. Buddhist principles involve Buddha's teaching, Thai proverbs, and folktales. To ensure consistency for this question, the respondents were asked another question that contained negative wording: "At our early childhood service, children are not taught any Buddhist principles." The results revealed that a sizable number of respondents $(56.2 \%, \mathrm{n}=132)$ always incorporated Buddhist principles into their teaching practices.

When incorporating Buddhist principles in their lesson plans, more than half of the respondents $(51.9 \%, \mathrm{n}=122)$ always taught the Five Precepts, whereas $14.5 \%$ $(n=34)$ never/rarely did this. The Five Rules of Morality is another name for the Five Precepts, which are the most common Buddhist principles observed by Thai people (Arayangkul, 2002). They consist of abstaining from: killing or hurting animals (other living creatures), stealing or taking others' belongings, misbehaving, telling lies, and drinking alcoholic beverages. These precepts were adjusted to be appropriate to children.

The survey respondents were asked, too, how often they encouraged children to learn about Buddha's teachings. Figure 15 showed that a considerable number of respondents $(43.4 \%, \mathrm{n}=102)$ always provided a session of listening to the Buddha's doctrine. This usually involves Buddhist monks preaching the Buddha's sermon to children and early childhood teachers at services. A small number $(24.7 \%, \mathrm{n}=58)$ said that they sometimes did this, while $31.9 \%(n=75)$ indicated that they never/rarely did. The data further revealed that $36.6 \%(\mathrm{n}=86)$ of respondents always organised fieldtrips to visit temples, whilst another $34.5 \%(\mathrm{n}=81)$ never/rarely promoted Buddhist practices through visiting a temple. In relation to encouraging children to follow Buddhist ways of living, most respondents always promoted the following activities: practising meditation $(71.5 \%, \mathrm{n}=168)$, praying to the Buddha $(75.7 \%, \mathrm{n}=$ 178), and observing important religious dates $(77.4 \%, \mathrm{n}=182)$. As shown in Figure 15 , only a small percent declared that they never/rarely did these activities. 


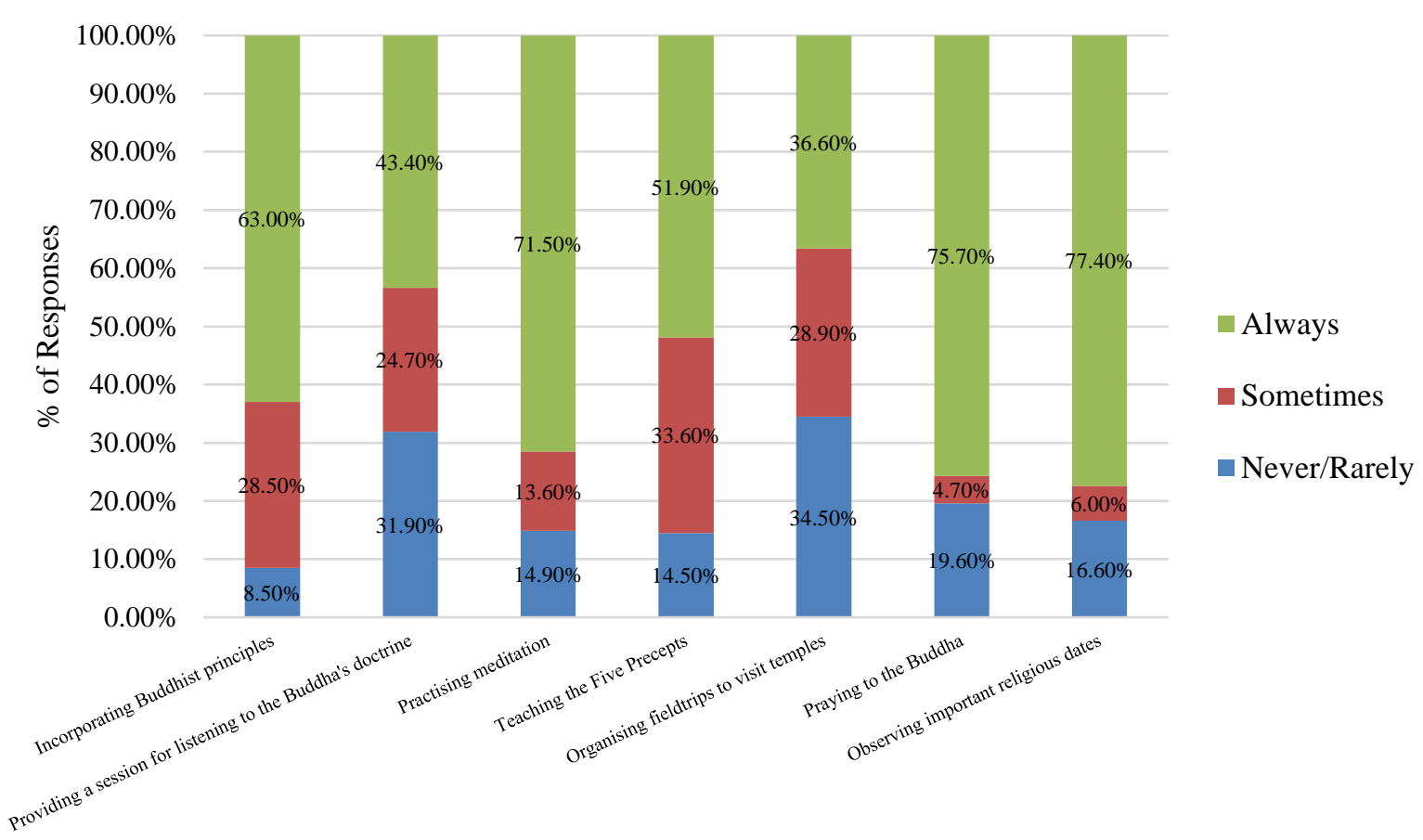

Figure 15. Teaching Buddhist principles and practices

\subsubsection{Thai Traditions and Other Important Dates}

The 2003 Early Childhood Curriculum emphasises that early childhood teachers need to encourage children to learn and behave in accordance with the context of their local community, society, and Thai culture (Ministry of Education, 2003b). The Manual of the 2003 Early Childhood Curriculum (Ministry of Education, 2003c) specifically talks about Thai traditions, including festivals and important dates when describing in detail what should be included when teaching young children about the curriculum area of People and places around children. Thai traditions always refer to festivals and important dates (see 2.3.2). Consequently, the survey included questions about the Loy Kratong festival, one of Thailand's most popular festivals, and Father's Day, which is also known as the National Day or King Rama IX's birthday. National Thai Language Day is another important date that was included in the survey. The survey respondents were asked how they promoted the Loy Kratong festival and other important dates.

The survey data indicated that the majority of respondents always taught children about Thai traditions and festivals $(91 \%, \mathrm{n}=214)$ and encouraged children to perform activities on Father's Day $(93.6 \%, \mathrm{n}=220)$. Only a very small number $(3 \%$, $\mathrm{n}=7)$ stated that they never/rarely did. As Figure 16 indicates, $83.4 \%(\mathrm{n}=196)$ claimed that they always decorated their classroom appropriately to reflect specific 
festivals. When respondents were asked about the Loy Kratong festival (see 2.7.3), a significant number $(89.8 \%, \mathrm{n}=211)$ stated that they always encouraged children to decorate floating baskets at their services. Figure 16 also shows that $49.3 \%(n=116)$ of the respondents always encouraged children to participate and do activities on the National Thai Language Day, while 26\% $(n=61)$ declared that they never/rarely did. This date was established for raising awareness of the Thai language. It is very important as the Thai language is the national and official language of Thailand.

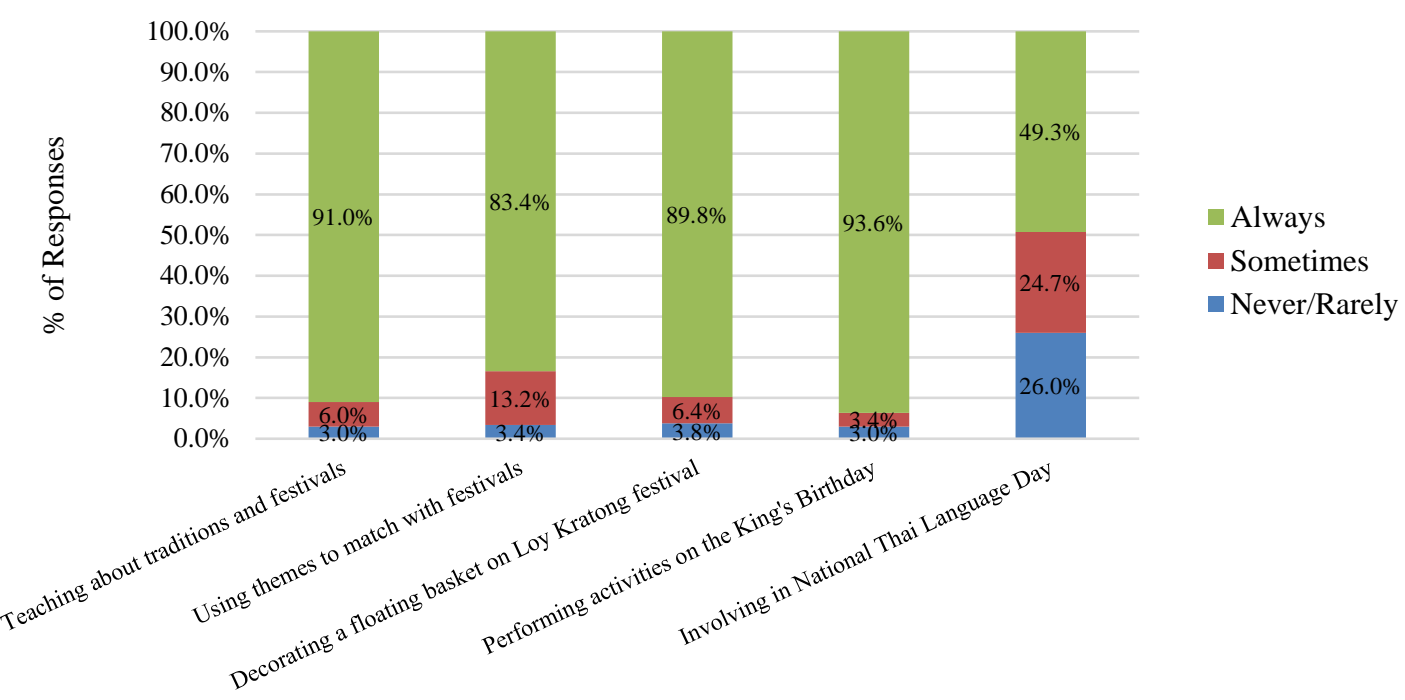

Figure 16. Promoting Thai traditions and other important occasions

\subsection{Survey Respondents' Perceptions of the Role of the Government in Promoting Thai Culture and Identity}

In order to address one of the main research questions, it was important to explore how the survey respondents perceived the Government's role in promoting Thai culture and identity. To gather information about this, respondents were asked to indicate their agreement on a set of questions using five-point Likert scales, ranging from strongly agree to strongly disagree.

The data indicated that most respondents $(88.5 \%, \mathrm{n}=208)$ agreed the Government has a major role in promoting Thai culture and identity, whereas a very small percentage $(3.9 \%, \mathrm{n}=9$ ) disagreed. As shown in Figure 17, the majority of respondents also agreed that the Government should provide support for the following: training manuals for early childhood teachers in regard to integrating Thai culture and identity into their teaching practices $(87.2 \%, \mathrm{n}=205)$; adding more specific sample 
activities into the 2003 Early Childhood Curriculum $(88.1 \%, \mathrm{n}=207)$; and giving explicit guidelines on how to integrate Thai culture and identity into their teaching practices in relation to relevant Government documents $(84.7 \%, \mathrm{n}=199)$. Only a very small number $(4.3 \%, \mathrm{n}=10)$ stated that they disagreed that the Government should provide support for these. Of these respondents, $87.3 \%(n=205)$ agreed that the Government should encourage children to be involved in projects funded by the Government with regard to promoting Thai culture and identity. Again, a small number $(3.4 \%, \mathrm{n}=8)$ disagreed. However, the majority of respondents $(85.9 \%, \mathrm{n}=202)$ claimed that the Government supplied sufficient support to the services.

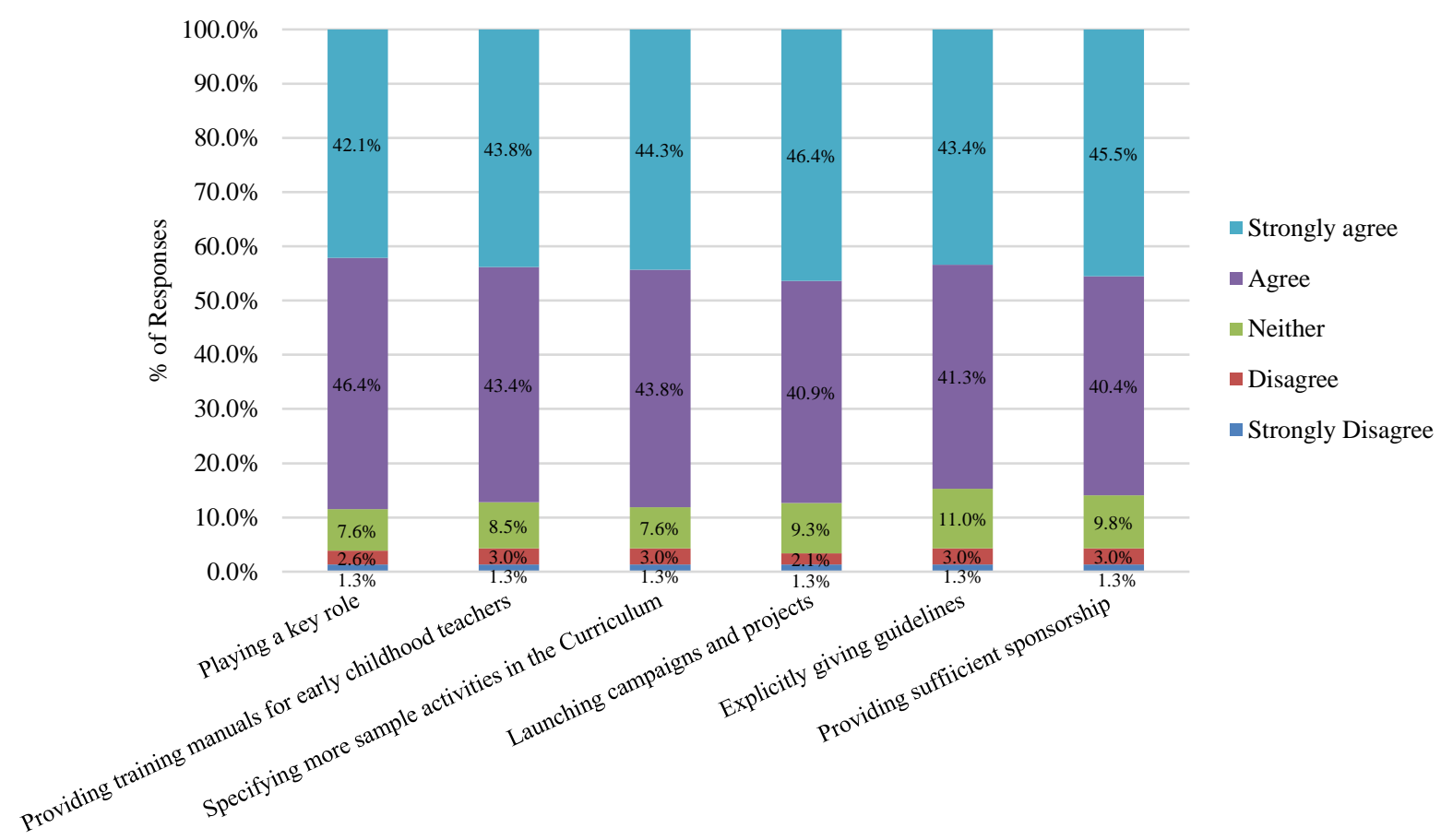

Figure 17. How respondents perceived the role of the Government

\subsection{Survey Respondents' Perception of the Parents' Participation}

The 2003 Early Childhood Curriculum aimed to encourage collaboration with families, communities, and early childhood services in order to provide education and care for children (Ministry of Education, 2003b). This section of the survey was used to elicit respondents' views about the role of parents in promoting Thai culture and identity in their services. They were asked to indicate their agreement to questions about parents' participation. When respondents were asked if they consulted parents 
when developing their lesson plans, $51.1 \%(\mathrm{n}=120)$ stated that they sometimes did and $28.5 \%(n=67)$ claimed that they never/rarely did. However, $20.4 \%(n=48)$ of the respondents always encouraged parents to be involved when they designed teaching plans.

The data revealed that many respondents $(77.4 \%, \mathrm{n}=182)$ always encouraged parents to participate in their service's activities, and 77\% $(\mathrm{n}=181)$ of them stated that parents always encouraged children to perform Wai. As shown in Figure 18, only a small number $(1.3 \%, \mathrm{n}=3)$ indicated that parents never/rarely engaged in either. Of these respondents, more than half $(51.5 \%, \mathrm{n}=121)$ stated that parents regularly attended teacher-parent meetings. Another $31.1 \%(\mathrm{n}=73)$ claimed that parents sometimes attended such meetings.

The frequency of responses in relation to the respondents keeping parents informed about their children's progress and parents helping with promoting Thai culture and identity are depicted in Figure 18 below. The range was from $89.8 \%$ ( $\mathrm{n}=$ $211)$ to $63.8 \%(\mathrm{n}=150)$ for parents who always did both. Regarding special events, such as Mother's Day and Father's Day, just over half of the respondents $(54.9 \%, \mathrm{n}=$ 129) declared that parents always participated in these activities.

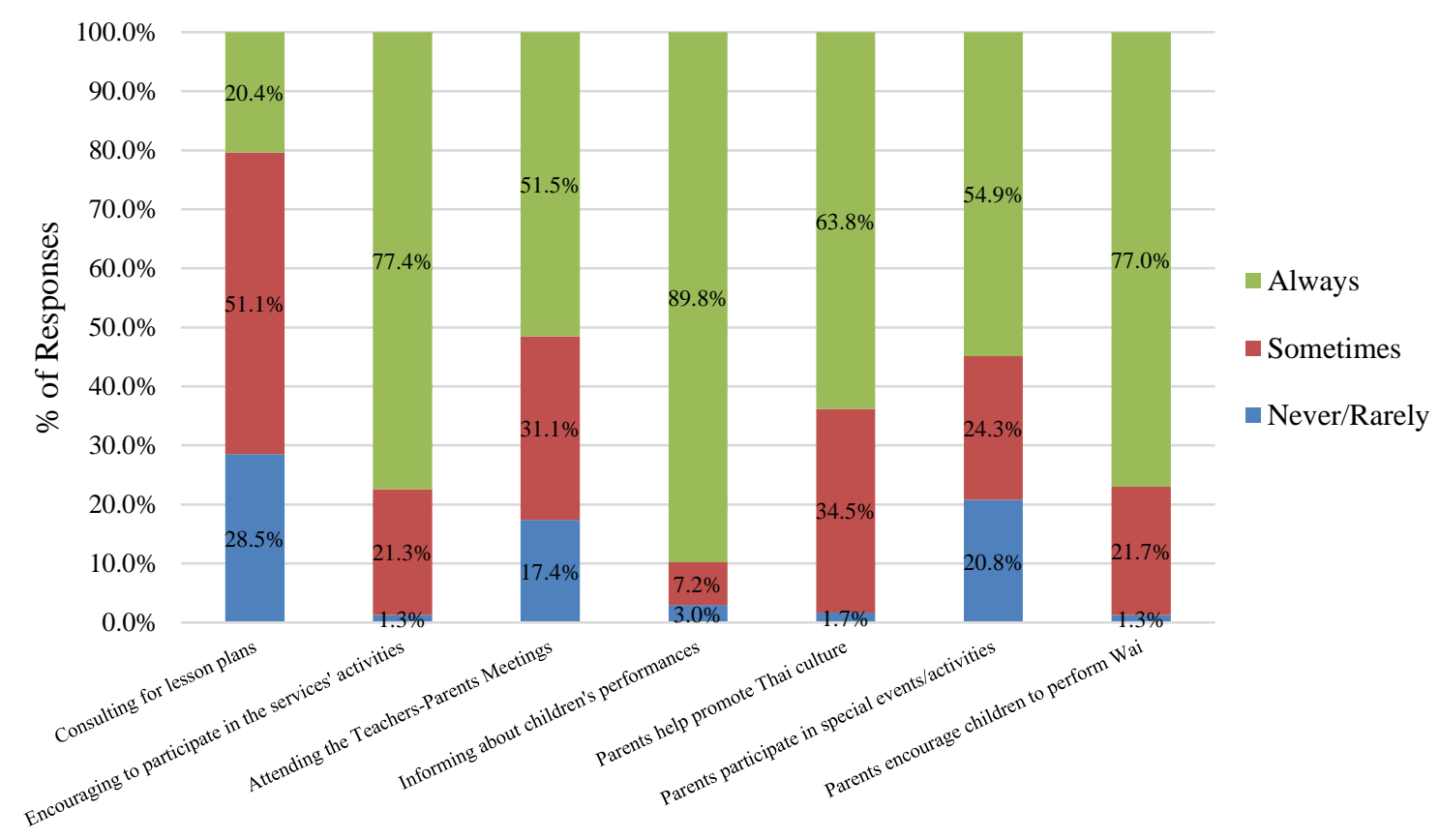

Figure 18. How respondents viewed the parents' role

From the survey data, it was interesting to see that the respondents from different age groups provided slightly different responses. For example, the 
respondents aged $20-29$ years indicated that they always encouraged children to be involved in role playing more than in other age groups. Another variation was noted from the respondents aged 50 years and older who were more likely to view themselves "Always and Sometimes" practitioners in relation to taking the curriculum guidelines into consideration and integrating Thai culture and identity into their teaching practices. They did not give any responses for "Never/Rarely" in the following practices: relying on the curriculum's guidelines, taking into consideration the curriculum's four learning contents, encouraging children to perform Wai, and teaching children about the Thai national flag.

\subsection{Chapter summary}

This chapter presented the quantitative data from the survey's 59 close-ended questions and two open-ended questions regarding the respondents' demographic information. The majority of respondents were female, aged between 30 and 39 years, and worked as early childhood teachers. In relation to the type of service, there were more preschool classes attached to primary schools than stand-alone kindergartens. Most services were classified as medium-size, with enrolments of 151 to 300 children.

When asked about implementing the 2003 Early Childhood Curriculum, a considerable number of the survey respondents indicated that they always based their teaching programme on the curriculum guidelines. This included taking into account children's individual differences, age and abilities, their social and cultural context, as well as the four learning contents and their developmental domains. In relation to integrating Thai culture and identity into their teaching practices, the majority of respondents revealed that they always encouraged children to learn four subsections. These included: performing Wai, learning about Thai history and the national flag, incorporating Buddhist principles, and observing important dates such as the Loy Kratong festival, Father's Day, and important religious dates.

The survey respondents viewed the Government as playing a significant role in promoting Thai culture and identity. The majority of them suggested that the Government should add more specific sample activities, including giving explicit guidelines related to promoting Thai culture and identity into the 2003 Early Childhood Curriculum. The respondents also perceived that the parents helped in promoting Thai culture and identity with children. They indicated that they always 
encouraged parents to participate in the services' activities and special events. They also informed parents about children's learning and development.

As mentioned previously, the survey included open-ended questions to allow respondents to provide additional information. In the next chapter, five of the openended questions are asked with regard to the survey respondents' opinions on the roles of the Government and children's parents in promoting Thai culture and identity with young children. These questions will be examined in the next chapter alongside the data from Phase Two: the multiple case study. 


\section{CHAPTER 6 \\ EARLY CHILDHOOD SERVICES' PERCEPTIONS OF HOW THAI CULTURE AND IDENTITY ARE PROMOTED WITH YOUNG CHILDREN}

In this chapter, data from the multiple case study and five of the open-ended survey questions were used to examine how Thai culture and identity are promoted in early childhood services in Thailand. The five open-ended questions presented in this chapter were posed to the survey respondents to explore their perceptions toward the role of the Government and children's parents. Analysis of the interview data from the multiple case study identified four major themes, three of which are presented in this chapter. They are:

1. Perceptions towards the 2003 Early Childhood Curriculum

This included principals' views on designing their services' early childhood curriculum alongside the official curriculum; how head teachers thought their lesson plans and teaching practices were influenced by the 2003 Early Childhood Curriculum (Ministry of Education, 2003b); and parents' understandings of the official curriculum.

2. The Role of the Government and the Umbrella Organisations

Principals, head teachers, and early childhood teachers were asked how they viewed the role of the Government and their umbrella organisations in relation to promoting Thai culture and identity. Participants were also questioned regarding support for the following: budget allocation, promoting events/campaigns, providing information on policies, and enforcement of policies.

3. Parents' Participation

Participants were asked how they viewed parents' participation, including how often services communicated with parents. Parents were interviewed as well to find out how they promoted Thai culture and identity at their child's service.

The fourth theme, Integrating Thai culture and Identity into Teaching Practices, will be discussed in Chapter 7. 
When examining each of the three themes, the questions asked in the semistructured interviews and the survey are presented in the same order for consistency. This is also the case for the participants involved in the multiple case study. The responses of the principals are presented first, followed by head teachers, then the early childhood teachers, and finally the parents. Pseudonyms are used to protect identities of multiple case study participants and services.

\subsection{Perceptions Toward the 2003 Early Childhood Curriculum}

Principals, head teachers, early childhood teachers and parents were asked different questions to explore their perceptions of the 2003 Early Childhood Curriculum (Ministry of Education, 2003b), while also acknowledging their various roles within the services.

\section{Principals}

Q.1 "Does your service develop its own early childhood curriculum by using guidelines from the 2003 Early Childhood Curriculum?"

Four principals, two vice-principals and two head teachers were interviewed. The head teachers were interviewed on behalf of two of the principals who were unavailable on the day scheduled. All the participants considered the 2003 Early Childhood Curriculum to be a framework that provided guidelines for early childhood education and care at their service. Four of the eight participants mentioned that they had designed and developed their own early childhood curriculum using the guidelines of the official curriculum. Principal Parkpoom (P2) from Primrose Service stated:

Our own early childhood curriculum was developed to be similar to the 2003 Early Childhood Curriculum. However, our teachers have limited knowledge to implement it. (January 26, 2016)

He did not provide any additional comments regarding the teachers' practices at the service.

Likewise, Jandee (HT5) claimed that Jamesia Service's early childhood curriculum was based on the official curriculum. The curriculum development chart she provided 
showed that a Curriculum Development Committee was responsible for this. The chart showed that the committee took into consideration the philosophy and vision of the 2003 Early Childhood Curriculum as well as the learning contents and process, and age-appropriate learning activities. It illustrated too that the service implemented their own curriculum using the Project Approach. This is a set of teaching strategies that teachers use to guide children through in-depth studies of real-world topics (Beneke \& Ostrosky, 2009). She added:

Teachers design their teaching plans by relying on the provision of experiences addressed in the official curriculum. They take into consideration the learning contents (stated in the curriculum) before designing appropriate learning activities for each stage of children's development. (February 9, 2016)

At Sunflower Service, Principal Surasak (P8) stated that "their service applies guidelines from the 2003 Early Childhood Curriculum when designing teaching plans" (March 3, 2016).

The participants from the other four services, Cherry Blossom, Daffodil, Foxglove, and Kalmia, all explained they had developed their own early childhood curriculum with specific goals and activities to reflect their social and cultural contexts, but these were still based on guidelines from the 2003 Early Childhood Curriculum. They each outlined why their services needed to take into consideration the communities where they were located. By way of example, Vice-Principal Danai (P4) from Daffodil Service noted:

Our community is very "special", so we need to consider its socialcultural diversity when implementing the official curriculum. The service is in Klongtoey district, which has a mixture of slum areas, with people living in poverty, as well as highly developed industrial areas. We try our best to provide appropriate early childhood education and care. However, we may have some limitations to follow every guideline in order to enhance children's learning and development. (February 15, 2016)

The principals, vice-principals and head teachers from the eight services revealed that their service developed its own curriculum using guidelines from the 2003 Early Childhood Curriculum. 


\section{Head teachers}

Q. 1 "How does Thainess fit into the 2003 Early Childhood Curriculum?"

The notion of Thainess refers to Thai nationalism or the nationalistic ideology which can be expressed through the practices of Thai culture and identity. One of the key principles of the curriculum states that early childhood teachers need to care for, and educate children taking into consideration their individual differences and their way of life within the context of their local community, Thai culture and society. Three of the eight head teachers, Pannee (HT2), Chanhom (HT3) and Darunee (HT4), from Primrose, Cherry Blossom, and Daffodil Services respectively, stated that the 2003 Early Childhood Curriculum provided a framework that encouraged early childhood teachers to teach children about Thai culture and identity. They noted that it was good to be able to design learning activities for themselves. For example, Pannee (HT2) explained:

Teachers have a wider range of opportunity to independently design lesson plans, learning activities, and integrate different aspects of Thai culture into their teaching practices. (January 26, 2016)

Chanhom (HT3) also remarked on how the early childhood teachers at Cherry Blossom Service designed lesson plans and integrated some dimensions of Thai culture and identity into their daily teaching practices:

One of the learning contents is People and place around children. This can include content about children's family and community. It can further connect the service's local culture, Buddhism and observations of important religious dates (see Appendix A). I think it is good that teachers can create their own lesson plans and material. (January 28, 2016)

In response to the same question, the other five head teachers from Anemone, Jamesia, Foxglove, Kalmia, and Sunflower Services said that the 2003 Early Childhood Curriculum did not clearly state how early childhood teachers should integrate Thai culture and identity into their lesson plans and suggested the curriculum should provide more guidelines. For instance, Anyamanee (HT1) from Anemone Service pointed out that although the curriculum did not provide any guidelines: 
It does mention that children should behave in accordance with local culture and Thai identity. This can enhance children's development. However, I think the 2003 Early Childhood Curriculum should provide more examples for integrating Thai culture into teaching practice. (December 8,2015 )

The head teacher from Sunflower Service, Sutana (HT8), also recommended that the 2003 Early Childhood Curriculum should be updated to reflect what was currently happening in Thailand.

Examples and guidelines of the curriculum should be up-to-date with the country's current situation and societal changes. (March 3, 2016)

Five out of the eight head teachers suggested that the curriculum needed to provide more precise guidelines and be updated.

Head teachers were also asked the following question:

Q. 2 "How does the 2003 Early Childhood Curriculum influence lesson plans and teaching practices?"

All eight services stated that they relied on the 2003 Early Childhood Curriculum's guidelines when designing their lesson plans and associated learning activities. For instance, Anyamanee (HT1) emphasised that at Anemone Service the learning content and process along with the key learning experiences were designed to promote children's holistic development in four domains: physical, emotional, social, and cognitive. One of the other head teachers Sutana (HT8), from Sunflower Service, commented that:

Teachers always include the four learning contents (The self, People and places around children, the Natural environment and Things around children). They take these into account when designing lesson plans. (February 4, 2016)

\section{Early Childhood Teachers}

Semi-structured interviews were carried out with 14 early childhood teachers. In the interview early childhood teachers were not specifically asked for their views about 
the 2003 Early Childhood Curriculum. However, two of the early childhood teachers did mention that their services always relied on the guidelines of the 2003 Early Childhood Curriculum. For example, Amornrat (T1) explained that at Anemone Service:

Teachers rely on lesson plans and add need-to-know content by making connections between the lesson content and children's reallife experiences. By doing this, children learn about daily life, not just the learning contents of the 2003 Early Childhood Curriculum. (December 18, 2015)

The other early childhood teacher, from Jamesia Service, Jintana (T5), commented "we always promote role-play and one way we do this is by encouraging children to dress up in traditional Thai costumes" (February 9, 2016).

Head teachers and early childhood teachers from the eight services stated that they relied on the curriculum's guidelines when fostering children's holistic development in the four developmental domains. Three of the head teachers, from Anemone, Cherry Blossom and Sunflower Services, also articulated how they integrated Thai culture and identity into their daily teaching practices.

\section{Parents}

Q.1 “Are you familiar with the 2003 Early Childhood Curriculum?"

A total of 17 parents were interviewed. They all indicated that they knew very little about the curriculum at their children's early childhood service. Three of the parents did, however, say they understood that the purpose of the early childhood curriculum was to prepare their children for primary school.

In summary, the interview responses indicated that principals, head teachers, and early childhood teachers did have a good understanding of the 2003 Early Childhood Curriculum, while the parents knew very little. Each service stated that they designed their own early childhood curriculum taking into consideration the guidelines from the official curriculum. The services did integrate some dimensions of Thai culture and identity in their planning. 


\subsection{The Role of the Government and the Umbrella Organisations}

Thailand's Ministry of Education is under the direct supervision of the Government and oversees three umbrella organisations: the OBEC, OPEC, and OHEC in relation to education administration and management (see 2.2.3). Another umbrella organisation is the EDU BMA, which mainly administers early childhood education provision at services under its supervision. The services under these four umbrella organisations must follow the guidelines of the 2003 Early Childhood Curriculum (Ministry of Education, 2003b), including the Government's relevant policies. They all receive funding support from the Government (see 2.2.4).

Principals, head teachers, and early childhood teachers were asked during their interviews how they viewed the Government's role, and what support their services had or expected to receive from the Government. The multiple case study participants' views about services' umbrella organisations were also explored. These data are presented next.

\section{Principals}

Q. 10 "How does the Government support your early childhood service in promoting Thai culture and identity?"

The principals discussed the Government's role in relation to their umbrella organisation. For instance, Principal Apinya (P1), from Anemone Service which operated under the OPEC, stated that the Government informed current regulations and policies at their service:

The Government usually informs our service what to do. However, our service has been proactive in promoting Thai culture and identity and incorporating Buddhist principles into our teaching practices for more than 10 years. Some Government policies are slightly outdated. (December 8, 2015)

At Primrose Service, Principal Parkpoom (P2) talked about how they apply the Government's policies "to fit in with our children and the service's context. Sometimes we cannot implement every single policy due to limited manpower and resources" (January 26, 2016).

Principal Chanin (P3) pointed out that the Government was also responsible for promulgating rules, regulations, and policies: 
I think what the Government does for Cherry Blossom Service is good enough. This includes budget and resource allocation. (February 1, 2016)

He further mentioned the Government issuing the 12 Core Values for Thai people. Principal Chanin (P3) thought that these were important for young children to follow in order to promote good citizenship.

Services Daffodil and Foxglove were under the umbrella of the EDU BMA (one of the sub departments of the Bangkok Metropolitan Administration [BMA]). At Daffodil Service, Vice-Principal Danai (P4) commented:

The current Governor of BMA provides information regarding educational policies for our service. I communicate what policies to follow to all administrators and teachers. I think the EDU BMA comes up with very good campaigns to promote Thai culture and identity; for example, SMART School Campaign. This focuses on encouraging children to have morality and citizenship. (February 1, 2016)

SMART School is one of the quality assurance campaigns evaluated by the EDU BMA. The criteria for a SMART school is success, morality, activities, relativity, and technology. Vice-Principal Fahprataan (P6) gave examples of other policies from the EDU BMA that were put in place to support Foxglove Service to promote such as the Loy Kratong festival and Thailand's National Children's Day (see Appendix A):

During the Loy Kratong festival, our service organises an essay writing competition about an important aspect of the Loy Kratong festival. Children are also encouraged to create a slogan on Children's Day. (February 15, 2016)

Kalmia Service, on the other hand, was not funded by the Government, nor the OPEC. Kanyakorn (HT7) explained that their service did not receive funding from OPEC but was still under its supervision:

The Government and OPEC usually provide information on policies and regulations for the service to follow, for example, wearing traditional Thai costumes once a week. (February 17, 2016) 
Principal Surasak (P8) from Sunflower Service commented that the "OPEC did promote Thai culture in terms of providing training manuals related to Buddhism for teachers. I think this type of support is good for our service” (February 9, 2016).

\section{Head teachers}

Head teachers were asked the same question as principals:

Q. 10 "How does the Government support your early childhood service in promoting Thai culture and identity?"

In response to this question, the Head Teacher from Anemone Service, Anyamanee (HT1), noted that "the Government is not involved too much with our service as we are private" (December 8, 2015). However, another Head Teacher, Chanhom (T3), who taught at Cherry Blossom Service under the direction of the OHEC, pointed out that the Government did provide support.

The OHEC provides information on policies of the service, including any important upcoming campaigns/events promoting Thai culture and identity, for example, wearing traditional Thai costumes. Our Thai Folk Wisdom Centre is funded by the Government. This centre is responsible for the 'Tiny Khon Tour' which is performed by our children. (January 28, 2016)

Chanhom (HT3) further explained that children from Cherry Blossom Service went to different places as requested by the Government or public sector organisations to perform Khon. This is a classical Thai performance which requires players to wear masks based on the tales of the epic Ramakian (derived from the Hindu epic, Ramayana). It involves singing, dancing, acting, and music. Singing is performed by an offstage chorus which also recites narrative and provides dialogue for the stories.

The OBEC was the umbrella organisation for the Sunflower Service. Sutana (HT8) explained that the organisation:

Provides information on policies, informs us of any upcoming campaigns/events related to promoting Thai culture and identity, for example, activities on Father's Day and Mother's Day (see Appendix A) and other important religious dates. We need to write a summary report for the OBEC stating how we do this. (March 3, 2016) 
The eight services considered that the Government, including the umbrella organisations, played an important role in promoting Thai culture and identity at their services. The Government provided information on formalised regulations such as the 12 Core Values, policies, and other campaigns to encourage services to organise relevant activities as a way of promoting Thai culture and identity with young children.

\section{Early Childhood Teachers}

Q. 10 "What do you think about the Government's role in promoting Thai culture and identity?"

The early childhood teachers who were interviewed thought that the Government played an important role in regard to this. Two of the early childhood teachers, Chitchan (T3) from Cherry Blossom Service and Keawkamon (T7) from Kalmia Service, said that the Government generally provided information on policies for their services. Furthermore, one of the early childhood teachers from Anemone Service, Amornrat (T1), mentioned that "the Government requires our service to wear traditional Thai costumes once a week in order to promote Thai culture and identity" (December 18, 2015). At Daffodil Service, Duangkamon (T4) explained their umbrella organisation's role:

The EDU BMA provides sufficient support to our service in relation to promoting Thai culture and identity. For example, it organises Thai manners competitions and it requires everyone in the service to wear traditional Thai costumes every Friday. (February 5, 2016)

Jintana (T5) commented that the policy of wearing traditional Thai costumes once a week for early childhood teachers at Jamesia Service was a good way to promote Thai culture and identity with young children. However, she felt that this should include children wearing traditional Thai costumes as well.

The other two early childhood teachers remarked that it was their services' responsibility to promote Thai culture and identity with children. Kanda (T7) pointed out that their service, Kalmia, should be responsible for promoting Thai culture and identity, rather than just relying on the Government (February 18, 2016). Fangkhaw (HT6), who was the only early childhood teacher at Foxglove, agreed that "promoting 
Thai culture and identity is the service's responsibility. I feel that the service should have full control for designing learning activities that are matched with its sociocultural context" (February 15, 2016).

In addition, the interview data revealed that the eight services wanted additional support from the Government in particular areas. For example, Jandee (HT5) stated their service, Jamesia, would like to get more teaching materials that were relevant to the promotion of Thai culture and identity with young children.

The Government should provide more visual aids; for example, CDs or DVDs about Thai traditions, Dhamma fables, folk tales, and other storybooks. (February 9, 2016)

Somjai (T8) from Sunflower Service also thought that the Government should promote "Thai culture and identity by organising relevant activities and encouraging children to participate in them. More importantly, wearing traditional Thai costumes should be a country-wide campaign" (March 4, 2016).

Two head teachers, Pannee (HT2) from Primrose Service and Darunee (HT4) from Daffodil Service, both pointed out that the Government should organise more activities related to promoting Thai culture and identity for young children. Another early childhood teacher from Primrose Service, Prannapha (T2), commented that the:

Content of Thai traditions and Buddhism should be explicitly included in the 2003 Early Childhood Curriculum. Thai history should be taught to children, and a notion of Thainess should be inculcated to children. (January 29, 2016)

Furthermore, Pinyo (T2), who also taught at Primrose Service, added that:

The Government should provide more teaching material and budget in this regard. (January 29, 2016)

A parent from Anemone Service, Apirak (Pr1), commented as well on the Government's role when asked about her perceptions toward the 2003 Early Childhood Curriculum (Ministry of Education, 2003b): 
I think it should be the Government's role to inform all parents about the 2003 Early Childhood Curriculum's content. Parents may have guidelines to work alongside teachers, in order to enhance children's learning and development. (December 18, 2015)

In summary, principals, head teachers, and early childhood teachers from the eight services indicated that the Government played an important role in promoting Thai culture and identity with young children. Aside from funding, the Government provided information on policies and regulations for the services to follow and put into practice such as requiring early childhood teachers to wear traditional Thai costumes once a week. However, the services also suggested areas where they would like more support from the Government, including organising more activities.

The survey respondents were also asked about the role of the Government in one of the open-ended questions.

Q 54. "What would you like the Government to do in order to promote Thai culture and identity in early childhood education?"

From 235 respondents who filled out the survey, 46.8\% $(n=110)$ answered this question. The following provides a summary of their responses:

- $25 \%(\mathrm{n}=59)$ thought the Government should promote Thai culture and identity by:

○ using media and launching relevant campaigns to promote Thai culture and identity $(12.7 \%, \mathrm{n}=30)$,

○ focusing on promoting traditional Thai costumes, manners, and correct use of the Thai language $(7.2 \%, \mathrm{n}=17)$

○ promoting Thai arts, traditional plays, food and dessert, and traditions $(2.2 \%, \mathrm{n}=5)$

○ teaching about Thai history, identity, and citizens' duties $(1.3 \%, \mathrm{n}=3)$

$\circ$ providing assistance to families to educate them about early childhood education so they can promote Thai culture and identity in their children $(0.8 \%, \mathrm{n}=2)$

○ raising awareness and understanding amongst early childhood teachers $(0.4 \%, \mathrm{n}=1)$ 
o coordinating working with the other sectors [primary and secondary] to promote Thai culture and identity $(0.4 \%, \mathrm{n}=1)$.

- $9.4 \%(n=22)$ felt that the Government should allocate more funding to early childhood education. For instance:

$\circ$ giving additional funding to the sector as well as learning and teaching resources $(6 \%, \mathrm{n}=14)$

o delivering training manuals for early childhood teachers on how to promote Thai culture and identity $(1.7 \%, \mathrm{n}=4)$

$\circ$ providing a variety of teaching resources relevant to their local community $(0.9 \%, \mathrm{n}=2)$

$\circ$ ensuring that all early childhood teachers are qualified $(0.4 \%, \mathrm{n}=1)$

$\circ$ giving more funding and attention to early childhood education in Thailand $(0.4 \%, \mathrm{n}=1)$.

- $6 \%(\mathrm{n}=14)$ claimed that the Government should promote Thai culture and identity in the official curriculum. For example:

○ explicitly stating in the 2003 Early Childhood Curriculum what Thai culture and identity activities should be taught to children $(2.6 \%, \mathrm{n}=6)$

$\bigcirc$ updating the official curriculum and providing examples of teaching practices $(1.7 \%, \mathrm{n}=4)$

○ incorporating Thai culture and identity as part of children's key experiences $(1.3 \%, \mathrm{n}=3)$. [These assist children to develop important skills through interacting with materials, objects and the people around them and by fostering morality and righteousness in the four domains, which include physical, emotional, social and cognitive development]

$\bigcirc$ including Thai manners as one of the learning contents $(0.4 \%, \mathrm{n}=1)$ [The curriculum states that children should learn through the following content: The self, People and places around children, the Natural environment and Things around children.]

- $6.4 \%(\mathrm{n}=15)$ of the respondents suggested that specific activities should be linked to the country's national policies including: 
○ establishing a policy that young children should wear traditional Thai costumes $(3.4 \%, \mathrm{n}=8)$

- launching a national Traditional Thai Costumes Day $(0.9 \%, \mathrm{n}=2)$

○ formalising a dress code for the wearing of traditional Thai costumes for all services $(0.9 \%, \mathrm{n}=2)$

○ establishing a national day to promote Thai culture and identity $(0.9 \%$, $\mathrm{n}=2)$

$\bigcirc$ ensuring that the policies for both public and private early childhood services are similar $(0.4 \%, \mathrm{n}=1)$.

To conclude, the survey respondents suggested ways that the Government could provide more support to the services regarding promoting Thai culture and identity. It was proposed that this could be done through organising more relevant campaigns and events, allocating more funding, and being more specific on how to do this in the curriculum.

Another question was posed in the survey in relation to the Government's role. Q. 55 "Do you think that the Government has a major role in promoting Thai culture and identity?"

This was answered by $62 \%(n=146)$ of 235 respondents who filled out the survey.

- Of these, the majority $(57 \%, \mathrm{n}=135)$ thought that the Government should play a major role in promoting Thai culture and identity. For instance:

○ $54.6 \%(n=128)$ considered the Government has a key role in doing this

○ $0.8 \%(\mathrm{n}=3)$ felt the Government has an important role, but early childhood teachers and parents play a more important role

○ $0.8 \%(\mathrm{n}=2)$ were of the opinion that the Government needs to do more than just focus on the festivals

○ $0.4 \%(\mathrm{n}=1)$ believed the Government should listen to early childhood services and provide information on policies and give instructions for them to follow. This is because they know the socio-cultural context of their service better than the Government 
○ $0.4 \%(\mathrm{n}=1)$ thought the Government should set up policies that promote Thai culture and identity in local communities and regionally

- A small number $(5 \%, \mathrm{n}=11)$ declared that promoting Thai culture and identity was not the sole responsibility of the Government. For example:

○ $2.4 \%(\mathrm{n}=5)$ thought it is not the Government's responsibility to promote Thai culture and identity

○ $1.4 \%(n=3)$ suggested everyone should be responsible, not just the Government

○ $0.4 \%(\mathrm{n}=1)$ believed the private sector should be involved to a greater extent in promoting Thai culture and identity

○ $0.4 \%(\mathrm{n}=1)$ considered Thai culture and identity are genuinely inherited by children. The Government should be supportive in terms of funding/budget

○ $0.4 \%(\mathrm{n}=1)$ thought the Government plays a supportive role, but it is the family who should have the main responsibility.

The survey responses indicated that the Government did have an important role in supporting their services to promote Thai culture and identity with appropriate policies and funding.

\subsection{Parents' Participation}

This research also explored how principals, head teachers, early childhood teachers, and parents viewed parents' participation in their children's early childhood service. The eight services indicated that parents had a significant role in doing so. The data from principals are presented first. This is followed by head teachers', early childhood teachers', and parents' responses.

\section{Principals}

Q.8 “How do you encourage parents' participation on Father's Day and Mother's Day?" 
The four principals, two vice-principals, and the two head teachers, interviewed on behalf of their principals, said that they encouraged parents to celebrate Father's Day and Mother's Day. The services usually organise activities to celebrate these two days before the actual day as they are Thailand's public holidays. For instance, at Primrose Service Principal Parkpoom (P2) stated:

Parents participate in activities on Father's Day and Mother's Day. This is another way that children can express their gratitude to their parents and teachers. (January 26, 2016)

Similarly, the Vice-Principal at Daffodil Service, Danai (P4), claimed that parents participated in these two days and on other special occasions as well:

Parents usually participate in the following activities: Father's Day and Mother's Day, Loy Kratong, and the service's annual celebration. This also includes any festivals and events held at the temple near the service. (February 4, 2016)

At Foxglove, Vice-Principal Fahprataan (P6) explained why they only encouraged parents to participate in some special occasions:

We usually invite parents to participate in activities on Father's Day and Mother's Day and Teacher Appreciation Day. We realise that parents have busy work schedules, so they are not always available to join every event. (February 15, 2016)

Kanyakorn (HT7) said their service invited parents to participate in the activities associated with Father's Day and Mother's Day but there were constraining issues:

Kalmia Service is very small and has insufficient parking space for parents. (February 17, 2016)

In addition to the question posed above, the participants were also asked:

Q.9 "What types of activities/events do parents usually participate in?"

The data revealed that the participation of parents varied at the eight services. For example, Principal Parkpoom (P2) noted that parents always provided support to events held at Primrose Service: 
Most of the parents attend Sports Day to see their children dressing up in colourful costumes and participating in a fancy-dressed parade. Parents also participate in the activities of the National Children's Day and Chinese New Year organised at the service. (January 26, 2016)

Parents were also supportive of events held outside of the service. Principal Parkpoom (P2) explained that:

Recently we had a traditional Thai dancing performance at the Tio Chew Association of Thailand. A group of parents volunteered to drive children to the event. Another group helped with make-up and costumes, while others contributed financially. (January 26, 2016)

In a similar way, at Cherry Blossom Service Principal Chanin (P3) mentioned:

Parents always support the service's activities. When we organise an event, the number of parents is equal to the number of students. They are actively involved in every activity at the service. (February $1,2016)$

Vice-Principal Danai (P4) from Daffodil Service discussed the importance of the community in relation to the role of parents:

Our wider community includes parents and people living within the area. Parents are important. When we encourage the wider community to be involved, our activities are always successful with their cooperation. We receive good support and cooperation from both the community and parents. (February 4, 2016)

At Jamesia Service, Jandee (HT5) also explained how parents participated in their service's activities:

Parents provide excellent support and cooperation at every event. They always volunteer in story-telling, assist with the Science Expo and promote reading during Reading Week. They volunteer as parent helpers in the classroom teaching children how to make soap. Once a month/semester parents perform a role-play on the stage (in order to show their active participation and involvement at their child's service). (December 8, 2015) 
The Science Expo was an in-house event at Jamesia Service. Children were involved in experimental and exploratory activities. Parents helped early childhood teachers to supervise children at each of the activity booths.

In relation to Foxglove Service, Vice-Principal Fahprataan (P6) explained that when they invited parents to join in activities it was mostly grandparents and other members of the family who came instead of children's parents:

The majority of children at this service do not live with their parents. Some of them do not have parents or their parents live in other provinces. Children stay with their relatives or grandparents. Some parents work as labourers and they need to relocate to working sites which are far from this area. (February 15, 2016)

At Kalmia Service, Kanyakorn (HT7) stated: "we encourage parents to be a part of our project committees as well as to participate in events held at the service. Parents always participate in every activity by volunteering or when they are asked to" (February 4, 2016). Likewise, Principal Surasak (P8) indicated that parents at Sunflower Service fully supported the service's activities, especially in relation to Buddhism:

Parents were a part of the audience and they assisted in the following: preparing a seat for a monk and picking up a monk from a temple. Similar to other activities on religious important dates or those related to Buddhism, we always receive great support and cooperation from parents. (March 3, 2016)

Principal Surasak (P8) further explained that they also organised Thet Mahachat at their service. This is a story about one of Buddha's past lives when a compassionate prince named Vessantarae gave away everything he owned as well as his children to help others. This story reflects the virtue of charity (Dhammathai, n.d.).

In summary, the principals discussed specific Thai festivals and important dates that children's parents participated in and the type of support they provided at their early childhood service.

\section{Head teachers}

Q.8 "How do parents participate at your early childhood service?" 
The Head teachers talked about the different ways in which parents participated at their services. By way of example, Anyamanee (HT1) from Anemone Service commented:

Parents help fund-raising activities by selling homemade cookies, small crafts, and home-cooking food. A good relationship between teachers and parents contributes to the success of organised events at the service. (December 8, 2015)

Pannee (HT2) from Primrose Service noted:

Parents are involved in food offering (to monks) activities in the morning (as they fast after midday) and provide financial support to our service. They also help set up a stage for children's performances on many occasions. (January 26, 2016)

At Cherry Blossom Service, Chanhom (HT3) pointed out that the participation of parents was a key factor in ensuring the success of events held:

We always receive great support from parents; for example, at the one-off Thai Culture Exhibition held last year a number of parents attended as visitors, while others were booth representatives and helped children in each booth. Moreover, some parents assisted in their child's programme as parent helpers. (January 28, 2016)

while at Sunflower Service, Sutana (HT8) talked about how parental support was important for children's learning and development:

Children can learn better if their parents also support them. Parents are very crucial of children's learning and development. At our service, parents join a food offering activity every Tuesday. (March $3,2016)$

Fangkhaw (HT6), however, mentioned that gaining support from parents was difficult at the Foxglove Service:

Parents are either born locally or are labour migrants that have relocated from other areas of the country. Migrant parents are always moving from place to place for work and this has a huge impact on children's learning and development, as they move with their parents. (February 9, 2016) 
Most of the head teachers agreed that the participation of parents was important at their service.

\section{Early Childhood Teachers}

Q.9 "How do parents participate in your service in order to promote Thai culture and identity?"

Amongst the eight services, early childhood teachers claimed that parents helped promote different aspects of Thai culture and identity. For example, Prannapha (T2) from Primrose Service talked about how parents encouraged their children to learn at home:

Parents are key persons in promoting Thai culture and identity. They encourage children to pray to the Buddha, visit a temple, and no talking while eating. (January 29, 2016)

Chitchan (T3) provided the following example of how parents participated where she worked:

Cherry Blossom Service organises a Parental Clinic once a week. It is a consulting session for parents to communicate with teachers and other parents about children's learning and development. Each parent shares their experiences and strategies of how they deal with their children. (January 28, 2016)

In line with Kanyakorn (HT7), from Kalmia Service, Duangkamon (T4) affirmed that “parents are involved in Daffodil Services' activities through volunteering and when asked" (February 5, 2016). She further remarked that parents at her service:

Encourage children to perform Wai daily and regularly go to a temple. (February 5, 2016)

Wai was promoted at many of the services, but not at Foxglove. Fangkhaw (HT6) explained: 
goodbye and thank parents for dropping them off at the service), some parents suddenly say: "No need to do that", "No point in doing that", "Why do you do that, just get going into the service. I need to rush off'. I think it is very challenging to nurture children to behave with good Thai manners if they are brought up in this kind of environment. (February 15, 2016)

In contrast to other services, parents' participation at Sunflower Service was a challenge. Somjai (T8) stated that their early childhood teachers expected more cooperation from parents in promoting Thai culture and identity:

Parents do not really provide good support, nor do they participate in the service's activities; for example, some children are not dressed up in traditional Thai costumes as required. This service promotes wearing traditional Thai costumes once a week. For children not wearing such clothing reflects that parents seem to give less attention to them. Another thing is that only a small number of parents join the service's activities even though we send out invitation letters to them. (March 4, 2016)

The early childhood teacher participants seemed to have a slightly different perspective toward the participation of parents at their service to that of the principals. Six of the eight services mentioned that parents were helpful in promoting Thai culture and identity with their children. However, the early childhood teachers at Foxglove and Sunflower Services mentioned that they expected more support from children's parents.

In the survey, the respondents were asked about parents' participation.

Q. 63 "Please give some examples of activities that parents usually participate in."

A large number of respondents $(84.3 \%, \mathrm{n}=198)$ answered this question. A summary of their responses is noted below:

- $56.2 \%(\mathrm{n}=132)$ of the respondents commented that parents usually participated in the following: Father's Day and Mother's Day, Children's Day, Teacher Appreciation Day, Sport Day, New Year and Christmas celebration, important religious dates, the services' annual celebrations, and the Loy Kratong festival (i.e., taking children to float their baskets). The respondents also mentioned that parents participated with their children in the Songkran festival, but this was celebrated during the holidays. 
- $23.8 \%(n=56)$ of the respondents indicated that parents participated in the services' activities by:

○ being parent helpers for specific activities such as supervising children on field trips. Parents also helped in the following ways: participating in a role-play; cooking for an event; joining a book club (which aims to encourage children to read more books), doing crafts with children, Art class (to help children to draw or paint); and joining in an exhibition and other projects $(17 \%, \mathrm{n}=40)$

$\circ$ volunteering at their service, but no specific activities were provided $(2.6 \%, \mathrm{n}=6)$

$\circ$ helping design teaching materials $(2.1 \%, \mathrm{n}=5)$

○ participating in the Project Approach activities $(2.1 \%, \mathrm{n}=5)$.

Other written comments revealed that parents helped in the following ways:

- $1.7 \%(n=4)$ regular attendance at teacher-parent meetings.

- $1.3 \%(\mathrm{n}=3)$ involved with offering food to Buddhist monks at services.

- $0.9 \%(\mathrm{n}=2)$ promoted Thai manners and encouraged children to Wai on a daily basis.

- $0.4 \%(n=1)$ encouraged children to learn about the country's agricultural lifestyle.

The respondents mentioned Thai festivals, important dates, and other activities including parents helping in the classroom and provided specific details regarding these. Another question posed in the survey was:

Q. 65 "What can parents do to promote Thai culture and identity at your early childhood service?"

Many survey respondents $66.8 \%(\mathrm{n}=157)$ answered this question:

- $28.1 \%(\mathrm{n}=66)$ of respondents claimed that parents should promote Thai culture and identity in the following ways: 
- encourage their children to have good manners. Wai and Kraab were mentioned as well as being polite when talking to others $(11.6 \%, \mathrm{n}=$ 27)

○ promote children wearing traditional Thai costumes and appropriate clothes $(10.2 \%, \mathrm{n}=24)$

○ observe Thai traditions and important religious dates with their children $(3.8 \%, \mathrm{n}=9)$

$\circ$ visit a temple with their children when observing important religious dates $(0.4 \%, \mathrm{n}=1)$

○ take their children to the countryside to learn about Thailand's traditional lifestyle, e.g., rice farming and crafting $(0.4 \%, \mathrm{n}=1)$

$\circ$ promote their children's correct usage of the Thai language $(0.4 \%, \mathrm{n}=$ $1)$.

○ assist services' activities such as joining an exhibition related to Thai culture and identity and encouraging children to wear traditional Thai costumes $(1.3 \%, \mathrm{n}=3)$.

- $6.8 \%(n=16)$ of the respondents suggested parents should promote Thai culture and identity outside their services by:

$\circ$ being a role model and supporting their children's learning and development $(4.2 \%, \mathrm{n}=10)$

$\circ$ encouraging their children to learn and practise Thai culture and identity at home $(2.6 \%, \mathrm{n}=6)$.

- $4.7 \%(\mathrm{n}=11)$ of the respondents claimed parents should teach morality to children and encourage them to be good citizens.

- $1.3 \%(\mathrm{n}=3)$, a very small number of respondents commented that their service needed more assistance from parents.

However, the other written comments of the survey respondents were more in line with the previous question. These included:

- $25.9 \%(n=61)$ of the respondents mentioned that parents had been involved in their service's activities. For example: 
- always participating in their service's activities $(22 \%, \mathrm{n}=52)$

- regularly attending a teacher-parent meeting and encouraging their children to follow their service's policies $(2.6 \%, \mathrm{n}=6)$

$\circ$ helping early childhood teachers to create teaching material $(1.3 \%, \mathrm{n}=$ $3)$.

In summa.3ry, parents were perceived as playing an important role in promoting Thai culture and identity in their children through Thai manners, traditions, costumes, norms, and observing important religious dates.

\subsubsection{Communication with Parents from the Services' Perspectives}

Data from the participants semi-structured interviews showed that communication between early childhood teachers and parents at the eight services took place daily, monthly, or once a semester. Four of the eight services discussed how they communicated with parents when they talked about the participation of parents. For example, at Primrose Service, Principal Parkpoom (P2) explained:

Parents are always informed by teachers through our weekly newsletter. (January 26, 2016)

Vice-Principal Danai (P4) from Daffodil Service stated that communication between early childhood teachers and children's parents mostly took place once a semester through teacher-parent meetings:

Our service regularly organises teacher-parent meetings. At a meeting, parents are informed about what they could do to support their children's learning and development. The service informs them about what types of support are needed. (February 4, 2016)

However, at Cherry Blossom Service, Chanhom (HT3) mentioned that their early childhood teachers communicated with parents on a daily basis:

Teachers and parents always keep each other updated with everything that happens at our service, including children's learning and developing performance. (January 28, 2016) 
Jintana (T5) from Jamesia Service asserted:

When designing activities for any special events, teachers always consult with parents for appropriate ideas to use. Sometimes, parents provide guidelines for the service to follow. If teachers take a lead then parents are very good supporters. (February 9, 2016)

In this section, the data from the survey in relation to communicating with parents are also presented. The following question was posed to the survey respondents:

Q. 64 "How often do you communicate with parents?"

In the survey, $79.6 \%(\mathrm{n}=187)$ of respondents answered this question.

- Of these 58.2\% ( $\mathrm{n}=137)$ claimed they communicated with parents on a daily basis by:

$\circ$ meeting in person, talking on the phone, or contacting them through online messenger (i.e., Facebook and LINE application) $(42.6 \%, \mathrm{n}=$ 100; among these, 26 respondents mentioned that they discussed children's development and academic progress with parents)

○ communicating through a performance/homework book and the service's newsletter $(14 \%, \mathrm{n}=33$; among these, one early childhood teacher stated that their service would contact parents by phone if there was an urgent problem)

- meeting in person twice a day but did not specify when they met (1.6\%, $\mathrm{n}=4)$.

- $12.3 \%(\mathrm{n}=29)$ of the respondents mentioned they communicated with parents on a regular basis by meeting with them:

$\circ$ two to four times a month $(8.1 \%, \mathrm{n}=19)$

$\circ$ once a month $(3.4 \%, \mathrm{n}=8)$

○ four to five times a month $(0.4 \%, \mathrm{n}=1)$

○ 12 times a month $(0.4 \%, \mathrm{n}=1)$.

- $4.4 \%(\mathrm{n}=10)$ of the survey respondents indicated that they communicated with parents on a weekly basis by: 
o talking with parents one to two times a week, but by phone if there was an urgent matter that needed discussing $(2.2 \%, \mathrm{n}=5)$

○ communicating three to four times a week $(2.2 \%, \mathrm{n}=5)$.

- $3 \%(\mathrm{n}=7)$ of the respondents pointed out that they talked to parents during teacher-parent meetings at their service.

- $1.3 \%(\mathrm{n}=3)$ stated that they communicated two to three times within a semester.

- In contrast, $0.4 \%(\mathrm{n}=1)$, one person revealed that she had few interactions with parents, but she usually contacted them by phone and in person if there was an urgent concern.

In summary, early childhood teachers and parents regularly communicated with each other in relation to children's academic progress and about what parents could do to support this. This varied between the services in relation to how often and how.

\subsubsection{Parents' Communication with Early Childhood Teachers}

Q. 4 "Do your child's teachers consult with you when they design lesson plans and learning activities?"

The data revealed that at five of the eight services early childhood teachers and parents had regular communication. For instance, at Anemone Service Areeya (Pr1) stated:

Teachers inform me how to support my child's learning by communicating through his homework book. They also provide a summary of what he learnt at the service in a weekly record. (December 18, 2015)

Similarly, Patcha $(\operatorname{Pr} 2)$ from Primrose Service mentioned that she also "used her child's homework books to communicate with teachers and to be informed about the service's activities" (January 29, 2016). One of the parents from Cherry Blossom Service, Chanjira (Pr3), noted that she had regular communication with her child's early childhood teachers: 
Teachers always tell me what to prepare with my child for the next lesson. For example, if his next lesson is about animals I help him by showing photos of different animals. (February 9, 2016)

While Jaruwan $(\operatorname{Pr} 5)$ indicated that she communicated with early childhood teachers at Jamesia Service on a monthly basis:

I meet with my child's teachers twice a month. They inform me about lesson plans and what aspects of my support the service needs. (February 9, 2016)

Parents from three of the eight services indicated that they communicated with their child's early childhood teachers through teacher-parent meetings. For instance, Duangjai ( $\operatorname{Pr} 4)$ pointed out that she attended teacher-parent meetings at the beginning of each semester at Daffodil Service:

I never discuss with teachers designing lesson plans or learning activities. They inform me of this information through teacherparent meetings. (February 5, 2016)

The parents from Foxglove and Sunflower Services, Fundee (Pr6) and Supatcha (Pr8), also remarked that they only communicated with their children's early childhood teachers through a teacher-parent meeting held each semester. In contrast to other parents, another parent from Foxglove Service, Fahrung (Pr6), stated: "I did not often communicate with my child's teachers" (February 16, 2016); however, this was due to time constraints.

In summary, parents communicated with their child's early childhood teachers through different means such as homework books, the services' newsletter, and teacher-parent meetings.

\subsubsection{Parents' Perception of their Participation at the Services}

Q. 2 "How often are you involved in activities or events at the service?"

The parents indicated that their participation in the services' activities was varied. For example, one of the parents from Anemone Service, Areeya ( $\operatorname{Pr} 1)$, stated: 
I participate in every activity (approximately twice a month). Some days, I spend almost half a day at this service for a meeting with a group of parents. I am also a parent helper in some lessons. (December 18, 2015)

Another parent, Pensri (Pr2), from Primrose Service, also helped in her child's early childhood programme, whilst one parent from Cherry Blossom Service, Chanjira (Pr3), explained how she participated:

I prepare my child to know how to work in a group and be a good team player. I help him with presenting and public speaking skills, and how to find information about topics. (February 9, 2016)

In terms of her involvement at Jamesica Service, Jintana (Pr5) revealed:

I often participate in the service's activities; for example, roleplaying and storytelling in the programme. My house is located a long way from the service, so I usually spend a whole day at the service and provide support for teachers if they ask for it. (February 9, 2016)

In a similar way, Kingkarn (Pr7) affirmed that she was always involved in Kalmia Service's activities:

I joined one of the Project Approach activities; I took my child to a fruit garden when she was learning about guava. I also help design relevant teaching materials. (February 19, 2016)

Another parent from the same service, Kanokporn $(\operatorname{Pr} 7)$, noted the following:

I participate in every activity such as the New Year's Party and the National Children's Day (see Appendix A). I am also one of the regular parent helpers. (February 19, 2016)

Salinthip (Pr8) from Sunflower Service stated that she often participated in various activities:

For example, cooking on an event day and participating in exhibitions organised by this service. (March 7, 2016) 
In contrast to most of the parents discussed above, only four of 17 claimed that their participation was minimal. Two of the four parents said they only participated when asked:

I participate in Daffodil's Service's activities when I am asked to do so. (Deejai (Pr4); February 5, 2016)

I occasionally join in the activities when I am requested by Jamesia Service to do so. (Jutamas (Pr5); February 9, 2016)

The other two parents indicated that they rarely participated in their service's activities. Duangjai (Pr4), also from Daffodil Service, pointed out:

I do not often participate in the service's activities. I am a street food seller; I need to be with my food cart all day. Most of the service's activities take place during the day. So, I do not have much chance to join. (February 5, 2016)

Another parent, Fahrung (Pr6), noted that she would like to participate in Foxglove Service's activities, but she rarely did:

I would love to join but I have never participated in any activities as I am very busy. (February 16, 2016)

In summary, parents outlined how they participated at their children's service, including assisting with activities and promoting their children's learning and development at home. Two of the parents, from Daffodil and Foxglove Services, were unable to participate due to work commitments.

\subsubsection{How Parents Promote Songkran Festival and Visakha Bucha Day}

Q.6 "How does your family celebrate Songkran festival?"

Songkran is another popular festival in Thailand (see 2.3.2). It takes place in mid-April during the school break, so children normally spend time with their parents and families at home. Parents claimed that they always promoted this festival; for example, Apirak (Pr1) from Anemone Service stated: 
I usually take my child to pay respect to my parents by performing a 'water pouring' to ask for their blessing. Then, my family visits a temple and plays water splashing among relatives, as a part of the celebration. (December 18, 2015)

Another parent, from Foxglove Service, Fundee (Pr6), mentioned that his family always celebrated Songkran festival by:

Having dinner together and participating in water splashing. (February 16, 2016)

Likewise, one of the parents at Sunflower Service, Supatcha $(\operatorname{Pr} 8)$, did the same activities and then her family performed a meritorious ritual for their ancestors at a temple.

Some of the parents, though, were not able to celebrate this festival with their children due to work commitments. This was illustrated by Fahrung (Pr6) from Foxglove Service:

I cannot take my child to do anything on Songkran day as I need to earn a living. My child can only do water splashing with other children near my food cart. (February 16, 2016)

Another parent, at Sunflower Service, Sawittree (Pr8), pointed out that:

I usually take my child on a holiday trip as my family is Islamic; we do not celebrate any Thai festivals. (March 7, 2016)

The parents were also asked during the interview:

Q.7 "What does your family usually do on Visakha Bucha Day?"

Visakha Bucha Day is one of the most important religious dates in Thailand (see Appendix A). Most of the parents said that they took their children to a temple. For instance, Areeya $(\operatorname{Pr} 1)$, a parent at Anemone Service, mentioned: 
My family offers food to Buddhist monks at a temple in the morning and walk with lighted candles held in our hands around a central sanctuary in a temple in the evening. (February 16, 2016)

Likewise, Patcha (Pr2) from Primrose Service followed the same ritual as Areeya (Pr1), while one of the parents from Cheery Blossom Service, Chanjira (Pr3), noted:

I always encourage my child to visi.t a temple on Visakha Bucha Day. My child is taught how to make a candle at the service. In the evening, I take my child to walk with lighted (handmade) candles held by hand around a central sanctuary hall at a temple. (February $9,2016)$

Another parent from the same service, Chanikarn (Pr3), encouraged her child to learn about the importance of Visakha Bucha Day by explaining its history. However, two other parents reported that they did not do anything on this important day due to the following reasons:

I cannot take them anywhere, as I need to earn a living. My child may join in the service's activity on this occasion. (Fahrung (Pr6); February 16, 2016)

Because my family is Islamic. My child is allowed to learn about Visakha Bucha Day, other important religious dates, and the Buddha's lifestory, but they cannot perform any rituals. (Sawittree (Pr8); March 7, 2016)

In summary, most of the parents indicated that they encouraged their children to be involved in Songkran and Visakha Bucha Day. Many families took their children to pay respect to their grandparents and celebrated the Songkran festival by engaging in water splashing. On Visakha Bucha Day, parents mentioned that they usually took their children to a temple to perform religious activities. However, some parents did not promote Songkran and Visakha Bucha Day due to their busy work schedules and religious affiliations.

\subsection{Chapter Summary}

Three main themes were presented in this chapter. The first was the multiple case study participants' perceptions toward the 2003 Early Childhood Curriculum. All eight 
services applied the official curriculum guidelines when developing their own early childhood curriculum.

The second theme identified was how the participants viewed the role of the Government and umbrella organisations in promoting Thai culture and identity. The services indicated that the Government, in particular, had an important role in promoting Thai culture and identity.

The third theme that emerged from the data was how children's parents encouraged their children to learn about Thai culture and identity. The majority of the services highlighted how parents supported and participated in their service's activities.

In the next chapter, the fourth theme of the study gathered from the multiple case study will be discussed. How each of the eight multiple case study services promoted Thai culture and identity in their daily teaching practices is explored in relation to the five key aspects of Thai culture and identity. 


\section{CHAPTER 7}

\section{INTEGRATING THAI CULTURE AND IDENTITY INTO TEACHING PRACTICES}

This chapter presents the findings from the fourth major theme that emerged from Phase Two of the study. Analysis of the interview data revealed five major aspects of Thai culture and identity that the multiple case study participants felt they integrated into their teaching practices. They are: Thai manners, Thai traditions, Thai folk wisdom, Thai social values and norms, and finally Buddhism. As in the previous chapter, when examining each of these aspects the Principals' comments are presented first. This is followed by the questions posed to the head teachers, early childhood teachers, and lastly the parents.

\subsection{Thai Manners}

To acknowledge the various roles participants had at their services, different questions were asked in order to explore how Thai manners were practised.

\section{Principals}

Q. 2 "What aspects of Thai culture and identity are practised at your service?"

All the participants revealed that Thai manners were important. For instance, the Principal at Anemone Service, Apinya (P1), stated that Thai people are associated with this aspect of their culture and identity:

Manners and humbleness are important. Wai is expressed as a greeting gesture and paying respect to people and places; for example, elders, parents, Buddha images, Buddhist monks, temples, and other sacred places. (December 8, 2015)

Similarly, Vice-Principal Danai (P4) from Daffodil Service outlined how children were expected to behave in relation to Thai manners:

Children should perform Wai, dress appropriately and speak politely with no shouting or screaming. They should also not talk while eating and be humble and respect others. (February 4, 2016) 
For Fahprataan (P6), the Vice-Principal at Foxglove Service, it was also essential that children displayed the proper gestures of Thai manners:

They should have calmness and self-control in every gesture such as walking calmly. We encourage children to pay respect to portraits of the King and Queen by curtsying (females) and bowing (males). (February 15, 2016)

The principals were also asked the following question:

Q. 11 "What do you think is the best way to express Thainess?"

There was agreement amongst the principals that Thai manners were the best way to express Thainess. By way of example, at Primrose Service, Principal Parkpoom (P2) asserted that "Wai is the best way for greeting and paying respect among Thai people that indicates the uniqueness of Thainess" (January 26, 2016). Likewise, the Principal at Cherry Blossom Service, Chanin (P3), said performing Wai and paying respect to others with humbleness are Thai-style characteristics. In a similar way, Jandee (HT5) from Jamesia Service remarked that:

The best way to express Thainess is through Thai manners. This includes Wai and being polite when speaking, greeting, and thanking others. Children need to have self-discipline, respect others, and bow when walking past elders. (February 9, 2016)

When answering this question, Principal Apinya (P1) at Anemone Service talked about how:

People should be treated with respect regardless of their social status; for example, Thai people respect others in regard to their seniority (i.e., age status). For instance, we call a fruit seller Aunt (in Thai: Bpaa) and call taxi drivers Uncle or Elder brother (in Thai: Loong or Phee). Thai people not only call older people by their names but they also bow when walking past them. (December 8, 2015)

Apinya (P1) further added that Thai culture includes greeting others using Wai, the traditional Thai greeting, being humble, behaving in a disciplined manner, respecting 
elders, and showing gratitude to the Nation and one's parents. In a similar way, VicePrincipal Danai (P4) from Daffodil Service stated that Thainess is expressed by:

Thai manners, especially Wai. Children need to be humble, modest, and polite. Parents and teachers must encourage them to respect their elders and have a polite manner when speaking and eating. (February 4, 2016)

The Vice-Principal at Foxglove Service, Fahprataan (P6), made similar comments. He pointed out that Thai manners include "paying respect to parents, teachers, elders, and the King and the Queen” (February 15, 2016). Likewise, Kanyakorn (HT7) from Kalmia Service stated that the best way to express Thainess is through Thai manners, which involves "performing Wai, being polite when speaking, greeting, and thanking others, being self-disciplined, respecting others and bowing when walking passing elders" (February 17, 2016).

Thai manners were seen to be important, particularly Wai, and were a unique way of expressing Thainess.

\section{Head Teachers}

Q.3 "What activities do you usually do to promote Thai culture and identity?"

The comments from head teachers revealed that Thai manners were essential in promoting Thai culture and identity. For instance, at Anemone Service, Anyamanee (HT1) described one of her lesson plans:

There are nine development areas involved in our lesson plans. One of them is behaviour/lifestyle which is related to promoting Thai manners. We design additional activities which might not correspond with lesson topics; however, it is necessary for children in their daily life. For example, being polite when greeting others and queuing (e.g., during a snack time), sitting properly (not with one's legs crossed when meeting with elders), and Kraab. (December 8, 2015)

In her response, Kanyakorn (HT7) from Kalmia Service included the physical gestures that children should make in accordance with Thai manners: 
One of the Kalmia Service's aspirations is to treasure Thai culture and traditions. We always focus on Thai manners (performing Wai and Kraab). Children are encouraged to be polite when speaking (such as a nice tone of voice), eating (with no talking), and walking (with self-control). They are also taught to bow when passing any elders. This is a very important aspect of Thai culture and identity. (February 17, 2016)

When this question was posed to the two other head teachers, Jandee (HT5) from Jamesia Service and Sutana (HT8) from Sunflower Service, they commented that their services promoted Thai culture and identity through Thai manners.

Early childhood teachers were asked the same question as head teachers.

\section{Early Childhood Teachers}

Q.1 "What activities do you usually do to promote Thai culture and identity?"

The early childhood teachers' answers disclosed how they promoted appropriate Thai manners with young children. For instance, at Primrose Service, Prannapha (T2) mentioned:

Children are encouraged to speak politely in accordance with Thai good manners. (January 29, 2016)

Early childhood teachers from Cherry Blossom Service said that children were involved in a Wai competition at their service once a year. Children kept practising until they could express their best gesture of Wai for the competition. One of the early childhood teachers from Daffodil Service, Dawadee (T4), pointed out:

Our service is one of the participants in a Thai manners' competition (involves Wai and other gestures) which is organised by the service's umbrella organisation, the EDU BMA. We always encourage children to perform Wai and behave politely. (February $5,2016)$

Another teacher from the same service, Duangkamon (T4), explained that promoting Thai culture and identity was encouraged in her classroom as well as in the wider community: 
Children are encouraged to perform Wai and visit a temple on a daily basis. They also pay respect to a Buddha image in a central sanctuary hall of a temple. (February 5, 2016)

The head teachers and early childhood teachers believed Thai manners were fundamental in promoting Thai culture and identity with young children.

\section{Parents}

Q.3 "How do you promote Thai culture and identity with your child (both at home and at the service)?"

Parents also highlighted that Thai manners were important to promote Thai culture and identity. By way of example, one of the parents from Anemone Service, Areeya (Pr1), stated:

I encourage my children to practise Wai and Kraab, be humble, respect others, and bow when passing elders. (December 18, 2015)

Similarly, Kingkarn (Pr7) from Kalmia Service said she always encouraged her child to do Wai and Kraab. Another parent from Cherry Blossom Service, Chanikarn (Pr3), shared the following:

In the past my child did not perform Wai to any teachers except for her own early childhood teacher (at her former service). But now, after enrolling at this service she performs a proper greeting of Wai and pays respect to every teacher and other elders as well. (February 9, 2016)

Parents were also asked the following:

Q.8 "Why do you think it is important to promote Thai culture and identity with young children?"

The parent-participants provided various reasons for promoting Thai culture and identity with young children. For example, Apirak (Pr1) from Anemone Service mentioned: 
I think it is important to inculcate Thai culture and identity starting in early childhood education. Children are still innocent and seem to absorb things easily. (December 18,2015 )

Another parent from Cherry Blossom Service, Chanikarn (Pr3), explained that promoting Thai culture and identity is essential to being Thai:

We should teach them about their nation, Thainess, and Thai culture. Children can learn from their families too so parents should tell them about the traditional Thai way of living. Moreover, we must speak Thai language clearly, so they can learn the correct usage. (February 16, 2016)

Deejai (Pr4) from Daffodil Service also commented that it is very important to "inculcate and encourage children to be involved in activities related to Thai culture and Thainess as a way of maintaining their unique Thai culture" (February 5, 2016):

A parent at Jamesis Service, Janjira (Pr5), pointed out a similar reason:

Because we are Thai, it is important to perform Wai. Children should pay respect with humbleness and courtesy. They should also wear appropriate clothing in accordance to propriety. (February 9, 2016)

Likewise, another parent, Kingkarn (Pr7), from Kalmia Service, said her children were Thai so it was important to practise Wai with them. She further explained that:

Thainess involves paying respect with humbleness and courtesy, hence children should also dress appropriately. A unique aspect of our culture is a Thai-style smile. I always teach my children to smile like this. I also encourage them to wear traditional Thai costumes, to eat Thai food and dessert, and to enjoy doing Thai folk play (which is traditional games). (February 9, 2016)

In summary, the traditional gestural styles of greeting and paying respect, Wai and Kraab, were mentioned as being an important aspect of Thai manners. Being polite when speaking, eating, and walking, as well as demonstrating self-discipline and selfcontrol, were also important. Many of the participants highlighted that the best way to express Thainess was through Thai manners. 


\subsection{Thai Traditions}

Traditions in Thailand include festivals and important dates. During the semistructured interviews two popular festivals, Loy Kratong and Songkran, were commented on by the participants. In Chapter 6, the Songkran festival was explored in relation to how parents helped promote this festival with their children. For this reason, only the Loy Kratong festival will be discussed in this section.

\subsubsection{Festivals}

Loy Kratong is one of the most popular festivals in Thailand, so participants were asked how this was celebrated at their service.

\section{Principals}

Q.3 "What activities does your service organise for children at the Loy Kratong festival?"

Seven of the eight services mentioned similar festive and traditional ritual activities that their services encouraged children to participate in. For example, Principal Parkpoom (P2) from Primrose Service stated that they always provide a temporary pond for children to float their baskets in. The principal from Cherry Blossom Service mentioned their service did this as well.

Vice-Principal Danai (P4) affirmed that at Daffodil Service they always promoted Thai local rites and traditions, especially during this festival:

Our school is located near a temple, so children can have a real experience of the Loy Kratong festival and how to float a basket into a river. (February 4, 2016)

Principal Surasak (P8) from Sunflower Service pointed out that at their service children learn how to make a floating basket and the history of this important festival. However, they do not organise any floating basket competition as they want to encourage children to think about how this might pollute the natural environment as not all baskets are biodegradable (March 3, 2016).

Learning about the Loy Kratong festival at Jamesia Service was different to other services. Jandee (HT5) explained: 
Children are encouraged to learn about this festival and make a floating basket. They are not allowed to perform any floating action or sing the Loy Kratong song because children's Christian parents are very strict about prohibiting this form of ritual at this service. Children can take their baskets to float with their Buddhist parents after school. (February 9, 2016)

The principals promoted the Loy Kratong festival in various ways.

\section{Head Teachers}

Q.3 "What activities do you usually do to promote Thai culture and identity?"

When head teachers were asked this question, six of them referred to Thai traditions. For example, Pannee (HT2) from Primrose Service mentioned activities associated with the Loy Kratong festival as well as Father's Day and Mother's Day. At the Cherry Blossom Service, Chanhom (HT3) stated that they integrated:

Thai traditions, customs, and culture into their teaching practices occasionally and also design specific learning activities to fit with the traditional celebrations. (January 28, 2016)

The other two head teachers, Darunee (HT4) from Daffodil Service and Jandee (HT5) from Jamesia Service, indicated that they encouraged children to participate in activities to celebrate Father's Day and Mother's Day as a way of promoting Thai culture and identity.

The head teachers were also asked:

\section{Head teachers}

Q. 4 "How does your early childhood team celebrate the Loy Kratong festival?"

All head teachers said they celebrated this festival at their services. For instance, at Anemone Service Anyamanee (HT1) stated that she taught children the significance of water in Thailand: 
It is a traditional practice that Thai people pay respect to the Goddess of water (in Thai: Phra Maae Khohng Khaa). (December $8,2015)$

At Sunflower Service, Sutana (HT8) also mentioned that "children usually learn about the importance of water as it is an important major natural source in Thailand, for example, for agriculture and transportation in the old days" (March 3, 2016).

Pannee (HT2) explained the activities that early childhood teachers did at Primrose Service at the Loy Kratong festival:

Children make a floating basket together with teachers. The service provides a temporarily made pond for children to float their baskets. (January 26, 2016)

The head teacher from Cherry Blossom Service, Chanhom (HT3), also described the activities that their service organised to celebrate the Loy Kratong festival:

Teachers design what resources and material children will use to make and decorate a floating basket. Some use recycled material, while others decide to make only one basket to share amongst the class to be more environmentally friendly. The service also provides a temporarily-made pond for children to float their baskets. (January 28, 2016)

The head teacher from Daffodil Service, Darunee (HT4), pointed out that children at their service made floating baskets the day before the festival. The early childhood teachers told the children why the country celebrated this festival, highlighting its importance.

\section{Early Childhood Teachers}

Q.3 "At your early childhood service how exactly do you celebrate Loy Kratong?"

Early childhood teachers stated that they encouraged children to be involved in the Loy Kratong festival by teaching them to make and decorate floating baskets. At Anemone, for example, Amornrat (T1) explained the activities that their service organised to celebrate this festival: 
Teachers explain the importance and the history of this festival to children. Children and their teachers make and decorate a floating basket together in the classroom. The service makes only one floating basket per classroom, so children can be involved in this activity. For decorating the basket with flowers, children are assigned to bring flowers from their houses so that there is no cost involved. (December 18, 2015)

Amornrat (T1) also mentioned that children would do different activities when making a floating basket depending on their age. The older children learn how to fold lotus petals for the basket, while the younger ones put flowers into a basket. At Primrose Service Pinyo (T2) pointed out that she "worked together with children to make a floating basket with banana trunks and leaves" (January 29, 2016). Early childhood teachers then encouraged children to float their handmade baskets in a temporarilymade pond.

Jintana (T5) from Jamesia Service stated that they taught children to learn about the importance and history of this festival but did not perform any ritual activities:

Teachers teach children about natural resources that are used to make a floating basket. (February 9, 2016)

In summary, all the services taught children the significance of the Loy Kratong festival and how to make a floating basket. The festival's ritual of floating baskets made by the children was carried out at every service except at Jamesia Service due to different religious beliefs.

\subsubsection{Important Thai Dates}

Important dates in Thailand are linked to Thai traditions. Principals' responses were reported in Chapter 6 regarding parents' participation (see 6.3). In this section, the interview data from head teachers, early childhood teachers and parents are presented.

\section{Head Teachers}

Q.5 "How does your service celebrate Father's Day and Mother's Day?" 
These two important dates are public holidays in Thailand. The data show that the services celebrated the birthdays of the King and Queen of Thailand beforehand. For instance, Anyamanee (HT1) explained that at Anemone Service:

Their royal duties are displayed on notice boards. Children can learn how the Royal Highnesses sacrifice themselves for the country. (December 8, 2015)

She provided the Mother's Day schedule from 2015. The objectives for celebrating Mother's Day were to express precedence to Her Majesty Queen Sirikit on her birthday with specific activities to do so and to encourage children to be grateful for their mothers. Likewise, according to Chanhom (HT3), at Cherry Blossom Service they arrange:

Special activities to extend best wishes to His Majesty King
Bhumibol Adulyadej and Her Majesty Queen Sirikit on their
birthdays. (January 28, 2016)

Jandee (HT5) from Jamesia Service also stated that important Thai dates were significant for promoting Thai culture and identity:

Children are encouraged to participate in activities for Father's Day and Mother's Day. This is an important way to pay respect to parents and extend best wishes to His Majesty King Bhumibol Adulyadej and Her Majesty Queen Sirikit on their birthdays. (February 9, 2016)

In addition to giving precedence to the King and Queen, six of the eight services invited children's fathers/mothers to participate in Father's Day and Mother's Day activities. The interview data indicated that children were encouraged to pay respect to their parents and make small gifts for them. By way of example, at Daffodil Service Darunee (HT4) explained that:

Children make cards or some other presents for their parents. We also invite their parents to participate in the service's activities. Children pay respect to their parents by performing Kraab and give them garlands to express their gratitude. (February 4, 2016) 
Fangkhaw (HT6) also described how Foxglove Service celebrated Father's Day and Mother's Day:

We explain why these two days are important. We usually encourage children to bring photographs (of their parents and themselves) and participate in a photo competition organised at the service. (February 15, 2016)

At Anemone Service, however, the head teacher Anyamanee (HT1) explained that parents were not invited to participate in the activities, expressing gratitude as they had concerns about those children "who did not live with their parents, had no parents, or lived with their grandmothers or other relatives" (December 8, 2015). She further commented:

Children are not happy at all if they see others are with their parents, while they have no one there for them. This seems to have a negative impact on children's feelings. (December 8, 2015)

Likewise, at Cherry Blossom Service, Chanhom (HT3) stated that:

We do not invite children's parents to participate in an expressing gratitude activity where their children pay respect to their parents by performing Kraab and giving them garlands. This can make children feel sad. (January 28, 2016)

\section{Early Childhood Teachers}

Q. 4 "What activities do you usually plan for Father's Day and Mother's Day?"

The data revealed that four of the eight services promoted Father's Day and Mother's Day through other activities as well. For instance, at Anemone Service children also created small gifts for their parents. Anchalee (T1) noted:

Children paint on old t-shirts from their mums and dads and then give them back to them as gifts. (December 18, 2015) 
At Daffodil Service, Duangkamon (T4) commented that children made little cards for their parents and participated in an activity to express gratitude. One of the early childhood teachers from Primrose Service, Prannapha (T2), said that for Father's Day:

Children are encouraged to view the King as a role model and to lead their lives by learning from his Royal duties and sacrifice for the country. Children are taught to do good things as a way to cherish the Royal Highnesses. (January 29, 2016)

At another service, Kalmia, Kanda (T7) mentioned that:

Children use record books to make their own list of the activities they would like to do for their parents. (February 18, 2016)

Other important Thai dates include Teacher Appreciation Day and services' annual celebrations. Five of the eight services promoted children's participation and learning about Thai culture and identity when celebrating these. For Teacher Appreciation Day, Principals Parkpoom (P2) and Kanyakorn (HT7) from Primrose and Kalmai Services respectively, and both early childhood teachers from Jamesia Service mentioned that they organised activities to encourage children to pay respect to their early childhood teachers and to feel grateful for what early childhood teachers do for them. By way of illustration, Kanyakorn (HT7) explained:

We have many activities at Kalmia Service to promote Thai culture and identity. For example, Teacher Appreciation Day (in Thai: Wai Kru ceremony). Children pay respect and express their gratitude to their teachers. (February 17, 2016)

In relation to services' annual celebrations, two of the eight services mentioned how children were taught about Thai culture and identity. For instance, Vice-Principal Danai (P4) remarked that at Daffodil Service:

Children are involved in a food offering to Buddhist monks in the morning (as they are fasting in the afternoon). (February 4, 2016)

while Chanhom (HT3) from Cherry Blossom Service explained: 
Children are involved in the service's activities, for example, listening to the Buddha's doctrines (in Thai: Dhamma) and learning about traditional Thai ways of living from visiting the countryside. (January 28, 2016)

Early childhood teachers from the same service also stated that children were encouraged to participate in activities in order to promote Thai culture and identity on their service's annual celebration day.

\section{Parents}

Q.5 "What is a recent activity you have participated in and when was it?"

Regarding promoting important Thai dates, parents indicated that they were involved in activities associated with these at their children's services. For example, Pinyo ( $\operatorname{Pr} 2)$ from Primrose Service revealed:

I participate in Chinese New Year celebration (see Appendix A), which the service usually organises each year. (January 29, 2016)

Another parent at Cherry Blossom Service, Chaat (Pr3), stated that he recently attended the service's New Year and Christmas party while Chanikarn (Pr3), from the same service, outlined her role during Sport Day: "I cooked some food to support this event" (February 9, 2016). Similarly, one of the parents at Jamesia Service, Jintana (Pr5), noted "I participated in the Sport Day as a supporter" (February 9, 2016).

In summary, Father's Day and Mother's Day were two significant dates which the services all celebrated. However, two of the services, Anemone and Cherry Blossom, did not invite children's fathers and mothers to participate in the activities associated with these two public holidays. Other important dates were also celebrated at the services with specific activities to promote Thai culture and identity with young children.

\subsection{Thai Folk Wisdom}

Folk Wisdom includes Thai language, traditional costumes, and learning about Thai food and desserts. and folk play. In this section Thai language is presented first 
followed by traditional Thai costumes. The other aspects of Thai folk wisdom are then discussed.

\subsubsection{Thai Language}

Four of the eight services said that they encouraged children to use correct Thai language. By way of example, Principal Apinya (P1) from Anemone Service stated:

Thainess also refers to our unique Thai language. We teach children to use the Thai language correctly and understand the true meaning of Thai words. (December 8, 2015)

Another Principal, Parkpoom (P2), from Primrose Service pointed out that Thai body language was another way to express Thai culture and identity while mentioning Thai language:

We should start with a smile. Thai people have a unique expression of the Siam smile (in Thai: Yim Siam). Moreover, children should use the Thai language correctly. (January 26, 2016)

The head teacher, from Jamesia Service, Jandee (HT5), also commented that "children should speak the Thai language clearly and correctly" (February 9, 2016).

None of the early childhood teachers mentioned anything about the Thai language. However, two of the parents claimed that it was important that their children could speak the Thai language very clearly. One of the parents from Cherry Blossom Service, Chanikarn $(\operatorname{Pr} 3)$, pointed out:

I always encouraged my child to speak Thai as their first language as they are both half Thai. (December 8, 2015)

while Jaruwan (Pr5), from Jamesia Service, said:

I use Thai names for my child, for example, Ton Rak (which means a crown flower). (February 9, 2016)

The correct use of the Thai language was commented on by four of the eight services and for one of the principals this was closely linked to Thainess. 


\subsubsection{Traditional Thai Costumes}

Six of the eight services indicated that they promoted the wearing of traditional Thai costumes during the Loy Kratong festival. By way of example, Principal Chanin (P3) commented:

Cherry Blossom Service has a traditional Thai costume competition during the Loy Kratong festival. (December 8, 2015)

According to Vice-Principal Fahprataan (P6):

Children dress up in traditional Thai costumes at Foxglove Service and participate in the best costume competition held during the Loy Kratong festival. (February 15, 2016)

The head teacher from the same service, Fangkhaw (HT6), commented:

We encourage children to perform traditional Thai dances and sing the Loy Kratong song during this festival. (February 15, 2016)

At Primrose Service this was also promoted. Pannee (HT2) stated that:

Our teachers encourage children to wear traditional Thai costumes, perform traditional Thai dances on a stage, and sing the Loy Kratong song during the Loy Kratong festival. (February 4, 2016)

This was mentioned as well by Sutana (HT8). At Sunflower Service she said that children were encouraged to wear traditional Thai costumes and participate in a costume competition during the festival. One of the parents from another service, Cherry Blossom, Chanjira (Pr3), commented on this too:

I always encourage my child to dress up in traditional Thai costumes for the Loy Kratong festival. (February 9, 2016)

The Principal of Anemone Service, Apinya (P1), explained that traditional Thai costumes could promote Thai culture and identity because they reflect the local community's culture. 
In addition to promoting the wearing of traditional Thai costumes during the Loy Kratong festival, the services revealed that they also encouraged this on other important dates. Vice-Principal Danai (P4) from Daffodil Service noted that:

Children perform traditional Thai dances on a stage by dressing up in traditional Thai costumes during the service's annual celebration. (February 4, 2016)

One of the early childhood teachers from Primrose Service, Pinyo (T2), indicated that the wearing of traditional Thai costumes was encouraged along with a traditional Thai dance "performed on a stage" on Father's Day and Mother's Day (January 29, 2016). At Cherry Blossom Service, Chitchan (T3) mentioned that their service fostered the wearing of traditional Thai costumes through:

A Thai masked play performance (in Thai: Khon) enacted and dressed up in characters of stories from the Ramakian. (January 28, 2016)

The wearing of traditional Thai costumes was encouraged at other times. By way of example, at Jamesia Service, Jandee (HT5) explained that "their service encouraged teachers and children to wear traditional Thai costumes every Friday" (February 9, 2016). An early childhood teacher from the same service, Jaruwan (T5), further noted:

We encourage children to dress up in traditional Thai costumes through role-play activity. There will be some outfits available for them to try on. Some children bring their own costumes from home. (February 9, 2016)

One of the parents from Anemone Service, Apirak (Pr1), articulated that "the best activity to express Thainess is to encourage children to wear traditional Thai costumes" (January 29, 2016).

In summary, the services encouraged children to wear traditional Thai costumes during the Loy Kratong festival, and on other special occasions. For some this was promoted weekly and during role-play periods. 


\subsubsection{Thai Food, Desserts, and Folk Play}

The interview data showed that three out of the eight services served traditional Thai food and dessert as part of their daily programme. Anyamanee (HT1) mentioned that "at Anemone Service we always serve Thai food and dessert" (December 8, 2015). Another head teacher from Jamesia Service, Jandee (HT5), stated that they regularly provided Thai dessert during lunchtime:

We always encourage children to eat Thai dessert, for example, steamed banana cake and banana in coconut milk. (February 9, 2016)

Thai dessert eaten in the old days was made by steaming and using coconut milk as the main ingredient, and it is still similar today. One of the early childhood teachers from the same service, Jaruwan (T5), added that "children were also encouraged to eat Thai food" (February 9, 2016). According to one parent from Cherry Blossom Service, Chanjira (Pr3), said that children at their service were persuaded:

To eat banana candies instead of chewing gum as it gives the same texture and it is Thai candy. They also eat banana chips instead of potato chips because it is healthier. (February 9, 2016)

Another parent from Kalmia Service, Kingkarn (Pr7), remarked too that they encouraged children to eat Thai food. It appeared, therefore, that services promoted Thai culture and identity through eating traditional Thai food and dessert.

In relation to Thai folk play, five of the eight services organised activities for children to learn about traditional games. For example, the head teacher at Sunflower Service, Sutana (HT8), stated they promoted Thai folk play during an outdoor activity, which is one of the six main activities of the Manual of the 2003 Early Childhood Curriculum (Ministry of Education, 2003c):

Children have a session of playing traditional Thai games outside the classroom. (February 1, 2016)

Chanhom (HT3), another head teacher, talked about a one-off event they did at Cherry Blossom Service to foster different aspects of Thai culture and identity. She explained they organised the event's activities related to Thai food, costumes, and folk play, 
while at Anemone Service, one of the early childhood teachers, Anchalee (T1), outlined some examples of folk play:

Children are involved in the following folk play: walking on coconut shells, kite flying, tossing and picking pebbles, playing hide and seek, and hiding a cloth behind one's back. (December 8, 2015)

One of the early childhood teachers, Jintana (T5), revealed that at Jamesi Service Thai folk play was promoted during a daily role-play period. A parent, Kingkarn (Pr7), from another service, Kalmia, noted that Thai folk play was another aspect of Thai culture and identity which should be promoted with children. The data revealed, therefore, that the services encouraged children to learn about Thai food and desert and folk play by including these as part of their daily programme.

\subsection{Thai Social Values and Norms}

This section presents the findings from the semi-structured interviews about how Thai social values and norms, which are part of Thai folk wisdom, are promoted at the services. The concept of sharing and gratitude, and the Government's 12 Core Values are regarded as Thai social values. Norms are the practices people in Thai society have been performing for many years, such as participating in the flag ceremony. Thai social values are discussed first.

At Anemone Service Principal Apinya (P1) stated that children should be taught the concept of gratitude in order to understand what they can give back to the country and their parents when they are older:

Thai culture and identity involve children paying respect, valuing and having national pride and gratitude towards the Nation, Religion, the Monarchy, and one's ancestors including parents. (December 8, 2015)

The Principal of Primrose Service, Parkpoom (P2), also talked about how children can express gratitude to their parents:

We tell them not to do anything that their parents would not like, for example, playing video games, and watching TV all the time. Children should do things that their parents prefer and/or tell them 
to do such as doing their homework regularly and paying respect to parents. (January 26, 2016)

Thai people are encouraged to be kind and share with others. The 2003 Early Childhood Curriculum stated that early childhood teachers should encourage children to "share things with others" (Ministry of Education, 2003b, p. 29). The services indicated that they reinforced this. For example, Principal Parkpoom (P2) from Primrose Service mentioned:

Teachers should teach children to share and be kind to others. (January 26, 2016)

Sharing and learning to be kind were also promoted at Cherry Blossom Service through a campaign called 'Voluntary Parents Visiting a Local Community'. Chanhom (HT3) explained that their service had launched this campaign where early childhood teachers, parents, and children worked together to encourage children to share with others and give back to their local communities:

It aims to improve the quality of local people's lives by giving financial support or donating necessities, for example, clothes, food, and medicine. (January 28, 2016)

Likewise, both early childhood teachers from Sunflower Service stated that it is important for children to learn how to share. By way of example, Salinthip (T8) commented:

Teachers encourage children to share toys among their friends. Children also learn how to work together in a group. (March 7, 2016)

As previously mentioned, the 12 Core Values were promulgated by the current Government in 2014 in order to foster children to become good citizens (Farrelly, 2016). During the semi-structured interviews, this was only mentioned by two services as another way of promoting Thai identity. For instance, Principal Chanin (P3) pointed out that at Cherry Blossom Service: 
We integrate these 12 Core Values into our daily teaching practices and design some learning activities to raise awareness of each one. (February 1, 2016)

During her interview the head teacher from Kalmai Service, Kanyakorn (HT7), talked about the 12 Core Values in relation to the Government's role. She stated that "their service takes into consideration these values and encourages children to follow them" (February 17, 2016).

Teaching Thai social values was seen to be another important aspect of Thai folk wisdom. Early childhood teachers encouraged children to be grateful to their parents, to their early childhood teachers, and to the Nation by expressing gratitude through organised activities. Children were supported to learn how to share and work with others. Fostering young children to behave in accordance with the 12 Core Values was only mentioned by two services, Cherry Blossom and Kalmia. Thai norms are discussed next.

\section{Principals}

Q. 4 "How do you teach Thai culture and values to young children?"

When asked this question, the principal of Cherry Blossom Service explained that their service encouraged children to learn about the traditional Thai way of living, which is one of the Thai norms. Chanin (P3) stated:

Sometimes we take children to learn at a temple. They also learn about Thai-style living (of old days) and rice planting at Baan Kru Thanee, including Thai folk play at this place. (January 28, 2016)

Baan Kru Thaneee is a learning centre located in the countryside not far from central Bangkok. Located in Pathumthanee province, the centre offers a wide range of activities for children such as planting rice, riding on buffaloes, planting local vegetables, harvesting local fruits, climbing up coconut trees, and learning about Thai folk play.

Vice-Principal Danai (P4) from Daffodil Service point out that the Thai national anthem and the flag were key components of Thai identity when asked the above question. 
Children are encouraged to learn about the importance of the national anthem and the Thai national flag. They need to stand still with respect when they hear and sing the anthem. (February 4, 2016)

The parent participants were asked the same question as the principles.

\section{Parents}

Q.3 "How do you promote Thai culture and identity with your child (both at home and at the service)?"

The parents from Cherry Blossom Service mentioned Baan Kru Thanee as well. For instance, Chanjira $(\operatorname{Pr} 3)$ commented that "it is a place where children can best learn about the traditional Thai lifestyle" (February 9, 2016). In addition to the learning activities that were available at Baan Kru Thanee, two other parents pointed out that children also learnt about traditional Thai ways of living by visiting other places. One of the parents from Anemone Service, Areeya (Pr1), pointed out:

Teachers take children to local communities in other provinces to learn how to plant and harvest rice, and rice processing. I think it is the best activity to promote Thai culture and identity at this service, as I cannot teach my child to do that. I do not have enough resources to support their learning in this area. (December 18, 2015)

Another parent, Chanikarn (Pr3), whose child attended Cherry Blossom Service, took responsibility to do this herself:

I take my child to the countryside to see how local people live their lives. This includes local markets and getting involved with local things. (February 9, 2016)

Another practice of Thai norms is the activities around the flag ceremony, which relate to the national flag and anthem. The teacher participants were explicitly asked about the Thai national flag. 


\section{Early Childhood Teachers}

Q. 2 "How do you teach children about the Thai national flag?"

Most early childhood teachers stated that they did not have a specific lesson plan for teaching this, but they discussed the importance of the flag with children and explained why everyone stands up to sing the national anthem every morning. For instance, Anchalee (T1) stated that early childhood teachers at Anemone Service always integrated understanding about the Thai national flag into their daily teaching practices:

Children sing the Thai National Anthem every day. We explain to them that this is an important part of Thai identity (the Nation, the Religion, and the Monarchy). The Thai national flag always appeared together with the King's and Queen's flags on the celebrations of their birthdays. (December 18, 2015)

Chitchan (T3) from another service, Cherry Blossom, explained that:

We do not have any particular lesson plans for this topic. We teach and incorporate the Thai national flag as part of our teaching programme. We have pictures of the Thai national flag on the wall in the classroom. We explain to the children the meaning of each stripe and how the flag is important to Thailand. We also tell them what they should do when they hear the Thai National Anthem. This is a way to respect the Nation. (January 28, 2016)

One of the early childhood teachers at Jamesia Service, Jintana (T5), noted the following:

This topic is included in the lesson unit of the Association of Southeast Asian Nations (ASEAN) community; children are taught about the Thai national flag and other countries' flags as well. (February 9, 2016)

The Sunflower Service early childhood teachers commented that when they taught children about the Thai national flag they also introduced a lesson topic about different shapes and colours (of an object), for example, rectangle, square, red, blue, orange, and white. This fits into one of the official curriculum's key learning contents, Things around children (Ministry of Education, 2003b). 
In summary, the services encouraged children to learn traditional Thai ways of living such as rice planting. Teaching children about the Thai national flag was also perceived as being very important.

\subsection{Buddhism}

During the semi-structured interviews, the multiple case study participants discussed how early childhood teachers incorporated Buddhist principles into their teaching practices, which religious dates were celebrated at their services, and which Buddhist practices were routinely observed. The responses from the parents regarding their participation during Visakha Bucha Day were discussed in Chapter 6 so are not included here (see 6.3.4). In this section, the multiple case study participants' responses are presented under two headings: Buddhist principles and Buddhists' practices. Buddhist principles are discussed first.

\subsubsection{Buddhist Principles}

\section{Principals}

Q.5 "Are there any Buddhist principles or Thai concepts taught at your service?"

Seven of the services, with the exception of Jamesia Service, explicitly stated what Buddhist principles were taught to young children. For example, Principal Apinya (P1) pointed out that in addition to the Buddhist principles, early childhood teachers at Anemone Service also incorporated the following:

The Four Divine States of Mind (in Thai: Brahmavihara) consist of loving-kindness, compassion, empathetic joy, and equanimity. (December 8, 2015)

Principal Parkpoom (P2) from Primrose Service stated that their service also incorporated into their daily programme Buddhist principles, but he did not specify which ones. Another Principal, Chanin (P3), referred to the campaigns that their service, Cherry Blossom, encouraged children to participate in as a way to teach them Buddhist principles such as the Peaceful Mind session and the Little Kid Learns Dhamma Camp.

At Daffodil Service Vice-Principal Danai (P4) mentioned: 
Teachers encourage children to learn about the Five Precepts. By doing this, they can realise that they are Buddhist. (February 4, 2016)

The Vice-Principal of Foxglove Service, Fahprataan (P6), likewise, revealed:

Teachers integrate Buddhist principles into daily teaching practices, especially the Five Precepts. (February 15, 2016)

Kanyakorn (HT7) from Kalmia Service and Principal Surasak (P8) from Sunflower Service also indicated that their services taught Dhamma fables and folk tales to their children, in addition to the Five Precepts.

\section{Head teachers}

Q.6 "What Buddhist principles or Thai concepts underpin your teaching practices?"

Two head teachers indicated that their services explicitly incorporated Buddhist principles into their daily teaching practices. By way of illustration, Anyamanee (HT1) explained how Anemone Service modified the Five Precepts so they would be easier for children to understand:

As the service is Buddhist-oriented, we take into account many Buddhist principles. We adjust the Five Precepts to match with children's age-appropriate practices, consisting of the following: do not harm or kill animals, do not steal from others, do not misbehave, do not tell lies or say anything bad, and do not become addicted to things which are bad for one's mind and health. (December 8, 2015)

Moreover, Anyamanee (HT1) also identified three other Buddhist principles they incorporated into their lesson contents and learning activities at their service:

1. The 12 Morality Habits are designed by the service and regarded as the service's main principles. These moral habits involve, for example, not harming others, upholding integrity and being generous and compassionate. 
2. The Four Noble Truths are one of the Buddha's teachings which aims to teach Buddhists to understand how to deal with suffering (this refers to anything that makes a person feel unhappy). The service applies these principles to teach children about things going on around them in the real world.

3. The Four Rules of Effort (in Thai: Phiian 4) consist of: doing good things (behaving themselves), maintaining good actions, abstaining from doing bad things and protecting oneself from bad things/actions. (December 8, 2015)

The Five Precepts were also taught to children at Sunflower Service. Sutana (HT8) indicated:

At this very young age, it is difficult to teach children to understand the Five Precepts. I always teach them to be ashamed when doing something bad/wrong. Teachers keep telling them not to hurt animals, nor take someone else's belongings. (March 3, 2016)

The early childhood teachers were asked the same question as the head teachers.

\section{Early Childhood Teachers}

Q.5 "What Buddhist principles or Thai concepts underpin your teaching practices?"

The early childhood teachers mentioned that their service also incorporated the Five Precepts into their teaching practices. However, Chitchan (T3) revealed that at Cherry Blossom Service they incorporated other Buddhist principles as well:

One of the most common principles is the Five Precepts. We also encourage children to realise the rules of action and its consequence (referred to the Law of Karma). We teach this by asking them to summarise what actions are seen as good or bad. This can help them to analyse problems that can occur each day. (January 29, 2016)

In line with the comments from Vice-Principal Danai (P4), Dawadee (T4) from the same service affirmed:

One of the key Buddhist principles applied in Daffodil Service's classrooms is the Five Precepts. This helps children learn to behave in a correct manner and avoid misbehaving. (February 5, 2016) 
In addition to the Buddhist principles, the services taught moral lessons to children through Thai proverbs and folktales. For example, at Foxglove Service, Vice-Principal Fahprataan (P6) stated:

Our Principal has a strong belief in Buddhism; therefore, she always mentions the Buddha's doctrines and Thai proverbs every time she meets with children whatever the occasion. (February 4, 2016)

Darunee (HT4) mentioned that at Daffodil Service they also taught Thai proverbs to children:

Teachers incorporate Thai proverbs into children's daily life; for example, "as a man sows, so shall he reap" and "keep doing good things and avoid doing bad things." (January 28, 2016)

Similarly, Fangkhaw (HT6) said that at Foxglove Service they incorporated moral lessons in the material taught to children, while Kanyakorn (HT7) from Kalmia Service pointed out:

We like to tell stories from Thai folktales to children. We incorporate Thai proverbs relevant to those tales into our teaching practices. For example, children are taught that carelessness can lead to failure from the Hare and the Tortoise story. (February 17, 2016)

Early childhood teachers were also asked the following:

Q.6 "How do these principles promote children's learning and development?"

Buddhist principles were perceived by the early childhood teachers as assisting children to manage themselves and their actions. For example, Amornrat (T1) stated that at Anemone Service:

Children can manage their emotions and action. They behave appropriately and politely. They know when it is a time to pay attention to teachers or play with friends. (December 18, 2015) 
Another early childhood teacher from Primrose Service, Prannapha (T2), commented that "children also learn how to give, take, and forgive others" (January 29, 2016), while at Cherry Blossom Service, Chadapha (T3) noted that "children behave themselves and respect others. They become calm and kind to others" (January 28, 2016). Likewise, Dawadee (T4) at Daffodil Service suggested that "children avoided doing bad things" (February 5, 2016) whereas Keawkamon (T7) from Kalmia Service explained that through being taught Buddhist principles:

Children will be able to survive in society, understand others, have better social and emotional development, and be able to work in a group. (February 18, 2016)

At Jamesia Service, which is Christian-oriented, early childhood teachers did not incorporate any Buddhist principles, but they did support children to learn other aspects of Thai culture and identity as explained by Jandee (HT5):

We do not teach any Buddhist principles, but we encourage children to learn about important religious dates (see Appendix A). This is because most of the children are Thai and they are growing to be Thai citizens. They need to learn about Thai culture and identity. (February 9, 2016)

One of the early childhood teachers from the same service, Jintana (T5), commented further:

We only talk about the Buddha in the lessons related to the observation of important religious dates. We teach children about the Buddha's life story, but we do not explicitly incorporate any particular Buddhist principles into our teaching practices. (February 9, 2016)

\section{Parents}

Q.3 "How do you promote Thai culture and identity with your child (both at home and at the service)?" 
When answering this question, three of the parents mentioned promoting Buddhists' practices with their children. By way of illustration, Chanjira ( $\operatorname{Pr} 3)$ explained what her child learnt from Cherry Blossom Service and how she supported this:

My child is taught to offer food to monks at the service, including praying to the Buddha, and listening to the Buddha's doctrines. I prepare food for my child for offering to monks. (February 9, 2016)

In summary, Buddhist principles were incorporated into the services' daily teaching practices except at Jamesia Service. How these principles supported children's learning and development were outlined by seven of the services.

\subsubsection{Buddhist Practices}

The eight services were specifically asked how they incorporated Buddhist practices. These findings are presented next.

\section{Principals}

Q.6 "Do you arrange any meditation at the service?"

Seven of the eight services stated that they encouraged children to practise meditation to promote Buddhists' practices. For example, Principal Apinya (P1) said that:

We arrange a meditation practice on every Buddhist Holy Day (see Appendix A) by having Buddhist monks to lead the session. On that day, everyone also offers the monks food and listens to preaching. (December 8, 2015)

Similar to Anemone Service, Principal Chanin (P3) noted that Cherry Blossom Service did the same, stating "it normally takes place once a month" (February 1, 2016). Principal Parkpoom (P2), likewise, mentioned that at Primrose Service early childhood teachers regularly encouraged children to be involved in meditation practice:

We also teach about the importance of observing important religious dates, so children will know what practices Buddhists usually do on those days. For example, on the Buddhist Lent Day (see Appendix A) the service arranges a mocked-up candlelight procession. (January 26, 2016) 
Vice Principal Danai (P4) commented that children practised meditation every morning at Daffodil Service and they were taught how Thai people usually observe important religious dates:

As our school is attached to a temple, children are taught a lot from the temple. For example, they walk with lighted candles held in their hands to observe important religious dates. Teachers also encouraged children to pray to the Buddha and learn about the Buddha's doctrines at our Dhamma Camp. (February 4, 2016)

At Dhamma Camp children are involved in the following religious activities: practising meditation, praying to the Buddha, and listening to the preaching of Buddha's teachings.

According to Vice Principal Fahprataan (P6), Foxglove Service also promoted meditation:

We encourage children to do meditation every morning. Children tend to be calmer and more disciplined after practising meditation. This also supports their mindfulness. (February 15, 2016)

Kanyakorn (HT7) also commented that children at Kalmia Service were encouraged to practise meditation in the afternoon while Principal Surasak (P8) from Sunflower Service pointed out that:

We usually practise meditation every Tuesday. The day starts with Buddhist monks giving a sermon, and they encourage everyone to practise meditation. We also do this before starting the afternoon session. This helps children focus on their afternoon lessons. (March 3, 2016)

At the seven services, children were encouraged to practise meditation.

Another question posed to principals was:

Q.7 "Do you organise any fieldtrips to visit a temple?" 
Four of the eight services indicated that they organised trips to temples. For instance, Vice Principal Fahprataan (P6) from Foxglove Service mentioned:

Children sometimes visit and learn from a nearby temple. We encourage their parents to take them to a temple when observing important religious dates. (February 15, 2016)

Like Foxglove Service, Principal Surasak (P8) explained that at Sunflower Service:

It is slightly difficult to organise a fieldtrip visiting a temple for this group of children. On important religious dates (see Appendix A), we encourage them to walk with lighted candles held in their hands around the Buddha image at the service. Then, we communicate to parents via our newsletter asking them to take their children to a temple for a real experience. On Tuesdays, children pray to the Buddha by using Bali language. (March 3, 2016)

At Jamesia Service, Jandee (HT5) indicated that their service did not take children on field trips to visit a temple. Their service did, however, use the Project Approach in their teaching and for children who share the same interests in learning about any specific topics, their early childhood teachers together with parents took them to experience such things on a weekend (February 9, 2016). The Project Approach was also used for teaching children at Kalmia Service. Kanyakorn (HT7) said their service promoted Buddhist practices through this approach and "if children would like to learn about a Buddhist monk's routine, we organise a fieldtrip visiting a temple for them" (January 26, 2016).

In addition, the data showed that two of the eight services said that they encouraged children who attend their service when visiting a temple to also learn about the artworks that they contain. By way of example, at Daffodil Service Vice Principal Danai (P4) stated:

We do not only take children to visit a temple, but we also encourage them to learn about artworks and sculptures inside a central sanctuary hall in a temple, including the Temple of Emerald Buddha (see 2.7.6). Thai arts are also fascinating. (February 4, 2016) 
Artworks, sculptures, and drawings in a temple usually illustrate the story of the Buddha and Thai folktales. Principal Chanin (P3) indicated too that when the children at Cherry Blossom Service visit a temple they learn as well about "those artworks and sculptures in the central sanctuary hall" (February 1, 2016).

Head teachers were also asked the same question as the principals.

\section{Head teachers}

Q.7 "Do you organise any fieldtrips to visit a temple?"

The data revealed that the majority of services encouraged children to visit a temple and did promote Buddhist practices in various ways. By way of example, Anyamanee (HT1) claimed that at Anemone Service:

Children occasionally visit a temple to observe important religious dates. We invite Buddhist monks to our service to observe important religious dates. Children experience how to offer food to monks and attend a session listening to the Buddha's doctrines. (December 8, 2015)

Similarly, Pannee (HT2) stated that at Primrose Service children were encouraged to be involved in Buddhist practices:

We occasionally organise a fieldtrip to a temple. Our teachers inform children about appropriate clothing for visiting a temple. We encourage children to practise meditation; pray to the Buddha; offer food to Buddhist monks and pay respect to them (by performing Kraab). (January 26, 2016)

Sutana (HT8) indicated, in line with Pannee (HT2)'s comments that at Sunflower Service early childhood teachers occasionally organised a fieldtrip visiting a temple but still promoted Buddhis practices:

We encourage children to pray to the Buddha and pay respect to Buddhist monks. Most of the time we take children outside the service, we may stop by any temple within that area. However, I think we should take children to visit a temple every Friday. (March $8,2016)$ 
Likewise, at Cherry Blossom Service, Chanhom (HT3) stated that children had a chance to visit a temple when they were going on a trip visiting a local community with early childhood teachers and parents:

The trip aims to improve the living quality of locals. We donate necessary things (i.e., clothes, food, and medicine), including money. Children have a chance to visit a temple within a community. (January 28, 2016)

At Daffodil Service, Darunee (HT4) noted that they did not go on a fieldtrip to visit a temple. Instead "we only encourage children to learn about and practise religious activities at the service and a nearby temple" (February 4, 2016). The head teacher at Foxglove Service, Fangkhaw (HT6), also said that they did not organise trips to a temple:

Children rarely visit a temple; they only learn about Buddhists' practices from their experiences when participating in the service's activities. (February 15, 2016)

The principals and head teachers occasionally took children to visit a temple. Some services did this when observing important religious dates, while for some others this was linked to the Project Approach.

Early childhood teachers were also asked a similar question to the principals regarding meditation.

\section{Early Childhood Teachers}

Q.7 "Do you arrange any meditation at the service and how does this promote children's learning?"

The early childhood teachers from the eight services responded that they did meditation with the children. For example, Amornrat (T1) stated:

Anemone Service encourages children to do meditation as well as other Buddhist practices, including praying to the Buddha, listening to preaching, learning about the Buddha's life story, and incorporating Buddha's doctrines into their daily-life practices. (December 18, 2015) 
An early childhood teacher from another service, Primrose, Prannapha (T2) outlined the benefits she believed came from children doing meditation:

Practicing meditation helps children to have more patience. Children can also control their mind to be calm and peaceful. (January 29, 2016)

Chitchan (T3) stated that at Cherry Blossom Service they incorporated various practices to promote Buddhist ways:

Children pray to the Buddha every day and join a big praying event with primary students every Thursday. They offer food to Buddhist monks once a week. On a monthly basis, they listen to preaching (Dhamma). (January 28, 2016)

Another early childhood teacher from the same service, Chadapha (T3), affirmed that: “during meditation practice children also learn about the Buddha's doctrines (in Thai: Dhamma)" (January 28, 2016). Similarly, Keawkamon (T7) noted that at Kalmia Service:

We encourage children to do at least one meditation session each day. They are also taught how to pray to the Buddha and to chant a loving-kindness (in Thai: Metta) blessing for all beings to be well and happy. (February 19, 2016)

Another early childhood teacher from the same service, Kanda (T7), stated that "meditation enhances children's social and emotional development. This supports children to have a longer concentration and be able to work in a group" (February 18, 2016). Likewise, Somjai (T8) from Sunflower Service also remarked that:

Meditation helps children increase their concentration and supports them to focus on learning activities. (March 4, 2016)

On the other hand, Jeerapa (T5) from Jamesia Service stated that their service did encourage children to practise meditation but for a specific purpose: 
We do encourage children to do meditation but not for the purpose of gaining merit. We ask them to meditate in order to increase children's concentration. (February 9, 2016)

All eight services encouraged children to practise meditation but at Jamesia Service this was not aligned to Buddhist practices. In the next section data from the parent interviews that related to Buddhist practices are presented.

\section{Parents}

Q.3 "How do you promote Thai culture and identity with your child (both at home and at the service)?"

When parents were asked this question, they referred to Buddhist practices. For example, one of the parents who was from Daffodil Service, Duangjai (Pr4), talked about food offering. In particular she said:

I encouraged children to do food offering at a temple near the service. (February 5, 2016)

One of the parents from Sunflower Service, Supatcha (Pr8), discussed how she promoted Buddhist practices with her child:

I am a Buddhist; I encourage children to visit a temple and pray to the Buddha on a regular basis. (March 7, 2016)

In summary, Buddhists' practices were another aspect of Thai culture and identity taught to children. At two of the services, children also learnt about artworks in a temple.

\subsection{Chapter Summary}

This chapter identified how the eight services promoted five main aspects of Thai culture and identity. The first aspect was Thai manners, especially the practice of Wai, that were perceived to be the important way to express Thainess. A second aspect was the celebration of Thai traditions. The services encouraged children to be engaged with cultural activities and practices associated with festivals and important dates. 
A third aspect was Thai folk wisdom. The services promoted this through different activities, including the correct use of the Thai language, and the wearing of traditional Thai costumes. The fourth aspect was Thai social values and norms. By promoting these, the services taught children the traditional Thai ways of living and the importance of the national flag. Buddhism was the fifth aspect and how this was promoted with children through Buddhist principles and practices was discussed.

The next chapter outlines the five themes of the key cultural activities that enable children to learn about Thai culture and identity. 


\section{CHAPTER 8 \\ DISCUSSION}

The aim of this study was to examine how Thai culture and identity are addressed in Thailand's 2003 Early Childhood Curriculum (Ministry of Education, 2003b). The following research questions were posed:

1. What activities and practices do early childhood services implement to promote Thai culture and identity with young children?

2. How do early childhood services perceive the roles of the Government in promoting Thai culture and identity with young children?

3. How do early childhood services view parents' roles in promoting Thai culture and identity with young children, and how do parents perceive their roles?

To answer these questions, this research employed a survey involving 34 early childhood services and a multiple case study including eight services in two districts of central Bangkok - Klongtoey and Wattana. A total of 235 responses were received from the survey, while the multiple case study involved 46 participants representing four different roles, which included principals, head teachers, early childhood teachers, and parents. The findings showed how the participants perceived they integrated Thai culture and identity in their programmes when implementing the 2003 Early Childhood Curriculum despite the general avoidance of culture in this developmentally based Thai curriculum (Ministry of Education, 2003a,b).

The survey results and multiple case study findings are presented in the previous three chapters. These findings revealed that all the 34 survey services integrated Thai culture and identity by including a wide range of cultural activities and practices in their programmes. Similar results were found for the eight services involved in the multiple case study which also promoted aspects of Thai culture and identity for children through everyday activities and practices. This chapter discusses and critiques how the activities and practices explored in this study mediated the cultivation of Thainess for children attending early childhood services in Thailand (Vygotsky, 1978; Wartofsky, 1979). This psychological blend of culture and identity is also referred to as Thainess (Connors, 2005; Klibthong, 2013; Malikhao, 2017; Meesuk, 2017). 
Despite relying on the 2003 Early Childhood Curriculum guidelines, the findings indicated that the services did integrate Thai culture and identity in their programmes (Ministry of Education, 2003a,b). Although the developmentally based curriculum document did not provide any guidelines for early childhood teachers in this area, the five key principles of the 2003 Early Childhood Curriculum clearly indicated that this was important (Ministry of Education, 2003a,b). One of the principles, for example, stated that early childhood teachers should care for and educate young children taking into consideration their individual differences and their way of life within the context of their local community, society, and Thai culture. Moreover, the curriculum also specified that teachers need to guide children's development "with the whole child concept through play and age-appropriate activities" (Ministry of Education, 2003b, p. 4, italics in the original). These principles therefore were taken into consideration.

The Government also has a significant role in Thailand's early childhood provision. With the aim of cultivating Thainess in young children, the Government has explicitly stated this in official documents (i.e. the Constitution of the Kingdom of Thailand and the 1999 National Education Act, revised in 2010) and the 2017 Early Childhood Curriculum (Ministry of Education, 2017a; Office of the Council of State, 2017; Office of the National Education Commission, 2010). The Government's intention for the curriculum, likewise, was to strengthen the relationships among families, communities, and early childhood services in relation to children's development (Rogoff, 2003; Williams, 1999). According to Williams, when applying this developmental type of curriculum, early childhood teachers should also design teaching materials and activities based on children's interests and development. As already stated, the curriculum did not provide guidance in this area, although the Manual of the 2003 Early Childhood Curriculum did provide detailed age-appropriate guidance for young children's developmental domains (Ministry of Education, 2003a,b,c).

Nevertheless, the curriculum and the accompanying Manual did not provide any specific guidelines or examples of learning activities to promote young children's learning about Thai culture and identity. These curriculum documents did not identify what aspects of Thai culture and identity early childhood services should take into consideration when implementing the 2003 Early Childhood Curriculum (Ministry of Education, 2003b). According to McLachlan et al. (2018), a curriculum also draws on 
a government's aspiration. This study highlights significant misalignments in curriculum implementation between the written goals and text of the early childhood education curriculum documents (Ministry of Education, 2003a,b,c), the Government's overarching cultural aspiration that Thai citizens, including children, demonstrate Thainess (Connors, 2005; Jamjuree, 2017; Traitongyoo, 2008), and the services' teaching practices in promoting Thai culture and identity with young children.

The 2003 Early Childhood Curriculum explicitly provided age-related characteristics for children's developmental age in physical, emotional, social, and cognitive domains (Ministry of Education, 2003b). Tongthaworn (2003) has also pointed out that the learning activities and experiences addressed in this official Thai curriculum reflect understandings of learning activities based on Piaget's constructivist theory. The curriculum employed a child-centred approach taking into account children's individual differences and ages, but generally avoided their social and cultural context, similar to developmentally appropriate practice (NAEYC, 2009). The official Thai early childhood curriculum emphasised the provision of experiences as well as the whole child concept, so it could also be regarded as a progressive curriculum with early childhood teachers adding learning experiences based on cultural values and reflecting the context of a child's learning environment (Saracho \& Spodek, 2002; Tanner \& Tanner, 2007). The early childhood teachers in this study did emphasise and add cultural activities and practices to the curriculum programme while also following its developmentally based approach.

The five key themes presented in the previous chapter demonstrated how the cultivation of Thai culture and identity was practised through everyday cultural activities in early childhood services. They included Thai manners, traditions, folk wisdom, social values and norms, and Buddhism. These themes are critically interpreted and discussed in this chapter in relation to the overarching research questions. This interpretive process further highlights implicit misalignments in the curriculum around the promotion of Thai culture and identity with young children attending early childhood services. Within the themes, the cultural activities and practices identified and analysed from the gathered data of both the survey and multiple case study are discussed in order to answer the study's three research questions. Overall, the eight services perceived that they played an important role in promoting culture and identity with young children. However, a small number of 
participants also argued that they needed more support from the Government and parents in particular aspects, such as promoting Thai manners and wearing traditional Thai costumes.

In the next section, cultural practices regarding Thai manners are discussed.

\subsection{Thai Manners}

Wai and Kraab were promoted as everyday practices at the early childhood services. These traditional "posing and gesturing" practices mediated children learning Thai culture and identity with their bodies (Trevarthen, 1998, p. 88). The eight services involved in the multiple case study all stated that they actively encouraged the practices of Wai and Kraab. One of the principals from Primrose Service, Parkpoom (P2), stated that in his opinion Wai is the best way to express Thainess. The services also encouraged children to perform Kraab as a way of expressing gratitude on Father's Day and Mother's Day.

In Chapter 2 these two practices were described; however, this study revealed that the services promoted only two levels of Wai but both types of Kraab. None of the services mentioned the third level of Wai, which is used to pay respect to people of the same age. It is possible that children were not explicitly taught to Wai to one another, which could explain why the third level of Wai was not referred to by any of the early childhood teachers or parents from the eight services. The practices of learning both types of Kraab were promoted at all eight services. Kraab and Wai may also be interpreted as mediating cultural artefacts. Kraab mediated children learning the concept of gratitude, which is considered an important Thai social value (Wartofsky, 1979). The majority of the survey respondents (91.4\%) also indicated that always in their daily teaching they encouraged children to perform Kraab and Wai.

In addition to Thai body language expressed in greeting gestures, the Thaistyled smile is also regarded as an important aspect of facial expression. Primrose Service's principal was the only one who mentioned this. He said that a Thai-styled smile (in Thai: Yim Siam) was widely used among Thai people and it was promoted with the young children at their service. Yim means smile and Siam was the former name of Thailand. Thailand is also known as the Land of Smile. This phrase "is often used to promote Thai social harmony" (Knutson, 2004, p. 151). This reflects "the disposition and culture of its people who are generally easy-going, hospitable, and 
friendly" (Browell, 2000, p. 109). Cultivating this cultural posing with young children could also promote characteristics of Thainess (Meesuk, 2017).

In the 2003 Early Childhood Curriculum (Thai version) "the gestures of Wai and paying respect" were included in the section on children's age-related characteristics for their social development (Ministry of Education, 2003a, p, 29). Interestingly, this was not included in the English version of the curriculum. The 2003 Early Childhood Curriculum (English version) did mention, however, that children should "show respect when meeting adults" (Ministry of Education, 2003b, p. 30). Wai is stated in the Thai version of the curriculum, while Kraab is not. This study suggests that Kraab is another unique gesture which can support the cultivation of Thainess. This aligns with Pinyoanuntapong (2013b) findings which inferred that Thai manners are significant in promoting Thai culture and identity.

The Government has an important role in promoting Wai and Kraab, which are regarded as intangible aspects of Thai culture and identity (Ministry of Culture, 2009). In 2003 there were no official regulations on how to perform Wai and Kraab. However, in 2010 the Government issued a book on Thai Manners which provides guidelines for these cultural practices, including other polite gestures and etiquette (Department of Cultural Promotion, 2010a). The Government's input shows the importance of Thai manners. This study highlights that Thai manners are a way of mediating Thai culture and identity and the cultivation of Thainess in young children. Two survey respondents $(0.4 \%)$ did suggest that the Government should include Thai manners as one of the curriculum's learning contents.

Children's parents also encouraged their children to perform Wai as an everyday practice. This was mentioned as well by most of the services in the multiple case study. In contrast to other services, the parents at Foxglove Service were perceived as not encouraging their children to perform Wai, but their early childhood teachers did. At this service the early childhood teachers stated that they expected more support from parents. Foxglove Service is located in the slum area of Klongtoey district. Many of the parents were manual labour workers on low incomes. During the interviews, children's parents at this service admitted that their participation was limited due to their work commitments. The head teacher from a different service noted too that the lack of car parks was another limitation to parents' participation. A large number of survey respondents $(77 \%)$ indicated that parents always encouraged children to perform Wai practices, while $11.6 \%$ of the respondents suggested that 
parents should also encourage children to have good manners, including performing Wai and Kraab.

These everyday cultural practices are the essential ways that mediate children learning their cultural and national identity, including expressing Thainess (Rogoff, 2003; Wartofsky, 1979). This was recognised to varying degrees by all the multiple case study participants and survey respondents.

\subsection{Thai Traditions}

As stated, Thai traditions include festivals and important dates. This section discusses the festivals first, followed by the important dates, the role of the Government, and how children's parents promote these Thai traditions.

\subsubsection{Festivals}

Engaging in cultural activities during the Loy Kratong and Songkran festivals was another way the services promoted Thai traditions that can also be interpreted as mediating children's learning about Thai culture and identity. This is regarded as one of the characteristics of Thainess (Pinthong, 2015). Each region of Thailand celebrates different traditions on different days. The eight services also celebrated these two festivals differently. Five of the eight services encouraged children to be actively engaged with primary artefacts, for example, making and floating a basket and singing the Loy Kratong song (Wartofsky, 1979). The early childhood teachers at Jamesia Service also encouraged children to make a floating basket in their classrooms, but they did not allow them to perform the other festival rituals for religious reasons. At the other two services, Daffodil and Foxglove, children instead attended an actual Loy Kratong festival at a temple where they were involved in floating a basket in the nearby river and singing the Loy Kratong song. It is likely that children attending the celebration of the Loy Kratong festival at a temple would also observe the Thai folk dance (in Thai: Ram Wong). Amongst the survey respondents, 90\% indicated that they always encouraged children to decorate floating baskets during this important festival. Children learned about the festival through their active participation in the ritual and community activities of the festival (Rogoff, 2013; Wartofsky, 1979). These cultural practices could also mediate children using their imaginations in play when celebrating the Loy Kratong festival. 
The Songkran festival is Thailand's most popular festival and it primarily involves parents as it takes place during the school break when early childhood services are closed. Questions related to this festival were not asked in the multiple case study for this reason; however, parents did refer to it. Many of the parent participants mentioned that they took their children to perform a water pouring ritual with their grandparents to mark the occasion of the Thai New Year. This also included their children playing in the activity of water splashing with their "families, neighbourhoods, and communities" (Rogoff, 2013, p. 102).

These two festivals were neither mentioned in the curriculum nor the Manual (Ministry of Education 2003a,b,c). The eight services as well as the parents, however, did refer to both festivals, also pointing out how they encouraged children to be involved in the festival celebrations.

\subsubsection{Important dates}

In addition to the Loy Kratong and Songkran festivals, the eight services also encouraged children to participate in activities associated with other important Thai occasions. The services celebrated Father's Day and Mother's Day, but in different ways. Some of the services put a lot more emphasis on activities when celebrating these two important dates. The cultural activities involved giving precedence to His Majesty the King and Queen of Thailand and organising an expressing gratitude activity as part of the celebrations. The expressing gratitude activity symbolically represents and mediates the concept of gratitude which is regarded as an important Thai social value. However, Anemone and Cherry Blossom Services did not organise any expressing gratitude activity for Father's Day and Mother's Day due to their concerns about children who did not live with their parents being upset. At these services, children instead were encouraged to make small gifts for their parents.

Regarding integrating Thai traditions into teaching practices, the study revealed that many of the survey respondents $(91 \%)$ indicated that they always taught children about Thai traditions and festivals, though not all survey services disclosed any additional information through an open-ended question about these. The majority of the respondents $(93.6 \%)$ revealed that they always did activities related to the King such as drawing the King's picture and narrating a story on the topic of My Beloved 
King on Father's Day. From the survey, the services also integrated these cultural activities and identity through celebrating these Thai traditions.

Although Thai traditions were not referred to as cultural experiences in the 2003 Early Childhood Curriculum, the Manual did provide examples of learning activities to teach one of the learning contents - People and places around children (Ministry of Education, 2003b,c). The Manual explained briefly, and very generally, that children should be aware that as Thai citizens they have a variety of Thai traditions. This view also aligns with the curriculum's principles stating that children should behave in accordance with their local culture and identity. However, these cultural aspirations were not explained in relation to the developmentally based curriculum. Neither the official Thai curriculum, nor its accompanying Manual provided guidelines for teaching Thainess (Ministry of Education, 2003a,b,c).

With regards to the Government's role in promoting Thai traditions, there is no official regulation on this; however, the promotion of traditions is addressed in the 12 Core Values (Farrelly, 2016). The multiple case study participants pointed out that the Government regularly informed them about policies to explain what activities and practices the services should do when observing and celebrating the Loy Kratong festival, Songkran festival, Father's Day, and Mother's Day. Moreover, the last three important events have been formalised as public holidays in Thailand, highlighting the importance the Government places on preserving and cultivating Thai culture and identity for Thai citizens, including young children (Rhein, 2017).

In relation to children's parents, these events helped promote these festivals and other important occasions. The multiple case study services pointed out how parents participated in these cultural activities. When children engaged with their early childhood teachers and parents, they could learn about Thai traditions through their social interactions within their cultural world (Rogoff, 2003; Vygotsky, 1978). This also included when they were involved in cultural activities within the wider community, in the early childhood service, at home and at other community places, such as temples.

Being actively involved in the cultural activities of Thai traditions mediated children's learning about their culture and identity (Rogoff, 2003). Young children's active participation in these cultural activities contributed as well to re-creating and maintaining these traditional celebrations and festivals of Thailand (Rogoff, 2003; Vygotsky, 1978). 


\subsection{Thai Folk Wisdom}

Thai folk wisdom is another aspect of Thai culture and identity. It refers to the expressions of local knowledge of Thai people (Connors, 2005). In this study, two cultural folk wisdom practices are addressed: Thai language and wearing traditional costumes.

\subsubsection{Thai Language}

Using Thai language reflects the nation's identity as it is the official and national language. The Principal from Anemone Service emphasised that Thai language is one of the unique features of Thainess. When I asked how the multiple case study participants integrated Thai culture and identity in their teaching practices, some stated that they encouraged children to learn to speak correct Thai language as part of fostering Thai unique identity.

The 2003 Early Childhood Curriculum explicitly stated that early childhood teachers should provide ways in which children's language can be enhanced, for example, "expressing their feelings in words; listening to stories, rhymes, and poems; and telling their own names" (Ministry of Education, 2003b, p. 32). This developmentally based curriculum emphasised fostering language for communication and thinking rather than learning about Thainess and Thai identity with young children. Pinyoanuntapong (2013b) has also pointed out that the Thai language is one of the learning contents that should be taught to children in order to promote desirable Thai characteristics.

The survey respondents were asked a question about how often children at their service were involved in the activities related to Thai language on the National Thai Language Day. Half of the respondents indicated that they used this day to highlight the importance of the Thai language by encouraging children to value it. This focus on the unique qualities of the Thai language also cultivated national pride amongst children (Pinthong, 2015). The survey respondents did not explain further about any details regarding this important date, apart from seeing the National Thai Language Day as mainly focused on verbal communication.

The Government plays a key role in cultivating Thai culture and identity through the Thai language. National Thai Language Day was formalised in 1999 with the aim of raising awareness of the importance of the Thai language and promoting 
the correct use of it (The Association of Thai Language Teachers of Thailand, 2015). Similarly, children's parents were seen as significant in promoting the Thai language in their children. Apart from the principals and head teachers, seven of the 17 parent participants commented that they encouraged children to learn the Thai language as a way of promoting Thai culture and identity.

In contrast to these responses, the 2003 Early Childhood Curriculum and its Manual did not mention the use of language in relation to culture and identity. The curriculum referred to communication and children's age-related characteristics within the emotional and cognitive development domains, suggesting the provision of key experiences to enhance cognitive development was through using verbal language (Ministry of Education, 2003a,b,c). The curriculum did not mention learning Thai culture and identity through the Thai language (Vygotsky, 1978). While language does relate to children's cognitive development (Catron \& Allen, 2008), it also relates to cultural identity but the official Thai curriculum did not address this area (Vygotsky, 1978).

Another cultural practice that can promote Thai culture and identity is the wearing of traditional Thai costumes. This is discussed in the next section.

\subsubsection{Wearing Costumes}

The wearing of traditional Thai costumes was another significant way that the services promoted children learning about their culture and identity. Wearing these traditional costumes represents Thainess and Thai identity. Early childhood services in this study stated that they encouraged children to wear traditional costumes for both role-play and for ritual performances. One of the early childhood teachers from Jamesia Service, Jaruwan (T5), stated that at their service children were encouraged to dress up in traditional Thai costumes through role-play activities. In this wearing of the costumes, children take on the representation of Thainess in their play and can use their imaginations to experience and play with feelings of Thainess (Bodrova \& Leong, 2015). Thai costumes can also be considered primary artefacts in role-play (Wartofsky, 1979).

Neither the 2003 Early Childhood Curriculum nor its Manual referred to the wearing of traditional Thai costumes; however, they both did mention that role-play should be promoted with young children to enhance their social development (Ministry 
of Education, 2003b,c). More recently, Pinyoanuntapong (2013b) included the wearing of traditional Thai costumes in the curriculum she developed with the aim of fostering desirable Thai characteristics with young children. In line with Pinyoanuntapong (2013b), the services in this study also promoted the wearing of traditional Thai costumes with young children. However, they indicated that the cultural practice of wearing traditional costumes, while not always promoted through role-play, could be done as well through other rituals and performances such as festivals.

The wearing of traditional Thai costumes represented the local culture of different communities (Arphattananon, 2018). It is likely that the families of children in this study came from other areas of Thailand, and traditional costumes vary in different parts of the country. One of the principals in this study affirmed that some children's parents may live in other provinces besides Bangkok or outside a service's area. Each region of Thailand has its unique style of costumes, so wearing traditional Thai costumes at the services could vary, thereby reflecting the diversity in children's family backgrounds.

The services revealed that the Government, and service umbrella organisations, played an important role in promoting the wearing of traditional Thai costumes. The Government's campaigns and policies mentioned by the services included the wearing of traditional Thai costumes every Friday (for early childhood teachers) and the costume competition on Loy Kratong festival (for children). One of the early childhood teachers at Daffodil Service indicated that their umbrella organisation, the EDU BMA, did actively support the wearing of traditional Thai costumes. At Cherry Blossom Service, the Government and their umbrella organisation (the OHEC) funded the Thai Folk Wisdom Centre run by the service and was responsible for the Tiny Khon Tour (see 6.2). Children at this service were encouraged to wear traditional Thai costumes in line with the Khon performance. The occasional alignment of Government and service policies increased the opportunities for children to wear and see traditional Thai costumes.

It was interesting that only one survey respondent suggested the Government should formalise a country-wide practice of wearing traditional attire by establishing a dress code and promoting this for both children and early childhood teachers. Such a policy could further reinforce the wearing of traditional Thai costumes in everyday life to support children learning their culture and identity. When asked how they 
promoted culture and identity, two of the parents from different services referred to the wearing of Thai national costumes.

Being involved in this everyday cultural activity relating to traditional Thai costumes mediates children learning their cultural identity (Rogoff, 2003). Young children's active engagement in these cultural activities contributed to learning Thai folk wisdom and ways of living (Rogoff, 2003; Vygotsky, 1978).

\subsection{Thai Social Values and Norms}

As the Department of Cultural Promotion (2010a) puts it, social values and norms are the other aspects representing Thai culture and identity, including Thainess. The word values can also refer to notions of loyalty, national pride, generosity, and respecting the country (Meesuk, 2017; Pinthong, 2015; Siraj-Blatchford, 1994). Norms involve a way of living and common practices within communities, societies, and throughout the nation (Department of Cultural Promotion, 2010a). The flag ceremony described earlier in this study is a practice which can illuminate the complexities of Thai social values and norms as explained below.

This ritualistic ceremony is performed twice daily at the same time all over Thailand, so it is part of Thai norms and children's everyday experiences. All the children and early childhood teachers at the eight services were required to participate in the flag ceremony. Many of the survey respondents (78.7\%) indicated they encouraged children to learn about the Thai national flag.

Early childhood teachers also taught children about how the Thai national flag and anthem represented Thailand and Thai history. The complex symbolism in the flag and anthem mediated children learning Thainess. Singing of the anthem and standing in a respectful manner is part of the flag raising ceremony. Teaching young children to sing the national anthem alongside raising the flag mediates them to learning Thainess and Thai identity through words and music (Wartofsky, 1979). Children were expected to control their bodies by standing still during the ceremony as a way of showing respect to both the flag and the nation. They could also internalise the importance of the three important pillars that mediated their learning Thai identity, consisting of the nation, religion, and the monarchy. As Traitongyoo (2008) puts it, the notion of Thainess includes the following symbols: the three pillars, national anthem, the (three-coloured) national flag, and the change of the name from Siam to 
Thailand. It is mandatory that all Thai people, including young children, need to observe the flag ceremony twice a day (Traitongyoo, 2008).

The importance of the Thai national flag was further highlighted in the way that all the early childhood services in this study had multiple paintings of the national flag displayed in various sites within their services, including their classrooms. I noticed this when visiting the services to carry out the semi-structured interviews. Utilising Wartofsky's (1979) categories of mediating artefacts, displaying the national flag is a primary artefact, while the activity of raising and lowering the flag becomes a secondary cultural artefact. Being engaged in singing the national anthem and standing still while doing so supports the creation of tertiary artefacts. These artefacts mediated children learning Thai culture and identity in different ways (Wartofsky, 1979).

The 2003 Early Childhood Curriculum did not mention this ritual activity, though the Manual of the 2003 Early Childhood Curriculum did list the activity of the flag ceremony as an example in the daily planning schedule for early childhood programmes (Ministry of Education, 2003b,c). However, these curriculum documents did not discuss the ceremony in light of promoting children's cultural identity or development. This flag ceremony is a common practice, but the activity was not discussed and was not related to children's development and learning.

Regarding Thai social values and norms, it was the Government that played an important role in promoting these social and cultural values and norms through official regulations. The services were required to organise the flag ceremony in order to pay respect to the symbol of Thailand and the Nation (Office of the Prime Minister, 1986). It was interesting that the multiple case study participants did not talk about the Government's role in relation to the flag ceremony and neither did the parent participants, although it is one of the everyday cultural practices the services did encourage children to perform.

The flag ceremony is an everyday cultural activity that mediates children learning Thai culture and identity through active participation in this ceremony. This study suggests that participating in the flag ceremony is one of the ways Thainess is cultivated in early childhood services. 


\subsection{Buddhism}

As stated, Buddhism is the dominant religion of Thailand. According to Thambaworn (2008), the conception of Buddhism can be used to foster children's development and learning in relation to their moral behaviour and spiritual growth with virtue. Two cultural practices are presented here. Incorporating Buddhist principles is discussed first, and this is followed with visiting a temple.

\subsubsection{Incorporating Buddhist Principles}

Buddhism plays a significant role in Thai culture, influencing patterns of beliefs, rites, and morality over many generations. Incorporating Buddhist principles was another way in which practices of the early childhood services mediated children learning Thai culture and identity. The majority of the services claimed that they taught the most common Buddhist principles to children through everyday practices. While 63 percent of the survey respondents indicated that their services always incorporated Buddhist principles into their daily teaching practices, $51.9 \%$ revealed that they always taught children about the Five Precepts (Rules of Morality).

Observing the Five Precepts was also considered to be a way of cultivating morality and the concept of moral shame. In accordance with the Five Precepts, young children in Thailand are explicitly encouraged to act with good intentions, to avoid harmful actions, and to feel ashamed if they behave poorly. According to Thambaworn (2008), early childhood teachers should cultivate the principles of merit and proper behaviour with young children. The head teacher from Sunflower Service pointed out that their service inculcated merit and proper behaviour with children through their behaviour. This could be through the activities children perform in accordance with morality (Gray \& MacBlain, 2012). Fear of wrong-doing expressed as shame (in Thai: Hiri-ottappa) is a significant aspect of Buddhist doctrine in Thailand. Thai proverbs were also taught to young children as a way of promoting Buddhism. One of the most common Thai proverbs, which is also a common biblical proverb, was 'as a man sows, so shall he reap', fitting with the Five Precepts by implying that moral actions too have consequences. All these moral principles can be reflected in the Law of Karma which is considered to be the mainstream of Buddhism (McCargo, 2004).

In contrast to the exclusively Buddhist religions emphasised in seven of the multiple case study services, Jamesia Service also incorporated other religious beliefs 
while encouraging children to learn about the Buddha's life story. This also included teaching the importance and history of important Buddhist religious dates (see Appendix A). As Buddhism is the dominant religion in Thailand, children needed to learn about it, according to the service's teaching staff. The children at Jamesia Service were also taught other religious rites (Ministry of Education, 2003b).

Incorporating Buddhist principles and proverbs into daily teaching practices mediated children learning Thai culture and identity through the meaningful and metaphorical use of words, for instance, the wordings of the Five Precepts and Thai proverbs. Buddhist principles may be understood as mediating artefacts on several levels simultaneously, as both metaphorical and concrete literal artefacts, thereby adding to the complexity of children's learning and development (Rogoff, 2003; Wartofsky, 1979).

The terms Buddhism and Buddhist principles were not explicitly stated in the 2003 Early Childhood Curriculum. Instead, the curriculum referred to children's "religious rites" (Ministry of Education, 2003b, p. 32). Children in each local community may have different religions or beliefs; therefore, the general term of religion was not used in the curriculum. The 2003 Early Childhood Curriculum stated that "cultivating morality and righteousness" was one of the "key experiences enhancing children's emotional development" (Ministry of Education, 2003a, p. 32). Consequently, fostering honesty and kindness through offering young children appropriate key experiences is seen as important. Such key experiences are ways of also incorporating Buddhist principles into teaching practices. According to Pinyoanuntapong (2013b) and Thambaworn (2008), having morality and selfdiscipline and incorporating Buddhist principles is promoted and included in early childhood education provision in Thailand.

When asked about children learning Buddhist principles, it was interesting that only a few of the multiple case study participants mentioned the role of the Government, and none of them referred to the 2003 Early Childhood Curriculum or children's parents in promoting Buddhism for young children (Ministry of Education, 2003b). One of the principals, Apinya (P1), remarked that Anemone Service has been teaching Buddhist principles for more than 10 years and sometimes the Government's policies were outdated. Principal Danai at Daffodil Service referred to the SMART campaign organised by their umbrella organisation, which was under the EDU BMA. Though the principal did not specify Buddhist principles incorporated with the 
SMART campaign, the campaign did aim to foster morality and citizenship with young children. Another principal, Surasak (P8) from Sunflower Service, pointed out that the Government was responsible for providing training manuals related to Buddhism for their early childhood teachers; however, he did not specify any details. Only one early childhood teacher, Prannapha (T2), who taught at Primrose Service, suggested that the content of Buddhism should be included in the curriculum.

This study suggests that incorporating Buddhist principles into daily teaching practices mediates children learning about Thai culture and identity, including cultivating their morality in traditional Thai and Buddhist ways. The Government does take into consideration the diversity of culture and religions of Thai people, including young children. This developmentally based curriculum aimed to cultivate morality and foster children to behave in accordance with their religious beliefs (Ministry of Education, 2003a,b).

Being engaged with the cultural activities of observing Buddhist principles mediated children learning their culture and identity (Rogoff, 2003). Young children's involvement in these can also enhance their Buddhist way of living and practice (Rogoff, 2003; Vygotsky, 1978).

\subsubsection{Visiting a Temple}

Visiting a temple was another explicitly Buddhist practice followed by many of the services in this study. Temple visiting was an everyday Thai cultural practice that mediated children learning about Thai culture and identity. A temple is closely connected with Buddhism (McCargo, 2004). All the multiple case study services encouraged children to visit a temple, but in different ways. Six of the services stated that they regularly took children to visit a temple. The other two services, Jamesia and Kalmia, commented that they encouraged parents to take their children to a temple.

From the researcher's experience, some paintings in a central temple sanctuary tell stories about people's way of living and illustrate the Buddha's teachings. As these are visual images, young children can read these paintings; adults whether parents or early childhood teachers can also engage in discussions of these stories with children. Yet only one of the services explicitly stated that they did this as part of following children's interests by implementing a Project Approach in their curriculum (Cole \& Gajdamaschko, 2007). From these cultural practices, the services provided real-life 
learning experiences with young children in accordance with their interests. When children visited a temple they also learnt about Thai traditional ways of living.

Using Wartofsky's (1978) categories of mediating artefacts, a temple itself is a primary artefact, while the activity of visiting a temple and following set procedures becomes a secondary cultural artefact. The use of imagination and being engaged in performing celebrations and rituals supports the creation of tertiary artefacts. These artefacts mediated children learning about Buddhism and Thai people's traditional ways of living, culture and identity.

The 2003 Early Childhood Curriculum did not mention visiting temples; however, it did state that children should behave in line with their religion and beliefs (Ministry of Education, 2003b). This showed how this cultural practice was highlighted in the curriculum. Nevertheless, the Manual of the 2003 Early Childhood Curriculum did state that visiting a temple, a mosque or a church was a key experience for promoting children's emotional development (Ministry of Education, 2003c). In addition to visiting a temple, the curriculum's Manual also referred to the Buddhist practice of offering food to Buddhist monks as another significant experience for enhancing young children's social development. This practice may also be performed when children visit a temple, as well as practising meditation (Pinthong, 2015).

One-third $(36.6 \%)$ of the survey respondents claimed that they always organised field trips to visit a temple. In regard to the role of the Government in promoting this practice, the participants did not refer to visiting temples during their interviews. In relation to parents' participation, children's parents were viewed as important facilitators who encouraged children to visit a temple during the Songkran festival and on Visakha Bucha Day (see Appendix A). One survey respondent suggested that parents should take children to a temple when observing important religious dates. This reflects that families and communities also played significant roles in promoting children's learning Thai culture and identity (Rogoff, 2013).

Visiting a temple is another cultural practice that mediates children learning Thai culture and identity, especially in relation to Buddhism (Wartofsky, 1979). Additionally, young children's active engagement with this practice enhanced their understandings of Thai ways of living and Buddhist practices. 
The cultural activities and practices discussed in the above sections (8.1-8.5) do mediate the process of learning culture and identity (Cole, 1996; Vygotsky, 1981; Wartofsky, 1979; Wertsch, 1985). The three overlapping levels of mediating artefacts described by Wartofsky help explain how the cultural activities and practices discussed in the findings sections of this study mediated children learning Thai culture and identity. The important cultural artefacts included:

- tangible cultural objects that may all be considered as primary artefacts, for example, the Thai national flag, traditional costumes, and floating baskets;

- verbal and non-verbal communication that can be regarded as both primary and secondary artefacts. This includes Thai language, body language, Buddhist principles, and important songs such as the national anthem and the Loy Kratong song;

- Thai traditions and social values and norms that may be considered as secondary artefacts, for instance Songkran and Loy Kratong festivals, and important Thai dates and ritual activities;

- Thai manners, including body gestures that can represent Thainess such as postures of Wai and Kraab. These can be interpreted as secondary and tertiary level mediating artefacts (Wartofsky 1979). Examples of tertiary artefacts also include the ways in which children use their imagination in role-play when being involved in the cultural activities and festivals; for instance, the activity of wearing traditional Thai costumes in Thai plays.

This section discussed the cultural practices and activities that early childhood services integrated into their daily teaching practices. Next a critique of Thailand's early childhood curriculum, including how Thai culture and identity are addressed in the curriculum, is presented.

\subsection{How Thainess Underpins the Curriculum}

As stated earlier, there are three revisions of Thailand's early childhood curriculum: 1997, 2003, and 2017. These developmentally based curricula outlined the learning contents that Thai children should be taught. The curricula also offered teachers opportunities to independently design their own lesson plans and learning activities by 
considering children's individual differences, interests, and their social and cultural contexts (Ministry of Education, 1997a, 2003a,b, 2017a). These three revisions of the early childhood curriculum are regarded as a progressive curriculum that allows teachers to design guided experience based on Thai cultural values when implementing the curriculum (Tanner \& Tanner, 2007).

This study is based on the 2003 Early Childhood Curriculum (Ministry of Education, 2003a,b). Despite this developmentally based curriculum not providing precise guidelines of how to promote Thai culture and identity with young children, the services did integrate everyday cultural activities and practices in their daily teaching programmes. It is interesting to note that Thailand's first early childhood curriculum in 1997 did in fact include some specific details of Thai culture and identity that should be taught to children. Thai manners, festivals, and important dates were described as key learning contents of the 1997 Pre-Primary Curriculum (Ministry of Education, 1997a). The 2017 Early Childhood Curriculum also provides precise guidelines for early childhood teachers on how to promote Thai culture and identity in young children through their daily teaching practices (Ministry of Education, 2017a). The latest version of the early childhood curriculum addresses the following aspects of Thai culture and identity that should be taken into consideration by early childhood teachers: Thai manners, important dates, symbols of Thailand (can be referred to as the Thai national flag and traditional Thai costumes), and Thai folk wisdom (Ministry of Education, 2017a). Table 7 below provides a comparison between the three different curricula.

Table 7

Comparison of Thailand's early childhood curricula

\begin{tabular}{|c|c|c|c|}
\hline & $\begin{array}{l}\text { The } 1997 \text { Pre-Primary } \\
\text { Curriculum }\end{array}$ & $\begin{array}{l}\text { The } 2003 \text { Early } \\
\text { Childhood Curriculum }\end{array}$ & $\begin{array}{c}\text { The } 2017 \text { Early } \\
\text { Childhood Curriculum }\end{array}$ \\
\hline $\begin{array}{l}\text { Curriculum's } \\
\text { objective }\end{array}$ & \multicolumn{3}{|c|}{$\begin{array}{l}\text { To support children's physical, emotional, social, and cognitive } \\
\text { development as appropriate for their age and individual potential }\end{array}$} \\
\hline $\begin{array}{l}\text { The Government's } \\
\text { aspiration }\end{array}$ & $\begin{array}{l}\text { To provide quality } \\
\text { early childhood } \\
\text { education for all } \\
\text { children throughout the } \\
\text { country. }\end{array}$ & $\begin{array}{l}\text { To provide quality } \\
\text { early education to all } \\
\text { young children } \\
\text { regardless of } \\
\text { geographical and } \\
\text { socio-economical } \\
\text { condition } \\
\text { To encourage children } \\
\text { to grow up to be good } \\
\text { citizens }\end{array}$ & $\begin{array}{l}\text { To support children's } \\
\text { learning and } \\
\text { development in a } \\
\text { changing society } \\
\text { To cultivate children's } \\
\text { morality, self- } \\
\text { responsibility } \\
\text { (including family, } \\
\text { society, community, } \\
\text { and the nation), and }\end{array}$ \\
\hline
\end{tabular}




\begin{tabular}{|c|c|c|c|}
\hline & & & $\begin{array}{l}\text { their awareness of } \\
\text { Thainess }\end{array}$ \\
\hline $\begin{array}{l}\text { Concept of } \\
\text { Thainess }\end{array}$ & $\begin{array}{l}\text { Teach children Thai } \\
\text { manners, festivals, and } \\
\text { important dates }\end{array}$ & $\begin{array}{l}\text { Teach children Thai } \\
\text { manners (Wai and } \\
\text { paying respect to } \\
\text { elders) }\end{array}$ & $\begin{array}{l}\text { Children learn about } \\
\text { Thai manners, } \\
\text { important dates, } \\
\text { symbols of Thailand, } \\
\text { and Thai folk wisdom }\end{array}$ \\
\hline $\begin{array}{l}\text { Precise guidelines } \\
\text { for promoting } \\
\text { Thai culture and } \\
\text { identity }\end{array}$ & $\begin{array}{l}\text { Children should be } \\
\text { taught: } \\
\text { - to be proud of being } \\
\text { Thai citizens; } \\
\text { - to obey their parents } \\
\text { and have good } \\
\text { manners; } \\
\text { - that they and their } \\
\text { friends might have } \\
\text { different religious } \\
\text { beliefs, but every } \\
\text { religion teaches people } \\
\text { to be good citizens; and } \\
\text { - to celebrate festivals, } \\
\text { important dates and } \\
\text { occasions, and } \\
\text { religious dates. }\end{array}$ & $\begin{array}{l}\text { No mention regarding } \\
\text { this in the curriculum }\end{array}$ & $\begin{array}{l}\text { Children need to be } \\
\text { taught: } \\
\text { - to have good manners } \\
\text { and morality; } \\
\text { - about important dates } \\
\text { and occasions, } \\
\text { religious dates, cultural } \\
\text { places in a community, } \\
\text { - significant symbols of } \\
\text { Thailand, Thai folk } \\
\text { wisdom, and to behave } \\
\text { in accordance with } \\
\text { local culture and } \\
\text { Thainess. }\end{array}$ \\
\hline $\begin{array}{l}\text { Teaching cultural } \\
\text { knowledge based } \\
\text { on religion }\end{array}$ & $\begin{array}{l}\text { Children learn about } \\
\text { practices of religious }\end{array}$ & $\begin{array}{l}\text { knowledge throu } \\
\text { nt dates and occa }\end{array}$ & ral activities and \\
\hline
\end{tabular}

The 2003 Early Childhood Curriculum did not include any specific examples of Thai culture and identity that needed to be taught and this posed challenges for some early childhood teachers, especially in terms of promoting Thai culture and identity with young children (Ministry of Education, 2003a,b). It would have been helpful if these cultural concepts had been included in the 2003 Early Childhood Curriculum (Ministry of Education, 2003a,b).

The cultivating and promotion of Thainess is the national objective of the Government and is one of the key factors for Thailand's early childhood curriculum (McLachlan et al., 2013, 2018). This has had a significant impact the development of the recently revised early childhood curriculum (Ministry of Education, 2017a). This is also evident in a number of official documents; for example, the Constitution of the Kingdom of Thailand, the 1999 National Education Act, and the national education plans (Office of the Council of State, 2017; Office of the National Education Commission, 2002, 2009, 2010, 2017). The Constitution states that the Government shall promote and cultivate Thai arts, culture, folk wisdom, and traditions (Office of the Council of State, 2017). 
The Government's aspiration is to promote Thai culture and identity with Thai people, especially young children. The Government of Thailand plays a key role in early childhood education provision in relation to the nation's historical, social, political, and cultural influences (Wood \& Hedge, 2016). The diagram below, Figure 19, shows the official documents that clearly outline where the cultivation of Thainess has been explicitly addressed, with the exception of the 2003 Early Childhood Curriculum (Ministry of Education, 2003a,b). It is the Government's responsibility to address this in policies and regulations. The notion of cultivating Thainess was incorporated in the curriculum's five key principles, but this was not articulated in an explicit manner (Ministry of Education, 2003a,b). 


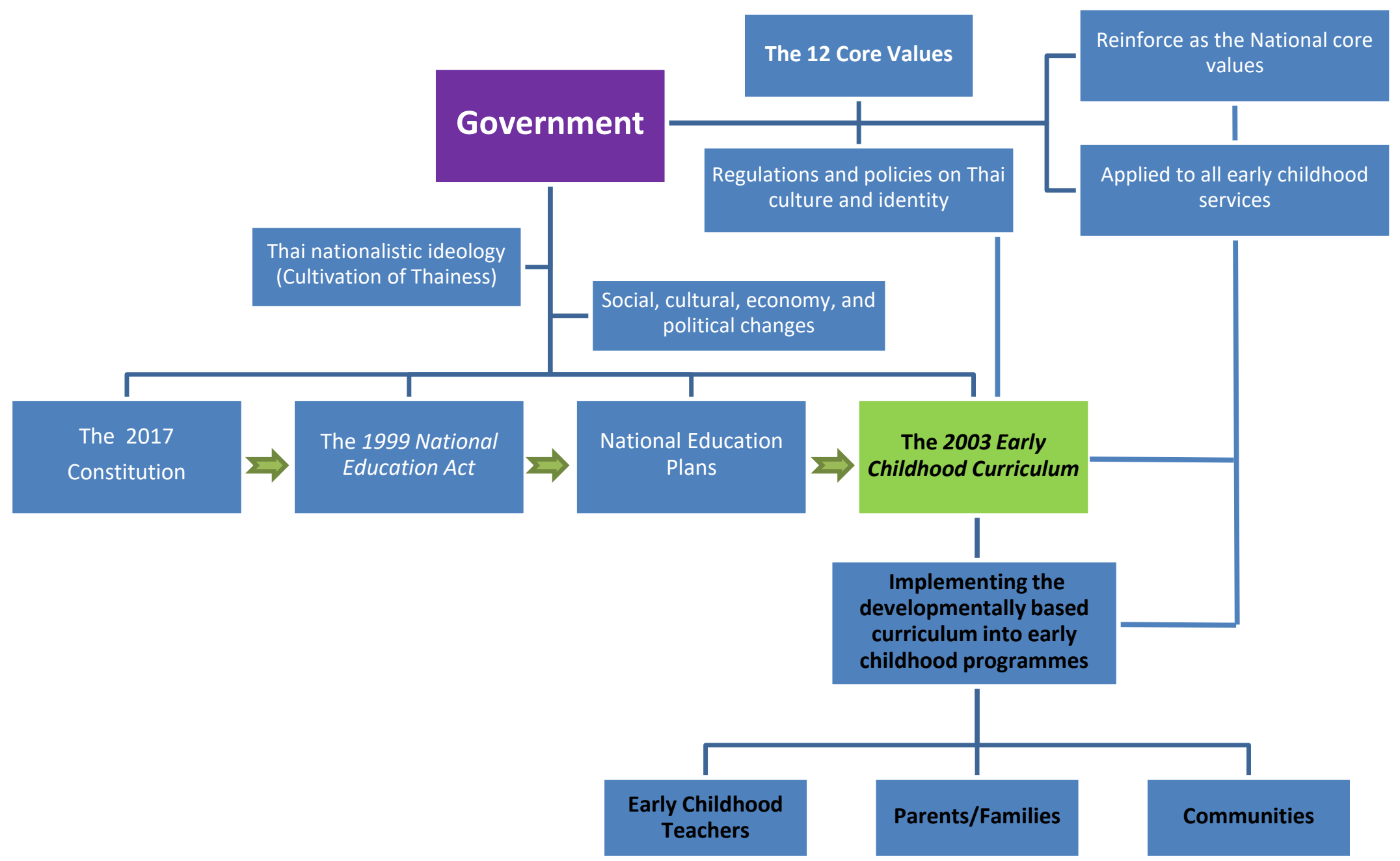

Figure 19. The Government's aspiration regarding the cultivation of Thainess 


\subsection{Thai Government's Role in Early Childhood Service Programmes}

This study showed that the Thai curriculum documents (Ministry of Education, 1997a, 2003a,b,c) played a lesser role than the Thai Government's other official documents in promoting Thai culture and identity and the cultivation of Thainess with young children in Thailand. The Government has a significant role in supporting the promotion of Thai culture and identity for all Thai citizens, including young children (see Figure 19). In addition to the nation's official documents, the Government's promulgated regulations focus on the cultivation of Thainess and citizenship (Department of Cultural Promotion, 2010b; Office of the Council of State, 2017; Office of the National Education Commission, 2010; Office of the Prime Minister, 2018). This is particularly obvious in the regulations regarding Thailand's three key pillars: the nation, religion, and monarchy (Connors, 2005; Farrelly, 2016; Selway, 2007). This was also evident in the classrooms at the early childhood services in this study where the Thai national flag and the portraits of the King and the Queen were displayed. Similarly, most of the survey respondents as well as the multiple case study participants said that they always encouraged children to learn about the three key pillars.

The regulations around the national flag further reflect the Government's promotion of Thai nationalism, including the influences of socio-political changes and capitalist ideas (Connors, 2005; Traitongyoo, 2008; Vella, 1978). The majority of the survey respondents claimed that they taught the Thai national flag to young children. In relation to the national flag, it is mandatory that Thai people, including young children, are involved in the everyday flag ceremony twice daily at the same times throughout the country (Connors, 2005). Being involved in the flag ceremony and singing the national anthem represents a way to be grateful to the Monarchy who made sacrifices for the nation's freedom and independence from colonisation. The flag ceremony was not addressed in the curriculum document, but it is mandated by the Government all over Thailand. Importantly, the flag ceremony also conveys cultural ideas around the importance of the three key pillars through the symbolism of the flag, songs, and words (Wartofsky, 1979).

The celebration of Father's Day, which is referred to as the National Day and King Rama IX's birthday, and Mother's Day are two other important cultural practices. These two dates represent the conception of giving precedence to the Monarchy, regarded as Thailand's public holidays (Connors, 2005). This was evident from the 
large number of survey respondents who always encouraged children to participate in the activities of Father's Day. From my personal experience as a Thai citizen, the Government organises many activities to celebrate these two days as a way to honour the Monarchy; for example, Thai people gather within their local community to attend the lighting candle ceremony to extend their best wishes to the King and the Queen. Most governmental and public places, including schools and services, exhibit the importance of these two dates on their notice boards. Despite Father's Day and Mother's Day not being mentioned in the curriculum, the multiple case study services and survey-respondents always encouraged young children to be involved in the specific activities associated with these two dates. Children learn not only about the importance of these dates, but also about Thai traditions, culture, and identity. Furthermore, the regulations regarding the Thai national flag are linked to the activities of Father's Day and Mother's Day celebrations.

All governmental offices, including schools and services, must display the Thai national flag at their premises on special occasions. Apart from the flag raising ceremony which takes place twice daily, this is another cultural activity that involves the national flag. For example, displaying the national flag on Father's Day and Mother's Day is a way of paying respect to His Majesty the King and the Queen of Thailand. The monarchy is one of the three key pillars of Thai identity which is denoted by the blue strip on the Thai national flag. As both Connors (2005) and Traitongyoo (2008) have pointed out the notion of Thai nationalistic ideology includes showing respect to the monarchy.

In addition to the official regulations, the Government does provide guidelines and teaching resources for early childhood teachers. In 2014, for example, around the time that the 12 Core Values were promulgated, the Office of the Basic Education Commission published a teaching manual called the Manual for Early Childhood Teachers to Integrate the 12 Core Values into their Teaching Practices, which focuses on how early childhood teachers could cultivate these values with young children. This teaching manual also contains material to assist early childhood teachers to teach young children about Thailand. For instance, when teaching about the Thai national flag young children also learn about the symbolic component of Thai national identity (i.e., the nation, the religion, and the monarchy) (Office of the Basic Education Commission, 2014). Regarding Thai history, early childhood teachers need to emphasise that Thailand has never been colonised by any European countries. This is 
one of the ways to promote Thai nationalistic ideology in children. When teaching about religion, early childhood teachers need to mention the characteristics of various religions as children may have different religious beliefs. In relation to the monarchy, children are taught about the importance and duties of all the Kings in Chakri dynasty, especially King Rama IX (King Bhumibol Adulyadej). For instance, Thailand's history, ruling system, and the key contribution of the current and previous Kings towards Thailand's prosperity and stability. This also includes giving basic information about Thailand's ruling system, which is a constitutional democracy.

More recently, the Government published a book, Culture, Ways of Five, and Folk Wisdom, which explains local traditions and other aspects of Thai culture in depth such as the history and importance of the Loy Kratong festival, with examples of Thai plays and their instructions, and description of Thai food and desserts (Department of Cultural Promotion, 2017). The multiple case study participants and the survey respondents, however, indicated that they would like the Government to provide additional teaching manuals to assist them to promote Thai culture and identity with young children. The official regulations and policies that early childhood services need to take into consideration were not seen to be sufficient for cultivating Thainess with young children. The Government could provide additional funding and resources to the Ministry of Education and the Teacher Council of Thailand who are responsible for teachers' professional development.

Early childhood teachers are required to plan their own teaching lessons. These need to be based on the curriculum's specific learning content and appropriate to children's interests and individual differences (Ministry of Education, 2003a,b). Using the existing teaching manuals, teachers can apply guided instructions and examples of cultural activities about Thai culture and identity in their lessons in order to create learning experiences for young children that are matched to their social and cultural contexts. However, some of the participants in this study indicated the Government could do more to support their teaching practices, for example, early childhood teachers dress in traditional Thai costumes every Friday whereas young children did this during the Loy Kratong festival. The Government could provide a teaching manual around the etiquette of wearing Thai national costumes (i.e., when and where it is appropriate to do so). Moreover, the wearing traditional Thai costumes is important as this helps raise awareness of Thai culture and identity. Providing such a manual may lead to formalising the wearing of traditional Thai costumes for teachers in early 
childhood services, which in turn might lead to the Government legislating this cultural practice. This is in line with Pinyoanuntapong's (2013b) suggestion that Thai costumes should be included in the curriculum's learning content. Children would be encouraged to learn more about Thai culture, identify and Thainess if this was a national regulation.

A new 20-year strategic national education plan, 2017 - 2036, for Thailand has been introduced by the Government and the Ministry of Education (Office of the National Education Commission, 2017). This plan has three key objectives: to improve the quality and efficiency of education management and provision in terms of its systems and procedures; to cultivate Thai people to become good citizens and behave in accordance with the Constitution of the Kingdom of Thailand (Office of the Council of State, 2017); and to encourage Thai people to live in a society which balances both Western capitalist ideas and a notion of Thainess. Nonetheless, there are no specific examples of Thai culture and identity illustrated in this educational plan. It is good to have this plan; however, it would be useful if it included the cultural practices and activities early childhood teachers should implement in order to promote Thainess in young children. The plan should include specific aspects of Thai culture which could contribute to good citizenship and cultivation of Thainess. This nationalistic ideology also focuses on strengthening national pride (Connors, 2015).

Thailand's Government does play an important role in supporting early childhood services to promote Thai culture and identity with young children. This includes passing enforced policies for the services to incorporate as nationwide practices, promulgating official documents as guidelines for teachers, and providing relevant training manuals for teachers. Nonetheless, as this study revealed, some early childhood teachers would like additional support to foster the cultivation of Thainess with young children.

\subsection{Implications of the Research}

My study contributes to the small body of literature that identifies how early childhood teachers and parents support the promotion of Thainess with young children through cultural activities and practices (Vygotsky, 1978; Wartofsky, 1979). As Thai culture is very unique, it needs to be cultivated and promoted with Thai people, especially young children. This study provides an understanding of how early childhood services in Thailand foster children's culture and identity and cultivate Thainess at their early childhood services and in their home environment. Teacher-participants in this study 
integrated cultural activities and practices into their daily teaching practices in order to encourage children to learn Thai culture and identity (Wartofsky, 1979; Wertsch \& Tulviste, 2005). Children's culture learning involves their interactive engagement with their social and cultural environment (Catron \& Allen, 2008, NAEYC, 2009). As Thambaworn (2008) put it, enhancing collaboration among families and the wider community is crucial for children's learning and development. The Government, as well as early childhood services, need to promote the participation of families in their children's early childhood education and their engagement in their local communities.

This study has shown that although the 2003 Early Childhood Curriculum did not provide precise guidelines, early childhood teachers did integrate Thai culture and identity in their daily teaching practices (Ministry of Education, 2003a,b). However, the early childhood services from both the survey and the multiple case study suggested that the Government needed to offer additional support to early childhood services to promote Thai culture and identity. Therefore, it would be helpful if the Government could provide additional teaching manuals with specific examples of appropriate cultural activities for early childhood teachers to incorporate into their teaching practices. Specific aspects of Thai culture should have been addressed more explicitly in the 2003 Early Childhood Curriculum (Ministry of Education, 2003b). This was firmly supported by Pinyoanuntapong's (2013b) research findings, which suggested that Thai manners and traditional costumes should be part of the learning content in the official curriculum. Interestingly, the newly revised 2017 Early Childhood Curriculum addresses this gap in some ways. It provides guidelines for promoting Thai culture and identity through developmentally based learning experience (Ministry of Education, 2017a).

Religious beliefs and local traditions need to be taken into consideration as Thailand is a multinational country (Department of Cultural Promotion, 2017; Office of the Basic Education Commission, 2014). The development of Thailand's early childhood curricula has been greatly influenced by societal changes, including an influx of different cultures, and the Government's aspirations (McLachlan et al., 2018; Saracho and Spodek, 2002). The Government aims to provide quality early childhood education and to foster young children to become good citizens (Ministry of Education, 1997a, 2013a,b, 2017a). By looking at the three revisions of Thailand's early childhood curriculum, the Government has been taking into account the cultural diversity in Thailand, evidently stated in the curricula as children should behave in 
accordance to their religions and beliefs. In addition to the curriculum document, this may also include other training manuals which aim to promote the cultivation of Thainess. For instance, the Government could consider formalising the wearing of traditional Thai costumes as a national practice by taking into account different styles of traditional costumes from each region of Thailand. The Ministry of Education in Thailand can benefit from this research study by aligning it with the Government's aspiration for maintaining Thainess.

Another implication of this study involves the services' context and location creating challenges for some parents' participation. One of the services claimed that parents were not able to participate in the service's activities, including those related to important Thai occasions, as there were not enough parking spaces. Another service within the Klongtoey district revealed that the diversity of parents' backgrounds influenced the promotion of Thai culture and identity with young children. The parents at this service relied on the service's practices for children to learn Thai culture and identity. Parents had busy working schedules, and some did not live near the early childhood service. The early childhood teachers argued that they needed more support from, and collaboration with children's parents, especially in relation to encouraging children to learn good Thai manners. This may explain why a very small number of survey respondents commented that their services needed more assistance from parents.

\subsection{Limitations and Recommendations for Further Study}

This study used two main methods for gathering data for the multiple case study: semistructured interviews and documentation. Including observation as an additional method would add another dimension to the data. This study did not employ observation methods to collect the data due to the researcher having limited experience in early childhood education. It could be worthwhile to also include children's voices in further studies.

Due to time constraints, I did not include primary school teachers in the study. The 2003 Early Childhood Curriculum stated that primary teachers are key persons in early childhood education (Ministry of Education, 2003b). Furthermore, some services were stand-alone and were not attached to a primary school. It is recommended that further studies in this area include primary teachers in order to get their perspective on teaching Thainess with young children. 
By considering cultural diversity, further studies could look at the diversity of early childhood staff in services. This might also provoke different points of view in relation to the promotion of Thai culture and identity and critique of the notion of Thainess. Moreover, it could also be useful and interesting to include other districts of Bangkok, as this study was carried out in Klongtoey and Wattana districts only, and/or compare urban and rural areas.

\subsection{Conclusion}

In 2003, Thailand's early childhood curriculum was promulgated for children from birth to 5 years of age (Ministry of Education, 2003a,b). The aim of the curriculum was to foster children's learning and development through developmentally based practices. Children were also encouraged to be good Thai citizens (Rattanathongkam, 2007). This thesis investigated how early childhood services encouraged this by examining what cultural activities and practices early childhood teachers integrated in their programmes when implementing the curriculum.

A major finding in this study was that the services cultivated Thainess with young children and did promote various aspects of Thai culture and identity in their everyday activities and practices. The key cultural practices addressed by the participants were not explicitly mentioned in the 2003 Early Childhood Curriculum (Ministry of Education, 2003b). Instead, they were strongly promoted in other government documents and policy (Department of Cultural Promotion, 2010b; Office of the Council State, 2010; Office of the National Education Commission, 2010; Office of the Prime Minister, 2018). This illustrated misalignments around curriculum interpretation between the Government's aspirations and the curriculum documents in relation to the cultivation of Thainess with young children.

In the other words, cultural activities and practices around promoting Thainess did not align with the curriculum focusing on children's age-related characteristics. Cultural activities and practices are not based on children's maturation; they require social interaction among children, their early childhood teachers, parents, and communities (Rogoff, 2003; Vygotsky, 1978). Despite not being addressed in the 2003 Early Childhood Curriculum (Ministry of Education, 2003b), the services in this study explicitly and implicitly integrated Thai cultural activities and practices into their daily programmes. These everyday activities and practices mediated children learning Thai culture and identity, including the cultivation of Thainess. 


\section{REFERENCES}

Alvestad, M., \& Duncan, J. (2006). "The value is enormous - It's priceless I think!" New Zealand preschool teachers' understandings of the early childhood curriculum in New Zealand: A comparative perspective. International Journal of Early Childhood, 38(1), 31-45.

http://dx.doi.org/10.1007/BF03165976

Angeles-Bautista, F. D. (2004). Early childhood care and education in South-East Asia: Working for access, quality and inclusion in Thailand, the Philippines and Vietnam. Bangkok, Thailand: UNESCO Asia and Pacific Regional Bureau for Education.

Arphattananon, T. (2018). Multicultural education in Thailand. Intercultural Education, 29(2), 149-162.

Athikomnantha, P. (1998). Sang Khohm Lae Wat Tha Na Tham Thai [Thai society and culture]. Retrieved from http://e-book.ram.edu/ebook/inside/html/dlbook.asp?code=AN357

Batson, B. A. (1977). The end of absolute monarchy in Siam (Doctoral thesis). Cornell University, Sydney, Australia. Retrieved from https://searchproquest-com.helicon.vuw.ac.nz/docview/302837223?pq-origsite=primo

Battaglia, M. (2011). Convenient sampling. In P. J. Lavrakas (Ed.), Encyclopedia of survey research methods (pp.149-151). Thousand Oaks, CA: Sage.

Bazeley, P., \& Richards, L. (2000). The NVivo qualitative project book. Thousand Oaks, CA; London: Sage.

Beneke, S., \& Ostrosky, M. (2009). Teachers' views of the efficacy of incorporating the Project approach into classroom practice with diverse learners. Early Childhood Research and Practice, 11(1), 1-9.

Bernstein, B. (1996). Pedagogy, symbolic control and identity: Theory, research, critique. British Journal of Sociology of Education, 18(1), 119-124.

Bodrova, E., \& Leong, D. L. (2001). Tools of the mind: A case study of implementing the Vygotskian approach in American early childhood and primary classrooms (Innodata Monographs 7). Geneva, Switzerland: International Bureau of Education.

Bodrova, E., \& Leong, D. J. (2015). Vygotskian and post-Vygotskian views on children's play. American Journal of Play, 7(3), 371-388. 
Bogdan, R., \& Biklen, S. K. (2007). Qualitative research for education: An introduction to theories and methods. Boston, MA: Pearson.

Browell, S. (2000). The land of smiles: People issues in Thailand. Human Resource Development International, 3(1), 109-119. doi.org/10.1080/136788600361975

Bryman, A. (2016). Social research methods ( $5^{\text {th }}$ ed.). Oxford, England: Oxford University Press.

Catron, C. E., \& Allen, J. (2008). Early childhood curriculum: A creative play model. Upper Saddle River, NJ: Pearson/Merrill Prentice Hall.

Chayaniyayodhin, S. (1970). Preschool education in Thailand. International Review of Education, 16(1), 107-110. doi.org/10.1007/BF01435954

Chenail, R. J. (2011). Interviewing the investigator: Strategies for addressing instrumentation and researcher bias concerns in qualitative research. Qualitative Report, 16(1), 255-262.

Choothai, P. (2007). Jit Dta Wit Tha Yaa Gaan Riian Gaan Saawn [Psychology of learning and teaching]. Nonthaburi, Thailand: Great Education.

Cohen, L., Manion, L., \& Morrison, K. (2018). Research methods in education ( $^{\text {th }}$ ed.). Oxon, England; New York, NY: Routledge.

Cole, M. (1996). Cultural psychology: A once and future discipline. Cambridge, MA: Belknap Press, Harvard University Press.

Cole, M., \& Gajdamaschko, N. (2007). Vygotsky and culture. In H. Daniels, M. Cole, \& J. V. Wertsch (Eds.), The Cambridge companion to Vygotsky (pp. 193-211). Cambridge, MA: Cambridge University Press.

Connors, M. K. (2005). Ministering culture: Hegemony and the politics of culture and identity in Thailand. Critical Asian Studies, 37(4), 523-551. doi.org/10.1080/114672710500348414

Copple, C., \& Bredekamp, S. (2009). Developmentally appropriate practice in early childhood programs serving children from birth through age eight ( $3^{\text {rd }} \mathrm{ed}$.). Washington, DC: National Association for the Education of Young Children.

Costello, S., \& Roodenburg, J. (2015). Acquiescence response bias: Yeasaying and higher education. The Australian Educational and Developmental Psychologist, 32(2), 105-119. doi:10.1017/edp.2015.11

Creswell, J. W. (2014). Research design: Qualitative, quantitative, and mixed methods approaches $\left(4^{\text {th }}\right.$ ed.). Thousand Oaks, CA: Sage. 
Creswell, J. W. (2018). Research design: Qualitative, quantitative, and mixed methods approaches $\left(5^{\text {th }}\right.$ ed.). Thousand Oaks, CA: Sage.

Czaja, R., \& Blair, J. (2005). Designing surveys: A guide to decisions and procedures $\left(2^{\text {nd }}\right.$ ed.). Thousand Oaks, CA: Pine Forge Press.

Daechakupt, Y. (1999). Gaan Seuk Saa Bpa Thohm Ma Wai [Early childhood education]. Bangkok, Thailand: Mac Press.

Davis, B., \& Sumara, D. (2002). Constructivist discourse and the field of education: Problems and possibilities. Educational Theory, 52(4), 409-428. doi:10.1111/j.1741-5446.2002.00409.x

Dayley, R. (2011). Thailand's agrarian myth and its proponents. Journal of Asian and African Studies, 46(4), 342-360. doi.org/10.1177/0021909611400547

Denzin, N. K., \& Lincoln, Y. S. (2005). The SAGE handbook of qualitative research $\left(3^{\text {rd }}\right.$ ed.). Thousand Oaks, CA: Sage.

Denzin, N. K., \& Lincoln, Y. S. (2018). The SAGE handbook of qualitative research ( $5^{\text {th }}$ ed.). Los Angeles: Sage.

Department of Cultural Promotion. (2010a). Maa Ra Yaat Thai [Thai manners]. Bangkok, Thailand: Ministry of Culture.I

Department of Cultural Promotion. (2010b). Phra Raat Cha Ban Yat Wat Tha Na Tham Haeng Chaat Phoot Sak Ga Raat 2553 [National Cultural Act B.E. 2553]. Bangkok, Thailand: Cabinet and Royal Gazette Publishing Office, The Secretariat of The Cabinet.

Department of Cultural Promotion. (2011). Wan Phaaw Haeng Chaat [The National Father Day]. Retrieved from

http://www.culture.go.th/culture th/ewt_news.php?nid=549\&filename=index Department of Cultural Promotion. (2017). Wat Tha Na Tham Withee Chee Wit Lae Phuum Bpan Yaa: [Culture, ways of living, and folk wisdom]. Bangkok, Thailand: Ministry of Culture.

Department of Education. (2014). National curriculum in England: Framework for key stages 1 to 4 . Retrieved from https://www.gov.uk/government/publications/national-curriculum-inengland-framework-for-key-stages-1-to-4/the-national-curriculum-inengland-framework-for-key-stages-1-to-4\#the-national-curriculum-inengland 
DeVries, R. (2002). Play in the early education curriculum: Four interpretations. In R. DeVries, B. Zan, C. Hildebrandt, R. Edmiaston, \& C. Sales (Eds.), Developing constructivist early childhood curriculum: Practical principles and activities (pp. 13-33). New York, NY: Teachers College Press.

DeVries, R., Edmiaston, R., Zan, B., \& Hildebrandt, C. (2002). What is constructivist education? Definition and principles of teaching. In R.

DeVries, B. Zan, C. Hildebrandt, R. Edmiaston, \& C. Sales (Eds.), Developing constructivist early childhood curriculum: Practical principles and activities (pp. 35-51). New York, NY: Teachers College Press.

Dhammathai. (n.d.). Thet Mahachat [Preaching about the story of one of Buddha's past lives: The Vessantara Jataka]. Retrieved from http://www.dhammathai.org/newspr/thesanachadok.php

Encyclopedia on Early Childhood Development. (2017). School readiness: Synthesis. Retrieved from http://www.child-encyclopedia.com/schoolreadiness/synthesis.

Epstein, A. S., \& Schweinhart, L. J. (2018). Educational tenets of the Highscope curriculum. In M. Fleer \& B. Van Oers (Eds.), International handbook of early childhood education (pp. 1347-1378). Dordrecht, Netherlands: Springer.

Farrelly, N. (2016). Being Thai: A narrow identity in a wide world. Southeast Asian Affairs, 331-344. doi.org/10.1355/9789814695671-023

File, N., Mueller, J., Wisneski, D. B., \& Stremmel, A. J. (2016). Understanding research in early childhood education: Quantitative and qualitative methods. Oxon, England,NY: Routledge.

Fleer, M. (1995). Challenging developmentally appropriate practice: An introduction. In M. Fleer (Ed.), DAP centrism: Challenging developmentally appropriate practice (pp. 1-10). Watson, ACT: Australian Early Childhood Association.

Fleer, M. (2008). A cultural-historical perspective on play: Play as a leading activity across cultural communities. In I. Pramling Samuelsson \& M. Fleer (Eds.), Play and learning in early childhood settings: International perspectives (pp. 1-17). London: Springer. 
Fleer, M. (2011). 'Conceptual play': Foregrounding imagination and cognition during concept formation in early years education. Contemporary Issues in Early Childhood, 12(3), 224-240. doi.org/10.2304/ciec.2011.12.3.224

Fleer, M., \& Van Oers, B. (2018). International trends in research: Redressing the north-south balance in what matters for early childhood education research. In M. Fleer \& B. Van Oers (Eds.), International Handbook of Early Childhood Education (pp. 1-30). Dordrecht, Netherlands: Springer.

Florez, I. (2008). Early childhood education: The developmentally appropriate practice debate. In T. L. Good (Ed.), 21st century education: A reference handbook (Vol. 2, pp. 396-404). Thousand Oaks, CA: SAGE. doi:10.4135/9781412964012.n43

Fosnot, C. T., \& Perry, R. S. (2004). Constructivism: A psychological theory of learning. In C. T. Fosnot (Ed.), Constructivism: Theory, perspectives, and practice (pp. 8-38). New York, NY: Teachers College Press.

Fraenkel, J. R., Wallen, N. E., \& Hyun, H. H. (2015). How to design and evaluate research in education ( $9^{\text {th }}$ ed.). New York, NY: McGraw-Hill Higher Education.

French, G. (2007). Children's early learning and development: A research paper. Dublin, Ireland: National Council for Curriculum and Assessment.

Göncü, A., \& Gauvain, M. (2012). Sociocultural approaches to educational psychology: Theory, research, and application. In APA educational psychology handbook, Vol 1: Theories, constructs, and critical issues (pp. 125-154). Washington, DC: American Psychological Association.

Gray, C., \& MacBlain, S. (2012). Learning theories in childhood. Los Angeles, CA: SAGE.

Grix, J. (2004). The foundations of research: A student's guide. New York: Palgrave Macmillan.

Guba, E. G., \& Lincoln, Y. S. (1994). Competing paradigms in qualitative research. In N. K. Denzin \& Y. S. Lincoln (Eds.), Handbook of qualitative research. Thousand Oaks, CA: Sage.

Hammersley, M. (2013). What is qualitative research? London: Bloomsbury. Harrison, H., Birks, M., Franklin, R., \& Mills, J. (2017). Case study research: Foundations and methodological orientations. Forum Qualitative 
Sozialforschung / Forum: Qualitative Social Research, 18(1), 1-17. doi. http://dx.doi.org/10.17169/fqs-18.1.2655

Hart, C. H., Burts, D. C., \& Charlesworth, R. (1997). Integrated curriculum and developmentally appropriate practice: Birth to age eight. New York, NY: State University of New York Press.

Hedegaard, M. (1998). Situated learning and cognition: Theoretical learning and cognition. Mind, Culture, and Activity, 5(2), 114-126. doi.org/10.1207/s15327884mca0502_5

Hedegaard, M. (2001). A new approach to learning in classrooms (Working Paper No. 96-01). Aarhus, Denmark: University of Aarhus, Centre for Cultural Research.

Henson, K. T. (2015). Curriculum planning: Integrating multiculturalism, constructivism, and education reform ( $5^{\text {th }}$ ed.). Gloveland, I: Long Glove Waveland Press.

Hermans, H. J. M. (2001). The dialogical self: Toward a theory of personal and cultural positioning. Culture \& Psychology, 7(3), 243-281. doi:10.1177/1354067X0173001

Hermans, H. J. M. (2012). Dialogical self theory and the increasing multiplicity of Ipositions in a globalizing society: An introduction. New Directions for Child and Adolescent Development, 2012(137), 1-21. doi:10.1002/cad.20014

Hoonchamlong, Y. (2007). Thai language and culture for beginners: Book 1. Bangkok, Thailand: Thai Language Program.

Hua, Z. (2009). The ongoing curriculum reform in China: Philosophy, objectives, and structure. In E. Ropo \& T. Autio (Eds.), International conversations on curriculum studies (pp. 187-196). Rotterdam, Holland: Sense.

Jamjuree, D. (2017). Teacher training and development in Thailand. Journal of Research and Curriculum Development, 7(2), 7-19.

Jangdecha, C., \& Larpkesorn, P. (2018). The structure of Thai education. In G. W. Fry (Ed.), Education in Thailand: An old elephant in search of a new mahout (Vol. 42, pp. 79-92). Singapore: Springer.

Jatuporn, O. (2016). Education for enculturating the "Thainess" ideology: Decolonising the Siamese colonial discourse in the social studies curriculum. Journal of International Social Studies, 6(2), 130-140. 
Jitsom, O. (2003). Bpan Haa Gaan Chai Lak Suut Gaawn Bpra Thohm Seuk Saa Phoot Sak Ga Raat Khaawng Ro:Hng Riian A Noo Baan Aehk Ga Chohn Nai Khaeht Groong Thaehp Ma Haa Na Khaawn:Problems of pre-school curriculum 1997 implementation in private kindergarten in Bangkok Metropolis: Master's thesis),.

Kasetsart University, Bangkok, Thailand). Retrieved from http://newtdc.thailis.or.th/docview.aspx?tdcid=155206

Johnson, R. B., \& Onwuegbuzie, A. J. (2004). Mixed methods research: A research paradigm whose time has come. Educational Researcher, 33(7), 14-26. doi.org/10.3102/0013189X033007014

John-Steiner, V., \& Mahn, H. (1996). Sociocultural approaches to learning and development: A Vygotskian framework. Educational Psychologist, 31(3/4), 191-206. .doi.org/10.1080/00461520.1996.9653266

Jones, M. (2009). The development of cultural identity in early childhood settings (Master's thesis). De Montfort University, Leicester, England. Retrieved from

https://www.dora.dmu.ac.uk/xmlui/bitstream/handle/2086/10698/Mhil.pdf?se quence $=1 \&$ is Allowed $=\mathrm{y}$

Jory, P. (1999). Thai identity, globalisation and advertising culture. Asian Studies Review, 23(4), 461-487. doi:10.1080/10357829908713251

Kanoksilapatham, B., \& Channuan, P. (2018). EFL learners' and teachers' positive attitudes towards local community based instruction. Indonesian Journal of Applied Linguistics, 7(3), 504-514. doi.org/10.17509/ijal.v7i3.9790

Kerdarunsuksri, K. (2015). Thainess in contemporary performances on Thailand's got talent. Paper presented at the Asian Conference on Arts \& Humanities, Japan. Retrieved from http://papers.iafor.org/wpcontent/uploads/papers/acah2015/ACAH2015_07680.pdf

Kim, H. K. (2011). Developmentally appropriate practice (DAP) as defined and interpreted by early childhood preservice teachers: Beliefs about DAP and influences of teacher education and field experience. Southeastern Regional Association of Teacher Educators (SRATE) Journal, 20(2), 12-22.

Kivunja, C., \& Kuyini, A. B. (2017). Understanding and applying research paradigms in educational contexts. International Journal of Higher Education, 6, 26. doi:10.5430/ijhe.v6n5p26 
Klibthong, S. (2013). Exploring Thai early childhood teachers' understanding, beliefs and concerns of inclusive education: A case study of an early childhood centre. MIER Journal of Educational Studies, Trends, and Practices, 3(1), 16-32.

Klongtoey District Office. (n.d.). Bpra Wat Khaawng Khaeht Khlaawng Dteeuy: The history of Klongtoey District. Retrieved from http://www.bangkok.go.th/khlongtoei/page/sub/40

Knutson, T. J. (2004). Thai cultural values: Smiles and sawasdee as implications for intercultural communication effectiveness. Journal of Intercultural Communication Research, 33(3), 147-157.

Kuwinpant, P. (2002). Thai society and culture. Retrieved from https://www.gsid.nagoyau.ac.jp/sotsubo/OFW2008_Thai_Society_by_ProfPreecha.pdf

Lave, J., \& Wenger, E. (2007). Practice, person, social world. In H. Daniels (Ed.), An introduction to Vygotsky (2nd ed., pp. 145-152). London, England: Routledge.

Lee, C. D. (2005). Signifying in the zone of proximal development. In H. Daniels (Ed.), An introduction to Vygotsky ( $2^{\text {nd }}$ ed.). London: Routledge.

Liu, C. C., \& Chen, I. J. (2010). Evolution of constructivism. Contemporary Issues in Education Research, 3(4), 63-66. doi.org/10.19030/cier.v3i4.199

Lutz, S., \& Huitt, W. (2004). Connecting cognitive development and constructivism: Implications from theory for instruction and assessment. Constructivism in the Human Sciences, 9(1), 67-90.

Mackenzie, N., \& Knipe, S. (2006). Research dilemmas: Paradigms, methods and methodology. Issues in Educational Research, 16, 193-205.

MacNaughton, G. (2003). Shaping early childhood: Learners, curriculum and contexts. Maidenhead, England: Open University Press.

Malikhao, P. (2017). Culture and communication in Thailand (Vol. 3). Gateway East, Singapore: Springer Singapore.

Marshall, C., \& Rossman, G. B. (2016). Designing qualitative research (6 ${ }^{\text {th }}$ ed.). Thousand Oaks, CA: Sage.

McCargo, D. (2004). Buddhism, democracy and identity in Thailand. Democratization, 11(4), 155-170. doi.org/10.1080/1351034042000234576 
McLachlan, C., Fleer, M., \& Edwards, S. (2013). Early childhood curriculum: Planning, assessment, and implementation. Cambridge; NY: Cambridge University Press.

McLachlan, C., Fleer, M., \& Edwards, S. (2018). Early childhood curriculum: Planning, assessment, and implementation. Cambridge: Cambridge University Press.

McLaren, P. (2007). Life in schools: An introduction to critical pedagogy in the foundations of education. Boston, MA: Pearson/Allyn \& Bacon.

Meesuk, J. (2017). A grieving nation: Exploring Thainess in the space of emotion (Master's thesis). Lund University, Lund, Sweden). Retrieved from https://lup.lub.lu.se/student-papers/search/publication/8927785

Merewether, J., \& Fleet, A. (2014). Seeking children's perspectives: A respectful layered research approach. Early Child Development and Care, 184(6), 897914. doi.org/10.1080/03004430.2013.829821

Merriam, S. B. (2009). Qualitative research: A guide to design and implementation. San Francisco, CA: Jossey-Bass.

Miller, P. H. (2011). Theories of developmental psychology $\left(5^{\text {th }}\right.$ ed.). New York, NY: Worth.

Ministry of Culture. (2009). Phaaen Maae Boht Wat Tha Na Tham Haeng Chaat Phoot Sak Ga Raat 2550 - 2559: National cultural master plan 2007 - 2016. Bangkok, Thailand: Author.

Ministry of Culture. (2013). Gaan Bpliian Bplaaeng Gaan Bpohk Khraawng Phoot Sak Ga Raat 2475: The political reform in 1932. Retrieved from https://www.m-culture.go.th /young/ewt_news.php?nid=176\&filename=index

Ministry of Culture. (2015). Bpra Phaeh Nee Laawy Gra Thohng: Loy kratong festival. Retrieved from https://www.mculture.go.th/surveillance/ewt_news.php?nid=912\& filename=index Ministry of Culture. (2016). Gaan Rak Saa Wat Tha Na Tham Khaawng Khwaam Bpen Chaat: Preserving the culture of Thai nation. Retrieved from https://www.m-culture.go.th /young/ewt_news.php?nid=165\&filename=index 
Ministry of Culture. (2018). Wan Phaa Saa Thai Haeng Chaat Bpee (B.E.) 2561:

The national Thai language day in 2018. Retrieved from https://www.mculture.go.th/th/ article_view .php?nid=18583

Ministry of Education and Research. (2014). Early childhood education and care.

Retrieved from https://www.regjeringen.no/en/topics/families-andchildren/kindergarden/early-childhood-education-and-care-polic/id491283/

Ministry of Education, New Zealand. (2017). Te whāriki: He whāriki mātauranga mō ngà mokopuna o Aotearoa: Early childhood curriculum. Wellington, New Zealand: Author.

Ministry of Education, Ontario. (2007). Early learning for every child today: A framework for Ontario early childhood settings. Retrieved from http://www.edu.gov.on.ca/childcare/oelf/continuum/continuum.pdf Ministry of Education, Sweden. (2018). Curriculum for the compulsory school, preschool class and school-age educare. Retrieved from https://www.skolverket.se/sitevision/proxy/publikationer/svid12_5dfee44715 d35a5cdfa2899/55935574/wtpub/ws/skolbok/wpubext/trycksak/Blob/pdf398 4.pdf?k=3984

Ministry of Education, Thailand. (1997a). Lak Suut Gaawn Bpra Thohm Seuk Saa

Phoot Sak Ga Raat 2540: Pre-primary curriculum 1997. Bangkok, Thailand: Author.

Ministry of Education, Thailand. 1997b. Khии Meuи Lak Suut Gaawn Bpra Thohm Seuk Saa Phoot Sak Ga Raat 2540: Manual of the pre-primary curriculum 1997. Bangkok, Thailand: Author.

Ministry of Education, Thailand. (2003a). Lak Suut Gaan Seuk Saa Bpa Thohm Ma

Wai Phoot Sak Ga Raat 2546: The 2003 early childhood curriculum (Thai Version). Bangkok, Thailand: Author.

Ministry of Education, Thailand. (2003b). Early childhood curriculum B.E. 2546 (A.D. 2003). Bangkok, Thailand: Author.

Ministry of Education, Thailand. (2003c). Кhии Meuи Lak Suut Gaan Seuk Saa Bpa Thohm Ma Wai Phoot Sak Ga Raat 2546 Manual of the 2003 early childhood curriculum (for three to five years old)]. Bangkok, Thailand: Author.

Ministry of Education, Thailand. (2017a). Lak Suut Gaan Seuk Saa Bpa Thohm Ma

Wai Phoot Sak Ga Raat 2560: The 2017 early childhood curriculum.

Bangkok, Thailand: Author. 
Ministry of Education, Thailand. (2017b). Khии Meuu Lak Suut Gaan Seuk Saa Bpa Thohm Ma Wai Phoot Sak Ga Raat 2560:Manual of the 2017 early childhood curriculum (for three to five years old). Bangkok, Thailand: Author.

Moore, F. J. (1974). Thailand: Its people, its society, its culture. New Haven, CT: HRAF Press.

Morrison, G. S. (2015). Early childhood education today. Essex, England: Pearson. Namuang, A. (2010). Gaan Bpa Dti Ruup Gaan Seuk Saa Khaawng Bpra Thaeht Thai: Educational reform in Thailand. Princess of Naradhiwas University Journal, 2(2), 112-121.

National Association for the Education of Young Children. (1993). A position statement of the National Association for the Education of Young Children: A conceptual framework for early childhood professional development. Retrieved from http://www.naeyc.org/about/position.asp

National Association for the Education of Young Children. (1997). A position statement of the National Association for the Education of Young Children: Developmentally appropriate practice in early childhood programs serving children from birth through age 8. Retrieved from http://www.naeyc.org/about/position.asp

National Association for the Education of Young Children. (2003). A position statement of the National Association for the Education of Young Children: Early childhood curriculum, assessment, and program evaluation. Retrieved from https://www.naeyc.org/sites/default/files/globallyshared/downloads/PDFs/resources/ position-statements/pscape.pdf

National Association for the Education of Young Children. (2009). Position statements on curriculum, assessment, and program evaluation. Retrieved from https://www.naeyc.org/sites/default/files/globally$\underline{\text { shared/downloads/PDFs/resources/ position-statements/KeyMessages.pdf }}$

Norris, N. (1997). Error, bias and validity in qualitative research. Educational Action Research, 5(1), 172-176. doi:10.1080/09650799700200020

Nuttall, J., \& Edwards, S. (2007). Theory, policy, and practice: Three contexts for the development of Australasia's early childhood curriculum documents. In L. Keesing-Styles \& H. Hedges (Eds.), Theorising early childhood practice: Emerging dialogues (pp. 1-24). Castle Hill, NSW: Pademelon Press. 
O’Sullivan, K., \& Tajaroensuk, S. (1997). Thailand: A handbook in intercultural communication. Sydney, NSW: National Centre for English Language Teaching and Research, Macquarie University.

Oberhuemer, P. (2005). International perspectives on early childhood curricula. International Journal of Early Childhood, 37(1), 27-37. doi.org/10.1007/BF03165830

Office of the Basic Education Commission. (2008). Early childhood education standards for internal quality assurance. Retrieved from http://bet.obec.go.th/eqag/images/EQAG/ EQAG_EarlyChildhoodEducationStandardEng_1-51.pdf .

Office of the Basic Education Commission. (2014). Gaan Jat Git Ja Gam Sanng Seerm Khoon Na Lak Sa Na Dek Bpa Thohm Ma Wai Dtaam Khaa Ni Yohm Lak 12 Bpra Gaan (Cha Bap Khruu) [A provision of learning activities promoting desirable characteristics in young children in accordance to the 12 Core Values (for teachers)]. Bangkok, Thailand: Ministry of Education.

Office of the Basic Education Commission. (2018). Naaeo Thaang Gaan Dam Neern Ngaan Gaan Sa Nap Sa Noon Khaa Chai Jaai Nai Gaan Jat Gaan Seuk Saa Bpee Ngohp Bpra Maan 2561 [Implementation of budget allocation for basic education in 2018]. Bangkok, Thailand: Author.

Office of the Basic Education Commission. (n.d.). Bpra Gaat Gra Suaang Seuk Saa Thi Gaan Reuuang Lak Gaehn Lae Naaeo Thaang Gaan Khat Leuuak Nak Riian Nak Seuk Saa Lae Sa Thaan Seuk Saa Pheuua Rap Raang Wan Phra Raat Cha Thaan: A proclamation of the Ministry of Education: criteria and guidelines for selecting students and educational institutions for the Royal Awards]. Retrieved from

http://www.obec.go.th/sites/obec.go.th/files/document/attachment/41185/475 732.pdf

Office of the Council of State. (2017). Rat Tham Ma Nuun Haeng Raat Cha Aa Naa Jak Thai [The constitution of the Kingdom of Thailand 2017]. Bangkok, Thailand: Author.

Office of the Education Council. (2013). Early childhood care and education in Thailand [Global Monitoring Report: Goal 1]. Retrieved from http://www.onec.go.th/onec_backoffice/uploads/Book/1237-file.pdf. 
Office of the National Education Commission. (1992). Phaaen Gaan Seuk Saa

Haeng Chaat Phoot Sak Ga Raat 2535 [National education plan 1992].

Bangkok, Thailand: Office of the Prime Minister.

Office of the National Education Commission. (2002). Phaaen Gaan Seuk Saa

Haeng Chaat Phoot Sak Ga Raat 2545 - 2559 [National education plan 2002

- 2016]. Bangkok, Thailand: Office of the Prime Minister.

Office of the National Education Commission. (2009). Phaaen Gaan Seuk Saa

Haeng Chaat Phoot Sak Ga Raat 2552 - 2559 [National education plan 2009

- 2016]. Bangkok, Thailand: Office of the Prime Minister.

Office of the National Education Commission. (2010). Phra Raat Cha Ban Yat Gaan

Seuk Saa Haeng Chaat Phoot Sak Ga Raat 2542 Gaae Khai Pheerm Dteerm

Cha Bap Thee 2 Phoot Sak Ga Raat 2545 Lae Cha Bap Thee 2 Phoot Sak Ga

Raat 2553 [National education act B.E. 2542 (1999) and amendments

(Second in B.E. 2545 (2002) and Third in B.E. 2553 (2010)]. Bangkok,

Thailand: Office of the Prime Minister.

Office of the National Education Commission. (2017). Phaaen Gaan Seuk Saa

Haeng Chaat Phoot Sak Ga Raat 2560 - 2579 [National Education Plan

2017 - 2036]. Bangkok, Thailand: Ministry of Education.

Office of the Prime Minister. (1986). Ra Biiap Sam Nak Naa Yohk Rat Tha Mohn

Dtree Waa Duay Gaan Chai Gaan Chak Reuu Gaan Sa Daaeng Thohng

Chaat Lae Thohng Khaawng Dtaang Bpra Thaeht Nai Raat Cha Aa Naa Jak

Phoot Sak Ga Raat 2529 [Regulations of the office of the Prime Minister on using, raising, and showing the Thai national flag and other nations' flags

A.D. 1986]. Bangkok, Thailand: Author.

Office of the Prime Minister. (2018). Ra Biiap Sam Nak Naa Yohk Rat Tha Mohn

Dtree Waa Duay Gaan Chai Gaan Chak Reuu Gaan Sa Daaeng Thohng

Chaat Lae Thohng Khaawng Dtaang Bpra Thaeht Nai Raat Cha Aa Naa Jak

Phoot Sak Ga Raat 2561 [Regulations of the Office of the Prime Minister on using, raising, and showing the Thai national flag and other nations' flags

A.D. 2018]. Bangkok, Thailand: Author.

Patton, M. Q. (2015). Qualitative research \& evaluation methods: Integrating theory and practice $\left(4^{\mathrm{h}} \mathrm{ed}.\right)$. Thousand Oaks, CA: SAGE. 
Peeters, J. (2007). Including men in early childhood education: Insights from the European experience. New Zealand Research in Early Childhood Education, $10,15-24$.

Penuel, W. R., \& Wertsch, J. V. (1995). Vygotsky and identity formation: A sociocultural approach. Educational Psychologist, 30(2), 83-92. doi.org/10.1207/s15326985ep3002_5

Perkins, D. (2011). Knowledge alive. In A. C. Ornstein, E. Pajak, \& S. B. Ornstein (Eds.), Contemporary issues in curriculum ( $5^{\text {th }}$ ed., pp. 242-247). Boston, MA: Pearson.

Phaphijitr, B. (2006). Bpra Phaeh Nee Wat Tha Na Tham Thai Lae Kha Dti Khwaam Cheuиa [Thai traditions, culture, and belief]. Bangkok, Thailand: Odeonstore Press.

Phinyoanantapong, S. (1994). Naaeo Gaan Jat Bpra Sohp Gaan Sam Rap Dek Bpa Thohm Ma Wai [Guidelines for provision of experiences for early childhood children]. In School of Educational Studies (Ed.), Lak Gaan Lae Naaeo Khit Thaang Gaan Bpa Thohm Ma Wai Seuk Saa Nuay Thee 9 - 12. [Principles of early childhood education (Unit 9 - 12)] (pp. 1 - 66). Bangkok, Thailand: Sukhothai Thammathirat Open University.

Phisanbut, D. (1982). Bpra Wat Gaan Seuk Saa Thai [History of Thai education]. Bangkok, Thailand: Faculty of Education, Chulalongkorn University.

Phoonsub, S. (2010). Wi Wat Tha Naa Gaan Khaawng Lak Suut Gaan Seuk Saa Bpa Thohm Ma Wai [Evolution of early childhood curriculum]. Retrieved from www.rncc.ac.th/Media/Early...3_54_2/unit2.ppt

Piaget, J. (1952). The origins of intelligence in children. New York, NY: W.W. Norton.

Pinthong, N. (2015). Publicising "Thainess" on the internet: Art of expressing through Thainess via website tourism authority of Thailand. Paper presented at the Third International Conference on Asian Studies, Japan. Retrieved from http://uniqueca.com/archieves/ proceedings/papers/Proceedings-bookFinal-8-25-2015.pdf

Pinyoanuntapong, S. (2013a). A model for promoting the development of basic Dharma traits in preschool children. Asia-Pacific Journal of Research in Early Childhood Education, 7(3), 45-67. 
Pinyoanuntapong, S. (2013b). The development of Thai early childhood education curriculum to promote desirable characteristics of preschool children. Procedia: Social and Behavioral Sciences, 88, 321-327. doi:https://doi.org/10.1016/j.sbspro.2013.08.512

Powell, K. C., \& Kalina, C. J. (2009). Cognitive and social constructivism: Developing tools for an effective classroom. Education, 130(2), 241-250.

Premsrirat, S. (2014). Redefining Thainess: Embracing diversity, preserving unity. In P. Liamputtong (Ed.), Contemporary socio-cultural and political perspectives in Thailand (pp. 3-22). Dordrecht, Netherlands: Springer.

Punch, K. (2003). Survey research: The basics. Thousand Oaks, CA: Sage.

Pupphavesa, W. (2002). Globalization and social development in Thailand. Paper presented at the Globalisation and Social Development Conference: Perspectives from Asia and Europe, Belgium. Retrieved from http://webh01.ua.ac.be/cas/PDF/CAS39.pdf

Rappa, A. L., \& Wee, L. (2006). Language policy and modernity in Southeast Asia Malaysia, the Philippines, Singapore, and Thailand. New York, NY: Springer.

Rattanathongkam, S. (2007). Sang Khohm Lae Wat Tha Na Tham Pheuua Gaan Seuk Saa [Society and culture for education]. Retrieved from http://ams.kku.ac.th/aalearn/resource/edoc/tech/2social.pdf

Renard, R. D. (2006). Creating the other requires defining Thainess against which the other can exist: Early-twentieth century definitions. Southeast Asian Studies, 44(3), 295-320.

Reynolds, C. J. (1998). Globalisation and cultural nationalism in modern Thailand. In J. S. Kahn (Ed.), Southeast Asian identities: Culture and the politics of representation in Indonesia, Malaysia, Singapore, and Thailand (pp.115145). Queenstown, Singapore: Institute of Southeast Asian Studies.

Rhein, D. (2017). International higher education in Thailand: Challenges within a changing context. Journal of Alternative Perspectives in the Social Sciences, 8(3), 281-298.

Rogoff, B. (2003). The cultural nature of human development. Oxford, England: Oxford University Press.

Roumkid, W. (1996). Phat Tha Naa Gaan Khaawng Lak Suut Gaan Seuk Saa Bpa Thohm Ma Wai Nai Bpra Thaeht Thai Ra Waang Bpee Phoot Sak Ga Raat 
2411 - 2538 [The development of early childhood education curriculum in Thailand during 1868 - 1995] (Master thesis). Chulalongkorn University, Bangkok, Thailand. Retrieved from http://cuir.car.chula.ac.th/handle/123456789/8173

Samuelsson, I. P., Sheridan, S., \& Williams, P. (2006). Five preschool curricula: Comparative perspective. International Journal of Early Childhood, 38(1), 11-30. https://doi.org/10.1080/1350293X.2015.1102416

Sandelowski, M. (2004). Qualitative research. In M. S. Lewis-Beck, A. Bryman, \& T. F. Liao (Eds.), The SAGE encyclopedia of social science research methods (pp. 893-894). Thousand Oaks, CA: SAGE.

Sanders, K., \& Farago, F. (2018). Developmental appropriate practice in the twentyfirst century. In M. Fleer \& B. van Oers (Eds.), International handbook of early childhood education (pp. 1379-1400). Dordrecht, Netherlands: Springer.

Saracho, O. N. (2017). Literacy and language: New developments in research, theory, and practice. Early Child Development and Care, 187(3-4), 299-304. doi:10.1080/03004430.2017.1282235

Saracho, O. N., \& Spodek, B. (2002). Contemporary perspectives in early childhood curriculum. Greenwich, CT: Information Age.

Saranukromthai. (n.d.). Khrohng Gaan Saa Raa Noo Grohm Thai Sam Rap Yao Wa Chohn Dooy Phra Raat Cha Bpra Sohng Nai Phra Baat Sohm Det Phra Jao Yии Hиаa [Thai junior encyclopedia project by Royal Command of H.M. the King]. Retrieved from http://kanchanapisek.or.th/kp6/sub/book/book.php?book=26\&chap=1\&page= chap1.htm

Sarobol, A. (2007). Bpra Wat Gaan Dtaeng Gaai [History of costumes]. Retrieved from http://www.human.cmu.ac.th/home/hc/ebook/006216/006216-03.pdf

Schiro, M. (2008). Curriculum theory: Conflicting visions and enduring concerns. Los Angeles, CA: Sage.

Schwandt, T. (1994). Constructivist and interpretivist approaches to human inquiry. In N. K. Denzin \& Y. S. Lincoln (Eds.), The landscape of qualitative research: theories and issues ( $2^{\text {nd }}$ ed., pp. 221-259). Thousand Oaks, CA: Sage. 
Selway, J. (2007). Turning Malays into Thai-men: Nationalism, ethnicity and economic inequality in Thailand. South East Asia Research, 15(1), 53-87. doi.org/10.5367/000000007780420480

Servaes, J. (2017). A village in the jungle: Culture and communication in Thailand. In P. Malikhao (Ed.), Culture and communication in Thailand (Vol. 3, pp. 49-69). Downtown Core, Singapore: Springer.

Siraj-Blatchford, I. (1994). The early years: Laying the foundations for racial equality. Staffordshire, England: Trentham Books.

Srisantisuk, S. (2000). Sang Khohm Lae Wat Tha Na Tham Thai: Lak Sa Na Gaan Bpliian Bplaaeng Lae Wit Tha Yaa Gaan Wi Jai [Thai society and culture: Characteristics, changes, and methodology]. Bangkok, Thailand: Faculty of Humanities and Social Sciences, Khon Kaen University.

Stake, R. E. (2006). Multiple case study analysis. New York, NY: The Guilford Press.

Tanner, D., \& Tanner, L. (2007). Curriculum development: Theory into practice. Upper Saddle River, NJ: Pearson Merrill/Prentice Hall.

Teptien, B., \& Trakulwong, P. (2007). Gaan Duu Laae Dek Bpa Thohm Ma Wai Khaawng Bpra Thaeht Thai [Early childhood care in Thailand]. Journal of Public Health and Development, 5(3), 117-128.

Thambaworn, N. (2001). Gaan Phat Tha Naa Gra Buaan Gaan Khit Nai Dek Bpa Thohm Ma Wai [Cognitive development of young children] ( $2^{\text {nd }} \mathrm{ed}$.). Bangkok, Thailand: Chulalongkorn University Press.

Thambaworn, N. (2008). Lak Suut Gaan Seuk Saa Bpa Thohm Ma Wai [The early childhood education curriculum] ( $3^{\text {rd }}$ ed.). Bangkok, Thailand: Chulalongkorn University Press.

The Association of Thai Language Teachers of Thailand. (2015). Wan Phaa Saa Thai Haeng Chaat [The national Thai language day]. Retrieved from https://www.attth.org/\%E0\%B8\%A7\%E0\%B8\%B1\%E0\%B8\%99\%E0\%B8 \%A0\%Е0\%B8\%B2\%Е0\%B8\%A9\%Е0\%B8\%B2\%Е0\%B9\%84\%Е0\%B8\%9 7\%Е0\%B8\%A2\%Е0\%B9\%81\%Е0\%B8\%AB\%E0\%B9\%88\%Е0\%B8\%87\% E0\%B8\%8A\%E0\%B8\%B2\%E0\%B8\%95\%E0\%B8\%B4/

The Teacher Council of Thailand. (2003). Phra Raat Cha Ban Yat Sa Phaa Kruu Lae Book Kha Laa Gaawn Thaang Gaan Seuk Saa Phoot Sak Ga Raat 2546 
[Teachers and educational personnel act 2003]. Bangkok, Thailand: Office of the Council of State.

Thongdee, S., \& Kanjanakij, S. (1994). Wi Wat Tha Naa Gaan Thaang Gaan Bpa Thohm Ma Wai Seuk Saa [Evolution of early childhood education]. In School of Educational Studies (Ed.), Lak Gaan Lae Naaeo Khit Thaang Gaan Bpa Thohm Ma Wai Seuk Saa Nuay Thee 1 - 4. [Principles of early childhood education (Unit 1 - 4)] (pp. 1-84). Bangkok, Thailand: Sukhothai Thammathirat Open University.

Thongsawang, T. (1994). Sang Khohm Thai [The Thai society]. Bangkok, Thailand: Odeonstore Press.

Tongthaworn, R. (2003). Early childhood constructivist teaching practices and philosophies of Thai teachers with four to five year old students. (Doctoral thesis). Indiana University of Pennsylvania, Pennsylvania, PA. Retrieved from https://search-proquest-com.helicon.vuw.ac.nz/docview/305297979?pq$\underline{\text { origsite }=\text { primo }}$

Traitongyoo, K. (2008). The management of irregular migration in Thailand: Thainess, identity and citizenship. (Doctoral thesis), University of Leeds, Yorkshire, England). Retrieved from http://etheses.whiterose.ac.uk/2053/ Trevarthen, C. (1998). The child's need to learn a culture. In M. Woodhead, D. Faulkner, \& K. Littleton (Eds., pp. 87-100), Cultural worlds of early childhood. London: The Open University.

UNESCO International Bureau of Education. (2006). Education for all global monitoring report 2007: Thailand early childhood care and education (ECCE) programmes. Retrieved from http://unesdoc.unesco.org/images/0014/001472/147249e.pdf.

UNESCO International Bureau of Education. (2011). World data of education $\left(7^{\text {th }}\right.$ ed). Retrieved from http://www.ibe.unesco.org/fileadmin/user_upload/Publications /WDE/2010/pdf-versions/Thailand.pdf.

Vartuli, S. E., \& Rohs, J. (2007). Selecting curriculum content that stimulates thought. Early Childhood Education Journal, 35, 393-396. doi.org/10.1007/s10643-007-0209-0

Vella, W. F. (1978). Chaiyo! King Vajiravudh and the development of Thai nationalism. Honolulu, HI: University Press of Hawaii. 
Vygotsky, L. S. (1934/1986). Thought and language. Cambridge, MA: MIT Press.

Vygotsky, L. S. (1978). Mind in society: The development of higher psychological processes. Cambridge, MA: Harvard University Press.

Vygotsky, L. S. (1981). The genesis of higher mental functions. In J. V. Wertsch (Ed.), The concept of activity in Soviet psychology (pp. 144-188). Armonk, NY: Sharpe.

Walliphodom, S. (2011). Phat Tha Naa Gaan Thaang Sangr Khohm: Wat Tha Na Tham Thai [Development towards society and culture in Thailand]. Bangkok: Muangboran Press.

Wartofsky, M. W. (1979). Models: Representation and the scientific understanding. Dordrecht, Holland: D. Reidel.

Watkhaolarm, P. (2005). Think in Thai, write in English: Thainess in Thai English literature. World Englishes, 24(2), 145-158. doi:10.1111/j.1467971X.2005.00399.x

Weber, E. (1984). Ideas influencing early childhood education: A theoretical analysis. New York, NY: Teachers College, Columbia University.

Wertsch, J. V. (1985). Vygotsky and the social formation of mind. Cambridge, MA: Harvard University Press.

Wertsch, J. V. (1991). Voices of the mind: A sociocultural approach to mediated action. London: Harvester Wheatsheaf.

Wertsch, J. V., \& Stone, A. C. (1985). The concept of internalisation in Vygotsky's account of the genesis of higher mental functions. In J. V. Wertsch (Ed.), Culture communication, and cognition: Vygotskian perspectives. Cambridge, England: Cambridge University Press.

Wertsch, J. V., \& Tulviste, P. (2005). L.S. Vygotsky and contemporary developmental psychology. In H. Daniels (Ed.), An introduction to Vygotsky ( $2^{\text {nd }}$ ed., pp. 57-78). London: Routledge.

Wiersma, W., \& Jurs, S. G. (2009). Research methods in education: An introduction ( $9^{\text {th }}$ ed.). Boston, MA: Pearson/Allyn \& Bacon.

Williams, L. R. (1999). Determining the early childhood curriculum: The evolution of goals and strategies through consonance and controversy. In C. Seefeldt (Ed.), The early childhood curriculum: Current findings in theory and practice (pp. 1-26). New York, NY: Teachers College Press. 
Wood, E., \& Hedges, H. (2016). Curriculum in early childhood education: Critical questions about content, coherence, and control. The Curriculum Journal, 27(3), 387-405. doi:10.1080/09585176.2015.1129981

Woodhead, M. (1999). Towards a global paradigm for research into early childhood education. European Early Childhood Education Research Journal, 7(1), 522. doi:10.1080/13502939985208291

Woodhead, M. (2000). Towards a global paradigm for research into early childhood. In H. Penn (Ed.), Early childhood services: theory, policy and practice. Buckingham, England: Open University Press.

Woodhead, M. (2005). Early childhood development: A question of rights. International Journal of Early Childhood, 37(3), 79-98. doi:10.1007/BF03168347

Yang, W., \& Li, H. (2018). Cultural ideology matters in early childhood curriculum innovations: A comparative case study of Chinese kindergartens between Hong Kong and Shenzhen. Journal of Curriculum Studies, 50(4), 560-585. doi:10.1080/00220272.2018.1428367

Yin, R. K. (2014). Case study research: Design and methods ( $5^{\text {th }}$ ed.). Los Angeles, CA: SAGE.

Yin, R. K. (2018). Case study research and applications: Design and methods (6 $^{\text {th }}$ ed.). Thousand Oaks, CA: SAGE.

Yodjew, J. (2012). Gaan Phat Tha Naa Dtuaa Chee Wat Sa Mat Tha Na Khruu Bpa Thohm Ma Wai Dtaam Maat Dtra Thaan Wi Chaa Cheep Khruu Daan Khwaam Ruu [The development of indicators for the capabilities of kindergarten teachers based on the teacher professional standards in the knowledge standards] (Master thesis). Naresuan University, Bangkok, Thailand). Retrieved from http://eds.a.ebscohost.com/eds/detail/detail?vid=2\&sid=70de61d7-e1a04a34-af60-37d869e6d4e4\%40sdc-vsessmgr01\&bdata=JnNpdGU9ZWRzLWxpdmU\%3d \#AN $=$ nur. $330358 \& \mathrm{db}=$ cat $07210 \mathrm{a}$ 


\section{APPENDICES}

\section{Appendix A: Thailand's Festivals and Important Dates}

\begin{tabular}{|c|c|}
\hline Festivals & Description \\
\hline Loy Kratong & $\begin{array}{l}\text { Thai people celebrate this festival by floating a basket on a } \\
\text { river to pay respect to the Goddess of water. This highlights } \\
\text { the importance of water in their daily lives. On this date, } \\
\text { children are involved in activities at their early childhood } \\
\text { services. }\end{array}$ \\
\hline Songkran & $\begin{array}{l}\text { This is a significant and well-known festival and is a public } \\
\text { holiday. Songkran festival is celebrated over three consecutive } \\
\text { days, which includes Thai New Year day, Family Day, and } \\
\text { Elders' Day. As this festival falls during the school break, } \\
\text { children usually celebrate this festival with their family. }\end{array}$ \\
\hline $\begin{array}{c}\text { Thai Important } \\
\text { Dates }\end{array}$ & Description \\
\hline Chinese New Year & $\begin{array}{l}\text { Also known as Lunar New Year or Spring Festival, Chinese } \\
\text { New Year is celebrated in China and other Asian countries } \\
\text { including Thailand, Singapore, Indonesia, and Vietnam. In } \\
\text { Thailand, the Chinese and Thai-Chinese population celebrate } \\
\text { this day by getting their families together to have a meal } \\
\text { together in the evening. They also clean their houses and pay } \\
\text { respect to their dead ancestors. This is not an official public } \\
\text { holiday in Thailand. }\end{array}$ \\
\hline Father's Day & $\begin{array}{l}\text { This is a public holiday celebrated on the } 5^{\text {th }} \text { December that is } \\
\text { also known as Thai National Day. On this day, Thai people } \\
\text { celebrate the birthday of His Majesty King Bhumibol } \\
\text { Adulyadej (King Rama IX). This is an important celebration, } \\
\text { and Thai people also extend their respect and gratitude to their } \\
\text { fathers and grandfathers. This date is celebrated at the early } \\
\text { childhood services before the national holiday. }\end{array}$ \\
\hline
\end{tabular}




\begin{tabular}{|c|c|}
\hline Mother's Day & $\begin{array}{l}\text { This is another public holiday which is observed on the } 12^{\text {th }} \\
\text { August. Thai people celebrate the Auspicious Birthday of } \\
\text { Queen Sirikit, the Queen Consort of King Bhumibol } \\
\text { Adulyadej. During this important date, Thai people also } \\
\text { extend their respect and gratitude to their mothers and } \\
\text { grandmothers. This date also is celebrated at the early } \\
\text { childhood services beforehand. }\end{array}$ \\
\hline $\begin{array}{l}\text { New Year } \\
\text { celebration }\end{array}$ & $\begin{array}{l}\text { This is a celebrating party which is organised at the end of the } \\
\text { year. Children's parents are usually invited to join early } \\
\text { childhood services' New Year party, which normally takes } \\
\text { place during the last week of the school term before the new } \\
\text { year. }\end{array}$ \\
\hline $\begin{array}{l}\text { Other Important } \\
\text { Religious Dates }\end{array}$ & $\begin{array}{l}\text { On these important religious dates, Thai people carry out } \\
\text { similar religious activities performed on the Buddhist Lent } \\
\text { Days. They usually visit a temple to offer food, practice } \\
\text { meditation, observe the Five Precepts, and pray to the Buddha. } \\
\text { In the evening on these important religious dates, they also } \\
\text { walk with a lighted candle in their hands around a central } \\
\text { sanctuary in a temple. Below is a brief description of each } \\
\text { important date. }\end{array}$ \\
\hline $\begin{array}{l}\text { Services' Annual } \\
\text { Celebrations }\end{array}$ & $\begin{array}{l}\text { This is an annual ceremony to commemorate when an early } \\
\text { childhood service was established therefore this is celebrated } \\
\text { on different dates. During this celebration, children are } \\
\text { encouraged to be involved in the following: offering food to } \\
\text { Buddhist monks and listening to the Buddha's doctrines in the } \\
\text { morning, performing Thai traditional dances on a stage, and } \\
\text { participating in other organised activities which aim to } \\
\text { promote the service. }\end{array}$ \\
\hline Sport Day & $\begin{array}{l}\text { This is a sporting event, which is held once a year at early } \\
\text { childhood services but organised on different dates. The aim } \\
\text { of Sport Day is to enhance children's physical development } \\
\text { and build unity among them, including promoting }\end{array}$ \\
\hline
\end{tabular}




\begin{tabular}{|c|c|}
\hline & $\begin{array}{l}\text { sportsmanship. Children are involved in various sport } \\
\text { activities and these vary at each service. }\end{array}$ \\
\hline $\begin{array}{l}\text { Teacher } \\
\text { Appreciation Day }\end{array}$ & $\begin{array}{l}\text { Teacher Appreciation Day (in Thai: Wan Kru) is celebrated } \\
\text { yearly on the } 16^{\text {th }} \text { January. Thai people believe that all } \\
\text { workplaces have a teacher (referring to those who teach, } \\
\text { coach, and supervise). Early childhood services encourage } \\
\text { children to attend the Wai Kru ceremony (Wai means paying } \\
\text { respect, Kru means a teacher) at their services in order to } \\
\text { express their gratitude and respect to their teachers. }\end{array}$ \\
\hline $\begin{array}{l}\text { The National } \\
\text { Children's Day }\end{array}$ & $\begin{array}{l}\text { This day is celebrated on the second Saturday in January each } \\
\text { year to highlight how important children are in Thai society } \\
\text { and their future roles as Thai citizens. The Government } \\
\text { usually promotes National Children's Day (in Thai: Wan Dek) } \\
\text { with a slogan. }\end{array}$ \\
\hline $\begin{array}{l}\text { Important Religious } \\
\text { Date }\end{array}$ & Description \\
\hline Buddhist Holy Days & $\begin{array}{l}\text { There are four Buddhist Holy Days (in Thai: Wan Phra) } \\
\text { observed every month and these vary depending on the phase } \\
\text { of the moon. Buddhist monks go out for their alms-round } \\
\text { (accepting food offerings from people) within their local } \\
\text { communities. Buddhist Holy Days are not public holidays but } \\
\text { some people in local communities still do food offerings at a } \\
\text { temple. During these days, Thai people pray to the Buddha, } \\
\text { observe the Five Precepts, and practice meditation. }\end{array}$ \\
\hline Buddhist Lent Day & $\begin{array}{l}\text { Buddhist Lent Day (in Thai: Wan Khao Phansa) marks the } \\
\text { period of the three lunar months during the rainy season } \\
\text { (approximately July through October) and this is a public } \\
\text { holiday. In earlier times, Buddhist monks used to travel } \\
\text { walking in their bare feet. Sometimes there were no footpaths, } \\
\text { so they had to use walkways in the fields. During the rainy } \\
\text { season, these walkways became very slippery. As a result, } \\
\text { monks fell in the fields which damaged local people's plants } \\
\text { and growing seeds. The Lord Buddha suggested all his }\end{array}$ \\
\hline
\end{tabular}




\begin{tabular}{|c|c|}
\hline & $\begin{array}{l}\text { followers (Buddhist monks) should stay at a temple during the } \\
\text { wet season to avoid causing damage to people's crops. } \\
\text { Today to celebrate Buddhist Lent Day today Thai people carry } \\
\text { out similar religious activities when observing other Buddhist } \\
\text { Holy Days such as visiting a temple to offer food to monks, } \\
\text { listening to the Buddha's doctrines, and practicing meditation. } \\
\text { These are performed in the morning. In the evening, people } \\
\text { usually walk with a lighted candle held in their hands around } \\
\text { a central sanctuary hall in a temple. } \\
\text { Another important event on this day is a candle procession and } \\
\text { offering. People, including children make a large candle and } \\
\text { give it to a temple. Some people believe that in doing so they } \\
\text { become brighter and smarter (as a metaphor of candlelight). } \\
\text { This public holiday is promoted nation-wide as a 'no drinking } \\
\text { alcohol day'. }\end{array}$ \\
\hline Visakha Bucha Day & $\begin{array}{l}\text { This is another important religious date, which is a public } \\
\text { holiday. It falls in the sixth lunar month, marking three } \\
\text { important incidents of the Lord Buddha: his birth, } \\
\text { enlightenment, and Nirvana (in English: passing away). These } \\
\text { events fall on the same date and month each year. During this } \\
\text { important religious date, Thai people perform similar religious } \\
\text { activities as performed on the Buddhist Lent Days, including } \\
\text { walking with a lighted candle in their hands around a central } \\
\text { sanctuary in a temple. }\end{array}$ \\
\hline
\end{tabular}




\section{Appendix B: Survey for Early Childhood Teachers}

\section{Demographic Data}

There are two areas of demographic data that we are collecting information about:

- Yourself as the respondent of this survey

- Characteristics of your early childhood service

\section{$\underline{\text { Respondent }}$}

1. Please indicate which age group you fit into:

$\square$ Under 20 years

$\square 20-29$ years

$\square 30-39$ years

$\square 40-49$ years

$\square 0+$ years

2. Please indicate your gender:

$\square$ Female

$\square$ Male

3. Please identify your current role within this early childhood service:

$\square$ Principal

Head Teacher

$\square$ Early childhood teacher

Teacher Assistant

4. How long have you been working in this role?

Less than 2 years

$2-5$ years

6 - 10 years

More than 10 years

5. How long have you been using the 2003 Early Childhood Curriculum?

$\square$ Less than 2 years

2 - 5 years

$\square$ - 10 years

$\square$ More than 10 years

6. Please indicate your highest qualification level:

Teacher Assistant's qualification

$\square$ Bachelor degree (please specify your major)

$\square$ Master degree (please specify your major)

$\square$ Doctoral degree (please specify your major)

$\square$ Other (please specify) 


\section{$\underline{\text { Characteristics of your early childhood service }}$}

7. Which district is your early childhood service located in?

$\square$ Klongtoey District

Wattana District

8. Is your early childhood service:

Kindergarten

Preschool (attached with primary school)

9. Please identify the following information about your early childhood service:

- Number of children (in early childhood education)

- Number of early childhood teachers

- Number of early childhood classrooms

\section{Implementing the 2003 Early Childhood Curriculum}

To what extent does your early childhood service follow the guidelines of the 2003 Early Childhood Curriculum? Please indicate by marking the response that most clearly matches your service's teaching practices, where:

$1=$ Never/Rarely

2 = Sometimes

3 = Always

\section{Always \\ Sometimes \\ Never/Rarely}

10. Our early childhood service is based on the guidelines from the 2003 Early Childhood Curriculum

11. We design our own lesson plans for daily teaching practices

12. Our lesson plans include some topics drawn from children's interests

13. Learning activities at our early childhood service are matched with children's age and abilities

14. We do not take into account the community's socio-cultural context when designing lesson plans or learning activities

15. Children's individual differences are a major consideration when designing lesson plans and learning activities

16. Our early childhood service covers the following learning contents: children's self, people and places around children, natural 
environment around children, and things around children (such as vehicles, shapes, colors, and things in their daily life)

17. Children are not given the opportunity for free play at our early childhood service

18. Our learning activities enhance children's physical development

19. Our early childhood service enhances children's emotions and cultivating morality and righteousness

20. We do not develop children's social character at early childhood service

21. At our early childhood service, we enhance children's cognitive skill

22. Children's language and communication skills are fostered at our early childhood service

23. We enhance children's imagination and creative thinking through our learning activities

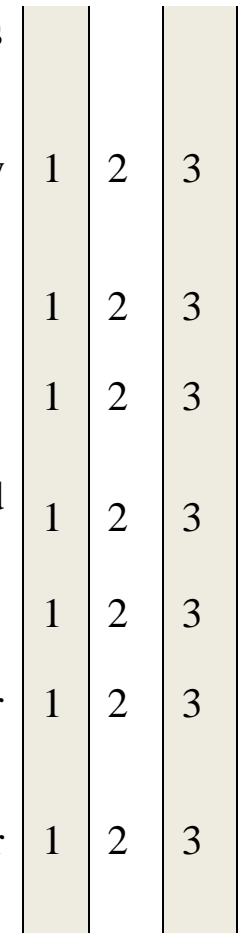

\section{Integrating Thainess and Thai culture into daily teaching practices}

To what extent does your early childhood service integrate Thainess and Thai culture into your teaching practices? Please indicate by marking the response that most clearly matches your service's teaching practices, where:

$1=$ Never/Rarely

2 = Sometimes

3 = Always

\section{Always}

Sometimes

Never/Rarely

24. At our early childhood service, children learn how to perform Wai, the Thai traditional style of greeting

25. Children are encouraged to bow when walking pass their elders

26. We do not teach children how to pay respect to elders

27. Our learning activities encourage children to share, help, and respect others

28. We identify and explain each strip of Thai national flag

29. Group activities allow children to take a leadership role

30. At our early childhood service, we do not teach children about selfdiscipline, responsibility, and honesty 


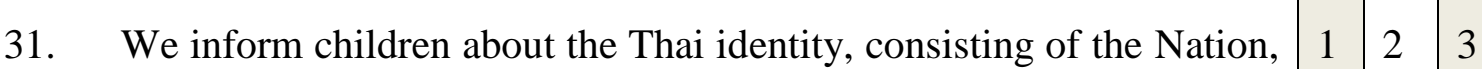
religion, and the King.

32. We incorporate some Buddhist principles into our teaching practices

33. At our early childhood service, we do not provide a session for listening to the Buddha's doctrine

34. We encourage children to practice meditation at our early childhood service

35. We teach children about the Five Precepts (Rules of Morality)

36. We organise fieldtrips to visit temples as part of our religious activities

37. Conserving our environment is not part of our early childhood service

38. At our early childhood service, we include a session for praying to the Buddha in the morning

39. We encourage children involved in an observation of important religious dates, such as Buddhist Lent Day and Visakha Bucha Day

40. Children are not taught about the history of Thailand

41. Children are taught the importance of traditions and festivals, for example, Loy Kratong Festival and Songkran festival

42. At early childhood service, we use theme to match the important festivals

43. Freeplay is encouraged at our early childhood service

44. During Loy Kratong festival, we work alongside children to make and decorate a floating basket from banana leaves

45. On the King's Birthday, National Father's Day, we do activities related to the King, such as drawing the King's picture and narrating a story in the topic of "My beloved King"

46. On National Thai Language Day, children are involved in any activities related to Thai language

47. At our early childhood service, children are not taught any Buddhist principles 


\section{Government's aspirations and roles in promoting Thai culture}

The list below includes examples of points of view about the Government's aspirations and roles in promoting Thai culture. Please indicate the extent to which you agree or disagree with each of the following statements by marking the response that most clearly matches your teaching team's experiences and/or how you feel, where:

$1=$ Strongly disagree

$2=$ Disagree

$3=$ Neither agree nor disagree

$4=$ Agree

$5 \quad=$ Strongly agree

Strongly agree

Agree

Neither agree nor

disagree

Disagree

Strongly disagree

48. The government has a role in promoting Thainess and Thai culture in early childhood education

49. The government should provide trainings for teachers on how to integrate Thai culture into our teaching practices

50. The government should specify more sample activities which can promote Thai culture in the Manual of the 2003 Early Childhood Curriculum for children aged three to five years

51. Children should be encouraged to participate in campaigns or projects related to promoting Thai culture, which are funded and launched by the government

52. In addition to the 2007 Constitution of the Kingdom of Thailand and the 1999 National Education Act, the government should explicitly give guidelines on how to integrate Thai culture into teaching practices

53. The government has a sufficient sponsorship regarding a promotion of Thai culture

54. What would you like the government to do in order to promote Thainess and Thai culture in early childhood education?

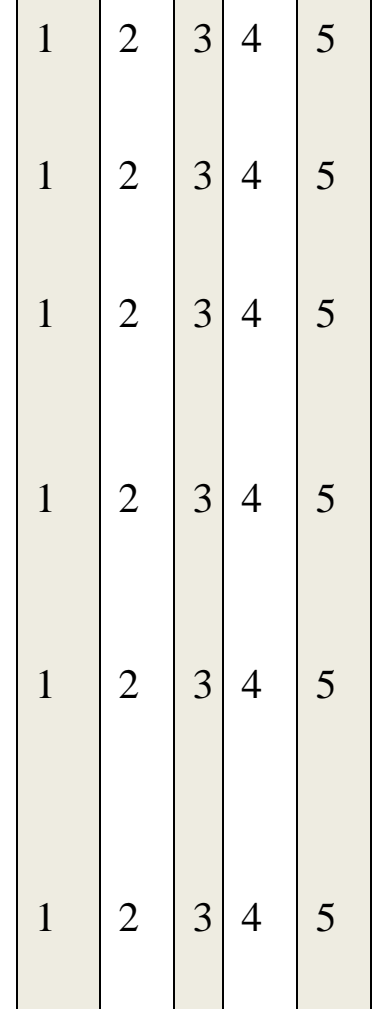


55. In your opinion, do you think that the government has a major role in promoting Thai culture?

\section{The parents' roles in promoting Thai culture}

To what extent are parents at your early childhood service involved in promoting Thai culture? Please indicate by marking the response that most clearly matches your service's experience, where:

$1=$ Never/Rarely

2 = Sometimes

3 = Always

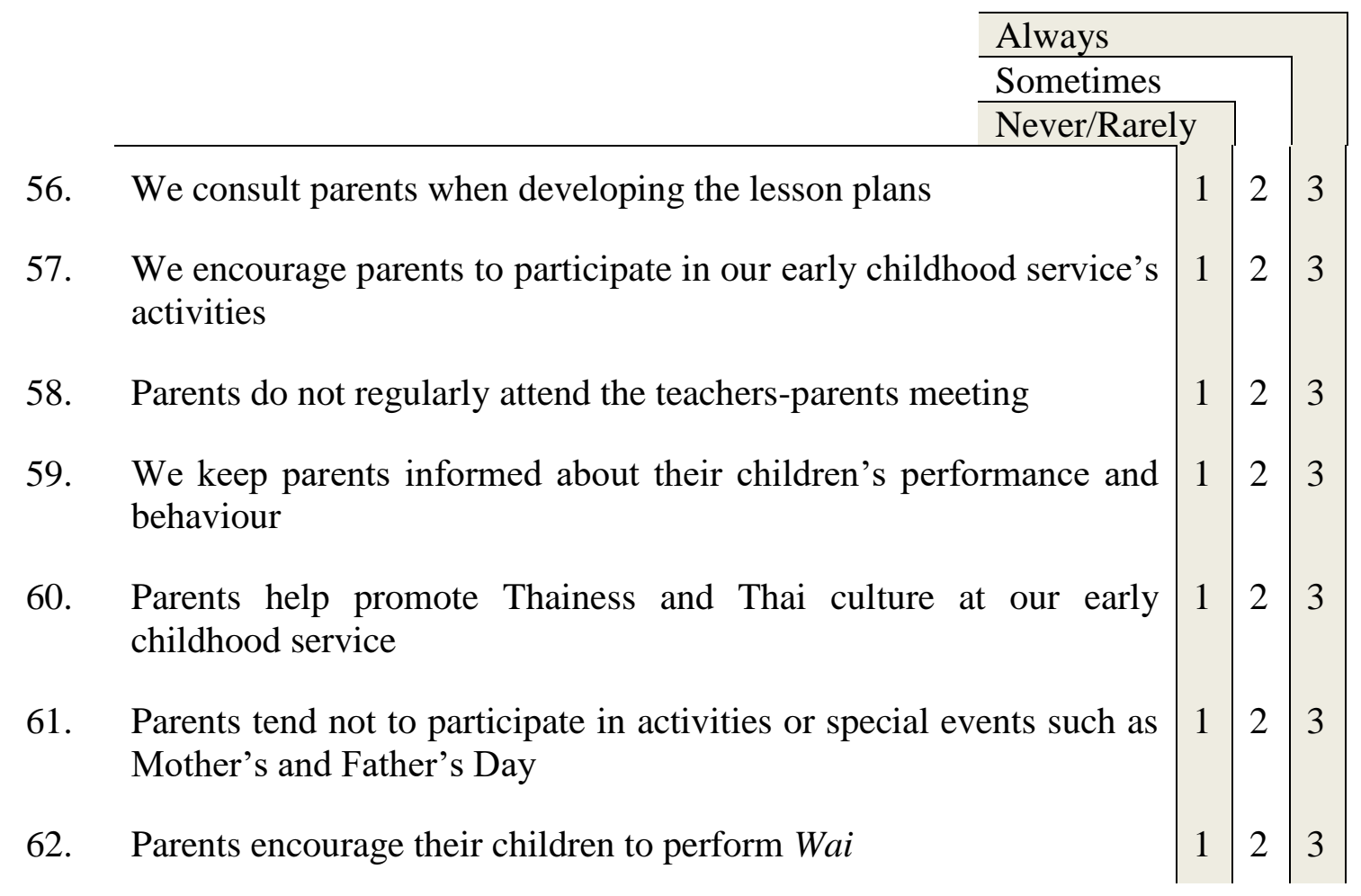


63. Please give some examples of activities that parents usually participate in.

64. How often do you communicate with parents?

65. What can parents do to promote Thai culture at your early childhood service?

Thank you for taking time to complete this questionnaire. 
Appendix C: Information Letters and Consent Forms for Umbrella Organisations, Principals, Early Childhood Teachers, and Teacher Assistants: Phase One (The Survey) 


\title{
Appendix C - 1
}

\section{Information Sheet for the Department of Education Bangkok Metropolitan Administration}

\author{
Research Project: \\ How does Thai Culture underpin the 2003 Early Childhood Curriculum in Thailand?
}

\begin{abstract}
Dear Sir/Madam
My name is Sureepan Iemamnuay, and I am a PhD student in School of Education at Victoria University of Wellington, New Zealand. I am writing to request your permission to conduct research in eight of your early childhood services located in the two districts of central Bangkok, Klongtoey and Wattana.
\end{abstract}

This research will investigate how Thai culture underpins the 2003 Early Childhood Curriculum in Thailand. As Thailand is the only country in Southeast Asia region which has not been colonised by other European countries, Thai culture is considered to be important and unique. Young children today need to aware of and conserve the traditional Thai culture, such as language, literature, artworks, sculpture, and Thai dance. Moreover, they have to serve as good representatives to express 'Thainess' (a lifestyle of Thai nationality with Thai unique culture).

The purpose of my study is to explore how early childhood teachers integrate Thai culture into their daily teaching practice. I also want to investigate how principals, early childhood Head Teachers, teachers and teaching assistants view the role of the government and parents in promoting Thai culture. Moreover, it will examine how parents promote Thai culture and their understanding of the 2003 Early Childhood Curriculum.

The findings of the research may be useful in providing guidelines for early childhood teachers to integrate Thai culture into their daily teaching practices that align with the principles of the 2003 Early Childhood Curriculum. This study may also be of interest to the various national organisations that oversee the early childhood sector and how they can better support early childhood teachers to implement Thai culture into early childhood curriculum. This research has been approved by the Victoria University of Wellington Human Ethics Committee [approval number]. If you have any concerns about the ethical conduct of the research you may contact the Victoria University HEC Convener: Associate Professor Susan Corbett. Email susan.corbett@ vuw.ac.nz or telephone +64-4-463 5480.

There will be two phases to the research. Phase one will involve a paper-based questionnaire, which will be sent to the eight early childhood services under your supervision located in Klongtoey and Wattana. Early childhood teachers and teacher assistants will be invited to fill out this questionnaire. I anticipate that this will take approximately 30 minutes to fill in. Participants will be asked to identify the name of their service on the questionnaire, however, all information provided will be treated as confidential. Names of individuals and services will not be used in reporting responses. 
Phase two includes two in-depth case studies, which will be randomly selected from the eight early childhood services who filled out the questionnaire and agreed to participate in the case studies. The case-study data will be generated through document analysis of teachers' workbooks, and interviews with School Principals, the early childhood Head teachers and two early childhood teachers who have a degree and two years of teaching experiences or more. I would like to also invite two parents from the early childhood teachers' classrooms to be participants in my study. Inferences from the document analysis will be shown and discussed further with the case-study teachers in the in-depth interview individually to avoid mistaken assumptions. It is anticipated that it may take up to one week to collect the data in each case study sites.

Participation in the research is voluntary and each participant may withdraw from the research at any point up to the final point of data collection $\underline{29 \text { February } 2016}$ without giving a reason.

Access to the data from the research will be restricted to my supervisors and me. The data will be securely stored as hard and soft copies. Both will be kept in password-protected files in a private computer and locked in filing cabinets in my home and my office. The data will be destroyed three years after the conclusion of the research. The data from the research will be published in my $\mathrm{PhD}$ thesis and academic journals and shared at education conferences. Participants will be given the opportunity to request a summary of the research findings.

I am requesting your permission to distribute the questionnaires to the services that belong to your organisation in Klongtoey and Wattana and, if selected, for them to participate in the two case studies. If you are willing for your early childhood services to participate in this study, I would appreciate it if you would communicate that you have consented to them being approached to participate.

I have attached the consent form for you to sign and the questionnaire that I will be sending out to participants for your information. If you require any further information or have any questions about this study, please do not hesitate to contact me or my supervisors listed below.

Researcher:

\section{Sureepan Iemamnuay}

Email: mink.iemamnuay@vuw.ac.nz

\section{Supervisors:}

\author{
Dr. Mary Jane Shuker \\ Senior Lecturer \\ School of Education, \\ Phone: +64 44639659 \\ Email: mary-jane.shuker@ vuw.ac.nz
}

\author{
Dr. Sophie Alcock \\ Senior Lecturer \\ School of Education, \\ Phone: +64 44636578 \\ Email: sophie.alcock@vuw.ac.nz
}




\section{Appendix C - 2}

\section{Consent Form for the Department of Education Bangkok Metropolitan Administration}

\section{Research Project:}

How does Thai Culture underpin the 2003 Early Childhood Curriculum in Thailand?

Please complete this form if you consent to Sureepan Iemamnuay conducting her doctoral research at your eight early childhood services located in Klongtoey and Wattana districts.

\section{By giving permission to conduct Sureepan's PhD study in the eight early childhood services, I/we understand that:}

I/We have been given information about this research project, and have had an opportunity to ask questions and have them answered to my/our satisfaction. I/We understand what is required of the participants from our eight early childhood services who take part in this research.

$\square$ Participation in the research is voluntary and the participants may withdraw from the study at any point up to the final point of data collection 29 February 2016 without giving a reason.

The services' identities and the participants' identities will be confidential.

$\square$ All research information will be stored in password-protected files and locked filing cabinets, and access will be restricted to the researcher. It will be destroyed three years after the conclusion of the research.

The data collected will be used for a doctoral thesis and academic purposes only, and $\mathrm{I} /$ we consent for it to be used in this manner.

I/We have been provided with contact details in case I/we have any further enquires about the research.

I/We consent to the researcher conducing her project in the eight early childhood services in Klongtoey and Wattana.

Name of person responding

Position

Signature

Date

Please indicate if you would like to receive a summary of the research findings when it is completed: $\quad \square$ Yes $\quad \square$ No

(The subject will be given a copy of this to keep after signing this form) 


\title{
Appendix C - 3
}

\section{Information Sheet for Principals of Early Childhood Services}

\author{
[Department of Education Bangkok Metropolitan Administration]
}

\section{Research Project:}

How does Thai Culture underpin the 2003 Early Childhood Curriculum in Thailand?

\section{Dear Sir/Madam}

My name is Sureepan Iemamnuay, and I am a PhD student in School of Education at Victoria University of Wellington, New Zealand. I am writing to request your permission for your early childhood service to participate in a questionnaire for my research.

This research will investigate how Thai culture underpins the 2003 Early Childhood Curriculum in Thailand. As Thailand is the only country in Southeast Asia region which has not been colonised by other European countries, Thai culture is considered to be important and unique. Young children today need to aware of and conserve the traditional Thai culture, such as language, literature, artworks, sculpture, and Thai dance. Moreover, they have to serve as good representatives to express 'Thainess' (a lifestyle of Thai nationality with Thai unique culture).

The purpose of my study is to explore how early childhood teachers integrate Thai culture into their daily teaching practice. I also want to investigate how principals, early childhood Head teachers, teachers and teacher assistants view the role of the government and parents in promoting Thai culture. Moreover, it will examine how parents promote Thai culture and their understanding of the 2003 Early Childhood Curriculum. The study will be carried out in two districts of central Bangkok, Klongtoey and Wattana.

The findings of the research may be useful in providing guidelines for early childhood teachers to integrate Thai culture into their daily teaching practices that align with the principles of the 2003 Early Childhood Curriculum. This study may also be of interest to the various national organisations that oversee the early childhood sector and how they can better support early childhood teachers to implement Thai culture into early childhood curriculum. This research has been approved by the Victoria University of Wellington Human Ethics Committee [approval number]. If you have any concerns about the ethical conduct of the research you may contact the Victoria University HEC Convener: Associate Professor Susan Corbett. Email susan.corbett@vuw.ac.nz or telephone +64-4-463 5480.

There will be two phases to the research. Phase one involves a paper-based questionnaire, which I am requesting to be carried out in your early childhood service. Early childhood teachers and teacher assistants will be invited to fill out this questionnaire. I anticipate that this will take approximately 30 minutes to fill in. Participants will be asked to identify the name of their service on the questionnaire, however, all information provided will be treated as confidential. Names of individuals and the service will not be used in reporting responses.

Phase two involves two in-depth case studies. The participants will be randomly selected from the eight early childhood services who filled out the questionnaire and agreed to participate in the case studies. The case-study data will be generated through document analysis of teachers' workbooks, and interviews with the School Principals, the early childhood Head teachers and 
two early childhood teachers who have a degree and two years of teaching experiences or more. I would like to also invite two parents from the early childhood teachers' classrooms to be participants in my study. Inferences from the document analysis will be shown and discussed further with the case-study teachers in the in-depth interview individually to avoid mistaken assumptions. It is anticipated that it may take up to one week to collect the data. If you agree for your service to be part of the case studies, I will provide you with more information about what will be required once a selection of case-study participants has been finalised. Your consent to take part in the second phase of the research would also be sought at the later stage of the study.

Participation in the research is voluntary and each participant may withdraw from the research at any point up to the final point of data collection 29 February 2016 without giving a reason.

Access to the data from the research will be restricted to my supervisors and me. The data will be securely stored as hard and soft copies. Both will be kept in password-protected files in a private computer and locked in filing cabinets in my home and my office. The data will be destroyed three years after the conclusion of the research. The data from the research will be published in my $\mathrm{PhD}$ thesis and academic journals and shared at education conferences. Participants will be given the opportunity to request a summary of the research findings.

I am requesting your permission to distribute the questionnaires to the early childhood teachers and teacher assistants in your service and if selected for them and others to participate in a case study. If you are willing for your early childhood service to participate in this study, I would appreciate it if you would communicate that you have consented to them being approached to participate.

I have attached the consent form for you to sign and the questionnaire that I will be sending out to participants for your information. I seek your assistance for your school administrator to distribute the questionnaire. An envelope will be provided for each participant to put in the filled questionnaire and then return it to the school administrator office to put in a sealed box to be collected at a later date agreed to. If you require any further information or have any questions about this study, please do not hesitate to contact me or my supervisors listed below.

Researcher:

\section{Sureepan Iemamnuay}

Email: mink.iemamnuay@vuw.ac.nz

\section{Supervisors:}

\author{
Dr. Mary Jane Shuker \\ Senior Lecturer \\ School of Education, \\ Phone: +64 44639659 \\ Email: mary-jane.shuker@vuw.ac.nz
}

Dr. Sophie Alcock

Senior Lecturer

School of Education,

Phone: +64 44636578

Email: sophie.alcock@vuw.ac.nz 


\section{Appendix C - 4}

\section{Consent Form for Principals of Early Childhood Services \\ [Department of Education Bangkok Metropolitan Administration]}

\section{Research Project:}

How does Thai Culture underpin the 2003 Early Childhood Curriculum in Thailand?

Please complete this form if you consent to Sureepan Iemamnuay conducting her doctoral research at your early childhood service.

\section{By giving permission to conduct Sureepan's $\mathrm{PhD}$ study in my early childhood service, I/we understand that:}

I/We have been given information about this research project, and I/we have discussed the research project with Sureepan Iemamnuay. I/We have had an opportunity to ask questions and have them answered to my/our satisfaction. I/We understand what is required of the participants from our early childhood service who take part in this research.

$\square$ Participation in the research is voluntary and the participants may withdraw from the study at any point up to the final point of data collection 29 February 2016 without giving a reason.

I/We understand that the service's identity and the participants' identities will be confidential.

All research information will be stored in password-protected files and locked filing cabinets, and access will be restricted to the researcher. It will be destroyed three years after the conclusion of the research.

The data collected will be used for a doctoral thesis and academic purposes only, and $\mathrm{I} / \mathrm{we}$ consent for it to be used in this manner.

I/We have been provided with contact details in case I/we have any further enquires about the research.

$\square$ I/We agree to organise with the School Administrator to distribute the questionnaire to the teachers and teacher assistants and have a sealed box for the filled questionnaires.

I/We consent to the researcher conducting her project in my/our service.

Name:

Position:

Signature:

Date:

Please indicate if you would like to receive a summary of the research findings when it is completed: $\quad \square$ Yes $\quad \square$ No

If yes, please indicate where it should be sent. If possible please provide an e-mail address, otherwise a postal address to which a hard copy can be sent 


\title{
Appendix $\mathbf{C}-5$
}

\section{Information Sheet for Early Childhood Teachers and Teacher Assistants [Department of Education Bangkok Metropolitan Administration]}

\author{
Research Project:
}

How does Thai Culture underpin the 2003 Early Childhood Curriculum in Thailand?

Dear Sir/Madam

My name is Sureepan Iemamnuay, and I am a PhD student in School of Education at Victoria University of Wellington, New Zealand. I am writing to request your permission to participate in a questionnaire for my research.

This research will investigate how Thai culture underpins the 2003 Early Childhood Curriculum in Thailand. As Thailand is the only country in Southeast Asia region which has not been colonised by other European countries, Thai culture is considered to be important and unique. Young children today need to aware of and conserve the traditional Thai culture, such as language, literature, artworks, sculpture, and Thai dance. Moreover, they have to serve as good representatives to express 'Thainess' (a lifestyle of Thai nationality with Thai unique culture).

The purpose of my study is to explore how early childhood teachers integrate Thai culture into their daily teaching practice. I also want to investigate how principals, early childhood Head teachers, teachers and teacher assistants view the role of the government and parents in promoting Thai culture. Moreover, it will examine how parents promote Thai culture and their understanding of the 2003 Early Childhood Curriculum. The study will be carried out in two districts of central Bangkok, Klongtoey and Wattana.

This research has been approved by the Victoria University of Wellington Human Ethics Committee [approval number]. If you have any concerns about the ethical conduct of the research you may contact the Victoria University HEC Convener: Associate Professor Susan Corbett. Email susan.corbett@ vuw.ac.nz or telephone +64-4-463 5480.

There will be two phases to the research. Phase one involves a paper-based questionnaire, which I am requesting to be carried out in your early childhood service. Early childhood teachers and teacher assistants will be invited to fill out this questionnaire. I anticipate that this will take approximately 30 minutes to fill in. Participants will be asked to identify the name of their service on the questionnaire, however, all information provided will be treated as confidential. Names of individuals and the service will not be used in reporting responses.

Phase two involves two in-depth case studies. The participants will be randomly selected from the eight early childhood services who filled out the questionnaire and agreed to participate in the case studies. The case-study data will be generated through document analysis of teachers' workbooks, and interviews with the School Principals, the early childhood Head teachers and two early childhood teachers who have a degree and two years of teaching experiences or more. I would like to also invite two parents from the early childhood teachers' classrooms to be participants in my study. Inferences from the document analysis will be shown and discussed further with the case-study teachers in the in-depth interview individually to avoid mistaken assumptions. It is anticipated that it may take up to one week to collect the data. If you agree to be part of the case studies, I will provide you with more information about what 
will be required once a selection of case-study participants has been finalised. Your consent to take part in the second phase of the research would also be sought at the later stage of the study.

Participation in the research is voluntary and each participant may withdraw from the research at any time up to the end of data collection period without giving a reason and without any negative repercussions.

Access to the data from the research will be restricted to my supervisors and me. The data will be securely stored as hard and soft copies. Both will be kept in password-protected files in a private computer and locked in filing cabinets in my home and my office. The data will be destroyed three years after the conclusion of the research. The data from the research will be published in my $\mathrm{PhD}$ thesis and academic journals and shared at education conferences. Participants will be given the opportunity to request a summary of the research findings.

If you are willing to participate in my study, I have attached a consent form and a questionnaire to fill in. An envelope will be provided for you to put in the filled questionnaire. I would highly appreciate your participation if you could complete and then return it to the school administrator who will collect them on my behalf by a date agreed to.

If you require any further information or have any questions about this study, please do not hesitate to contact me or my supervisors listed below.

Researcher:

Sureepan Iemamnuay

Email: mink.iemamnuay@vuw.ac.nz
Supervisors:

Dr. Mary Jane Shuker

Senior Lecturer

School of Education,

Phone: +64 44639659

Email: $\underline{\text { mary-jane.shuker@ vuw.ac.nz }}$

Dr. Sophie Alcock

Senior Lecturer

School of Education,

Phone: +64 44636578

Email: sophie.alcock@vuw.ac.nz 


\section{Appendix C - 6}

\section{Consent Form for Early Childhood Teachers and Teacher Assistants \\ [Department of Education Bangkok Metropolitan Administration]}

\section{Research Project:}

How does Thai Culture underpin the 2003 Early Childhood Curriculum in Thailand?

Please complete this form if you consent to Sureepan Iemamnuay conducting her doctoral research.

I have read the information letter about the research project and understand the purpose of the research.

I understand that my responses will be kept confidential to the researcher and the supervisors.

I understand that the research data will be stored in password-protected files and locked filing cabinets, and access will be restricted to the researcher. It will be destroyed three years after the conclusion of the research.

I understand that my participation in the research is voluntary and I may withdraw from the study any time up to the end of the data collection period without giving a reason and without any negative repercussions.

$\square$ The data collected will be used for a doctoral thesis and academic purposes only, and I consent for it to be used in this manner.

I have been provided with contact details in case I have any further enquires about the research.

I consent to participate in Phase Two of this research under the conditions stated on the information sheet.

Name of early childhood service:

Name of participant: Position:

Signature:

Date:

Please indicate if you would like to receive a summary of the research findings when it is completed: Yes No

If yes, please indicate where it should be sent. If possible please provide an e-mail address, otherwise a postal address to which a hard copy can be sent 
Appendix D: Information Letters and Consent Forms for Principals, Head Teachers, Early Childhood Teachers, and Parents: Phase Two (The Multiple Case Study) 


\title{
Appendix D - 1 \\ Information Sheet for Principals of Case-Study Early Childhood Services
}

\author{
[Department of Education Bangkok Metropolitan Administration]
}

\section{Research Project:}

How does Thai Culture underpin the 2003 Early Childhood Curriculum in Thailand?

\section{Dear Sir/Madam}

My name is Sureepan Iemamnuay, and I am a doctoral student in School of Education at Victoria University of Wellington, New Zealand. As you may know, the previous phase of my research was successful due to your support in obtaining the teacher-participants' opinions on how they integrate Thai culture into their daily teaching practices. I am now writing to request your permission and consent to conduct the next phase of the research at your service.

This research has been approved by the Victoria University of Wellington Human Ethics Committee [approval number]. If you have any concerns about the ethical conduct of the research you may contact the Victoria University HEC Convener: Associate Professor Susan Corbett. Email susan.corbett@vuw.ac.nz or telephone +64-4-463 5480.

Phase two will involve semi-structured interviews with you, the early childhood Head Teacher and two early childhood teachers, randomly selected from the questionnaire responses, who have a degree and two years of teaching experiences or more. I would like to also invite two parents from the early childhood teachers' classrooms to be participants in my study. The case study will be undertaken in the following manner:

- Visiting, information and ethical consent: I would like to visit your service to have a meeting with you and other participants to obtain consent to conduct the case study. All the participants will be provided with information about the research for their consideration prior to making an informed decision to participate in the research. The individual participants' information will be treated as confidential. Participation in the research is voluntary and each participant may withdraw from the research at any point up to the final point of data collection 29 February 2016 without giving a reason and without any negative repercussions.

- Scheduling: A mutually suitable out of school time will be negotiated and a schedule drawn up, at a time and place designated by the early childhood service. It is anticipated that it may take up to one week to collect the data.

- Collecting data: The case-study data will be generated through document analysis of teachers' workbooks and lesson plans and how they implement the 2003 Early Childhood Curriculum. Inferences from the document analysis will be shown and discussed further with the case-study teachers in the in-depth interview individually to avoid mistaken assumptions.

All of the interviews will be audio-recorded and the words written down. At the end of the interview, I will summarise the main points and check with the participants if the summary reflects their opinions. They will be welcome to suggest changes. The 
participants will also be sent a transcript of the interview for accuracy and makes changes. The semi-structured interview should take approximately $30-45$ minutes.

Name of your service, your name, and the other participants will not be reported in the study. Pseudonym will be used. Access to the data from the research will be restricted to my supervisors and me. The data will be securely stored as hard and soft copies. Both will be kept in password-protected files in a private computer and locked in filing cabinets in my home and my office. The data from the research will be published in my $\mathrm{PhD}$ thesis and academic journals and shared at education conferences. Participants will be given the opportunity to request a summary of the research findings.

Your permission to conduct the research at your service would be highly appreciated. If you are willing to participate, I would appreciate it if you would sign the consent form.

If you require any further information or have any questions about this research project, please do not hesitate to contact me or my supervisors.

Researcher:

\section{Sureepan Iemamnuay}

Email: mink.iemamnuay@ vuw.ac.nz
Supervisors:

Dr. Mary Jane Shuker

Senior Lecturer

School of Education,

Phone: +64 44639659

Email: mary-jane.shuker@vuw.ac.nz

Dr. Sophie Alcock

Senior Lecturer

School of Education,

Phone: +64 44636578

Email: sophie.alcock@vuw.ac.nz 


\section{Appendix D - 2}

\section{Consent Form for Principals of Case-Study Early Childhood Services \\ [Department of Education Bangkok Metropolitan Administration]}

\section{Research Project:}

How does Thai Culture underpin the 2003 Early Childhood Curriculum in Thailand?

Please complete this form if you consent to Sureepan Iemamnuay conducting her doctoral research at your early childhood service.

\section{By giving permission to conduct Sureepan's PhD study at my early childhood service, I/we understand that:}

I/We have been given information about this research project, and I/we have discussed the research project with Sureepan Iemamnuay. I/We have had an opportunity to ask questions and have them answered to my/our satisfaction. I/We understand what is required of the participants from my/our early childhood service who take part in this research.

Participation in the research is voluntary and the participants may withdraw from the study any time up to the end of the data collection period without giving a reason and without any negative repercussions.

I/We understand that the service's identity and the participants' identities will be confidential.

All research information will be stored in password-protected files and locked filing cabinets, and access will be restricted to the researcher. It will be destroyed three years after the conclusion of the research.

The data collected will be used for a doctoral thesis and academic purposes only, and $\mathrm{I} /$ we consent for it to be used in this manner.

I/We have been provided with contact details in case I/we have any further enquires about the research.

I/We consent to provide relevant documents about the 2003 Early Childhood Curriculum implementation to the researcher.

I/We understand that the participating the Head Teacher, teachers and parents will be interviewed after school hours.

I/We understand that all interviews will be conducted at a time and place designated by the early childhood service.

I/We understand that the data collected from document reviews and interviews will be treated as confidential.

I/We consent to the researcher audio-recoding the interview.

I/We understand that all participants will have the opportunity to check the summary and transcripts for accuracy and make changes. They also have an opportunity to receive a copy of the summary of the research.

I/We consent to participate in this research under the conditions stated on the information letter. 
Name:

Position:

Signature:

Date:

Please indicate if you would like to receive a summary of the research findings when it is completed:

$\square$ Yes

$\square$ No

If yes, please indicate where it should be sent. If possible please provide an e-mail address, otherwise a postal address to which a hard copy can be sent

(The subject will be given a copy of this to keep after signing this form) 


\title{
Appendix D - 3
}

\section{Information Sheet for Case-Study Early Childhood Head Teachers}

\section{[Department of Education Bangkok Metropolitan Administration]}

\author{
Research Project:
}

How does Thai Culture underpin the 2003 Early Childhood Curriculum in Thailand?

\section{Dear Sir/Madam}

My name is Sureepan Iemamnuay, and I am a doctoral student in School of Education at Victoria University of Wellington, New Zealand. The previous phase of my research, which was a paper-based questionnaire, was successful due to your early childhood service's support. I am now seeking your consent to participate in Phase Two of this study.

This research has been approved by the Victoria University of Wellington Human Ethics Committee [approval number]. If you have any concerns about the ethical conduct of the research you may contact the Victoria University HEC Convener: Associate Professor Susan Corbett. Email susan.corbett@ vuw.ac.nz or telephone +64-4-4635480.

Phase two will involve semi-structured interview with you, the School Principal, and two early childhood teachers, randomly selected from the questionnaire responses, who have a degree and two years of teaching experiences or more. I would like to also invite two parents from the early childhood teachers' classrooms to be participants in my study. The case study will be undertaken in the following manner:

- Information and ethical consent: You will be provided with information about the research for your consideration prior to making an informed decision to participate in the research. Participation in the research is voluntary and you may withdraw from the research at any point up to the final point of data collection 29 February 2016 without giving a reason and without any negative repercussions.

- Scheduling: If you consent to be involved a mutually suitable out of school time will be negotiated at a time and place designated by you. It is anticipated that it may take up to one week to complete all the data collection at your service.

- Collecting data: The case-study data will be generated through document analysis of your lesson plans and workbooks, and how you implement the 2003 Early Childhood Curriculum. Inferences from the document analysis will be shown and discussed further during an in-depth interview with you to avoid mistaken assumptions.

Your interview will be audio-recorded and the words written down. At the end of the interview, I will summarise the main points and check with you the summary reflect your opinions. You will be welcome to suggest changes. You will also be sent a transcript of the interview for accuracy and makes changes. The semi-structured interview should take approximately $30-45$ minutes. 
Name of your service, your name, and the other participants will not be reported in the study. Pseudonym will be used. Access to the data from the research will be limited to my supervisors and me. The data will be securely stored as hard and soft copies. Both will be kept in password-protected files in a private computer and locked in filing cabinets in my home and my office. The data from the research will be published in my $\mathrm{PhD}$ thesis and academic journals and shared at education conferences. Participants will be given the opportunity to request a summary of the research findings.

At this point, I hope that you will be able to participate in this research. If you are willing to participate in my study, I would appreciate it if you would sign a consent form and I will be in touch with you to schedule a time to meet.

If you require any further information or have any questions about this research project, please do not hesitate to contact me or my supervisors.

Researcher:

\section{Sureepan Iemamnuay}

Email: mink.iemamnuay@vuw.ac.nz
Supervisors:

Dr. Mary Jane Shuker

Senior Lecturer

School of Education,

Phone: +64 44639659

Email: mary-jane.shuker@vuw.ac.nz

Dr. Sophie Alcock

Senior Lecturer

School of Education,

Phone: +64 44636578

Email: sophie.alcock@vuw.ac.nz 


\section{Appendix D - 4}

\section{Consent Form for Case-Study Early Childhood Head Teachers \\ [Department of Education Bangkok Metropolitan Administration]}

\section{Research Project:}

How does Thai Culture underpin the 2003 Early Childhood Curriculum in Thailand?

Please complete this form if you consent to Sureepan Iemamnuay conducting her doctoral research.

I have been given information about this research project, and have discussed the research project with Sureepan Iemamnuay. I have had an opportunity to ask questions and have them answered to my satisfaction.

$\square$ I understand that my participation in the research is voluntary and I may withdraw from the study any time up to the end of the data collection period without giving a reason and without any negative repercussions.

I understand that the data collected from document reviews and interviews will be treated as confidential.

$\square$ I consent to the researcher audio-recoding the interview.

$\square$ All research information will be stored in password-protected files and locked filing cabinets, and access will be restricted to the researcher. It will be destroyed three years after the conclusion of the research.

$\square$ The data collected will be used for a doctoral thesis and academic purposes only, and I consent for it to be used in this manner.

I have been provided with contact details in case I have any further enquiries about the research.

$\square$ I consent to providing the researcher with my lesson plans and teaching materials.

$\square \quad$ I understand that I will have the opportunity to check the summary and transcripts for accuracy and make changes. I also have an opportunity to receive a copy of the summary of the research.

$\square$ I consent to participate in this research under the conditions stated on the information letter.

Name of early childhood service:

Name of participant:

Signature:

Date:

Please indicate if you would like to receive a summary of the research findings when it is completed: Yes No

If yes, please indicate where it should be sent. If possible please provide an e-mail address, otherwise a postal address to which a hard copy can be sent 


\title{
Appendix D - 5
}

\section{Information Sheet for Case-Study Early Childhood Teachers}

\section{[Department of Education Bangkok Metropolitan Administration]}

\author{
Research Project: \\ How does Thai Culture underpin the 2003 Early Childhood Curriculum in Thailand?
}

\author{
Researcher: \\ Sureepan Iemamnuay
}

Dear Sir/Madam

Thank you for your participation in the questionnaire of my research (Phase One). I am writing to inform you that you have been selected to be one of the participants to participate in the case study (Phase two) as part of my research project on how Thai culture underpins the 2003 Early childhood Curriculum. I am seeking your consent to participate in Phase Two of this study.

This research has been approved by the Victoria University of Wellington Human Ethics Committee [approval number]. If you have any concerns about the ethical conduct of the research you may contact the Victoria University HEC Convener: Associate Professor Susan Corbett. Email susan.corbett@ vuw.ac.nz or telephone +64-4-4635480.

Phase two will involve semi-structured interviews with the School Principal, the early childhood Head Teacher, you and one other early childhood teacher, randomly selected from the questionnaire responses, who have a degree and two years of teaching experiences or more. I would like to also invite two parents from the early childhood teachers' classrooms to be participants in my study. The case study will be undertaken in the following manner:

- Information and ethical consent: You will be provided with information about the research for your consideration prior to making an informed decision to participate in the research. Participation in the research is voluntary and you may withdraw from the research at any point up to the final point of data collection 29 February 2016 without giving a reason and without any negative repercussions.

- Scheduling: If you consent to be involved a mutually suitable out of school time will be negotiated at a time and place designated by you. It is anticipated that it may take up to one week to complete all the data collection at your service.

- Collecting data: The case-study data will be generated through document analysis of your workbooks and lesson plans, and how you implement the 2003 Early Childhood Curriculum. Inferences from the document analysis will be shown and discussed further with the case-study teachers in the in-depth interview individually to avoid mistaken assumptions.

Your interview will be audio-recorded and the words written down. At the end of the interview, I will summarise the main points and check with you the summary reflect your opinions. You will be welcome to suggest changes. You will also be sent a 
transcript of the interview for accuracy and makes changes. The semi-structured interview should take approximately $30-45$ minutes.

I would also appreciate you asking two children's parents from your class if they would be willing to participate in this research. I will follow-up with the parents themselves to explain about my research. I would also like to seek your assistance in directing any queries from the parents of the children to me, should they make any contact with you about the research. The names of your service, your name and the children's names will not be used in the reporting in the study. Pseudonyms will be used.

Name of your service, your name, and the other participants will not be reported in the study. Pseudonym will be used. Access to the data from the research will be restricted to my supervisors and me. The data will be securely stored as hard and soft copies. Both will be kept in password-protected files in a private computer and locked in filing cabinets in my home and my office. The data from the research will be published in my $\mathrm{PhD}$ thesis and academic journals and shared at education conferences. Participants will be given the opportunity to request a summary of the research findings.

At this point, I hope that you will be able to participate in this research. If you are willing to participate in my study, I would appreciate it if you would sign a consent form and I will be in touch with you to schedule a time to meet.

If you require any further information or have any questions about this research project, please do not hesitate to contact me or my supervisors.

Researcher:

\section{Sureepan Iemamnuay}

Email: mink.iemamnuay@vuw.ac.nz
Supervisors:

Dr. Mary Jane Shuker

Senior Lecturer

School of Education,

Phone: +64 44639659

Email: mary-jane.shuker@vuw.ac.nz

Dr. Sophie Alcock

Senior Lecturer

School of Education,

Phone: +64 44636578

Email: sophie.alcock@vuw.ac.nz 


\section{Appendix D - 6}

\section{Consent Form for Case-Study Early Childhood Teachers}

\section{[Department of Education Bangkok Metropolitan Administration]}

\section{Research Project:}

How does Thai Culture underpin the 2003 Early Childhood Curriculum in Thailand?

Please complete this form if you consent to Sureepan Iemamnuay conducting her doctoral research.

I have been given information about this research project, and have discussed the research project with Sureepan Iemamnuay. I have had an opportunity to ask questions and have them answered to my satisfaction.

$\square$ I understand that my participation in the research is voluntary and I may withdraw from the study any time up to the end of the data collection period without giving a reason and without any negative repercussions.

$\square$ I understand that the data collected from document reviews and interviews will be treated as confidential.

I consent to the researcher audio-recoding the interview.

All research information will be stored in password-protected files and locked filing cabinets, and access will be restricted to the researcher. It will be destroyed three years after the conclusion of the research.

The data collected will be used for a doctoral thesis and academic purposes only, and I consent for it to be used in this manner.

I have been provided with contact details in case I have any further enquiries about the research.

$\square$ I consent to providing the researcher with my lesson plans and teaching materials.

$\square$ I understand that I will have the opportunity to check the summary and transcripts for accuracy and make changes. I also have an opportunity to receive a copy of the summary of the research.

I agree to help asking two children's parents from my class to participate in this research.

I consent to participate in this research under the conditions stated on the information letter.

Name of early childhood service:

Name of participant:

Signature: Date:

Please indicate if you would like to receive a summary of the research findings when it is completed: Yes No

If yes, please indicate where it should be sent. If possible please provide an e-mail address, otherwise a postal address to which a hard copy can be sent 


\title{
Appendix D - 7
}

\section{Information Sheet for Parent/Legal Guardian}

\section{[Department of Education Bangkok Metropolitan Administration]}

\author{
Research Project:
}

How does Thai Culture underpin the 2003 Early Childhood Curriculum in Thailand?

\section{Dear Sir/Madam}

My name is Sureepan Iemamnuay, and I am a doctoral student in School of Education at Victoria University of Wellington, New Zealand. Dr Mary Jane Shuker and Dr Sophie Alcock from Victoria University of Wellington, New Zealand are my supervisors for this study.

This research has been approved by the Victoria University of Wellington Human Ethics Committee [approval number]. If you have any concerns about the ethical conduct of the research you may contact the Victoria University HEC Convener: Associate Professor Susan Corbett. Email susan.corbett@ vuw.ac.nz or telephone +64-4-463 5480.

This research will explore how Thai culture underpins the 2003 Early Childhood Curriculum and how early childhood teachers integrate Thai culture into their daily teaching practice. This will be examined alongside how parents promote Thai culture and their understanding of the 2003 Early Childhood Curriculum. The study will be carried out in two districts of central Bangkok, Klongtoey and Wattana.

In order to gain an in-depth understanding of how you promote Thai culture in your child's early childhood service and at home, I am seeking permission to interview you. A semistructured interview will take approximately $30-45$ minutes. The interview will be audiorecorded and the words written down. At the end of the interview, I will summarize the main points and check with you that the summary reflects your opinions. You are welcome to suggest changes.

Your name and the name of the name of the early childhood service will not be reported in the study. Pseudonyms will be used. You may withdraw at any point up to the final point of data collection by 29 February 2016 without giving a reason.

The data from the research will be published in my $\mathrm{PhD}$ thesis and academic journals and shared at education conferences. Access to the data from the research will be restricted to my supervisors and me. The data will be securely stored and then destroyed three years after the conclusion of the research. Participants will be given the opportunity to request a summary of the research findings.

At this point, I hope that you will be able to participate in this research. If you are willing to participate in my study, I would appreciate it if you would sign a consent form and I will be in touch with you for scheduling an interview.

If you require any further information or have any questions about this research project, please do not hesitate to contact me or my supervisors. 
Researcher:

\section{Sureepan Iemamnuay}

Email: mink.iemamnuay@ vuw.ac.nz
Supervisors:

Dr. Mary Jane Shuker

Senior Lecturer

School of Education,

Phone: +64 44639659

Email: mary-jane.shuker@vuw.ac.nz

Dr. Sophie Alcock

Senior Lecturer

School of Education,

Phone: +64 44636578

Email: sophie.alcock@vuw.ac.nz 


\section{Appendix D - 8}

\section{Consent Form for Parent/Legal Guardian}

\section{[Department of Education Bangkok Metropolitan Administration]}

\section{Research Project:}

How does Thai Culture underpin the 2003 Early Childhood Curriculum in Thailand?

Please complete this form if you consent to Sureepan Iemamnuay conducting her doctoral research.

I have been given information about this research project, and have discussed the research project with Sureepan Iemamnuay. I have had an opportunity to ask questions and have them answered to my satisfaction.

I understand that my participation in the research is voluntary and I may withdraw from the study any time up to the end of the data collection period without giving a reason and without any negative repercussions.

$\square$ I understand that the data collected from document reviews and interviews will be treated as confidential.

I consent to the researcher audio-recoding the interview.

All research information will be stored in password-protected files and locked filing cabinets, and access will be restricted to the researcher. It will be destroyed three years after the conclusion of the research.

$\square$ The data collected will be used for a doctoral thesis and academic purposes only, and I consent for it to be used in this manner.

$\square \quad$ I have been provided with contact details in case I have any further enquiries about the research.

$\square$ I understand that I will have the opportunity to check the summary and transcripts for accuracy and make changes. I also have an opportunity to receive a copy of the summary of the research.

I consent to participate in this research under the conditions stated on the information letter.

Name of early childhood service:

Name of participant:

Signature:

Date:

Please indicate if you would like to receive a summary of the research findings when it is completed: Yes No

If yes, please indicate where it should be sent. If possible please provide an e-mail address, otherwise a postal address to which a hard copy can be sent 
Appendix E: Examples of Interview Questions for the Principals, Head Teachers, Early Childhood Teachers and Parents/Legal Guardians (Phase Two: The Multiple Case Study) 


\section{Principals}

1. Does your early childhood service develop its own early childhood curriculum (ECC) by using guidelines from the 2003 Early Childhood Curriculum? (Yes/No - please explain)

2. Can you tell me about any aspects of Thainess and Thai culture are practiced at your early childhood service?

3. Does your early childhood service celebrate Loy Kratong festival? What sort of activities do you organise for the children?

4. How do you teach Thai culture and values with young children?

5. Are there any Buddhist principles or Thai concepts that underpin your early childhood service? (Yes/No - please explain)

6. Do you arrange any meditation at your early childhood service? (Yes/No - please explain where and how often). If no, does the service have any plans to incorporate this into their programme?

7. Do you organise any fieldtrips to visit temples? (Yes/No - please explain where and how often). If not, why is this the case? Any future plans to do so?

8. How do you encourage parents' participation at your early childhood service? Do parents attend the teacher-parent meetings, but not other activities?

9. What types of activities/events do parents usually participate in your early childhood service? What do you do for Father's and Mother's Day?

10. How does the government support your early childhood service in promoting Thai culture? How could the government support your service better?

11. What do you think it is the best way to express Thainess and Thai culture? What aspects do you consider to be the most important? Role of parents in doing this?

\section{Prompts:}

1. Early childhood services may have its own curriculum designed by using the guidelines from the 2003 Early Childhood Curriculum. How long has it been developed?

2. For example, lesson about Thai national flag, teaching about Thai history, and encouraging children to be aware of Thai identity and Thai culture. How this is implemented? Any other compulsory practices?

3. If no, why don't they celebrate this occasion?

4. How does the early childhood service raise awareness of and encourage children to be proud of being Thai? How do they teach and promote Thai culture among children?

5. Services may incorporate Buddhist principles or Thai concepts into their lessons. Please give some examples. How do they impact children's learning?

6. If yes, how often and when was the last session? 


\section{Head Teachers}

1. Can you tell me how you think Thainess fit into the 2003 Early Childhood Curriculum?

2. In your early childhood service how does the 2003 Early Childhood Curriculum influence lesson plans and teaching practices?

3. What activities do you usually plan to promote Thai culture? You mentioned in your lesson plans you incorporate Thai culture into your teaching practices. Can you give explain those activities in more detail?

4. How does your early childhood team celebrate during Loy Kratong festival?

5. How does your early childhood service celebrate on Father's and Mother's Day?

6. Are there any Buddhist principles or Thai concepts that underpin your teaching practices? How do they impact children's learning?

7. Do you organise any fieldtrips to visit Temples? (Yes/No - please explain). If not, why is this the case? Any future plans to do so?

8. Tell me about how parents participate in your early childhood service? Do parents attend the teacher-parent meetings, but not other activities?

9. How does the government support your early childhood service in promoting Thai culture? How could the government support your service better?

\section{Prompts:}

1. For example, what is your opinion about the concepts of Thai culture underpinning the 2003 Early Childhood Curriculum? How do you follow the guidelines of the curriculum in responding to children's individual differences and their community context?

2. What do you consider to be the positive and/or negative impact from implementing the curriculum? Is it difficult to incorporate the guidelines from the curriculum in your planning lessons?

3. For example, using the Thai traditional greeting (Wai), encouraging children to involve in Thai traditions and celebration, teaching them about Thai history.

4. For instance, a service may or may not arrange any activities on this special occasion. If yes, what does your service normally do? If no, why do you not celebrate this occasion?

5. Are parents invited to participate? What is the parents' response? How could you further encourage parents' participation?

6. Services may incorporate Buddhist principles or Thai concepts into their lessons. Please give some examples. If no, is there any Thai-way characteristics they promote in their children? 


\section{Early Childhood Teachers}

1. What activities do you usually do to promote Thai culture? You also mentioned in your lesson plans you incorporate Thai culture into your teaching practices. Can you give explain those activities in more details?

2. How do you teach children about a topic of a 'Thai national flag'?

3. At your early childhood service do you celebrate the Loy Kratong festival? How exactly do you celebrate this festival?

4. What activities do you plan to do on Father's and Mother's Day?

5. What Buddhist principles or Thai concepts underpin your teaching practices?

6. How do these principles promote children's learning and development?

7. Do you promote any meditation practice at your early childhood service? How do you think this promotes children's learning?

8. Do you have any problems integrating Thainess and Thai culture into your teaching practices? What types of support assist you to do this better?

9. How do parents participate in your early childhood service to promote Thainess and Thai culture?

10. What do you think is the government's role in promoting Thai identity and Thai culture?

\section{Prompts:}

1. For example, teaching children to pay respect elders, performing Wai, and learning about the Thai identity (the nation, the religion, and the King)

2. Can you share me with your lesson plans or any related teaching materials in relation to this?

3. If no, why do not they celebrate this occasion?

4. Do parents participate any activities in your classroom on these two days? Do you have workbooks or relevant documents for these occasions?

5. Please give a specific example of incorporating Buddhist principles into your classroom.

6. Is there any positive or negative impacts on children? 


\section{Parent/Legal Guardian}

1. Are you familiar with the 2003 Early Childhood Curriculum? (Yes/No - please explain)

2. How often are you involved in activities or events at your child's early childhood service?

3. How do you teach Thai culture and values with young children?

4. Do the teachers consult with you when designing lesson planning and learning activities?

5. Can you tell me about any recent events/activities which you have participated in and when was it?

6. How does your family celebrate during Songkran festival?

7. What do your family usually do on Visakha Bucha Day?

8. Why do you think it is important to promote Thai culture and identity with young children? What do you think the role of your child's service should be in this regard?

9. In your opinion, what learning activities at your child's early childhood service can help promote Thainess?

\section{Prompts:}

1. If yes, how do you know about this? Do you know from this service?

2. Parents may only attend the teacher-parent meeting. Please give some examples of activities that you always participate in.

3. What sorts of Thai values you encourage your children to do?

4. Parents may participate in a classroom as a guest speaker in the topic of "Children's dream to be in the future".

5. How often do you usually participate in school activities? How do they feel about their participation?

6. What are the specific activities do you do with children? Any water splashing? 


\section{Appendix F: Qualitative Codebook}

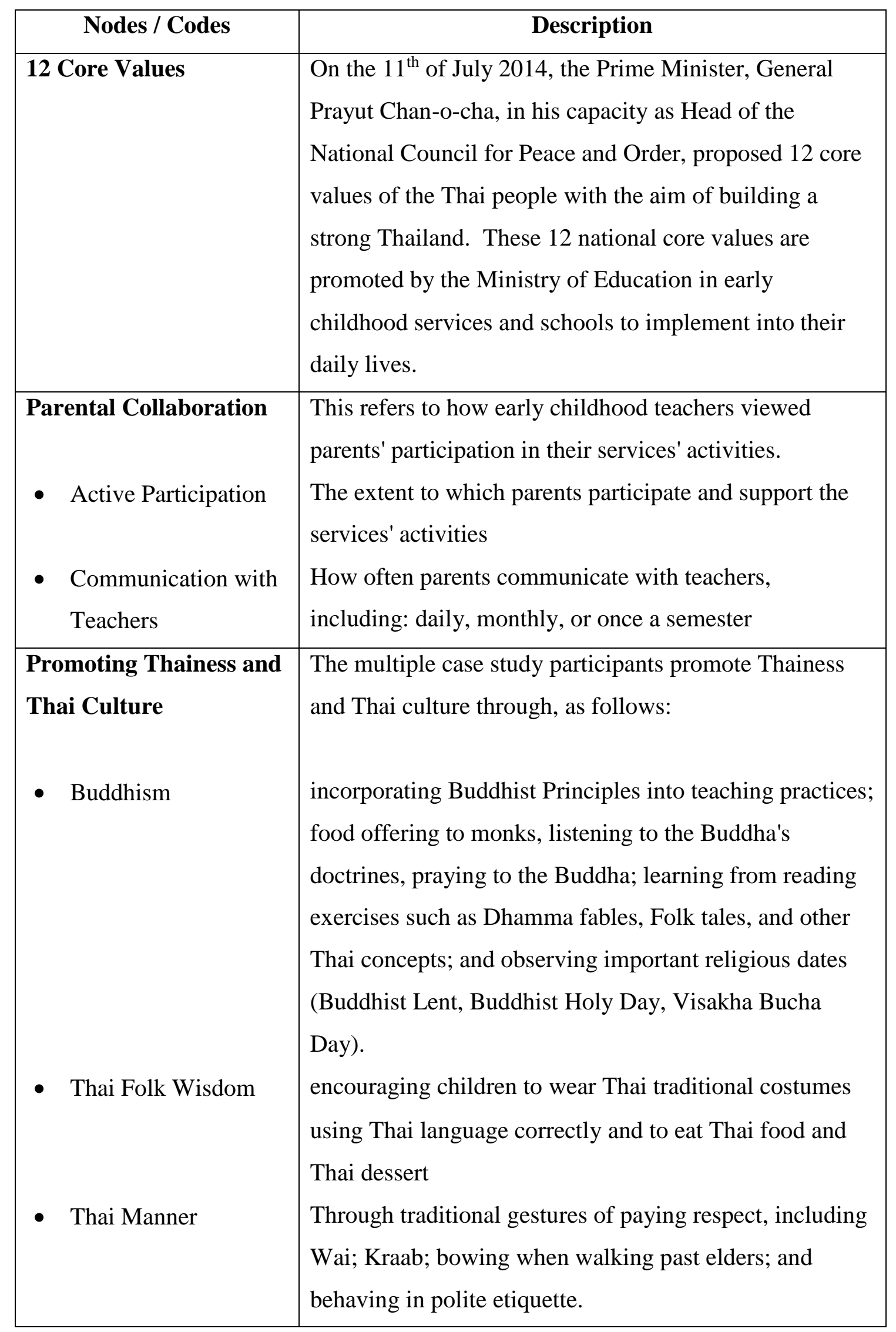




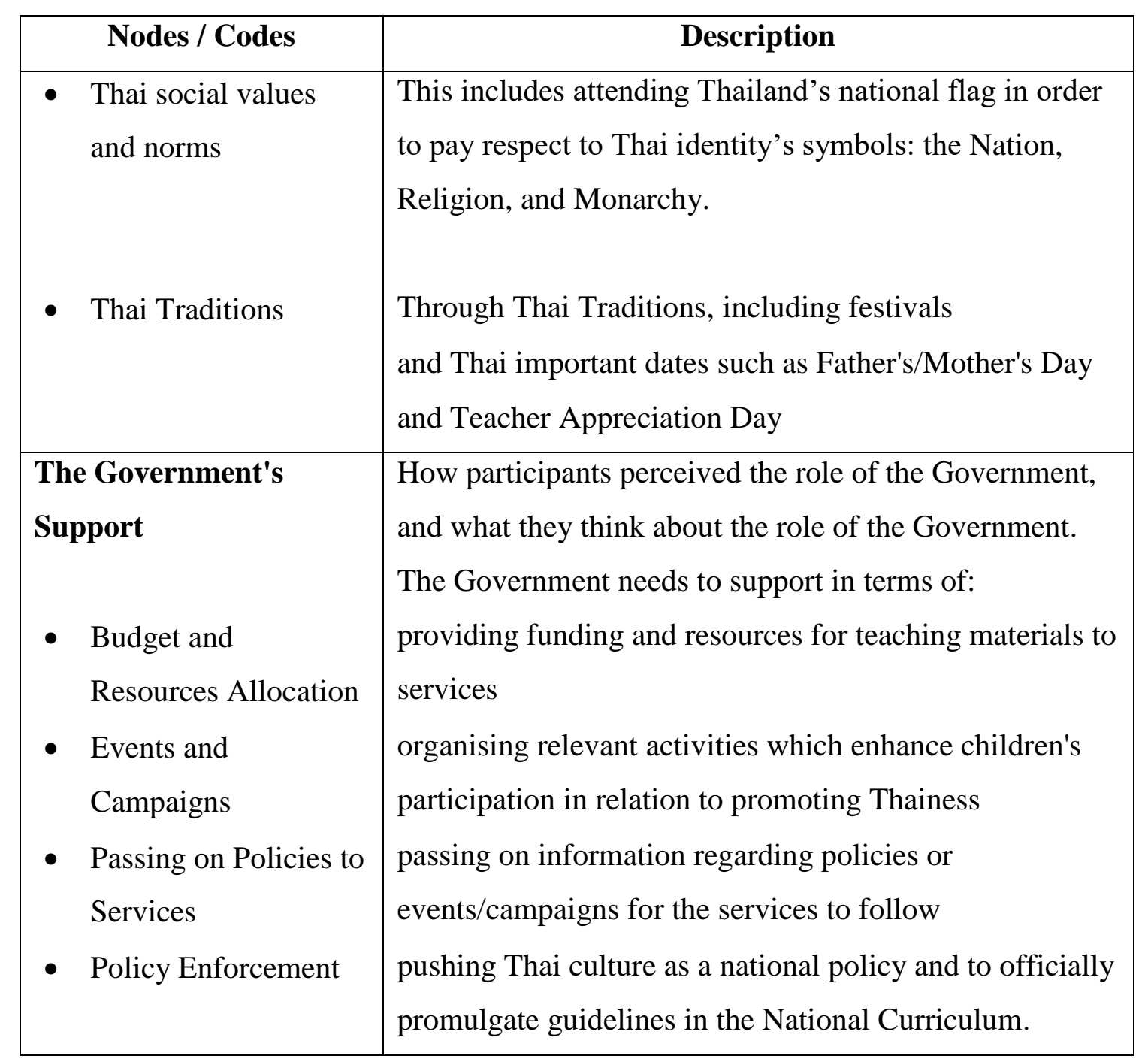


Appendix G: Cross-Tabulation Analysis

\begin{tabular}{|c|c|c|c|c|c|c|c|c|}
\hline \multirow[b]{2}{*}{ Thai Manners } & \multicolumn{4}{|c|}{ OPEC } & \multirow{2}{*}{$\begin{array}{c}\text { OHEC } \\
\text { Cherry } \\
\text { Blossom }\end{array}$} & \multirow{2}{*}{$\begin{array}{c}\text { OBEC } \\
\text { Sunflower }\end{array}$} & \multicolumn{2}{|c|}{ EDU - BMA } \\
\hline & Anemone & Primrose & Jamesia & Kalmia & & & Daffodil & Foxglove \\
\hline Wai & $\begin{array}{l}\text { Paying respect } \\
\text { to people/ } \\
\text { place/objects }\end{array}$ & $\begin{array}{l}\text { A way of } \\
\text { greeting and } \\
\text { paying } \\
\text { respect }\end{array}$ & $\begin{array}{l}\text { Wai and } \\
\text { respect } \\
\text { others }\end{array}$ & Wai & $\begin{array}{l}\text { Wai and } \\
\text { paying respect } \\
\text { to others }\end{array}$ & $\begin{array}{c}\text { Wai and } \\
\text { paying respect }\end{array}$ & $\begin{array}{l}\text { Wai people } \\
\text { and Buddha } \\
\text { image }\end{array}$ & $\begin{array}{l}\text { Wai and paying } \\
\text { respect to parents, } \\
\text { teachers, elders, and } \\
\text { the King and the } \\
\text { Queen. }\end{array}$ \\
\hline Kraab & Kraab & & & Kraab & & & & \\
\hline $\begin{array}{l}\text { Etiquette } \\
\text { (Appropriate and } \\
\text { polite manners in } \\
\text { each action) }\end{array}$ & $\begin{array}{l}\text { - Being polite } \\
\text { when greeting } \\
\text { elders and } \\
\text { others } \\
\text { - Queuing } \\
\text { - Sitting } \\
\text { properly }\end{array}$ & $\begin{array}{l}\text { - Speaking } \\
\text { politely }\end{array}$ & $\begin{array}{l}\text { - Being } \\
\text { polite when } \\
\text { speaking } \\
\text { - Having } \\
\text { self- } \\
\text { discipline }\end{array}$ & $\begin{array}{l}\text { - Speaking in a } \\
\text { nice manner } \\
\text { - when eating do } \\
\text { not talk } \\
\text { - Walk calmly }\end{array}$ & & $\begin{array}{l}\text { - Speak } \\
\text { politely } \\
\text { - Eating } \\
\text { properly } \\
\text { - Self- } \\
\text { discipline }\end{array}$ & $\begin{array}{l}\text { - Speaking } \\
\text { with a nice } \\
\text { tone } \\
\text { - Eating } \\
\text { without } \\
\text { talking } \\
\text { - Behave in a } \\
\text { polite manner }\end{array}$ & $\begin{array}{l}\text { - Use a polite } \\
\text { manner when } \\
\text { speaking and eating } \\
\text { - walk calmly } \\
\text { - having self- } \\
\text { control }\end{array}$ \\
\hline $\begin{array}{l}\text { Bow when } \\
\text { passing elders }\end{array}$ & Yes & & Yes & Yes & & & & Yes \\
\hline $\begin{array}{l}\text { How to promote } \\
\text { Thai manners }\end{array}$ & $\begin{array}{l}\text { Teachers } \\
\text { designed } \\
\text { additional } \\
\text { learning } \\
\text { activities to } \\
\text { promote Thai } \\
\text { manners in } \\
\text { children }\end{array}$ & & & $\begin{array}{l}\text { Promoting Thai } \\
\text { manners is one } \\
\text { of the services' } \\
\text { aspiration }\end{array}$ & & & $\begin{array}{c}\text { Teachers } \\
\text { encouraged } \\
\text { children to } \\
\text { participate in } \\
\text { Wai } \\
\text { competition }\end{array}$ & $\begin{array}{c}\text { Teachers } \\
\text { encouraged children } \\
\text { to Wai parents at } \\
\text { the school gate and } \\
\text { pay respect to the } \\
\text { photos of the King } \\
\text { and the Queen by } \\
\text { bowing (for male) } \\
\text { and curtsying (for } \\
\text { female) }\end{array}$ \\
\hline
\end{tabular}

*Thai manners were the best way to express Thainess 


\begin{tabular}{|c|c|c|c|c|c|c|c|c|}
\hline & \multicolumn{4}{|c|}{ OPEC } & \multirow{2}{*}{$\begin{array}{c}\text { OHEC } \\
\text { Cherry } \\
\text { Blossom }\end{array}$} & \multirow{2}{*}{$\frac{\text { OBEC }}{\text { Sunflower }}$} & \multicolumn{2}{|c|}{ EDU - BMA } \\
\hline Thai traditions & Anemone & Primrose & Jamesia & Kalmia & & & Daffodil & Foxglove \\
\hline $\begin{array}{l}\text { Loy Kratong } \\
\text { - Teaching about } \\
\text { the importance of } \\
\text { this festival and } \\
\text { how to make a } \\
\text { floating basket }\end{array}$ & $\begin{array}{c}\text { Yes } \\
\text { (Importance of } \\
\text { Water) }\end{array}$ & Yes & Yes & Yes & Yes & $\begin{array}{c}\text { Yes } \\
\text { (Importance of Water } \\
- \text { as a source of } \\
\text { transportation and } \\
\text { agriculture) }\end{array}$ & Yes & Yes \\
\hline $\begin{array}{l}\text { - Floating a basket } \\
\text { in a temporarily- } \\
\text { made pond } \\
\text { provided by the } \\
\text { services }\end{array}$ & Yes & Yes & No & Yes & Yes & Yes & & Yes \\
\hline - Singing a song & & Yes & No & Yes & & Yes & & Yes \\
\hline $\begin{array}{l}\text { How did early } \\
\text { childhood services } \\
\text { do this? }\end{array}$ & $\begin{array}{l}\text { The service } \\
\text { offered } \\
\text { children a } \\
\text { real-life } \\
\text { experience } \\
\text { (Floating a } \\
\text { basket) }\end{array}$ & $\begin{array}{l}\text { - Work together } \\
\text { with children to } \\
\text { make a floating } \\
\text { basket } \\
\text { - Children's } \\
\text { drawing and } \\
\text { colouring a } \\
\text { kratong }\end{array}$ & $\begin{array}{l}\text { ONLY } \\
\text { Learning } \\
\text { about the } \\
\text { festival }\end{array}$ & $\begin{array}{l}\text { The service } \\
\text { offered } \\
\text { children a } \\
\text { real-life } \\
\text { experience } \\
\text { (Floating a } \\
\text { basket) }\end{array}$ & $\begin{array}{l}\text { The service } \\
\text { offered children } \\
\text { a real-life } \\
\text { experience } \\
\text { (Floating a } \\
\text { basket) }\end{array}$ & $\begin{array}{l}\text { Teachers taught } \\
\text { children to fold a } \\
\text { petal of a floating } \\
\text { basket by starting } \\
\text { with folding paper } \\
\text { first }\end{array}$ & $\begin{array}{l}\text { Children were } \\
\text { encouraged to } \\
\text { learn from a } \\
\text { real-life } \\
\text { experience at } \\
\text { a nearby } \\
\text { temple }\end{array}$ & $\begin{array}{l}\text { The service } \\
\text { offered children } \\
\text { a real-life } \\
\text { experience } \\
\text { (Floating a } \\
\text { basket) }\end{array}$ \\
\hline Songkran & & & & & & & & \\
\hline $\begin{array}{l}\text { HOW TO: } \\
\text { - Performing a } \\
\text { water pouring to } \\
\text { parents, elders, or } \\
\text { grandparents } \\
\text { - Playing water } \\
\text { splashing }\end{array}$ & Yes & Yes & Yes & Yes & Yes & $\begin{array}{l}1^{\text {st }} \text { parent: Islamic - } \\
\text { NO! } \\
2^{\text {nd }} \text { parent: YES and } \\
\text { also performed a } \\
\text { meritorious ritual for } \\
\text { their ancestors }\end{array}$ & Yes & $\begin{array}{l}1^{\text {st }} \text { parent: YES } \\
2^{\text {nd }} \text { parent: NO, } \\
\text { a mother needs } \\
\text { to earn for a } \\
\text { living }\end{array}$ \\
\hline
\end{tabular}




\begin{tabular}{|c|c|c|c|c|c|c|c|c|}
\hline & \multicolumn{4}{|c|}{ OPEC } & OHEC & OBEC & \multicolumn{2}{|c|}{ EDU - BMA } \\
\hline Thai traditions & Anemone & Primrose & Jamesia & Kalmia & $\begin{array}{l}\text { Cherry } \\
\text { Blossom }\end{array}$ & Sunflower & $\begin{array}{c}\text { Daffodi } \\
\text { l }\end{array}$ & Foxglove \\
\hline $\begin{array}{l}\text { Father's / } \\
\text { Mother's Day }\end{array}$ & $\begin{array}{l}\text { Sample of the } \\
\text { event in } 2015\end{array}$ & & & & & & & \\
\hline $\begin{array}{l}\text { - Giving precedence } \\
\text { to the King and the } \\
\text { Queen }\end{array}$ & $\begin{array}{l}\text { Their royal } \\
\text { duties are } \\
\text { displayed on } \\
\text { notice boards }\end{array}$ & $\begin{array}{c}\text { Yes } \\
\text { (Taking the } \\
\text { King as a role } \\
\text { model) }\end{array}$ & Yes & Yes & Yes & Yes & & \\
\hline $\begin{array}{l}\text { - Making something } \\
\text { for children's mums } \\
\text { and dads }\end{array}$ & $\begin{array}{l}\text { Painted on } \\
\text { their old } \\
\text { t-shirts }\end{array}$ & & & $\begin{array}{l}\text { Record book for } \\
\text { things they have } \\
\text { done for their } \\
\text { parents at home. } \\
\text { Children will } \\
\text { make a list of } \\
\text { things they } \\
\text { would like to do } \\
\text { for their parents. }\end{array}$ & & & Cards & $\begin{array}{c}\text { Photo } \\
\text { competition }\end{array}$ \\
\hline $\begin{array}{l}\text { - Inviting parents to } \\
\text { attend the } \\
\text { expressing gratitude } \\
\text { activity (performing } \\
\text { Kraab and giving } \\
\text { garlands to them) }\end{array}$ & $\begin{array}{l}\text { NO } \\
\text { (concerns } \\
\text { about children } \\
\text { who did not } \\
\text { live with their } \\
\text { parents - bad } \\
\text { impacts on } \\
\text { children's } \\
\text { feeling) }\end{array}$ & Yes & Yes & $\begin{array}{c}\text { NO } \\
\text { (concerns about } \\
\text { children who } \\
\text { did not live with } \\
\text { their parents - } \\
\text { bad impacts on } \\
\text { children's } \\
\text { feeling) } \\
\text { NO parking } \\
\text { space! }\end{array}$ & $\begin{array}{c}\text { NO } \\
\text { (concerns about } \\
\text { children who } \\
\text { did not live with } \\
\text { their parents - } \\
\text { bad impacts on } \\
\text { children's } \\
\text { feeling) }\end{array}$ & Yes & Yes & Yes* \\
\hline
\end{tabular}

*interesting point: special context of the service and parental support - still inviting parents on the Father's and Mother's days. 


\begin{tabular}{|c|c|c|c|c|c|c|c|c|}
\hline & \multicolumn{4}{|c|}{ OPEC } & \multirow{2}{*}{$\begin{array}{c}\text { OHEC } \\
\text { Cherry } \\
\text { Blossom }\end{array}$} & \multirow{2}{*}{$\frac{\text { OBEC }}{\text { Sunflower }}$} & \multicolumn{2}{|c|}{ EDU - BMA } \\
\hline Thai traditions & Anemone & Primrose & Jamesia & Kalmia & & & Daffodil & Foxglove \\
\hline $\begin{array}{l}\text { Teacher } \\
\text { Appreciation } \\
\text { Day }\end{array}$ & & Yes & Yes & Yes & & & & \\
\hline HOW TO & & \multicolumn{3}{|c|}{$\begin{array}{l}\text { Wai Kru Ceremony - expressing gratitude } \\
\text { activity to teachers: paying respect and feeling } \\
\text { grateful for what teachers do for them }\end{array}$} & & & & \\
\hline $\begin{array}{l}\text { Services' } \\
\text { Annual } \\
\text { Celebrations }\end{array}$ & & & & & Yes & & Yes & \\
\hline HOW TO & & & & & $\begin{array}{l}\text { Children were } \\
\text { involved in a } \\
\text { session of } \\
\text { listening to the } \\
\text { Buddha's } \\
\text { doctrine and } \\
\text { learning } \\
\text { traditional ways } \\
\text { of living from } \\
\text { the countryside }\end{array}$ & & $\begin{array}{c}\text { Food offering } \\
\text { and } \\
\text { Performing } \\
\text { traditional } \\
\text { dances with } \\
\text { dressing up in } \\
\text { Thai traditional } \\
\text { costumes }\end{array}$ & \\
\hline
\end{tabular}




\begin{tabular}{|c|c|c|c|c|c|c|c|c|}
\hline & \multicolumn{4}{|c|}{ OPEC } & \multirow{2}{*}{$\begin{array}{c}\text { OHEC } \\
\text { Cherry } \\
\text { Blossom }\end{array}$} & \multirow{2}{*}{$\frac{\text { OBEC }}{\text { Sunflower }}$} & \multicolumn{2}{|c|}{ EDU - BMA } \\
\hline $\begin{array}{l}\begin{array}{l}\text { Thai Folk } \\
\text { Wisdom }\end{array} \\
\end{array}$ & Anemone & Primrose & Jamesia & Kalmia & & & Daffodil & Foxglove \\
\hline $\begin{array}{l}\text { - Learning about } \\
\text { the Thai national } \\
\text { flag by explaining } \\
\text { each stripe and } \\
\text { Thai identity }\end{array}$ & $\begin{array}{c}\text { Yes } \\
\text { Drawing, } \\
\text { colouring, and } \\
\text { paper-cutting } \\
\text { the flag shape }\end{array}$ & $\begin{array}{l}\text { Pictures of } \\
\text { Thai national } \\
\text { flags in a } \\
\text { classroom }\end{array}$ & $\begin{array}{c}\text { Go beyond } \\
\text { Thai national } \\
\text { flag; teaching } \\
\text { ASEAN } \\
\text { countries too }\end{array}$ & $\begin{array}{l}\text { Teach lyrics } \\
\text { and } \\
\text { encourage } \\
\text { children to } \\
\text { memorise } \\
\\
\text { Drawing, } \\
\text { colouring, } \\
\text { and paper- } \\
\text { cutting the } \\
\text { flag shape }\end{array}$ & $\begin{array}{l}\text { Pictures of Thai } \\
\text { national flags in } \\
\text { a classroom } \\
\text { Drawing, } \\
\text { colouring, and } \\
\text { paper-cutting the } \\
\text { flag shape }\end{array}$ & $\begin{array}{l}\text { Teach a lesson } \\
\text { topic about } \\
\text { shapes and } \\
\text { colours too }\end{array}$ & $\begin{array}{l}\text { Drawing, } \\
\text { colouring, and } \\
\text { paper-cutting the } \\
\text { flag shape }\end{array}$ & $\begin{array}{c}\text { Teach lyrics and } \\
\text { encourage } \\
\text { children to } \\
\text { memorise }\end{array}$ \\
\hline $\begin{array}{l}\text { - Singing national } \\
\text { anthem }\end{array}$ & Yes & Yes & NO & Yes & Yes & NO & $\begin{array}{l}\text { Yes - learnt the } \\
\text { importance and } \\
\text { what to do when } \\
\text { hearing the song }\end{array}$ & Yes \\
\hline - Thai Language & Yes & Yes & Yes & Yes & Yes & Yes & & \\
\hline $\begin{array}{l}\text { - Learning Thai } \\
\text { history }\end{array}$ & & $\begin{array}{l}\text { Yes - as it is a } \\
\text { national pride }\end{array}$ & & & & & & \\
\hline $\begin{array}{l}\text { - Learning } \\
\text { traditional ways } \\
\text { of living }\end{array}$ & $\begin{array}{l}\text { From local } \\
\text { communities }\end{array}$ & & & & $\begin{array}{l}\text { From Baan Kru } \\
\text { Thanee and the } \\
\text { countryside }\end{array}$ & & & \\
\hline
\end{tabular}




\begin{tabular}{|c|c|c|c|c|c|c|c|c|}
\hline & \multicolumn{4}{|c|}{ OPEC } & \multirow{2}{*}{$\begin{array}{c}\text { OHEC } \\
\text { Cherry } \\
\text { Blossom }\end{array}$} & \multirow{2}{*}{$\begin{array}{c}\text { OBEC } \\
\text { Sunflower }\end{array}$} & \multicolumn{2}{|c|}{ EDU - BMA } \\
\hline $\begin{array}{l}\text { Thai Folk } \\
\text { Wisdom }\end{array}$ & Anemone & Primrose & Jamesia & Kalmia & & & Daffodil & Foxglove \\
\hline Thai values & & & & & & & & \\
\hline $\begin{array}{l}\text { - A concept of } \\
\text { Sharing } \\
\text { (Kindness) }\end{array}$ & Yes & Yes & & & $\begin{array}{l}\text { Through the } \\
\text { service's } \\
\text { campaign } \\
\text { (Visiting local } \\
\text { community) - } \\
\text { donating money } \\
\text { and necessities }\end{array}$ & Yes - share toys & & \\
\hline
\end{tabular}

\section{HOW TO:}

- Some services promoted this concept on Loy Kratong event. Each programme created only one floating basket and children altogether shared one kratong to float on a temporarily made pond.

- This concept was promoted through Sport Day activities at Service 2, 3, 5, and 7). Children also learnt about how to work as a group, be patient and have sportsmanship. This enhanced children's physical and mental development

\begin{tabular}{|c|c|c|c|c|c|c|c|c|}
\hline $\begin{array}{l}\text { - A concept of } \\
\text { gratitude }\end{array}$ & $\begin{array}{l}\text { To the Nation } \\
\text { and parents }\end{array}$ & $\begin{array}{l}\text { Tell children } \\
\text { not to do } \\
\text { anything their } \\
\text { parents }\end{array}$ & \multicolumn{6}{|c|}{$\begin{array}{l}\text { These services did not mention this concept as Thai values, but they promoted this concept through the } \\
\text { following important dates: Father's, Mother's, and Teacher Appreciation Day. }\end{array}$} \\
\hline $\begin{array}{l}\text { - } 12 \text { Core Values } \\
\text { (leads to be a } \\
\text { good citizenship) }\end{array}$ & Make links & Make links & $\begin{array}{l}\text { Make links } \\
\text { Have a sense } \\
\text { of publicity }\end{array}$ & $\begin{array}{l}\text { Explicitly } \\
\text { mentioned }\end{array}$ & $\begin{array}{l}\text { Explicitly } \\
\text { mentioned }\end{array}$ & Make links & Make links & Make links \\
\hline
\end{tabular}

\section{HOW TO:}

- Although other services did not explicitly mention the 12 core values, they have still promoted through their daily teaching practices. 


\begin{tabular}{|c|c|c|c|c|c|c|c|c|}
\hline \multirow[b]{2}{*}{ Buddhism } & \multicolumn{4}{|c|}{ OPEC } & \multirow{2}{*}{$\begin{array}{l}\text { OHEC } \\
\text { Cherry } \\
\text { Blossom } \\
\end{array}$} & \multirow{2}{*}{$\begin{array}{c}\text { OBEC } \\
\text { Sunflower }\end{array}$} & \multicolumn{2}{|c|}{ EDU - BMA } \\
\hline & Anemone & Primrose & Jamesia & Kalmia & & & Daffodil & Foxglove \\
\hline \multicolumn{9}{|l|}{$\begin{array}{l}\text { Buddhist } \\
\text { principles }\end{array}$} \\
\hline - The Five Precepts & Yes! & Yes & & Yes & Yes & Yes & Yes & Yes \\
\hline $\begin{array}{l}\text { - Moral lessons } \\
\text { (Thai proverbs and } \\
\text { folktales) }\end{array}$ & $\begin{array}{l}\text { Link to the } 12 \\
\text { Morality } \\
\text { Habits } \\
\text { (Designed by } \\
\text { the service) }\end{array}$ & & & $\begin{array}{l}\text { Children were } \\
\text { taught that } \\
\text { carelessness } \\
\text { can lead to } \\
\text { failure from } \\
\text { the Hare and } \\
\text { the Tortoise } \\
\text { story }\end{array}$ & $\begin{array}{c}\text { Yes } \\
\text { (see How To) }\end{array}$ & $\begin{array}{c}\text { Yes } \\
\text { (see How To) }\end{array}$ & $\begin{array}{l}\text { - As a man sows, } \\
\text { so shall he reap } \\
\text { - Keep doing } \\
\text { good things and } \\
\text { avoid doing bad } \\
\text { things }\end{array}$ & $\begin{array}{c}\text { Yes } \\
\text { (not mention } \\
\text { what it is) }\end{array}$ \\
\hline - Other principles & $\begin{array}{l}\text { - Four Divine } \\
\text { States of Mind } \\
\text { - The } 12 \\
\text { Morality } \\
\text { Habits } \\
\text { - The Four } \\
\text { Noble Truths } \\
\text { - The Four } \\
\text { Rules of } \\
\text { Efforts }\end{array}$ & & & & $\begin{array}{c}\text { - The Law of } \\
\text { Karma }\end{array}$ & & & \\
\hline
\end{tabular}

*Service 5 did not corporate any Buddhist principles, but they did teach children about the Buddha's lifestory and important religious dates 


\begin{tabular}{|c|c|c|c|c|c|c|c|c|}
\hline \multirow[b]{2}{*}{ Buddhism } & \multicolumn{4}{|c|}{ OPEC } & \multirow{2}{*}{$\begin{array}{c}\text { OHEC } \\
\text { Cherry } \\
\text { Blossom } \\
\end{array}$} & \multirow{2}{*}{$\begin{array}{c}\text { OBEC } \\
\text { Sunflower }\end{array}$} & \multicolumn{2}{|c|}{ EDU - BMA } \\
\hline & Anemone & Primrose & Jamesia & Kalmia & & & Daffodil & Foxglove \\
\hline $\begin{array}{l}\text { Buddhist } \\
\text { principles }\end{array}$ & & & & & & & & \\
\hline HOW TO: & $\begin{array}{l}\text { - How they } \\
\text { modified the } \\
\text { Five Precepts } \\
\text { to be easier for } \\
\text { children to } \\
\text { understand } \\
\text { - Example of } \\
\text { how they } \\
\text { taught the } \\
\text { Four Noble } \\
\text { Truth }\end{array}$ & & & & $\begin{array}{l}\text { Asked children } \\
\text { to summarise } \\
\text { their actions and } \\
\text { think which one } \\
\text { is good or bad, } \\
\text { and its } \\
\text { consequence too }\end{array}$ & $\begin{array}{l}\text { Taught children } \\
\text { to have } \\
\text { conscience and } \\
\text { to feel ashamed } \\
\text { when doing } \\
\text { something } \\
\text { wrong }\end{array}$ & & \\
\hline $\begin{array}{l}\text { How these } \\
\text { principles } \\
\text { promote } \\
\text { children's } \\
\text { learning and } \\
\text { development }\end{array}$ & $\begin{array}{l}\text { Manage their } \\
\text { emotions and } \\
\text { actions }\end{array}$ & $\begin{array}{l}\text { Learn to give, } \\
\text { take, and } \\
\text { forgive }\end{array}$ & & $\begin{array}{l}\text { Be able to } \\
\text { survive in a } \\
\text { society, } \\
\text { understand } \\
\text { others, and } \\
\text { work in a } \\
\text { group }\end{array}$ & $\begin{array}{l}\text { Behave } \\
\text { themselves and } \\
\text { respect others }\end{array}$ & & $\begin{array}{l}\text { Avoid doing bad } \\
\text { things }\end{array}$ & \\
\hline
\end{tabular}




\begin{tabular}{|c|c|c|c|c|c|c|c|c|}
\hline \multirow[b]{2}{*}{ Buddhism } & \multicolumn{4}{|c|}{ OPEC } & \multirow{2}{*}{$\begin{array}{l}\text { OHEC } \\
\text { Cherry } \\
\text { Blossom }\end{array}$} & \multirow{2}{*}{$\begin{array}{c}\text { OBEC } \\
\text { Sunflower }\end{array}$} & \multicolumn{2}{|c|}{ EDU - BMA } \\
\hline & Anemone & Primrose & Jamesia & Kalmia & & & Daffodil & Foxglove \\
\hline $\begin{array}{l}\text { Buddhist } \\
\text { practices }\end{array}$ & & & & & & & $\begin{array}{l}* \text { Thai arts } \\
\text { from a temple }\end{array}$ & \\
\hline $\begin{array}{l}\text { - Meditation } \\
\text { practice }\end{array}$ & Yes & Yes & $\begin{array}{l}\text { Meditation for } \\
\text { increasing } \\
\text { children's } \\
\text { concentration }\end{array}$ & Yes & Yes & Yes & Yes & Yes \\
\hline $\begin{array}{l}\text { - observing } \\
\text { religious dates }\end{array}$ & $\begin{array}{l}\text { Visakha } \\
\text { Bucha } \\
\text { And } \\
\text { Holy days }\end{array}$ & $\begin{array}{l}\text { Visakha } \\
\text { Bucha } \\
\text { And } \\
\text { Buddhist Lent }\end{array}$ & $\begin{array}{l}\text { Visakha } \\
\text { Bucha }\end{array}$ & $\begin{array}{l}\text { Visakha Bucha } \\
\text { And } \\
\text { Buddhist Lent }\end{array}$ & $\begin{array}{c}\text { Visakha Bucha } \\
\text { And } \\
\text { Holy days }\end{array}$ & Visakha Bucha & $\begin{array}{l}\text { Visakha } \\
\text { Bucha }\end{array}$ & Visakha Bucha \\
\hline $\begin{array}{l}\text { - Praying to the } \\
\text { Buddha }\end{array}$ & Yes & Yes & & Yes & Yes & Yes & Yes & NO \\
\hline $\begin{array}{l}\text { - Visiting a } \\
\text { temple }\end{array}$ & Yes & Occasionally & $\begin{array}{c}\text { No, but } \\
\text { learning about } \\
\text { a temple } \\
\text { through } \\
\text { Project } \\
\text { Approach }\end{array}$ & $\begin{array}{l}\text { No, through } \\
\text { Project } \\
\text { Approach }\end{array}$ & $\begin{array}{l}\text { Yes, through a } \\
\text { trip visiting local } \\
\text { community }\end{array}$ & $\begin{array}{l}\text { Occasionally } \\
\text { And rely on } \\
\text { parents' } \\
\text { support }\end{array}$ & No & $\begin{array}{l}\text { P - Yes but rely } \\
\text { on parental } \\
\text { support } \\
\text { H - Rarely visit }\end{array}$ \\
\hline $\begin{array}{l}\text { - Offering food to } \\
\text { Buddhist monks }\end{array}$ & Yes & Yes & & Yes & Yes & Yes & Yes & NO \\
\hline $\begin{array}{l}\text { - Listening to the } \\
\text { Buddha's } \\
\text { doctrines }\end{array}$ & Yes & Yes & & NO & Yes & Yes & Yes & NO \\
\hline $\begin{array}{l}\text { - Kraab Buddhist } \\
\text { monks }\end{array}$ & & Yes & & & & & & \\
\hline
\end{tabular}




\section{Appendix H: Ethics Approval Letter (*)}

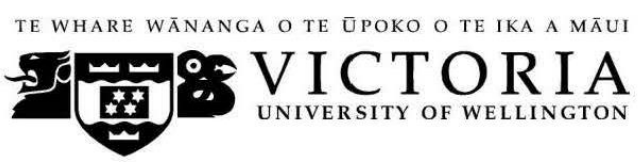

MEMORANDUM

\begin{tabular}{l|l}
\hline TO & Sureepan lemamnuay \\
\hline COPY TO & Mary Jane Shuker \\
\hline FROM & AProf Susan Corbett, Convener, Human Ethics Committee \\
\hline \multicolumn{2}{|l}{} \\
\hline DATE & 20 October 2015 \\
\hline PAGES & 1 \\
\hline
\end{tabular}

SUBJECT

Ethics Approval: 22229

How does Thai Culture underpin the 2003 Early Childhood Curriculum in Thailand?

Thank you for your application for ethical approval, which has now been considered by the Standing Committee of the Human Ethics Committee.

Your application has been approved from the above date and this approval continues until 30 June 2017. If your data collection is not completed by this date you should apply to the Human Ethics Committee for an extension to this approval.

Best wishes with the research

Kind regards

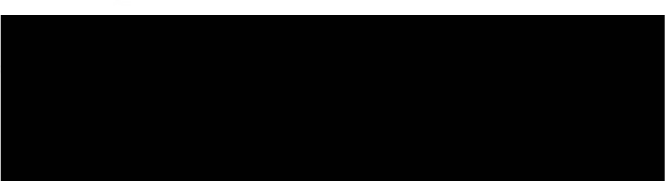

Susan Corbett

Convener, Victoria University Human Ethics Committee

(*) Title of the study was recorded at the proposal stage of this study 